\title{
ENGLACIAL HYDROLOGY OF ANNETTE PLATEAU, A TEMPERATE ALPINE GLACIER, SOUTHERN ALPS, NEW ZEALAND
}

by

Kolja Schaller

A thesis

submitted to the Victoria University of Wellington in partial fulfilment of the requirements for the degree of Master of Science in Physical Geography.

Victoria University of Wellington 2013 



\begin{abstract}
The movement of water through temperate glaciers is important for understanding fundamental issues within glaciology. These include glacier induced floods, glacier dynamics and run-off prediction. Traditional englacial hydrology is thought to consist of interconnected tubular channels that merge downglacier and drain through the glacier to the bed. However, englacial hydrology is much debated as the links between the glacier surface and bed are not well understood. Ground penetrating radar (GPR) is a geophysical tool that is well suited for studying glaciated areas. Recent ice coring attempts in New Zealand's temperate alpine glaciers were not successful in coring to bedrock due to the interception of water at depth. This highlights the need for a better understanding of the englacial hydrology of temperate systems. This study investigates the englacial hydrology at Annette Plateau where on three occasions the interception of water has prevented successful coring to the glacier bed. Ground penetrating radar was used to conduct two high-resolution surveys on Annette Plateau in early spring 2011 and early summer 2011. Acrossglacier profiles were acquired at $20 \mathrm{~m}$ spacing to enable tracking of englacial reflectors between profiles. Models of temperate englacial features were made to aid feature identification within radar profiles. Radar data is compared with density, stratigraphy and chemistry results from the $45 \mathrm{~m}$ ice core obtained at Annette Plateau in winter 2009. The early-summer survey indicates an increase in the glacier's water content compared with the early-spring survey. Englacial reflectors show evidence of (a) spatially continuous englacial conduits, (b) the formation of a water table feature which shallows down glacier, and (c) detailed bedrock topography. Hydropotential surfaces, calculated for the water table and bedrock horizons, show the direction of water flow. Ice core chemistry shows a correlation between the depth of the water table and a significant hiatus indicated by tritium dating. We infer that an extensive water table has
\end{abstract}


formed on an old melt surface where ice from approximately 1930-1991 has been removed. This water table responds to seasonal temperature changes and hydrological inputs. 


\section{Acknowledgments}

Thanks to the greatest team of supervisors and friends; Brian Anderson, Huw Horgan, Uwe Morgenstern and Andrew Mackintosh. Without your support this project could not have happened. Cheers Huw and Brian for your detailed knowledge of glaciers, seismic processing software, the bike rides and barefoot mountain climbing. Cheers Andrew for helping to get my thesis chugging along in the early stages. Thanks to Uwe Morgensten from GNS who aided with funding, gave me the initial inspiration for the project and processed the ice core described in this study.

To the fantastic field team: Brian Anderson, Lawrence Kees, Laura Kehrl and Claire Webster, that helped at various stages with the radar surveys. The field was not always easy going, thanks for dragging the radar and making it happen. Thanks L dizzle for introducing me to the ways of the radar.

Thanks for various help or glacier related chats along the way; Katrin Sattler, Trevor Chinn, Alice Doughty, Ruzica Dadic, Andrew Rae, Brook Tozer, Hamish McKoy and Adrian Benson for the late night discussions and technical assistance.

A massive thanks to my younger brothers Cassy, Sunny, Paascalino for always rocking, and being the best bro's any brother could have. Thanks to my mum Eva for your positive thoughts, support and love! Cheers to my dad Giovanni for your awesomeness and supporting me at all times.

To the 521 office rockers Brook, Rory, Grant for all the banter and laughs. A 
iv

special call out goes to Brook for all the food that we shared and Jackson for your support and fun during the first year in the office that is no longer.

To Miriam for all your love and support over the last years, which has made this thesis seem like a breeze.

To the ever so chill friends of the teepee Nathan, Mitchel, Dana, Vaughan and Paascalino for the epic meals and good flat vibes. A big call out also goes to the band for all your understanding over the last year, we will get the EP out one day!

A large acknowledgement also goes out to Mac and Will the backyard brewers, and Hamish and Erin for the fun missions and urban farming, and to Tom for being the man and always having good yarns.

Thanks to the last minute editing team for being legends Bella, Nick, Meagan, and Roger for describing edits over the phone!

Lastly I thank all the people that I have not mentioned, but have been awesome along the way. 


\section{Contents}

$\begin{array}{ll}\text { List of Figures } & \text { ix }\end{array}$

List of Tables $\quad$ xiii

1 Introduction $\quad \mathbf{1}$

1.1 Overview ............................. 1

1.2 Structure of temperate alpine glaciers . . . . . . . . . . . 3

1.3 Hydrology of temperate alpine glaciers . . . . . . . . . . 6

1.4 Temperate ice cores . . . . . . . . . . . . . . . . . 13

1.5 Motivation for study . . . . . . . . . . . . . . . 17

1.5.1 Annette Plateau Glacier . . . . . . . . . . . . . . . 17

1.5.2 Research objectives . . . . . . . . . . . . . . 19

2 Methodology 21

2.1 Ground penetrating radar . . . . . . . . . . . . . . . . 21

2.2 GPR uses in glacial environments . . . . . . . . . . . . . . . . 22

2.2.1 Theoretical and physical principles of radar . . . . . . . . . 24

2.3 GPR arrangement and acquisition settings . . . . . . . . . . . . 27

2.3 .1 GPR survey . . . . . . . . . . . . . . . . . . . 29

2.4 Data processing . . . . . . . . . . . . . . . . . . . . . . . . . . . . . 31

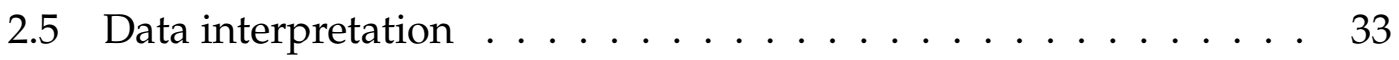

2.5.1 Horizon picks . . . . . . . . . . . . . 33

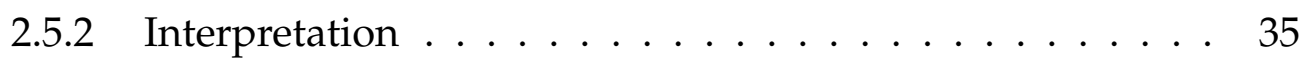

2.6 Potential errors . . . . . . . . . . . . . . . 36

2.7 Synthetic radar models . . . . . . . . . . . . . . 37 
2.7.1 Englacial models . . . . . . . . . . . . . . 39

2.7 .2 Ice impurities . . . . . . . . . . . . . . . . 41

2.7 .3 Ice density . . . . . . . . . . . . . . . . . 43

2.8 Hydropotential surfaces . . . . . . . . . . . . . . . . 44

3 Results $\quad 47$

3.1 Radar data . . . . . . . . . . . . . . . . . . 47

3.1 .1 Bedrock topography . . . . . . . . . . . . 50

3.1.2 Englacial reflectors . . . . . . . . . . . . . . 59

3.1.2.1 Point reflectors . . . . . . . . . . . 60

3.1.2.2 Banded Surface reflectors . . . . . . . . . . . 62

3.1.2.3 Reflection horizon . . . . . . . . . . 65

3.1.2.4 Initial reflection horizon . . . . . . . . . 69

3.1.3 Tracking of englacial reflectors . . . . . . . . . . . 70

3.2 Synthetic radargrams . . . . . . . . . . . . . . . . . 74

3.3 Observed and synthetic radar comparison . . . . . . . . . . . . 81

3.4 Hydropotential surfaces . . . . . . . . . . . . . . . 85

3.5 Ice core and radar data comparison . . . . . . . . . . . . . . 88

4 Discussion $\quad 91$

4.1 Englacial hydrology of Annette Plateau glacier . . . . . . . . . . . 91

4.1 .1 Englacial conduits . . . . . . . . . . . . . 91

4.1.2 Water table .................... 95

4.2 Temporal changes in hydrology . . . . . . . . . . . . . . . . 97

4.3 Conceptual model for englacial hydrology . . . . . . . . . . . . . 99

4.4 Ice core and radar data comparison . . . . . . . . . . . . . . . 101

4.5 Ice cores from the Southern Alps of New Zealand . . . . . . . . . 103

5 Conclusions $\quad 105$

5.0.1 Completed research objectives . . . . . . . . . . . . . . . . . . . . . . . . . . . . .

5.0 .2 Future work . . . . . . . . . . . . . . . 108

$\begin{array}{llr}6 & \text { Bibliography } & 109\end{array}$ 
CONTENTS

7 Appendix 


\section{List of Figures}

1.1 Hydrological features of a temperate glacier . . . . . . . . . . . 4

1.2 Glacier accumulation and ablation wedge model . . . . . . . . 5

1.3 Glacier equipotential and theoretical water flow . . . . . . . . . 10

1.4 Englacial conduit formation . . . . . . . . . . . . . . 12

1.5 Temperate englacial drainage pattern . . . . . . . . . . . . . . 12

1.6 Study area . . . . . . . . . . . . . . . . . . 18

2.1 Ski towed GPR set-up . . . . . . . . . . . . . . . . 30

2.2 MATGPR model example (water table) . . . . . . . . . . . . 43

3.1 Surveyed profiles using GPR . . . . . . . . . . . . . . . . . . . . . . . . . . . . 48

3.2 September GPR survey . . . . . . . . . . . . . . . . . . . . . . . . . . . . . . . . . . . . . . 59

3.3 December GPR survey . . . . . . . . . . . . . . . . . . . 50

3.4 Bed reflection . . . . . . . . . . . . . . . . 51

3.5 Annette Plateau bed contour map . . . . . . . . . . . . . . 53

3.6 September distribution of bed picks . . . . . . . . . . . . . 54

3.7 September distribution of inferred bed picks . . . . . . . . . . 54

3.8 September distribution of combined bed picks . . . . . . . . . 55

3.9 December distribution of bed picks . . . . . . . . . . . . . 56

3.10 December distribution of inferred bed picks . . . . . . . . . . . 57

3.11 December distribution of combined bed picks . . . . . . . . . 58

3.12 Point reflector radar examples . . . . . . . . . . . . . . . . 61

3.13 September distribution of point reflectors . . . . . . . . . . . . 61

3.14 December distribution of point reflectors . . . . . . . . . . . 62

3.15 Banded surface reflector examples . . . . . . . . . . . . . . 64 
3.16 September distribution of banded surface reflectors . . . . . . . . 64

3.17 December distribution of banded surface reflectors . . . . . . . . . 65

3.18 Reflective horizon (water table) radar examples . . . . . . . . . . 67

3.19 September distribution of reflective horizon . . . . . . . . . . . 67

3.20 December distribution of reflective horizon . . . . . . . . . . . . 68

3.21 September distribution of initial reflective horizon . . . . . . . . 69

3.22 December distribution of initial reflection horizon . . . . . . . . . 70

3.23 Continuity of englacial point reflectors September survey . . . . . 72

3.24 Continuity of englacial point reflectors December survey . . . . . 73

3.25 Water conduit synthetics . . . . . . . . . . . . . . . 75

3.26 Mixed air and water conduit synthetics . . . . . . . . . . . 76

3.27 Air cavity and ice impurity synthetics . . . . . . . . . . . . . 77

3.28 Watertable and bedrock synthetics . . . . . . . . . . . . . 78

3.29 Ice core density synthetics . . . . . . . . . . . . . . . . . . . 79

3.30 Crevasse synthetics . . . . . . . . . . . . . . . . 80

3.31 Observed and synthetic conduit reflection . . . . . . . . . . . 83

3.32 Observed and synthetic watertable reflection . . . . . . . . . . . 84

3.33 Observed and synthetic bed reflection . . . . . . . . . . . . 85

3.34 Hydropotential at glacier bed . . . . . . . . . . . . . . . . 87

3.35 Hydropotential of reflective horizon (water table) . . . . . . . . . 88

3.36 Tritium and density record from Annette Plateau ice core (2009) . 90

4.1 Plan view of hydrological features at Annette Plateau . . . . . . . 99

4.2 Profile view of hydrological features at Annette Plateau . . . . . . 100

7.1 Profile 1077 September . . . . . . . . . . . . . . . . . . . . . 124

7.2 Profile 1078 September . . . . . . . . . . . . . . . . . . . 125

7.3 Profile 1079 September . . . . . . . . . . . . . . . . . . . 126

7.4 Profile 1080 September . . . . . . . . . . . . . . . . . . 127

7.5 Profile 1081 September . . . . . . . . . . . . . . . . . . . . 128

7.6 Profile 1082 September . . . . . . . . . . . . . . . . . . . . . . 129

7.7 Profile 1083 September . . . . . . . . . . . . . . . . . . . . 130

7.8 Profile 1084 September . . . . . . . . . . . . . . . . . . . 131

7.9 Profile 1085 September . . . . . . . . . . . . . . . . . . 132 
7.10 Profile 1086 September . . . . . . . . . . . . . . . . . . . . 133

7.11 Profile 1087 September . . . . . . . . . . . . . . . . . . . . . 134

7.12 Profile 1088 September . . . . . . . . . . . . . . . . . . . 135

7.13 Profile 1089 September . . . . . . . . . . . . . . . . . . . 136

7.14 Profile 1090 September . . . . . . . . . . . . . . . . . . . 137

7.15 Profile 1091 September . . . . . . . . . . . . . . . . . . . . 138

7.16 Profile 1092 September . . . . . . . . . . . . . . . . . . . . . 139

7.17 Profile 1095 September . . . . . . . . . . . . . . . . . . . 140

7.18 Profile 1097 September . . . . . . . . . . . . . . . . . . . . 141

7.19 Profile 1098 September . . . . . . . . . . . . . . . . . . . . 142

7.20 Profile 1181 December . . . . . . . . . . . . . . . . . . 143

7.21 Profile 1182 December . . . . . . . . . . . . . . . . . . . . 144

7.22 Profile 1183 December . . . . . . . . . . . . . . . . . 145

7.23 Profile 1184 December . . . . . . . . . . . . . . . . . . . . 146

7.24 Profile 1185 December . . . . . . . . . . . . . . . . . . 147

7.25 Profile 1186 December . . . . . . . . . . . . . . . . . . . 148

7.26 Profile 1187 December . . . . . . . . . . . . . . . . . . . . 149

7.27 Profile 1188 December . . . . . . . . . . . . . . . . . . . 150

7.28 Profile 1189 December . . . . . . . . . . . . . . . . . . . 151

7.29 Profile 1190 December . . . . . . . . . . . . . . . . . . . 152

7.30 Profile 1192 December . . . . . . . . . . . . . . . . . . 153

7.31 Profile 1193 December . . . . . . . . . . . . . . . . . . . 154

7.32 Profile 1194 December . . . . . . . . . . . . . . . . . . 155

7.33 Profile 1195 December . . . . . . . . . . . . . . . . . . 156

7.34 Profile 1196 December . . . . . . . . . . . . . . . . . 157

7.35 Profile 1197 December . . . . . . . . . . . . . . . . . . 158

7.36 Profile 1198 December . . . . . . . . . . . . . . . . . . . . 159

7.37 Profile 1199 December . . . . . . . . . . . . . . . . . . . 160

7.38 Profile 1200 December . . . . . . . . . . . . . . . . . . 161

7.39 Profile 1201 December . . . . . . . . . . . . . . . . . . 162

7.40 Profile 1202 December . . . . . . . . . . . . . . . . 163

7.41 Profile 1203 December . . . . . . . . . . . . . . . . . . . 164

7.42 Profile 1204 December . . . . . . . . . . . . . . . . . 165 
7.43 Profile 1206 December . . . . . . . . . . . . . . . . . 166

7.44 Profile 1207 December . . . . . . . . . . . . . . . . . 167

7.45 Profile 1208 December . . . . . . . . . . . . . . . . . . . . 168

7.46 Profile 1209 December . . . . . . . . . . . . . . . . . . . . . . . . 169

7.47 Profile 1210 December . . . . . . . . . . . . . . . . . . . . . 170

7.48 Profile 1211 December . . . . . . . . . . . . . . . . . . . . 171

7.49 Profile 1214 December . . . . . . . . . . . . . . . . . . . . . 172

7.50 Profile 1215 December . . . . . . . . . . . . . . . . 173 


\section{List of Tables}

2.1 Electrical properties of englacial materials . . . . . . . . . . . 39

2.2 Ice core density and relative permittivity $\ldots \ldots \ldots$. . . . . 42 


\section{Chapter 1}

\section{Introduction}

\subsection{Overview}

Paleoclimate records describe the Earth's climatic history. By understanding the mechanisms behind past climate changes these records can inform potential changes to the earth's climatic system in the future. Climatic data aids the understanding of spatial and temporal climate variability enabling a better understanding of the global climate system (Petit et al., 1999). The worlds highest resolution climate records for the past one million years come from ice cores collected in polar regions (Masson-Delmotte et al., 2006). The combination of low temperatures, which retain the original ice chemistry, low accumulation rates and thick ice depth make the polar regions excellent sites for retrieving climate records (Petit et al., 1999).

Ice cores for climate interpretation from temperate environments are difficult to obtain due to higher temperatures (Schwikowski et al., 2006). Temperate glacial environments generally experience high melt rates, large variability in snow accumulation, low ice thickness and complex ice flow, all of which cause difficulty when locating sites that are well suited for ice core retrieval (Anderson et al., 2010a). High-quality paleoclimate records are relatively lacking from southern hemisphere mid-latitude sites such as New Zealand. Records from these areas would greatly aid the understanding of the global climate system 
(Schwikowski et al., 2006).

As a result of ongoing anthropogenic carbon emissions atmospheric carbon dioxide concentrations are steadily increasing (Solomon, 2007). The increases in greenhouse gases is resulting in an increase of the earth's global mean temperature (Solomon, 2007). Many physical and biological environments are experiencing increased change as the warming climate pushes local environments further out of equilibrium (Solomon, 2007). Temperate alpine glaciers are sensitive to environmental change (Purdie et al., 2011). During the last 5 decades almost all alpine glaciers globally have experienced retreat in part due to global warming (Kaser et al., 2004; Oerlemans, 2005, 1994; Wang et al., 2011). In some areas of the world such as Tibet and areas of China glacier retreat has had catastrophic implications in terms of fresh water supply (Liu et al., 2003).

Englacial meltwater is the largest threat to successfully obtaining climate records from temperate glacial environments. Meltwater affects ice by altering the original chemistry laid down by snow accumulation causing it to be unsuitable for climate interpretation (Ruddell and Budd, 1990). Ice core retrieval is also threatened by the interception of englacial meltwater which causes difficulty and potential termination of coring when using a mechanical drill (Anderson et al., 2010a). Therefore the largest uncertainties when locating potential ice coring sites are the spatial variability of englacial meltwater and the effects of melt water.

Ice coring has previously been attempted in the Southern Alps of New Zealand. Purdie et al. (2011) used ice core data collected from the Tasman Glacier in 2004 which assisted in revealing two years of net accumulation data. Analysis of the core showed a homogenisation of $\delta \mathrm{D}$ below $20 \mathrm{~m}$, indicating the ice was affected by melt water. In June 2009 various sites were drilled as part of the New Zealand Ice Coring Project in order to gain ice cores from New Zealand ice (Morgenstern, 2009). An ice core at Annette Plateau was drilled to a depth of 45 $\mathrm{m}$ at which depth englacial water was intercepted and the drill hole flooded to a depth of $13 \mathrm{~m}$ prohibiting further drilling. Two other sites on the glacier were 
also drilled and intercepted water at $10 \mathrm{~m}$ and $5 \mathrm{~m}$. The limiting factor of the ice coring project was the spatial variation of water within the glacier.

Ground penetrating radar (GPR) is a geophysical technique well suited to studying glacial environments, and may be a solution to understanding the spatial variability in englacial hydrology for ice core retrieval (Arcone and Kreutz, 2009; Campbell et al., 2012). The technique has been used in the past to determine ice depth, ice dynamics and englacial structures (Arcone and Kreutz, 2009; Campbell et al., 2012). Ground penetrating radar is used in this study to determine englacial hydrology to help identify potential ice coring sites in a temperate environment.

\subsection{Structure of temperate alpine glaciers}

The basic structure of a temperate alpine glacier includes an accumulation zone, at the head of the glacier which gains mass, and an ablation zone, the area of the glacier which looses mass, on the lower part of the glacier (Figure 1.1). These zones are not exclusive as accumulation can occur over the whole glacier, as does ablation. The accumulation and ablation zones are separated by the equilibrium line above which snow remains after the summer ablation period (Benn and Evans, 1998). Mass balance is the sum of inputs and outputs from a glacial system (Anderson et al., 2010b). A glacier with positive mass balance has accumulated more mass than it has ablated and vice versa for a glacier with a negative mass balance. Therefore advancing glaciers typically have a positive mass balance, and retreating glaciers a negative mass balance. Ice flow through a glacier can be simply illustrated through the wedge concept, which shows the mass lost and gained in a glacier as two wedges (Figure 1.2). In order for the glacier to be in steady state the accumulation and ablation must be equal (Sugden and John, 1976). Glaciers with steeper mass balance gradients have higher rates of ablation and accumulation, and therefore higher ice flow velocities (Benn and Evans, 1998). 


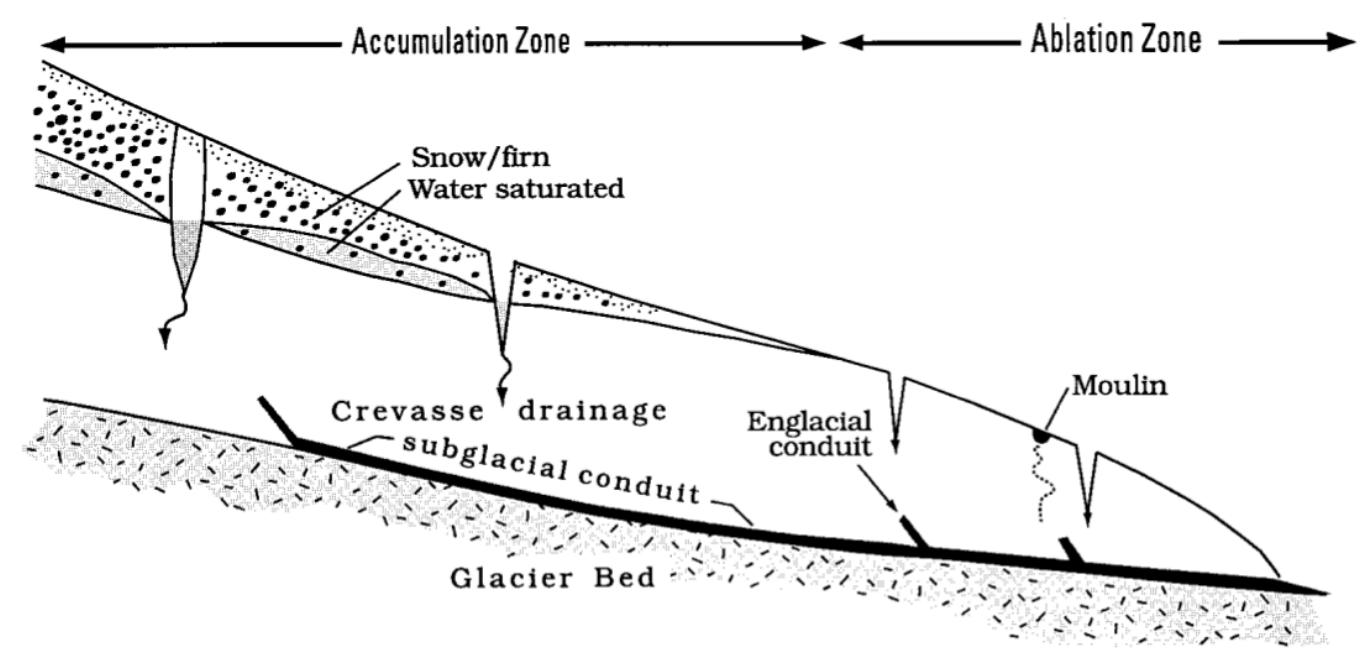

Figure 1.1: Figure shows idealised longitudinal profile through temperate glacier showing important hydrological features. Water percolates through snow and firn in the accumulation zone, which forms a perched water table above the glacier ice. The water enters the glacier body through crevasses. In the ablation zone, shown once seasonal snow has melted water enters the glacier through crevasses and moulins. Figure modified from Fountain and Walder (1998).

The four major controls on the glaciers thermal regime (ice temperature) are the following: heat exchange between the glacier and the atmosphere, the temperature of accumulating snow or rainfall, the frictional heat from internal ice deformation and glacier flow, and the geothermal heat flux (Paterson, 1994; Benn and Evans, 1998). Temperate glaciers have a thermal regime at which the ice body is at pressure melting point throughout the year, often at or relativity close to $0^{\circ} \mathrm{C}$ (Paterson, 1994). The surface layer of the glacier however, responds to seasonal and diurnal temperature changes and therefore can become cooler than the main ice body (Paterson, 1994). Changes in the temperature in the surface layer of the glacier are most significant when the seasonal temperature changes are largest (Paterson, 1994). In the winter, consistent cold temperatures cause the ice to cool from the surface downward .

The energy exchange at the glacier surface is controlled by the energy balance between the meteorological state of the atmosphere and the physical conditions of the glacier (Hock, 2005). During periods of increased temperatures, gener- 


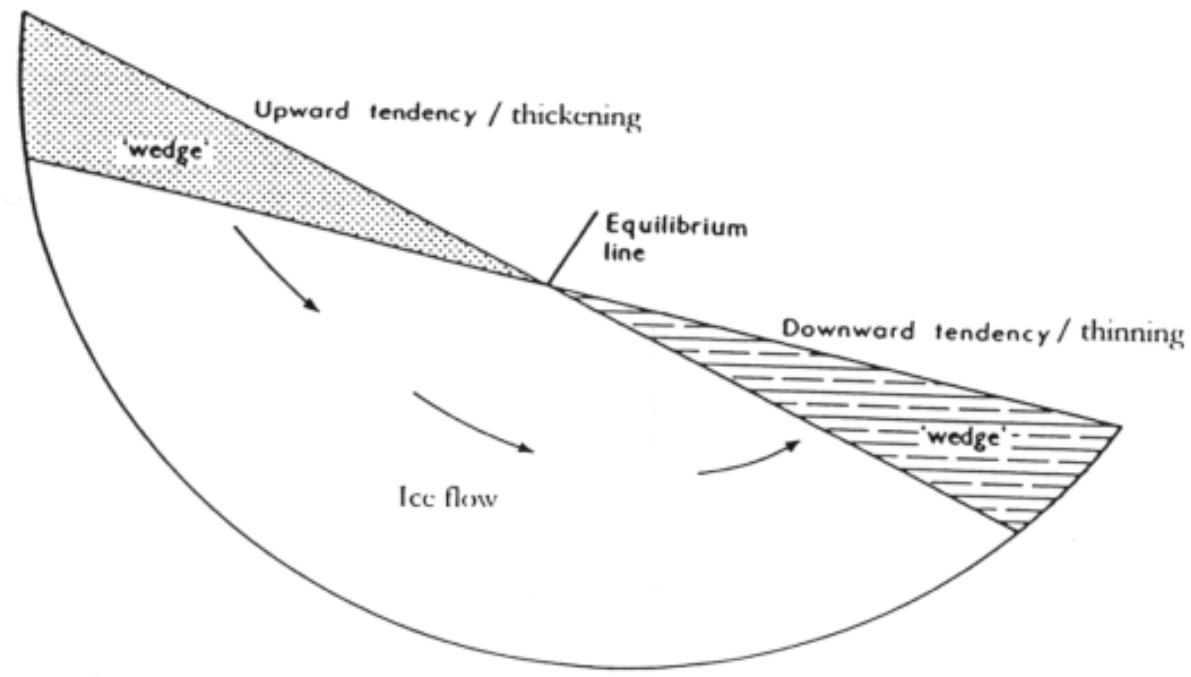

Figure 1.2: Figure shows idealised longitudinal profile glacier showing the net accumulation wedge. Net accumulation increases up-glacier and net ablation increases down-glacier. These are separated by the equilibrium line. Increased net accumulation and ablation rates relate to an increase in ice velocities in order to maintain an equal surface profile. Modified from Sugden and John (1976).

ally spring and summer months, the glacier surface warms but not over $0^{\circ} \mathrm{C}$. A study by Oerlemans and Klok (2002) of the Morteratsch glacier in Switzerland found that the turbulent fluxes, sensible and latent heat flux account for approximately $25 \%$, and direct short-wave and long wave radiation account for approximately $75 \%$ of the energy exchange between the glacier and the atmosphere. However in maritime climates such as New Zealand, the turbulent fluxes contribute a higher amount to the energy balance (Laumann and Reeh, 1993). This is shown in a study by Anderson et al. (2010b) on Brewster glacier, South Island, New Zealand, which found that the turbulent fluxes accounted for $52 \%$ of the energy available to melt the glacier surface.

Meltwater forms due to the positive energy at the glacier surface and releases latent heat as it refreezes. Additionally meltwater moving through the glacier adds positive energy to the glacier, causing the upper surface of the glacier to 
approach and remain at pressure melting point (Benn and Evans, 1998). The lower portion of the glacier remains at pressure melting point throughout the year and is not affected by surface temperature fluctuations (Benn and Evans, 1998; Paterson, 1994).

Glacier dynamics refers to the dynamic processes through which glaciers deform and move under the influence of gravity . The rate of internal deformation is primarily defined by the glacier's surface slope, temperature and ice thickness (Paterson, 1994). In temperate glaciers ice deforms as a brittle medium in approximately the upper $30 \mathrm{~m}$, below this the pressure is sufficient to cause plastic deformation (Paterson, 1994). Basal sliding is the mechanism by which the glacier slides on the bed through the presence of water and/or the sediment deformation at the base of the glacier (Murray et al., 2000b).

Crevasses are the dominant surface feature on glaciers. Crevasses are fractures that form where the ice is subject to tension, for example in areas of high glacier bed slopes, around bends, or in areas where the glacier is constrained due to a narrowing or widening valley (Hambrey and Alean, 2004). These surface features are important entry points for surface water into the ice body (Fountain and Walder, 1998).

\subsection{Hydrology of temperate alpine glaciers}

The movement of water through a glacier is important for understanding fundamental issues within glaciology. These include glacier induced floods, glacier dynamics and run-off prediction from glaciated drainage basins (Fountain and Walder, 1998). Glacial hydrology is characterised by three hydraulic systems: supraglacial, on the surface of the glacier; englacial, within the glacier; and subglacial, at the base of the glacier. These sub-environments may interconnect or act separately (Menzies, 1995). The characteristics of a glacier's hydrological system are shown to be closely coupled to glacier motion and internal ice deformation (Willis et al., 2009; Hubbard and Nienow, 1997; Anderson et al., 
2004). The thermal regime of the glacier is important to understand the prevailing hydrological system and to determine glacier dynamics. Temperate glaciers typically contain approximately 1-2 percent water and higher water contents of 2-4 percent are associated to glaciers with water-filled structures e.g., conduits and moulins (Pälli, 2003).

Meltwater enters the glacier's hydrological system through seasonal snowpack melt, ice ablation, basal and englacial melt (Figure 1.1). Rainfall can also contribute meltwater to the glacial system through melting snow at the glacier surface. In maritime climates melt is typically dominated by turbulent transfers, whereas in continental climates, ablation due to direct radiation is more significant (Willis, 1995; Laumann and Reeh, 1993; Letreguilly, 1988). Meltwater can also be produced within the glacier body through energy exchange. These energy exchanges are made up of four categories: viscous dissipation; latent heat; advection and geothermal heat (Paterson, 1994). Viscous dissipation is the process by which melting is caused by frictional forces and sensible heat between ice and water flowing due to gravitational forces. Latent heat transfer occurs when infiltrating water refreezes within the glacier causing a net increase in ice temperature (Paterson, 1994). Advection is the process by which heat is moved into the glacier through infiltration of meltwater or rain. The transfer of heat from the earth crustal materials into glacier ice is known as geothermal heating which is typically $0.06 \mathrm{Wm}^{-2}$ at the surface (Paterson, 1994). The amount of meltwater within the glacier system is typically highest over the summer ablation period and smallest during winter, emphasising the seasonality of glacier hydrology (Paterson, 1994).

Firn is porous and permeable and is typically deepest in the accumulation zone (Herron and Langway Jr, 1980). The firn may be partially saturated and act as a buffer, smoothing out water inputs into the glacier (Fountain, 1989). The rate of water movement into the glacier depends on the permeability and saturation of the firn (Ambach et al., 1981). It is common for a water saturated layer to form where the glacier's near impermeable ice body and the wet firn meet (Schneider, 1999). A study by Schneider (1999) investigated the saturated water layer 
at the the firn ice transition zone using firn cores and water table measurements. The water table took approximately 3 days to respond to inputs. One of the bore holes intersected a water-filled conduit that showed diurnal variations in flow, which is thought to be associated with diurnally produced melt water. Water tables typically respond to water inputs in 1-3 days (Lang et al., 1977; Oerter and Moser, 1982; Schneider, 1999), although diurnal variations have been observed in a few studies (Fountain, 1989).

The thickness of the water table depends on water inputs which can vary greatly seasonally from no inputs in winter to tens of millimetres per day in summer (Lang et al., 1977; Oerter and Moser, 1982). Snow accumulation generally increases with elevation causing increased firn thickness, therefore the depth to the water saturated layer typically deepens up-glacier (Fountain and Walder, 1998). The depth to the water table may be $40 \mathrm{~m}$ deep in high accumulation sites (Lang et al., 1977). This water layer can be viewed in a hydrological sense as an unconfined perched aquifer (Fountain and Walder, 1998).

Water typically enters and moves through the glacier through conduit structures such as crevasses, moulins and channels within the ice (Munro, 2005). The dominant entry route for supraglacial meltwater into the glacier body is crevasses. Moulins are also important entry points, however, these are restricted to the ablation zone (Fountain and Walder, 1998). The depth to the water saturated layer which typically forms at the firn ice interface is thought to be controlled by crevasse spacing as crevasses cause upglacier meltwater to drain (Fountain and Walder, 1998). This can be described as a stepped pattern with the riser representing the crevasse and the tread as the water saturated layer. The traditional view of englacial hydrology is described as web of tubular channels which drain through the glacier or to the glacier bed (Shreve, 1972; Rothlisberger, 1972). This view is much debated as the formation of links between crevasses and the glacier body are not well understood (Fountain and Walder, 1998). Research by Fountain et al. (2005) of the Storglaciaren, a small Swedish glacier, shows evidence for fractures as the main hydraulic link within temperate glaciers. 
Englacial channels form through the movement of water melting ice surfaces. Channels exist if the melting of the channel sides due to water flow is greater than the inward ice creep which causes the channel to move towards closure (Rothlisberger, 1972; Shreve, 1972). Shreve (1972) shows that englacial drainage should form an upward branching tree like network. The study also shows that the mean flow direction should dip steeply down-glacier. This pattern is based on meltwater following the hydrological equipotential, which is governed by the gradient of the total potential energy, gravity and ice pressure (Figure 1.3). This hypothesis is supported by Fountain (1993). However, field evidence shows that conduit paths are not limited to this pattern. This is possibly due to the varying ice conditions and structure within the glacier body and non steady state water inputs.

The distribution and geometry of englacial conduits is not well known due to the difficulty of studying internal glacial features. Additionally there is little data on englacial water pressures and flow rates within channels. Studies using hot-water borehole techniques to drill into glaciers have given insight to englacial hydrology. Studies combining borehole analysis with video footage have been used by Harper and Humphrey (1995); Murray et al. (2000a); Fountain et al. (2005); Hooke and Pohjola (1994); Hart et al. (2011); Copland et al. (1997); Pohjola (1994) to study englacial channel size, distribution and flow rates. Englacial channel diameters of up to $0.1 \mathrm{~m}$ are typically found across the studies. Englacial flow rates are generally between approximately $0.010 .1 \mathrm{~m} / \mathrm{s}$ which fits in well with other dye-tracing research (Hooke and Kohler., 1988).

Harper and Humphrey (1995) used video observations from 16 boreholes in a temperate valley glacier and found englacial structures made up less than $3 \%$ of the glacier's ice body. These structures included voids and englacial conduits. Voids are glacial structures which are not known to be connected to the active hydraulic system (Fountain and Walder, 1998). It is thought englacial void spaces are possibly remnant sections of a previously active hydraulic system (Pohjola, 1994). Many of the studies using borehole methods, intercepted 


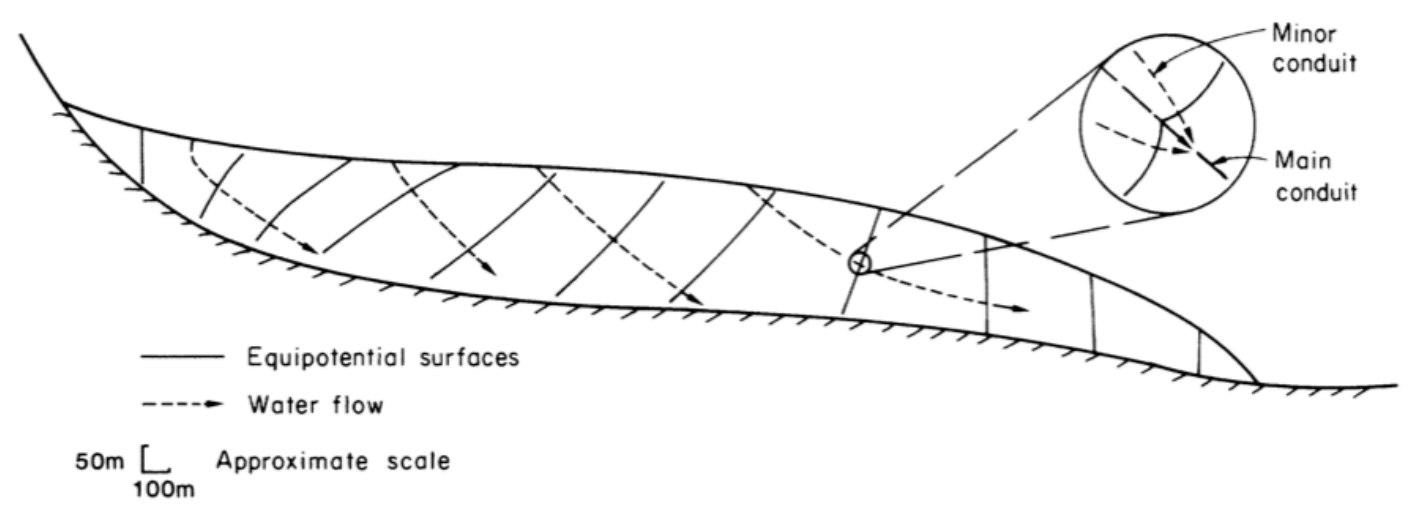

Figure 1.3: Diagram shows a longitudinal profile through glacier showing dipping equipotential surfaces and theoretical routing of englacial water flow, from (Hooke, 1989). The insert shows dimpling at intersection between conduit and equipotential surface and the diversion of smaller routes toward the main conduit

englacial conduits during drilling which gives strong evidence towards the existence of an active conduit system.

Copland et al. (1997) used 11 boreholes on the Haut Glacier d'Arolla, Switzerland and found that the englacial channels accounted for $0.1 \%$ of vertical ice thickness. However a study by (Pohjola, 1994) on Storglaciaren, Sweden, found englacial channels to account for $1.3 \%$ of the observed ice column, suggestive of a more extensive englacial system. These studies using borehole data indicate the majority of englacial channels to be near horizontal.

Recent studies using caving techniques have mapped englacial conduit systems (Gulley, 2009). The primary work has been done on polythermal glaciers, however, one temperate glacier was also mapped (Gulley et al., 2009). The Matanuska glacier in Alaska is $43 \mathrm{~km}$ long and $6.5 \mathrm{~km}$ wide, and was studied approximately $2 \mathrm{~km}$ from the terminus. The glacier was found to have a range of steep to gently dipping conduits between $1-4 \mathrm{~m}$ in diameter. The englacial drainage was made up of single unbranching conduits which were linked to the orientation of the glacier's principle stresses or pre-existing drainage paths. Conduit formation was found to be through surface water intercepting longitudinal or shear crevasses forming a fracture dominated system. Conduit 
formation through longitudinal crevasses formed steeply dipping conduits up to 40 degrees steepness. Shear crevasses formed lower angle conduits which abruptly changed direction where other crevasses were intercepted (Gulley, 2009).

Recent developments in radar techniques have enabled GPR to be useful in the study of glacial environments. Murray et al. (2000a) combines video borehole data with a GPR survey on a small temperate glacier in Iceland to study the glacier's water content. The water content of the glacier rises from $0.23-0.34 \%$ at the surface to $3.0-4.1 \%$ at $28 \mathrm{~m}$ depth. The sharp rise in water content was interpreted to be the piezometric surface, below which the water content drops to $2.4-3.3 \%$. Below this surface, until the bed of the glacier near $100 \mathrm{~m}$, the water content gradually drops to $0.09-0.14 \%$.

Studies show that englacial drainage is crevasse based (Lang et al., 1977; Schommer, 1977). A crevasse acts as a sink truncating supra-glacial flow causing water to enter the ice body. As water fills a crevasse it causes hydraulic pressure to increase which can cause fractures to propagate typically in a down-glacier direction due to the stress field in the ice. A constant water supply and flow causes fractures to enlarge due to the viscous dissipation of flowing water (Paterson, 1994). Ice motion causes the closure of fractures which can lead to the formation of moulins which may also remain active if there is constant annual water being supplied from the supraglacial system. Moulins form near vertical shafts which can extend tens of meters long into the glacier body.

The formation of englacial conduits is thought to originate from the base of crevasses (Fountain and Walder, 1998). Conduits are thought to form near horizontal passageways at the base of crevasses which drain into smaller steeply dipping vein structures forming a tree like network (Shreve, 1972). It is also thought that water enters the glacier's body through smaller fractures which form at crevasse bottoms, through fracture propagation (Fountain and Walder, 1998). It is hypothesised by Fountain and Walder (1998) that water flowing at the base of a crevasse causes downward melting and widening causing the initiation of englacial conduits. The research also suggests that this process oc- 
Time $\longrightarrow$

A.

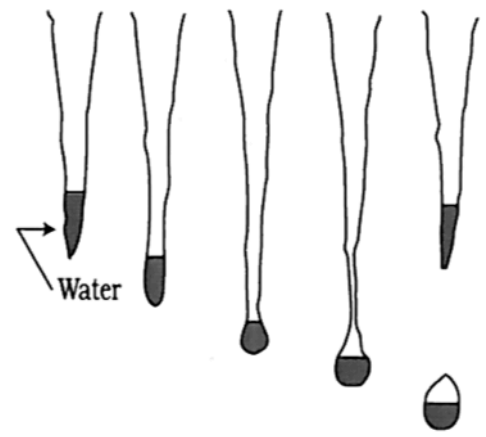

B.

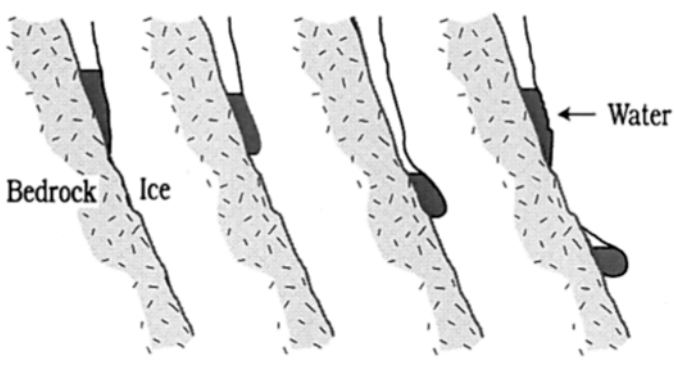

Figure 1.4: Characteristic evolution of an englacial conduit, (a) as a crevasse bottom stream and (b) a glacier bed interface stream. Cutting down is caused by the flowing water melting the conduit base. Figure from Fountain (1989).

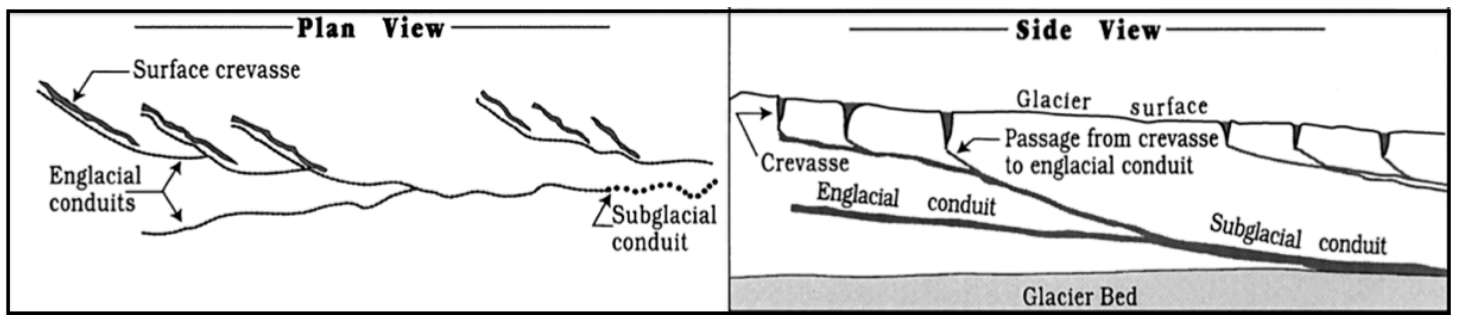

Figure 1.5: Hypothetical drainage pattern modified from Fountain and Walder (1998). Crevasse bottom streams generate gently dipping conduits and steeply dipping conduits (Shreve, 1972), which are formed where water moves through veins or micro-fractures in glacier ice.

curs on the glacier margin at the bed ice interface (Figure 1.4). Ice creep in the glacier body causes the upper section of the crevasse to close isolating the conduit (Hooke, 1984). The conduit remains in a steady state condition if the rate of ice creep is equal to the down cutting caused by melting due to water movement (Hooke, 1984; Fountain and Walder, 1998). Circular and lenticular conduit shapes were found by Pohjola (1994) which agrees with the expected conduit shape due to down cutting. Additionally research by Hooke (1984) show that over time conduits become vertically elongated.

It is thought that englacial channels in the ablation zone are more extensive than in the accumulation zone due to increased meltwater inputs (Fountain and Walder, 1998). Englacial channels in the accumulation zone are thought to be more steady state as the firn stores water and filters out diurnal inputs produc- 
ing increased consistency in water supply (Fountain and Walder, 1998). However, it is unknown whether conduits in the accumulation or ablation zone truly reach steady state conditions due to fluctuations in water supply. A plan and side view of englacial hydrology are shown in Figure 1.5 suggested by Fountain and Walder (1998).

Previously it was thought that the movement of water along grain boundaries in polycrystalline ice was very significant (Nye and Frank, 1973). This process is known as the primary permeability and the current understanding regards it as insignificant as it only supplies a small volume of the overall water inputs to the glacier body (Lliboutry, 1997).

Water draining through the englacial system may make it to the subglacial system at the bed of glacier. At this point water will follow the steepest potential gradient towards the snout of the glacier (Benn and Evans, 1998; Hooke, 1989; Shreve, 1972). The subglacial drainage system is broken into two end members these are a 'fast' channelised system which drains water more quickly than a 'slow' linked cavity system. Therefore water pressures are typically lower in a fast channelised system relative to a linked cavity system with the same input (Raymond et al., 1995).

\subsection{Temperate ice cores}

Climate records from ice cores are fundamental to our understanding of past climate and climate change (Petit et al., 1999). The best climatic records for the past one million years are found in polar regions due to cool temperatures and high ice thickness (Masson-Delmotte et al., 2006). Increased temperatures within the mid latitudes present difficulties when locating and extracting quality climatic records from ice (Schwikowski et al., 2006; Purdie et al., 2011). Quality ice records from the mid latitudes would contribute to the overall understanding of the global climate system (Schwikowski et al., 2006; Villalba et al., 2009). 
Lonnie Thompson pioneered ice coring outside of the polar regions in the 1970s. Thompson et al. (1986) drilled two $150 \mathrm{~m}$ cores gaining approximately $1500 \mathrm{yrs}$ of ice core record from the Quelccaya Ice Cap, Peru, an area that had very few paleo climate proxies. Thompson et al. (1998) also collected a 25,000-year climate record from ice on the Altiplano Plateau, Bolivia from $3700 \mathrm{~m}$ a.s.l. Ground penetrating radar was used to study englacial structures, which proved useful in determining a drill site.

Ice coring sites need certain attributes to ensure the best chance of gaining a quality climate record. Ideally the site would contain a long continuous record, unaffected by melt water percolation, therefore retaining original ice chemistry (Anderson et al., 2010a). The annual preservation of snow due to cool temperatures creates a continuous ice core record. Higher elevation sites are better suited as temperature decreases with elevation (Sturman et al., 1996).

The length of the ice core depends on the depth of glacier ice. The paleoclimate record length depends on the number of annual ice layers preserved in the ice core. Therefore both glacier depth and net accumulation rate are important factors to consider when locating potential ice coring sites (Anderson et al., 2010a). Mean annual regional precipitation rates indicate the amount of snow an area receives per year. Sites with low precipitation rates are typically preferred as they provide longer climate records, as less snow falls in a given season enabling a higher number of years to be preserved in the ice record. Precipitation across the Southern Alps is highest on the western side of the main divide and decreases towards the east (Kees, 2011). Therefore sites towards the eastern side of the main divide are desired. The actual length and quality of the ice core record is not known until the core is analysed, therefore sites showing the best potential are chosen (Anderson et al., 2010a).

Glacier slope and orientation also affect the ice core record. High angle glaciers are exposed to larger driving stresses and experience more internal ice deformation than low-angle glaciers (Paterson, 1994). Internal ice deformation causes 
the original ice stratigraphy to alter meaning the record may not be continuous. The orientation of the glacier affects the amount of incoming solar radiation (Anderson et al., 2010a). In the Southern Hemisphere the sun peaks in the northern part of the sky. Therefore glaciers oriented to the north are exposed to higher levels of solar radiation which typically increases water inputs due to higher melt rates. Hence, southward oriented glaciers are typically better sites for gaining quality climate records. Lastly the site has to be safe to conduct research (Anderson et al., 2010a).

An assessment of ice core retrieval in the Southern Alps by Ruddell and Budd (1990) concluded that the New Zealand environment was not suitable for ice core retrieval and the analysis of stable isotopes through the use of conventional methods. Melt water percolation and isotopic alteration affects snow from elevations of $2400 \mathrm{~m}$ and higher, which lowers the possibility of attaining a climate record that can extend over 100 yrs (Ruddell and Budd, 1990). They also noted that a reliable technique for dating ice over $100 \mathrm{yrs}$ had not yet been developed. Recent advances in ice coring technology increase the possibilities of gaining an ice core from previously unsuitable locations including the Southern Alps. Advances in the understanding of the climatic significance of glaciochemical species in glacier ice and reliable dating techniques in the range of $100-1000$ years increase the feasibility of gaining climatic records from the Southern Alps.

Ice coring in the Southern Alps of New Zealand to gain climate records has been done. Annette Plateau in the Aoraki region was cored using a mechanical drill in 2009 (Morgenstern, 2009). Studies using ground penetrating radar indicated an ice thickness of approximately $120 \mathrm{~m}$, however, due to the interception of englacial water only the upper $45 \mathrm{~m}$ of core was able to be drilled (Anderson et al., 2010a). Purdie et al. (2011) use ice core data and direct glaciological records to construct net accumulation over the last 24 yrs for the Tasman Glacier, New Zealand. The integration of additional ice core data collected from the Tasman Glacier in 2004 assisted in describing two years of net accumulation data. Analysis of the core showed a homogenisation of $\delta \mathrm{D}$ below $20 \mathrm{~m}$, which shows the ice was affected by melt water. Tritium is used in ice core analysis 
for ice dating. Tritium is a radio active isotope which has a half life of $12.3 \mathrm{yrs}$ and is suited for age control in the range of 100 yrs (Morgenstern, 2004). This dating process has been used on ice cores collected from the Southern Alps of New Zealand including the ice core from Annette Plateau.

Ice coring studies in Patagonia show similar characteristics to the New Zealand environment. The Patagonia ice fields are positioned at similar latitude to the Southern Alps of New Zealand and are also dominated by a westerly airflow (Schwikowski et al., 2006). A study by Schwikowski et al. (2006) investigates the Patagonia ice fields as a potential area to gain Southern Hemisphere mid latitude climate records. Three shallow firn cores were retrieved at a range between 1550 - $2300 \mathrm{~m}$ a.s.l. to assess the suitability of ice as potential climate archives. Within the lower altitude cores, there were signs of melt water percolation. The $2300 \mathrm{~m}$ a.s.l. elevation core ( $5 \mathrm{~m}$ in depth) indicated a preserved glacio-chemical signature over a two year period. This suggested that potential climate archives might be found in ice above $2300 \mathrm{~m}$ a.s.l. and well suited sites may be found on the eastern margin of the ice fields due to lower accumulation rates.

Other ice coring research in the Patagonia Ice Fields show the affects of meltwater percolation (Aristarain and Delmas, 1993; Matsuoka and Naruse, 1999; Yamada, 1987). Yamada (1987) extracted a $37.6 \mathrm{~m}$ core from the San Rafael Glacier at an elevation of $1296 \mathrm{~m}$ and found a water soaked layer from 19-25 m above the ice firn transition. Aristarain and Delmas (1993) retrieved a firn core of 13 $\mathrm{m}$ from the Perito Moreno Glacier at $2000 \mathrm{~m}$ elevation. Clear seasonal $\delta \mathrm{D}$ signals were found preserved in the record, however, other chemical tracers were significantly effected by melt water percolation. Matsuoka and Naruse (1999) drilled a firn core from the Northern Patagonia ice field from Hielo Patagonico Norte, South America. A $14.5 \mathrm{~m}$ firn core was obtained at an altitude of 1500 $\mathrm{m}$ a.s.l. Analysis showed that below $6 \mathrm{~m}$ the core was significantly affected by melt water percolation. The upper $6 \mathrm{~m}$ of snow was thought to have accumulated over the prior winter, therefore unaffected by summer melt. A study by (Takeuchi et al., 2009) drilled $51 \mathrm{~m}$ into the Dunde ice cap in Western China in 
1987 and 2002. The ice core covered approximately the last 150 yrs and showed evidence of increased melting since 1987 with a lowering in net annual precipitation.

Ice cores retrieved in the European Alps have proven useful for past climate interpretation. Eichler et al. (2001) drilled a $125 \mathrm{~m}$ ice core at an elevation of $4200 \mathrm{~m}$ a.s.l. from Monte Rosa massif, Swiss Southern Alpine Chain. The upper $10 \mathrm{~m}$ of snow accumulation was unaffected by melt. From 10-25 m core depth melt water percolation largely affected the ice core by preferential leaching of various chemical signals. It is suspected that melt water originated from a crevasse system above the drilling site and flowed into the glacier at $11 \mathrm{~m}$ depth before permeating downwards to the ice firn interface at $18 \mathrm{~m}$. The melt water drained off the glacier without refreezing and did not affect the ice below $24 \mathrm{~m}$, providing a well preserved climate record from 1937-1994 (Eichler et al., 2000). Ground penetrating radar was also used around the core site to assess the flow behaviour and locate englacial structures such as the firn ice interface.

Gaining quality ice cores from mid latitude temperate glaciers in dynamic environments is difficult. Climatic records will become increasingly affected by melt as global temperatures increase (Solomon, 2007). Mid latitude climatic records look to be largely compromised by melt water percolation, which in turn affects the chemical signal in the ice and the quality of the climatic history recorded. The major uncertainties within ice coring are the spatial variability of englacial water and whether it has affected ice chemistry.

\subsection{Motivation for study}

\subsubsection{Annette Plateau Glacier}

The motivation for this study grew out of the need to better understand the spatial variability of englacial water at Annette Plateau glacier to aid future ice core retrieval. Annette Plateau was drilled in 2009 as part of the New Zealand 


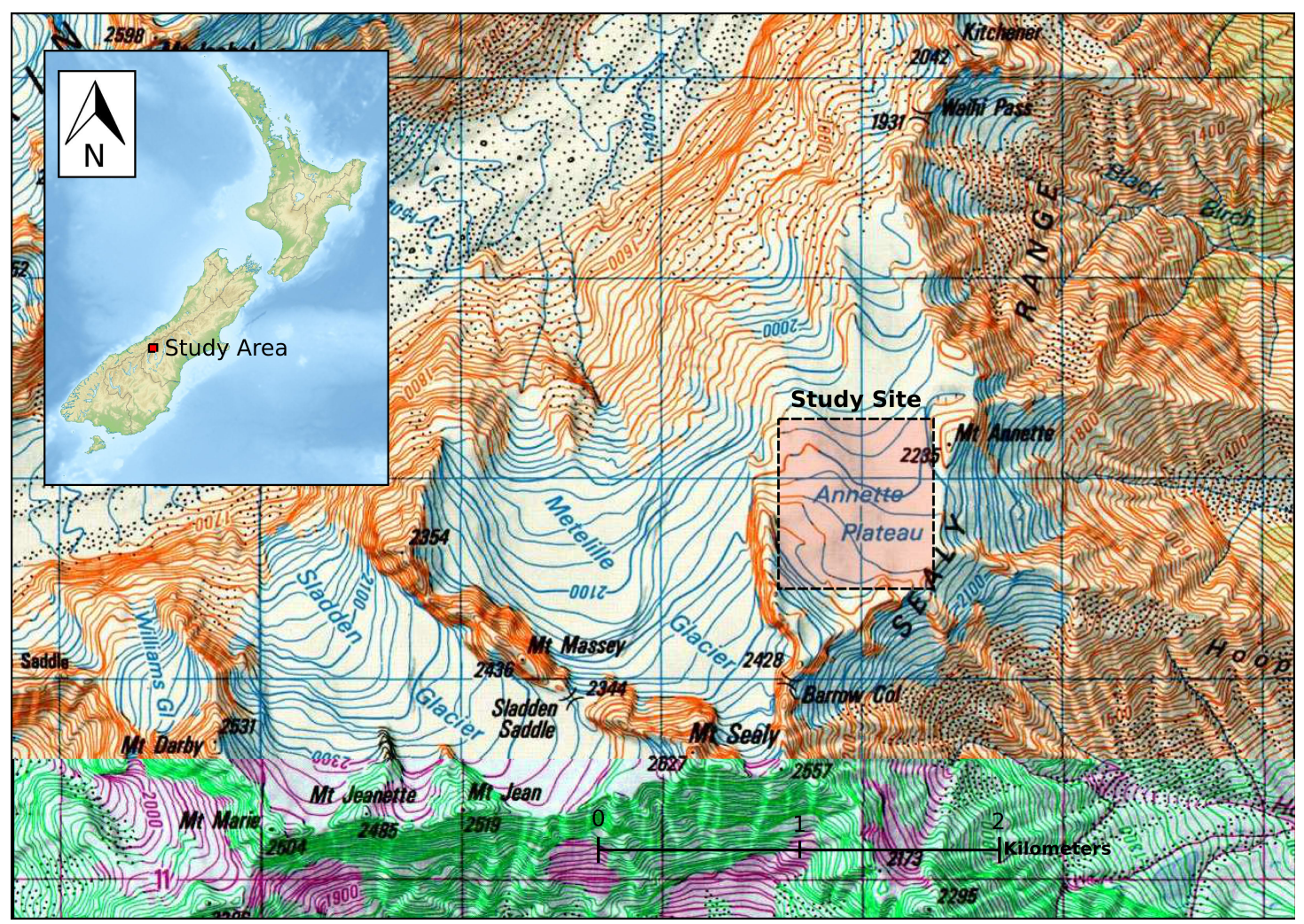

Figure 1.6: Map showing location of Annette Plateau (LINZ, 2011)

Ice Coring Project in order to gain ice cores from New Zealand ice (Morgenstern, 2009). The ice coring attempts at the site were not successful at gaining an ice core to the glacier bed due to the interception of water. This study uses two high-resolution $100 \mathrm{MHz}$ GPR surveys conducted on the upper part of the glacier in September and December 2011 to investigate englacial hydrology and lower uncertainty when locating ice coring sites. Other sites in the South Island also show potential for ice core records, however they are not as safe and less accessible. For example it has been suggested that the best ice core record in the Southern Alps maybe located on the shoulder of Mt Tasman at $3300 \mathrm{~m}$ a.s.l., however this site is currently to dangerous for research to be conducted. The ice dynamics and accumulation at the site are also not well understood.

Annette Plateau is a temperate, maritime glacier located at the northern end of Sealy Range, Mt Cook National Park, South Island, New Zealand (Figure 1.6). 
The Sealy Range is the first range east of the main divide in the Pukaki catchment. The Mueller Glacier lies directly to the west and the Tasman Valley and Lake Pukaki to the east. Annette Plateau is positioned at $2200 \mathrm{~m}$ a.s.l. and is oriented in a south-north direction sloping gently (at $2^{\circ}$ ) to the north ( $43^{\circ} 45 \mathrm{~S}$, $170^{\circ} 03 \mathrm{E}$ ). The glacier is approximately $500 \mathrm{~m}$ wide by approximately $900 \mathrm{~m}$ in length and is a largely crevasse free offering a safe working environment. Research shows an ice depth of $120 \mathrm{~m}$, a relativity high average accumulation rate of $1.7 \mathrm{~m}$, w.e (Kees, 2011) and simple flow regime which is expected in small low-angle glaciers, resulting in a well suited site to locate a climate record. This study is the first of its kind using high resolution GPR profiles across the full width of a glacier to study englacial hydrology.

\subsubsection{Research objectives}

The aim of this study is to improve our understanding of englacial hydrology at Annette Plateau, a high altitude temperate glacier and to assess the glacier for potential ice coring sites. The objectives are:

1. Use high resolution GPR surveys to understand water presence and pathways within Annette Plateau, and create a conceptual model of englacial hydrology.

2. Compare two GPR surveys to understand seasonal changes in water distribution/glacier hydrology over a four-month period (Sept - Dec 2011).

3. Compare existing ice core stratigraphy with GPR profiles to better understand radar data.

4. Assess Annette Plateau for potential ice coring sites and indicate the degree to which ice cores from South Island glaciers are adversely affected by melt-water.

The following chapters will describe the methods used and results gained in completing these objectives. 


\section{Chapter 2}

\section{Methodology}

\subsection{Ground penetrating radar}

Ground penetrating radar (GPR) is a tool well-suited for studying glacial environments. The low dielectric constant of ice means that radio waves effectively penetrate ice and snow sub-surfaces (Jol, 2009). Radio echo sounding was first used in 1957 to study ice thickness and other features within polar glaciers. The approach can be traced back to 1933 in Antarctica at Admiral Byrd's base where it was realized that radio waves were transparent through ice. The ineffectiveness of radar altimeters was reported by pilots flying in polar regions, which prompted the first radar research in 1957 (Waite and Schmidt, 1961). Since the initial findings, radio echo sounding and ground penetrating radar devices have been greatly improved and used extensively to study ice and snow environments (Woodward and Burke, 2007). Radar techniques have also been used in many other fields including mineral exploration, the study of near-surface sediments, groundwater research and construction to locate buried objects such as pipes.

Ground penetrating radar works by transmitting radio waves into the subsurface, which are reflected by internal reflectors (Plewes and Hubbard, 2001). Internal reflections occur at changes in the relative dielectric constant, which is caused by physical or chemical changes in the properties of the subsurface or 
due to material orientation (Plewes and Hubbard, 2001). The reflected radio waves are recorded by a receiving antenna, converted into a digital waveform and stored. Common radio wave frequencies are between 1 and $1000 \mathrm{MHz}$ (Woodward and Burke, 2007). The lower the frequency the greater the depth of penetration and the higher the frequency the greater the resolution. Therefore there is a trade-off between resolution and penetration depth. Data are displayed in the form of a radargram, a plot showing signal amplitude in millivolts (mV) against the two-way travel time (TWTT) in nanoseconds (ns) (Davis and Annan, 1989). There are different types of radar survey design, however, a common-offset design is used by most commercial radar units. This involves moving the antenna and transmitter at a fixed spacing across a survey transect. Other types of radar surveys include common midpoint surveys where the receiving and transmitting antennas are progressively moved the same distance away from a central point (Annan, 2004).

\subsection{GPR uses in glacial environments}

Ground penetrating radar has been used to study a large range of features in glacial environments including: crevasse distribution and structure; the glacier bed, englacial pathways; water content and to determine potential ice coring sites (Woodward and Burke, 2007).

The glacier bed has been extensively imaged through the use of GPR. This is typically done to study ice thickness and ultimately to construct subglacial topography (Sharp et al., 1993; Fountain and Jacobel, 1997; Flowers and Clarke, 1999). Flowers and Clarke (1999) used radar on the Trapridge Glacier, Canada, to image the glacier bed. The bed reflections are used to interpolate a glacier bed and to study the subglacial drainage system. The glacier bed is also imaged to study ice volume and mass balance and has been used to locate potential ice coring sites (Thompson, 1992). 
Near surface and deeper crevasse features were studied with GPR by Glover and Rees (1992) which determined two characteristic radar responses. Reflections from shallow firn crevasses displayed reflection free zones perpendicular to the crevasse wall. Deeper crevasses, near the bottom of the firn or in glacial ice and resulted in scattered hyperbolic reflections.

Englacial water pathways have also been imaged using GPR. This has been done by imaging profiles across the glacier (Jacobel and Raymond, 1984; Walford and Kennett, 1989; Irvine-Fynn et al., 2006). The initial studies of englacial hydrology using GPR were done by Jacobel and Raymond (1984) by completing a fixed point radar survey to record the changes in internal reflections. This was done at weekly and daily time-scales and it was interpreted that reflections were from decimetre scale, water-filled, channels which had changing flow rates due to altering water inputs. Similarly Arcone and Yankielun (2000) used GPR to study englacial pathways within the Black Rapids Glacier, Alaska. Two of the horizons imaged in the upper section of the glacier are interpreted as meandering drainage channels. Closer to the ablation zone a more complex branching drainage structure is interpreted, which is thought to be fed by near-surface melt.

Research by Irvine-Fynn et al. (2006) looks at the seasonal evolution of englacial hydrology over the summer ablation period on the Stagnation Glacier, a polythermal glacier in the Canadian Arctic. The study examines results of three GPR surveys covering about $2 \mathrm{~km}$ of the lower glacier. The results show increased noise and the appearance and disappearance of internal reflectors. This was interpreted to be due to an increase in the water content in the temperate ice within the glacier. Other research by Moorman and Michel (2000) used GPR to study the ice thickness and depth to englacial tunnels near the terminus of a high Arctic glacier. The analysis of point source reflectors allowed the internal ice velocity to be determined. The polarity of internal reflections were analysed to identify drainage passages and profile intersections were used to interpolate between features. 
A study by Murray et al. (2000a) uses a combination of GPR and borehole measurements on a small steep temperate valley glacier in Iceland. These were used to create a velocity profile of the glacier as the radar velocity through ice is proportional to the water content. The highest water contents of 3.0-4.1\% were found at $28 \mathrm{~m}$ depth with a radar velocity of $0.149 \mathrm{~m} \mathrm{~ns}(-1)$ which was interpreted as the pieziometric surface.

\subsubsection{Theoretical and physical principles of radar}

Modern GPR units typically consist of a control unit and a transmitting and receiving antenna. The control unit controls the parameters such as timing of outgoing and recorded signal (Gruber et al., 1996). The incoming signal is sampled and stored as a digital waveform. This can generally be uploaded onto a computer for post processing.

The radar works by transmitting a short high voltage pulse to the antenna which sends electromagnetic radiation (EMR) into the surrounding area at a certain frequency (Gruber et al., 1996). The transmitting antenna emits one pulse which is one wavelength long each time it receives a signal from the control unit. The outgoing signal has the shape of a small negative, a large positive and again a small negative amplitude (Gruber et al., 1996). The phase polarity of the reflected signal (e.g. +-+ or -+- ) gives detail on the interface between subsurface materials. When a GPR emits electromagnetic radiation it releases a bandwidth of frequencies which is proportional to the frequency emitted, known as the center frequency. In order to resolve the incoming signal the sample rate needs to be twice the highest waveform frequency. Therefore the sample rate which is selected when collecting GPR data is very important to set correctly (Annan, 2004). This critical sampling rate is called the Nyquist frequency.

The propagation of radar signals in ice is primarily governed by two electrical properties; (1) the relative electrical permittivity, also known as the 'relative dielectric constant' and (2) electrical conductivity (Plewes and Hubbard, 2001). 
Electrical permittivity describes the ability of the material to store an electric charge. The permittivity is described relative to the permittivity of a vacuum therefore called 'relative' permittivity (Annan, 2004; Gruber et al., 1996). In this study relative permittivity will be used to describe relative electrical permittivity and dielectric constant. Relative permittivity $\varepsilon$ is described in equation below:

$$
\varepsilon=\varepsilon_{1} / \varepsilon_{0}
$$

Where $\varepsilon_{1}$ is the absolute permittivity of a material and $\varepsilon_{0}$ the permeability of a vacuum, free space (Gruber et al., 1996).

The electrical conductivity of a material describes its ability to conduct an applied electrical current (Annan, 2004). The electrical conductivity of ice is controlled by temperature or impurity content. Impurities are typically caused by volcanic aerosols, seasonal dust or sea salt. Impurities are generally more important in polar ice as they are commonly washed out due to melt water within temperate environments (Plewes and Hubbard, 2001). Reflections caused by the changes in relative permittivity in glacial environments are typically caused by; water, debris, sediment, air cavities, orientation of ice crystals c-axis, changes in ice chemistry and the underlying geology at the bed of the glacier (Woodward and Burke, 2007). The relative permittivity of ice is approximately 3 and water approximately 80 . The large difference in relative permittivity between these substances generates high amplitude returns.

The sequencing of phase polarity (e.g. +-+ or -+- ) from the reflected radar signal gives detail of the interface between imaged materials (Plewes and Hubbard, 2001). This is based on the relative permittivity of common materials found within ice such as water and air. Water, which has a higher relative permittivity than ice produces a +-+ signal response whereas air, which has a lower relative permittivity, has a -+- signal response. This provides an effective technique for interpreting subsurface reflectors (Arcone et al., 1995; Plewes and Hubbard, 2001). 
The propagation of radar signals can be looked at as signal velocity, signal attenuation and signal resolution (Plewes and Hubbard, 2001). Signal velocity is the speed of the propagating wave through a given medium. The wave speed through air is $0.3 \mathrm{~m} / \mathrm{ns}$ and $0.16 \mathrm{~m} / \mathrm{ns}$ in temperate ice. The lower the relative electrical permittivity of a material the higher the signal velocity (Gruber et al., 1996). The signal velocity $v$ through a medium is shown is equation below:

$$
v=c / \sqrt{\varepsilon}
$$

Where $c$ is the speed of light in free space and $\varepsilon$ is the relative permittivity of the medium (Gruber et al., 1996). Where the radio wave velocity for the subsurface material is known the TWTT, in nanoseconds of a horizon, can be converted into depth. If the velocity is unknown it can be derived from the analysis of hyperbolic reflections on a common mid-point survey (Annan, 2004). Signal velocity in ice is primarily dependent on water content and ice density (Arcone, 2002).

Signal attenuation is the combination of electrical losses and scattering losses within natural materials, which is caused by a variety of processes. Scattering causes the largest amount of attenuation. Scattering is the energy loss due to reflection, refraction and diffraction. Attenuation losses increase with increasing frequency therefore the lower the frequency the greater signal penetration within a medium. Reflections caused by scattering from the subsurface of interest is called signal. Unwanted scatter is termed cluster or noise. The aim of processing radar data is to improve the signal to noise ratio in order to gain the clearest possible image of the subsurface. Geometrical spreading of radio-wave energy with distance from the source also causes signal attenuation at a rate of $1 / r^{2}$ where $r$ is the radius (Gruber et al., 1996).

The resolution of the reflected signal is directly related to the signal frequency. This is theoretically equal to one quarter of the wavelength (Reynolds, 1997). Wavelength and frequency are related in following equation:

$$
\lambda=v / f
$$


Where $\lambda$ is the wavelength, $v$ is the velocity and $f$ is the frequency. However in reality the actual resolution is reduced to one-half or one-third of the wavelength due to the complex interactions between transmitted waves and the ground (Sheriff and Geldart, 1982). This study uses a $100 \mathrm{MHz}$ frequency antenna which relates to a wavelength of $3 \mathrm{~m}$ in ice therefore resolution is 0.75 $\mathrm{m}$ to $1.5 \mathrm{~m}$. Theoretically this is shown in the equation below where $(\beta)$ is the theoretical vertical resolution:

$$
\beta=v / 4 f
$$

Where $v$ is the radio wave velocity and $f$ is the frequency. Reflections will occur from layers down to $1 / 32$ the wavelength which in ice is $0.094 \mathrm{~m}$.

\subsection{GPR arrangement and acquisition settings}

This study used a $100 \mathrm{MHz}$ Mala RAMAC impulse radar unit made by Mala Geosciences. The radar unit was used with a Mala Pro ex-control unit with a $100 \mathrm{MHz}$ rough terrain antenna (RTA) with $2.2 \mathrm{~m}$ antenna separation. A Garmin Etrex hand-held global positioning system (GPS) was used in conjunction with the GPR to record the position. During the second survey a Trimble GeoXH GPS was also used and the data post-processed for higher accuracy. The GPR unit was towed across the glacier surface by a skier for both surveys. The the control unit was mounted in a backpack and a display monitor attached with a shoulder strap while the RTA was towed behind (Figure 2.1). This set-up offered good manoeuvrability and minimal risk to data quality and skier safety.

The $100 \mathrm{MHz}$ antenna was chosen for the survey as the $100 \mathrm{MHz}$ frequency provides reasonable penetration, in temperate ice upto approximately $200 \mathrm{~m}$, and a resolution of $0.75-1.5 \mathrm{~m}$ (Gruber et al., 1996). The aim was to image englacial features through the depth of the glacier and also gain bed reflections as attenuation increases greatly with frequencies over $100 \mathrm{MHz}$ (Davis and Annan, 1989). The high voltage pulse transmission aids good signal penetration. The RTA used in this study is an unshielded antenna and releases a radar beam in a 
conical form rotated around the axis of the antenna into the surrounding area.

Acquisition settings are the settings used to collect the data. If these are not set correctly the depth of recorded data and resolution may be inadequate and/or low quality. The time window sets the length of time the antenna receives the trace signal therefore determines the depth which can be resolved. Research by Kees (2011) using GPR on the Annette Plateau in 2009 determined that the greatest depth to the bed of the glacier was approximately $120 \mathrm{~m}$. A time window which allows recording at a depth of $30 \%$ greater than the expected deepest reflector is recommended (Jol, 2009). Therefore a time window which equated to depth of $150 \mathrm{~m}$ was selected to be sure that the bed would be imaged if possible. The depth of imaged subsurface is calculated by the following equation:

$$
D=v t / 2
$$

Where $D$ is the depth of the lowest observed reflector, $v$ is the velocity of radiowaves through a medium of interest, and $t$ is the TWTT nanoseconds. The accepted wave velocity in pure ice is $0.167 \mathrm{~m} / \mathrm{ns}$ (Murray et al., 2000a; Reynolds, 2011; Dowdeswell and Evans, 2004) which, combined with a time window of $1790 \mathrm{~ns}$ equated to a depth of approximately $150 \mathrm{~m}$. The selected time window was changed over the course of both surveys as the ice depth on the upper part of the glacier is shallower than the lower area, therefore a smaller time window of 1008 ns was used in the upper profiles during the December survey. The sampling frequency was set for each survey which ranged from $872 \mathrm{MHz}$ to 2007 $\mathrm{MHz}$.

The distance between each measurement point is known as the step size. If the step size is too large certain features and areas with steep dips will not be resolved. The largest distance between measurement points which is able to resolve subsurface features is related to the Nyquist principle where the distance between samples should not be larger than $1 / 4$ to $1 / 2$ the wavelength (Jol, 2009). This is not an issue in this study as a high sample rate was used and data were collected at a low horizontal velocity which resulted in a mean steep size of $0.15 \mathrm{~m}$. It is suggested that a maximum step size of $0.25 \mathrm{~m}$ is used for a 
$100 \mathrm{MHz}$ survey (Jol, 2009).

Stacking is done to improve the signal to noise ratio, by averaging several samples that are recorded at the same time. Traces were stacked 4 times in the September survey and 16 times in the December survey. Increasing number of stacks was done to resolve increased amounts of internal reflectors caused by higher water contents in the glaciers during the melt season.

\subsubsection{GPR survey}

The first survey was completed on the 29 of September 2011 near the end of the winter season. Parallel profiles were completed across the glacier surface perpendicular to the down-glacier direction. Profiles were spaced $20 \mathrm{~m}$ apart beginning at the upper most part of the glacier and continued to $500 \mathrm{~m}$ downglacier. The $20 \mathrm{~m}$ profile spacing was used in order to potentially resolve continuity of englacial features as suggested by Irvine-Fynn (2004). Due to a lack of time on the glacier, profiles in a down-glacier direction where not able to be collected. The survey was marked out using measuring tape and visual markers at the ends of the profiles.

The second survey took place on the 2nd of December 2011 which is early summer. This survey used a similar set-up to the initial survey with a few improvements. A Trimble GPS was used with profiles mapped out in order to follow profiles more accurately and also record GPS locations with better accuracy. These data were merged with the GPR data through the time domain recorded by the Garmin Etrex GPS. Profiles were also completed down-glacier, perpendicular to cross-glacier transects, to complete a gridded pattern and enable correlation between profiles. A total of five down-glacier profiles were completed with a spacing of $100 \mathrm{~m}$ and a length of approximately $660 \mathrm{~m}$. Two perpendicular crossing profiles were also completed across the 2009 ice coring site in order to correlate profiles with ice core data. 


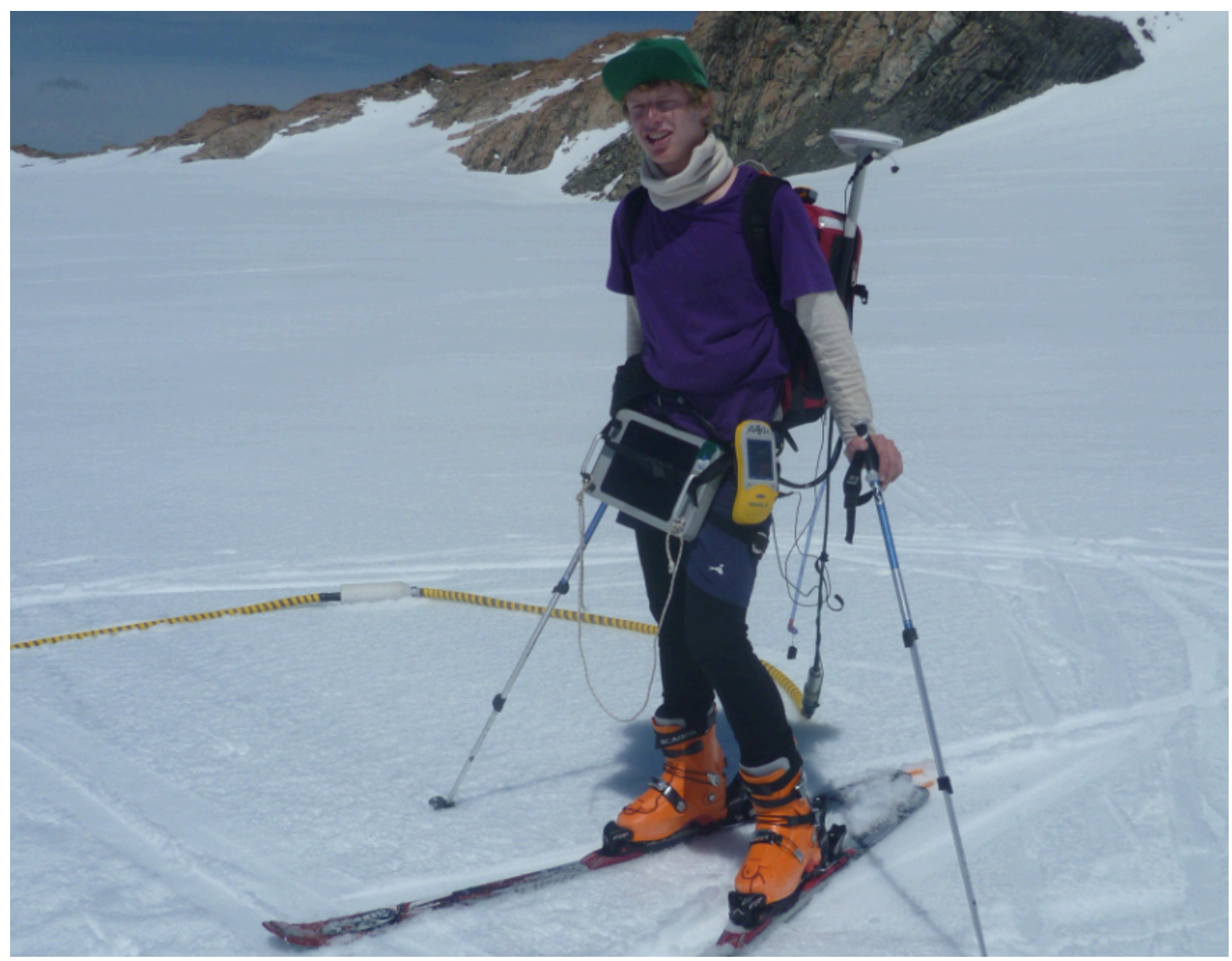

Figure 2.1: Photo displaying ski towed GPR set-up; $100 \mathrm{MHz}$ Antenna (yellow cord on snow surface), Display unit, Control unit in backpack, Trimble GPS and ski gear

\section{Logistics}

From a logistical stance the fieldwork was challenging. Logistics involved transporting all GPR equipment and personal gear including ski equipment from Aoraki/Mount Cook village to Annette Plateau. The field crew and all equipment were transported by helicopter for which clear weather and low wind speeds were required for flying conditions. During both the fieldwork trips there was typically a $1-3$ day wait for good weather conditions. During this time the field crew spent time relaxing and ensuring all equipment was in working order. 


\section{Improvements in data collection}

Suggested improvements for future work are to have spare GPR batteries, as these were commonly a limiting factor in gaining extra profiles and high quality data. It is noted that the final profiles surveyed in the December survey had issues with timing due to low battery power. Timing issues were resolved through post processing.

\subsection{Data processing}

The radar data were processed using Claritas the seismic processing software package developed by the Institute of Geological and Nuclear Sciences (GNS), Wellington, New Zealand. The radar data were converted into a suitable format to be used in Claritas, as the original data were formatted for use in proprietary radar software. The aim of processing data is to increase the signal to noise ratio to make the data as visually clear as possible without removing any of the interpretable data. Processed data can then be used for interpretation and digitization. Low quality data collected in the field can not be edited through processing, therefore it is important the original data are of a high standard (Jol, 2009). This study focuses on interpreting the englacial features from the surface of the glacier to the bed during two surveys at the end of the winter season and early summer.

Filters are applied to the data in order to remove noise or to enhance particular features (Jol, 2009; Annan, 2004). The alteration of data is done by altering, suppressing or removing signal data from a particular frequency or frequencies. Many different types of filters exist from simple band pass filters to complex combined spatial and temporal filters. Simple filters remove either the low or high frequency components within a trace. Temporal filters work along the time axis of the trace data and spatial filters along a number of traces with distance (Jol, 2009). The data collected within this study displayed a high frequency speckled component which was removed through the use of a Butterworth fil- 
ter. The advantage of using a Butterworth filter it that it retains the correct relative amplitude data. This type of filter is recommended for radar surveys below $200 \mathrm{MHz}$, however it, can be problematic and cause ringing (repetition of data) in data collected with higher frequency antennas (Jol, 2009). A range of filters were tested but a low pass Butterworth filter of: 50, 100 performed the best in removing noise and was used on all radar data.

The data were also passed through a dewow filter which removes the low frequency bias common in radar data. The low frequency bias is caused by the initial high amplitude reflectors such as the ground and air reflection which swamps the recorded signal. This is recorded as a low frequency wave visible in the data. The dewow filter is effectively a low cut filter which reduces data to a mean zero level (Jol, 2009).

The first arrival time caused by the air/ground reflection is typically referred to as time zero. In some cases jumps occur in the first arrival along the trace profile which can be caused by electronic instability and variations in the antenna air gap. The time zero correction is made in order to adjust traces so they start at a common reflector. Some issues were encountered with the timing of the received traces in the last 7 profiles collected in the December survey. The timing of received traces were corrected by picking along a common reflector and applying a static shift. Time zero corrections were also made later during the interpretation stage in order to correlate between profiles.

Gain functions are applied to data in order to counteract transmission losses caused by spherical spreading and attenuation of signal with depth. There are different types of gain functions for example, constant gain, exponential gain and automatic gain control (AGC). These functions work by amplifying the signal down the trace in time. The gain function used in this study was a smooth median gain.

Migration is a processing technique which is typically used in an attempt to improve profile resolution and create a more spatially correct image of the sub- 
surface. The subsurface velocity and the distance between traces are used to create a more realistic subsurface image by collapsing hyperbolas to point sources and correcting dipping reflectors. The migration process uses the following assumptions; the velocity structure of the subsurface is known, data are collected with no antenna separation, attenuation does not occur and that the source signal propagates spherically. In some cases unmigrated data can be better used for interpretation. Migration was applied to the data in this study with a velocity of $0.167 \mathrm{~m} / \mathrm{ns}$ accepted for pure ice (Annan, 2004) and an average distance of $0.15 \mathrm{~m}$ was calculated between traces. Although the velocity of the GPR over the subsurface was not always consistent trace spacing of $0.15 \mathrm{~m}$ worked well to resolve hyperbolic reflections. The migration worked well and hyperbolic reflections were returned to point sources, however, some point and bed reflections became less clear. Therefore a migrated and unmigrated dataset were both processed for interpretation.

\subsection{Data interpretation}

Radar interpretation was done using Seisware, a seismic software package which runs on a windows operating system. Seisware is very well suited for data visualization and allows profiles to be viewed simultaneously. The software also enables cross cutting profiles to be viewed in a single profile view. The software is limited in its ability to apply complex processing, however, this is not an issue as processing was completed in Claritas prior to importing into Seisware.

\subsubsection{Horizon picks}

Reflectors and reflective horizons were located and picked using Seisware. The source of reflectors picked were assumed to be located directly below the profile traversed. In actual case this assumption is incorrect as the radar emits energy in the shape of an elliptical cone perpendicular to the traversed profile therefore returns may come from any source within the elliptical footprint. 
Profiles were picked from left to right, down-glacier, beginning with the upper most profile then sequentially viewed down-glacier in order to follow reflective horizons. After reviewing the radar data a series of reflective patterns were recognized within the data. These reflective patterns became the basis for horizon and reflection picks. The reflective patterns were compared to actual subsurface glacial features to aid the picking process.

Horizons picked are listed below:

1. Lowest solid continuous reflector - (bed).

2. Lowest solid semi-continuous reflector - (bed inferred).

3. Point reflector; isolated concentrated internal reflector - (englacial water or cavity).

4. Internal reflector; semi-continuous internal reflector near approximately 150 ns - (water table).

5. Initial internal reflector; continuous reflector near approximately $40 \mathrm{~ns}$ (winter snow base).

6. Banded surface reflector; banded vertical reflector extending from nearsurface (crevasse, surface water percolation).

7. Dipping layer; continuous reflector dipping from surface.

8. Concave surface - Continuous concave internal reflector.

Horizons were picked manually or using an auto-pick function if the reflector was continuous. Horizons were picked on the upper limit of the first positive phase return. Picking parameters were set to search for the closest positive phase within $20 \mathrm{~ns}$. Solid reflective horizons such as the bed were typically picked from full profile view, then a zoom was applied to edit and confirm the position of picks. Smaller reflectors were typically picked using a $2-4$ times zoom. 


\subsubsection{Interpretation}

The interpretation of englacial reflections is based on other glacial investigations using GPR, ice core data from Annette Plateau and the synthetic radargrams produced in this study. The ice core data shows that there is water present at certain depths within the glacier which varies spatially. Interpretation of englacial reflectors is difficult therefore as discussed above reflection patterns were developed to ensure consistency within interpretation.

The underlying bedrock topography of a glacier is typically the most apparent reflective horizon. Many studies using GPR have succeeded in imaging the bedrock topography of glaciers. The bed is typically described as the lowest solid continuous reflector (Irvine-Fynn, 2004; Baelum and Benn, 2011; Moran et al., 2003; Murray et al., 1997; Woodward et al., 2003).

Water or air-filled conduits which are crossed at an angle to flow direction produce hyperbolic point source reflectors. These can be concentrated to a point source reflector through applying the migration function (Jol, 2009). It is widely accepted that a water conduit within an ice medium produces a +-+ phase sequence whereas an air over ice interface produces a -+- phase sequence (Jol, 2009; Murray et al., 2000a; Woodward and Burke, 2007; Arcone et al., 1995). Air cavities also produce lower amplitude reflections due to the lower dielectric contrast between ice and air (Jol, 2009; Woodward and Burke, 2007).

Water table features are common within temperate alpine glaciers (Murray et al., 2000a; Schneider and Jansson, 2004). They typically form at the interface of the glacier's near impermeable ice body and the base of the firn (Fountain and Walder, 1998). A water table horizon was interpreted at $24 \mathrm{~m}$ depth at the interface between clean and noisy trace sections in a study by Murray et al. (2000a) of a temperate glacier. The noisy returns in temperate ice are caused by the strong dielectric contrast between ice and water which can be up to $4 \%$ (Murray et al., 2000a). Other studies of polythermal glaciers have also documented this change from clean to noisy trace sections as the change from cold to temperate 
ice (Bjornsson et al., 1996; Hamran et al., 1996; Odegard et al., 1997; Moore et al., 1999; Irvine-Fynn, 2004). Feature identification is difficult within the temperate ice due to the amount of noise caused by a high water contents (Irvine-Fynn, 2004).

Crevasse features are able to be identified in radar data. Near surface and deeper crevasse features were studied with GPR by Glover and Rees (1992). The study found two characteristic radar responses. Reflections from shallow firn crevasses displayed reflection free zones perpendicular to the crevasse wall. Deeper crevasses, near the bottom of the firn or in glacial ice and resulted in scattered hyperbolic reflections.

\subsection{Potential errors}

Potential errors in this study may come from a range of sources. Firstly the accuracy of the etrex hand held GPS is $+-5 \mathrm{~m}$, and can be greater when satellite coverage is poor. The degree of potential error from inaccurate GPS data will not greatly effect the final results in regard to the overall size of the study area.

Other possible errors may be due to the differences in wave speed velocities through the glacier. An accepted pure ice wave-speed of $0.167 \mathrm{~m} / \mathrm{ns}$ was used when migrating radar data and for the time depth conversion of englacial features (Dowdeswell and Evans, 2004). Defining the complete velocity structure of the glacier is out of the scope of this study. The error associated with a slightly incorrect wave-speed is minimal. For example the wave-speed of $0.16 \mathrm{~m} / \mathrm{ns}$ is often used for glaciers with high water contents which would cause a depth conversion error of $3 \mathrm{~m}$ at the deepest reflector within this study. This study is focused on the structure of the hydrological system not the exact position and depth of conduits. Therefore, depth conversion errors of this size will not effect overarching outcomes. 
Alterations in distance between traces due to a non-constant velocity when towing GPR is another potential source of error for the migration process. A nonconsistent velocity can affect the horizontal resolution of the data. The mean trace spacing of $0.15 \mathrm{~m}$ was calculated and proved to be the most effective at migrating hyperbolas when tested against other trace spacings. The horizontal resolution of the data can be affected if the trace spacing is greater than a quarter of the wavelength which would equal a trace spacing of $0.75 \mathrm{~m}$. It is highly unlikely that trace spacing of $0.75 \mathrm{~m}$ were acquired as this would require a surface velocity of five times the mean. During GPR data collection the field crew aimed to maintain a steady walking velocity.

The subjective nature of interpreting radar data may also cause errors. There are a total of 9 different horizons/reflection events that were picked and interpreted from 49 radar profiles within this study which shows that there is potential for a high amount of subjective error. The amount of error associated with data interpretation can not be defined, as interpreting a reflection is subjective. However, the reflective patterns interpreted and picked throughout the study remained consistent and were based on other studies and synthetics, therefore subjective error can be minimised.

The potential errors associated with the subjective nature of picking reflectors may also cause errors. A realistic error in picking reflection events could be upto approximately $20 \mathrm{~ns}$ as picks were set to search for the closest positive signal phase within $20 \mathrm{~ns}$ which relates to an error of +- approximately $3.3 \mathrm{~m}$. Possible errors of this size are negligible in terms of the overall aims of the study.

\subsection{Synthetic radar models}

Synthetic radar-grams were modelled using MATGPR a free radar processing software package by Tzanis and Kafetsis (2004) from the University of Athens. 
Structural models were built using the 2-D model building function within MATGPR. Models were built to create a basis of comparison for the field data to modelled data.

Models were built using a background medium with the electrical properties of temperate ice. Hypothetical englacial features were constructed using polygons and circular shapes which were inserted graphically or through a co-ordinate system (Figure 2.2). Features were positioned in the center of the model and assigned values to simulate the mediums actual electrical properties; relative permittivity, background resistivity and relative magnetic permittivity (see Table 2.1). Electrical properties of materials varied through the literature therefore the most common values were used. Electrical properties for wet bedrock were used as it is assumed that water exists at the base of Annette Plateau glacier and other glaciers in temperate environments. The relative magnetic permittivity $\left(m_{r}\right)$ for sedimentary materials is negligible and typically has a value of $m_{r}$ $=1$, (Martinez and Byrnes, 2001) which was used in models.

The models are a simplification of the actual complex geometry of structures within englacial environments. The synthetic radargrams are used as indicators for the scale and pattern of reflections in observed data. Models were built on a $40 \mathrm{~m}$ wide by $20 \mathrm{~m}$ deep surface in order to capture the full extent of reflected synthetics and for ease of comparison between models. Models were run using the Spilt-step 2-D Forward Modelling function. This function generates matrices for the relative properties of the structural model and computes the velocity structure. Models were run at a grid size of 0.1 by $0.05 \mathrm{~m}$ (400/400 cells). In some cases features in the structural model were too small to be resolved by the original grid and the grid size was reduced to 0.08 by $0.04 \mathrm{~m}$ (500/500 cells). Synthetics were run using a sample rate of $0.94 \mathrm{~ns}$ which was used during data acquisition. To enable visual comparison between the synthetics and observed radar data the synthetics were output using a grey colour scale with an amplitude spectrum colour range of $(-8: 6)$ similar to that of the processed data. The center trace of each synthetic was also plotted which displays relative amplitude and phase polarity. The majority of these were plotted on an amplitude 


\begin{tabular}{|l|l|l|l|}
\hline Material & Relative Permittivity $(K)$ & Resistivity $(\Omega)$ & Wave Velocity $(\mathrm{m} / \mathrm{ns})$ \\
\hline Air & 1 & 0 & 0.3 \\
Ice $($ Pure) & 3.2 & $2 \times 10^{5}$ & 0.167 \\
Fresh Water & 80 & $3 \times 10^{3}$ & 0.0335 \\
Wet bedrock & 15 & 0.1 & 0.0099 \\
Ice Impurity & 3.183 & $2 \times 10^{5}$ & 0.167 \\
\hline
\end{tabular}

Table 2.1: Table shows electrical properties; Relative Permittivity $(K)$, Resistivity $(\Omega)$, Wave Velocity (m/ns), of common englacial materials, modified from (Annan, 2004; Catania et al., 2008), ice resistivity from (Moore, 1988; Jaccard, 2006), air resistivity (Pawar et al., 2009) bedrock type is Schistose Greywacke from (Lillie and Gunn, 1964) and Ice Impurity is $(\mathrm{NaCl} 7,656 \mathrm{ug} / \mathrm{L})$

scale from $(-8: 8)$ although for few synthetics with high amplitude returns an increased scale was used. These were $(-10: 10),(-20: 20)$ and $(-30: 30)$.

In order to compare between models and observed data it is important to know the shape of the source wavelets as the polarity of these affects the polarity of reflections. The forward modelling tool which was used to build synthetic radargrams uses a ricker wavelet. The similarity of the modelled wavelet and observed wavelet was determined using an autocorrelation function on the observed data. Autocorrelation is a radar processing function which cross correlates a wavelet with itself it determine the similarity the source wavelet through summing the trace. The outcome for the observed data was a ricker wavelet therefore, modelled data and observed data are comparable.

\subsubsection{Englacial models}

A range of models were built using spatial geometries and electrical properties which attempt to represent englacial features in the natural environment. The models range in complexity although all features were added symmetrically in the center of the model. The dimensions of the models are listed below:

1. Conduit

(a) Water filled conduit 
Conduits were modelled using a range of diameters which are listed below:

- $0.1 \mathrm{~m}$

- $0.2 \mathrm{~m}$

- $0.5 \mathrm{~m}$

- $1 \mathrm{~m}$

(b) Air filled conduit

- $0.2 \mathrm{~m}$

- $0.5 \mathrm{~m}$

- $1 \mathrm{~m}$

(c) Mixed water and air conduit

- $0.2 \times 0.4 \mathrm{~m}$

- $0.5 \times 1 \mathrm{~m}$

2. Crevasse features

(a) Crevasse $(8 \mathrm{~m}$ in length, $1 \mathrm{~m}$ wide at surface, thinning to $0.2 \mathrm{~m}$ at base)

(b) Covered crevasse (crevasse begins $4 \mathrm{~m}$ below surface, $8 \mathrm{~m}$ in length, $1 \mathrm{~m}$ wide at surface, thinning to $0.2 \mathrm{~m}$ at base)

(c) Crevasse with water at base ( $8 \mathrm{~m}$ in length, $1 \mathrm{~m}$ wide at surface, thinning to $0.2 \mathrm{~m}$ at base, with $0.2 \times 0.4 \mathrm{~m}$ water filled conduit at base)

(d) Covered crevasse with water at base (crevasse begins $4 \mathrm{~m}$ below surface, $8 \mathrm{~m}$ in length, $1 \mathrm{~m}$ wide at surface, thinning to $0.2 \mathrm{~m}$ at base, with $0.2 \times 0.4 \mathrm{~m}$ water filled conduit at base)

3. Water table

(a) Water filled layer (20 $\times 0.2 \mathrm{~m}$ at $10 \mathrm{~m}$ depth)

(b) Water filled conduits closely spaced, see Figure 2.2 (water conduits of $0.2 \mathrm{~m}$ in diameter spaced at $5 \mathrm{~m}$ intervals at $10 \mathrm{~m}$ depth) 
4. Glacier Bed

(a) Low angle bed $6^{\circ}$

(b) High angle bed $45^{\circ}$

5. Impurities and density

(a) High $\mathrm{NaCl}$ concentration

(b) Layers changing ice density (similar to observed ice core data)

\subsubsection{Ice impurities}

Alterations in ice chemistry cause a change the relative permittivity of the ice although, these are generally quite small (Matsuoka et al., 1997). A study by Matsuoka et al. (1997) looked at the changes in relative permittivity with sodiumchloride $(\mathrm{NaCl})$ at a concentration of 7,656 ug/L, which is likely in temperate marine environments. This had the affect of lowering the relative permittivity by 0.017 which was also modelled in a synthetic. This was done to observe the effects of acidic ice within non-acidic ice in the reflected trace. The highest concentration of sodium within the ice core was $300 \mathrm{ug} / \mathrm{L}$ therefore the actual change in relative permittivity would be lower than what was modelled. The high $\mathrm{NaCl}$ concentration was used in the synthetic model to observe the amplitude of the reflected signal. This was compared to the amplitude of returns from other synthetic features to determine if changes in the ice chemistry could be interpreted within the Annette Plateau Glacier.

The resistivity of the ice is also effected by the increase of $\mathrm{NaCl}$. This change is not accounted for within the model as the relationship between resistivity and sodium concentration within ice is unknown. The relationship between conductivity and chloride within ice has been published by Moore et al. (1992). The relationship was used to calculate the change in resistivity and gave a value of $6 \times 10^{5} \Omega$ which is a greater resistance than the value used within the models. 


\begin{tabular}{|l|l|l|}
\hline Ice core top depth $(\mathrm{m})$ & Density $\left(\mathrm{g} \mathrm{cm}^{-3}\right)$ & Relative Permittivity $(\mathrm{K})$ \\
\hline 0 & 0.45 & 1.91 \\
1 & 0.55 & 2.16 \\
2 & 0.70 & 2.52 \\
3 & 0.72 & 2.58 \\
4 & 0.74 & 2.63 \\
5 & 0.71 & 2.57 \\
6 & 0.74 & 2.65 \\
7 & 0.77 & 2.73 \\
7 & 0.74 & 2.64 \\
10 & 0.78 & 2.75 \\
11 & 0.79 & 2.77 \\
12 & 0.71 & 2.57 \\
13 & 0.78 & 2.74 \\
14 & 0.78 & 2.74 \\
15 & 0.76 & 2.68 \\
16 & 0.79 & 2.78 \\
17 & 0.78 & 2.75 \\
18 & 0.77 & 2.74 \\
19 & 0.80 & 2.80 \\
\hline
\end{tabular}

Table 2.2: Table shows ice core density and relative permittivity changes with depth; Relative Permittivity $(K)$ and density $\left(\mathrm{g} \mathrm{cm}^{-3}\right)$ 


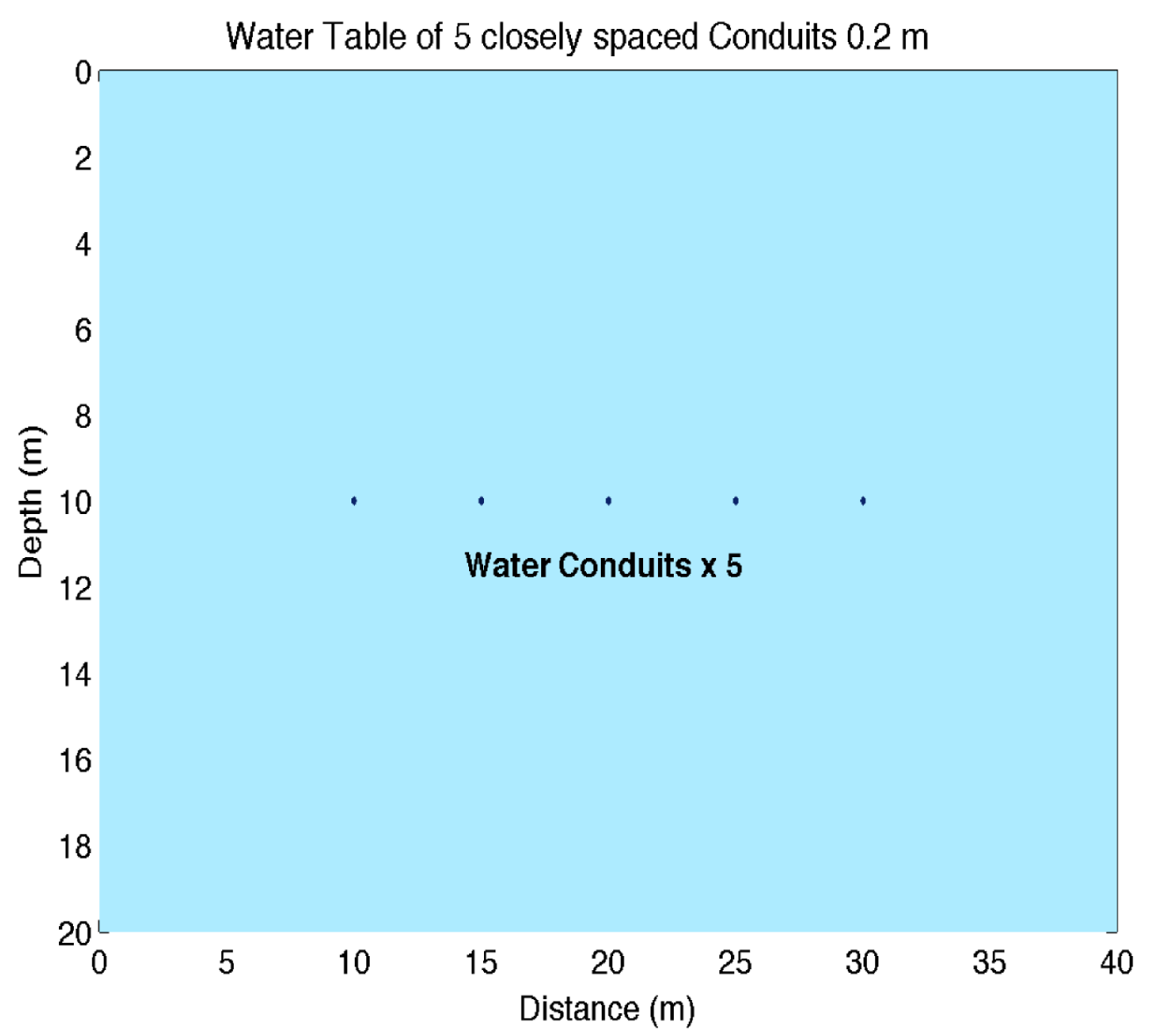

Figure 2.2: Figure showing model built using MATGPR. The model consists of temperate ice with water conduits of $0.2 \mathrm{~m}$ in diameter spaced at $5 \mathrm{~m}$ intervals. The temperate ice is the background medium, light blue in colour and the water conduits are represented by dark blue circles. Electrical properties of relative permittivity $(K)$, background resistivity $(\varrho)$ and magnetic permeability $(\mu)$ were assigned to the different mediums within each model (see table 2.1). All models were run at $100 \mathrm{MHz}$.

\subsubsection{Ice density}

The effect of ice density on relative permittivity was researched since the late 1960's and refined by Kovacs et al. (1995). The relationship is shown in the following equation:

$$
\varepsilon_{r}=(1+0.845 \rho)^{2}
$$

Where $\varepsilon_{r}$ is the relative permittivity and $\rho$ is the specific gravity of ice in $\mathrm{g} / \mathrm{cm}^{3}$. 
A typical ice specific gravity of ( $\rho=0.917$ ) relates to a permittivity of 3.15 which agrees with typical ice permittivity values (Kovacs et al., 1995; Fujita et al., 2000). The ice core density profile was used to calculate respective relative permittivity and modelled to compare with observed radar data, see Table 2.2.

\subsection{Hydropotential surfaces}

Hydropotential describes where water will flow due to pressure differences on a surface within a medium. This principle can be used to understand where water will flow on surfaces within the glacier, for example at the bed or a water table. The water pressure at any point within the glacier can be thought of simply as equal to the pressure of the overlying ice. Water flow is perpendicular to equipotential contours. Hydropotential $(\phi)$ within a glacier is explained within the equation below from Paterson (1994).

$$
\phi=\phi_{0}+\rho_{i} g z_{s}+g\left(\rho_{w}-\rho_{i}\right) z
$$

Where $\phi_{0}$ is a constant, $\rho_{i}$ is the density of ice, $g$ is gravity, $z_{s}$ is surface elevation (surface slope) and $\rho_{w}$ is the density of water and $z$ is the bed elevation. The equation shows that the surface slope of the glacier is 10 times more influential than the bed slope in determining flow.

Hydropotential maps were produced using the glacier surface elevation data collected using the Trimble GeoXH GPS and the horizons picked within the glacier from the December 2011 survey. Hydropotential maps were created for the bed surface and the water table surface, however, they relie on the assumption of a spatially uniform water pressure. Hydropotential maps were not made for the September survey as the GPS used during the survey was unable to collect accurate elevation data. It is expected that these would be similar to the December survey as changes in glacier ice thickness and slope between surveys is minimal.

The horizons and reflectors that were picked using Seisware were used to create 
grid files using Seisware. The grids were created using a $20 \times 20 \mathrm{~m}$ resolution as profile spacing was $20 \mathrm{~m}$. A minimum curvature spline interpolation technique was used which produces the smoothest possible surface while following the data as closely as possible. The horizon data were exported as text files and used to mask data at a later stage.

The hydropotential maps were produced through shell scripting in bash using GMT commands. The script used the gridded horizon, surface elevation data and a time depth velocity conversion of $0.167 \mathrm{~m} / \mathrm{ns}$. The maps were then masked using the horizon picks to exclude grid areas which did not have sufficient data. The masks were created using the same resolution as the grids $20 \mathrm{x}$ $20 \mathrm{~m}$. 


\section{Chapter 3}

\section{Results}

\subsection{Radar data}

In this section radar results from both the September and December 2011 surveys will be shown. Features will be described from upper to lower glacier. The features identified within the profiles will be described, beginning with the bedrock topography, followed by the interpretation of water table, conduit features, and other internal reflectors which were picked. All radar data and picks are shown in the Appendix.

The radar survey took place from the head of the glacier to $660 \mathrm{~m}$ down-glacier, however, the lower $240 \mathrm{~m}$ did not include profiles in a cross-glacier direction due to time constraints (see Figure 3.1). The area of the glacier which was surveyed with both cross- and down-glacier profiles (upper $420 \mathrm{~m}$ of the glacier) will be the focus in the following descriptions. For ease of descriptions the following terms will be used to represent different zones of the glacier; upper (from the head of the glacier) consists of $0-150 \mathrm{~m}$; mid $150-300 \mathrm{~m}$ and lower $300-420 \mathrm{~m}$. Reference maps of both radar surveys showing profile names can be seen in Figures 3.2 and 3.3. 


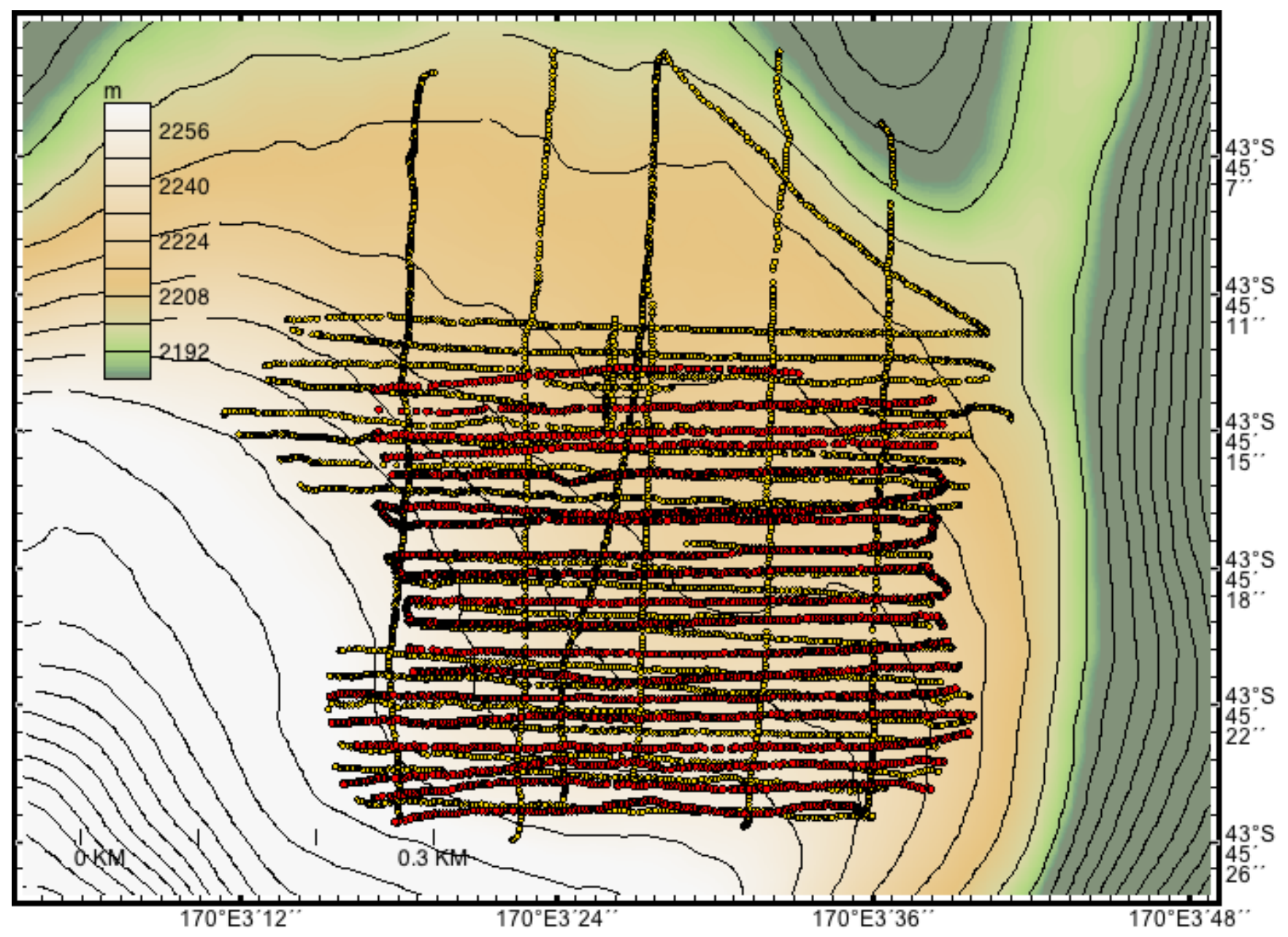

Figure 3.1: Illustration shows surveyed profiles at Annette Plateau. Red profiles show September survey and yellow profiles show December survey. Colour and contours denote elevation.

The depth of englacial reflections will be expressed in nanoseconds (ns), which is the two-way travel time (TWTT), and a conversion into meters at the widely accepted velocity of radio waves in pure ice of $0.167 \mathrm{~m} / \mathrm{ns}$ (Woodward and Burke, 2007). It is expected that this value will vary through the glacier as signal velocity in ice is primarily dependent on water content and ice density (Arcone, 2002). The presence of snow and firn in the upper layers of the glacier means the depth conversion at $0.167 \mathrm{~m} / \mathrm{ns}$ will underestimate the actual depth. It is also important to note that the data were not static corrected, therefore all depths given will be approximately $10-15 \mathrm{~ns}(0.8-1.3 \mathrm{~m})$ deeper than reality. Trace amplitudes from synthetic and observed data are shown within this section. 
Trace amplitudes are normally given in microvolts $(\mathrm{uV})$ but processing of radar data alters original trace amplitudes. In this report trace amplitudes are plotted to describe relative changes in trace amplitude.

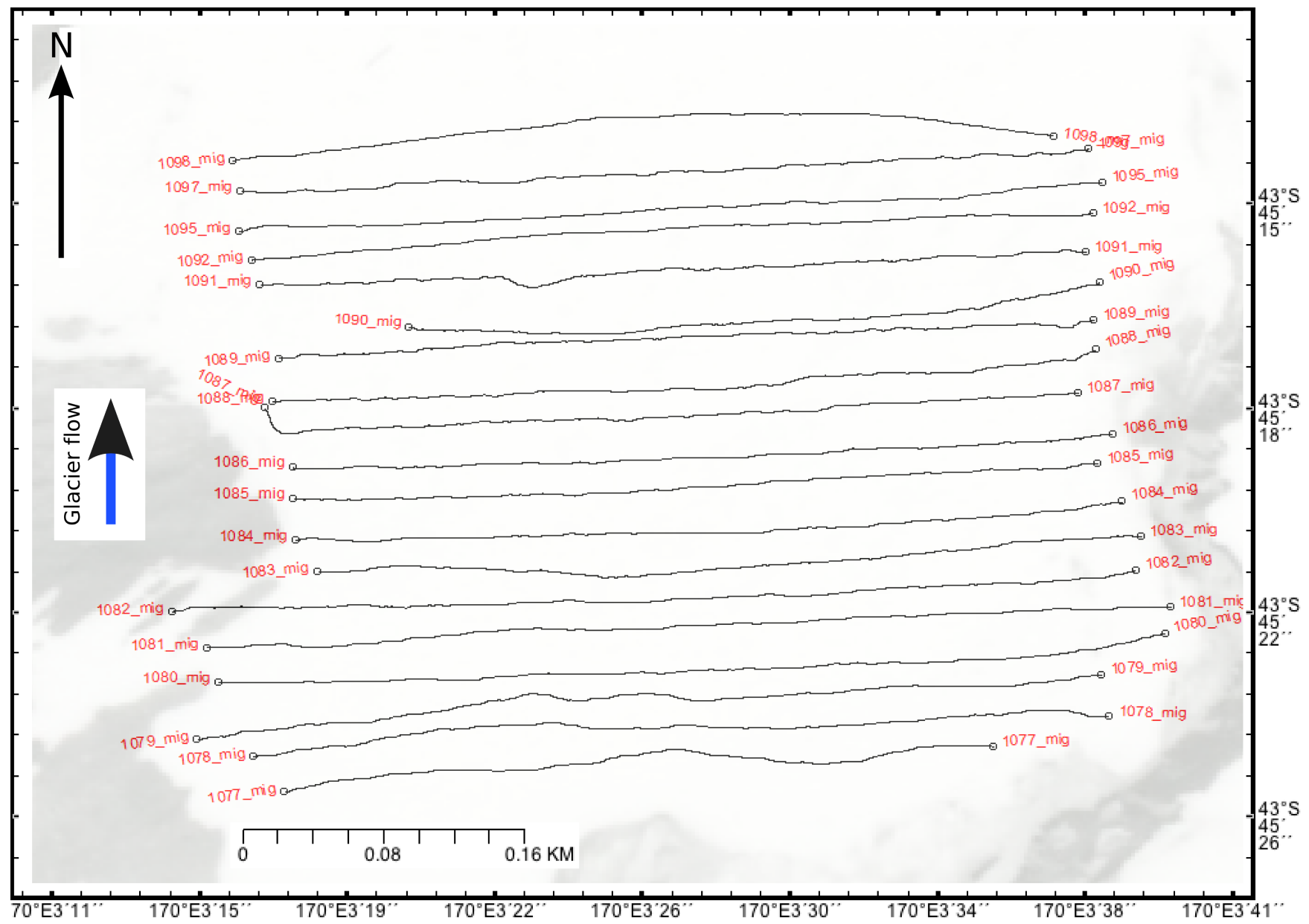

Figure 3.2: September GPR survey locations at Annette Plateau. Transects are labelled with profile numbers. See appendix for radar profiles. 


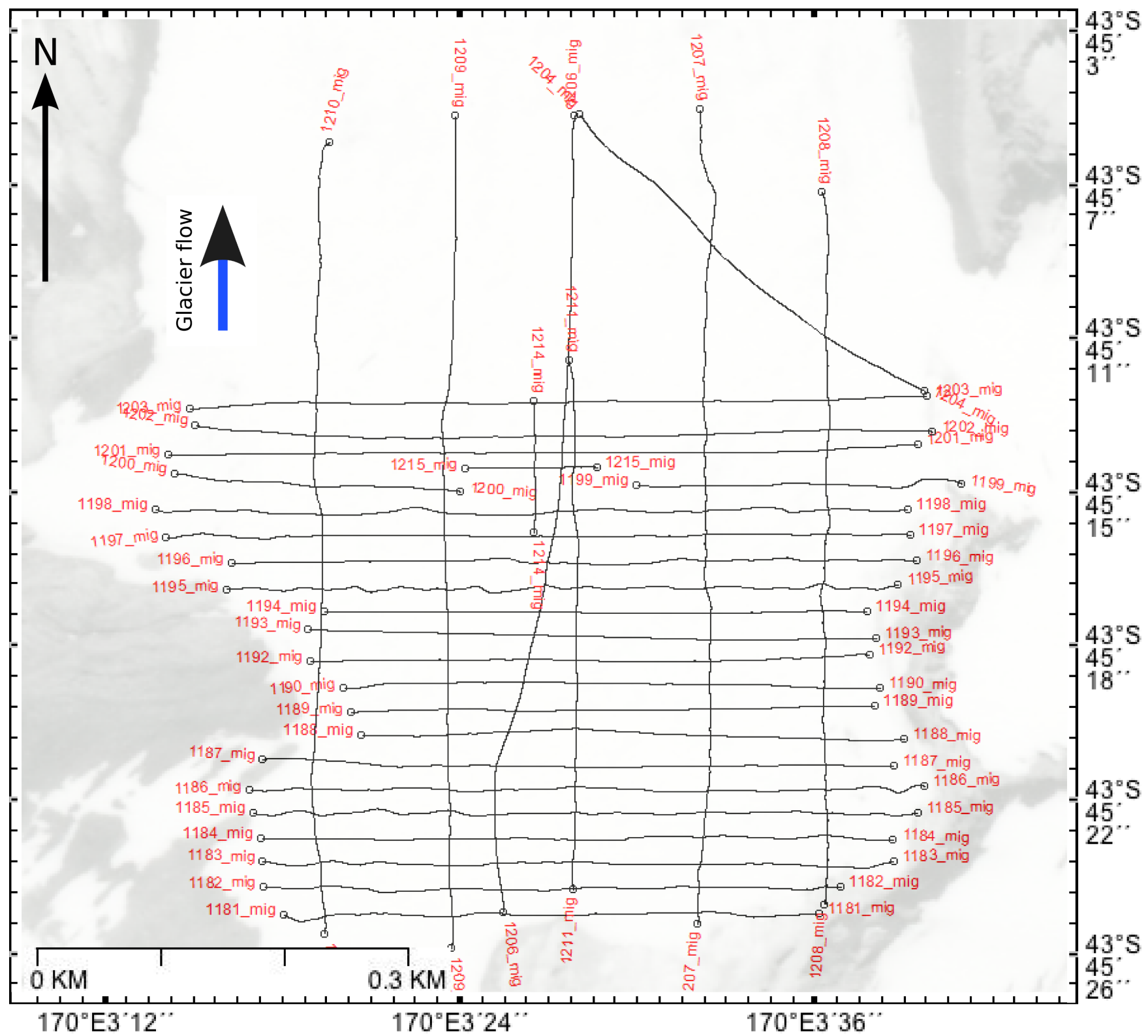

Figure 3.3: December GPR survey locations on Annette Plateau. Transects are labelled with profile numbers.

\subsubsection{Bedrock topography}

The bed reflection defines the clearest horizon in both the September and December survey. The bed reflection and wave phase from a clear bed reflection can be seen in Figure 3.4. A contour map of the bedrock topography is shown 


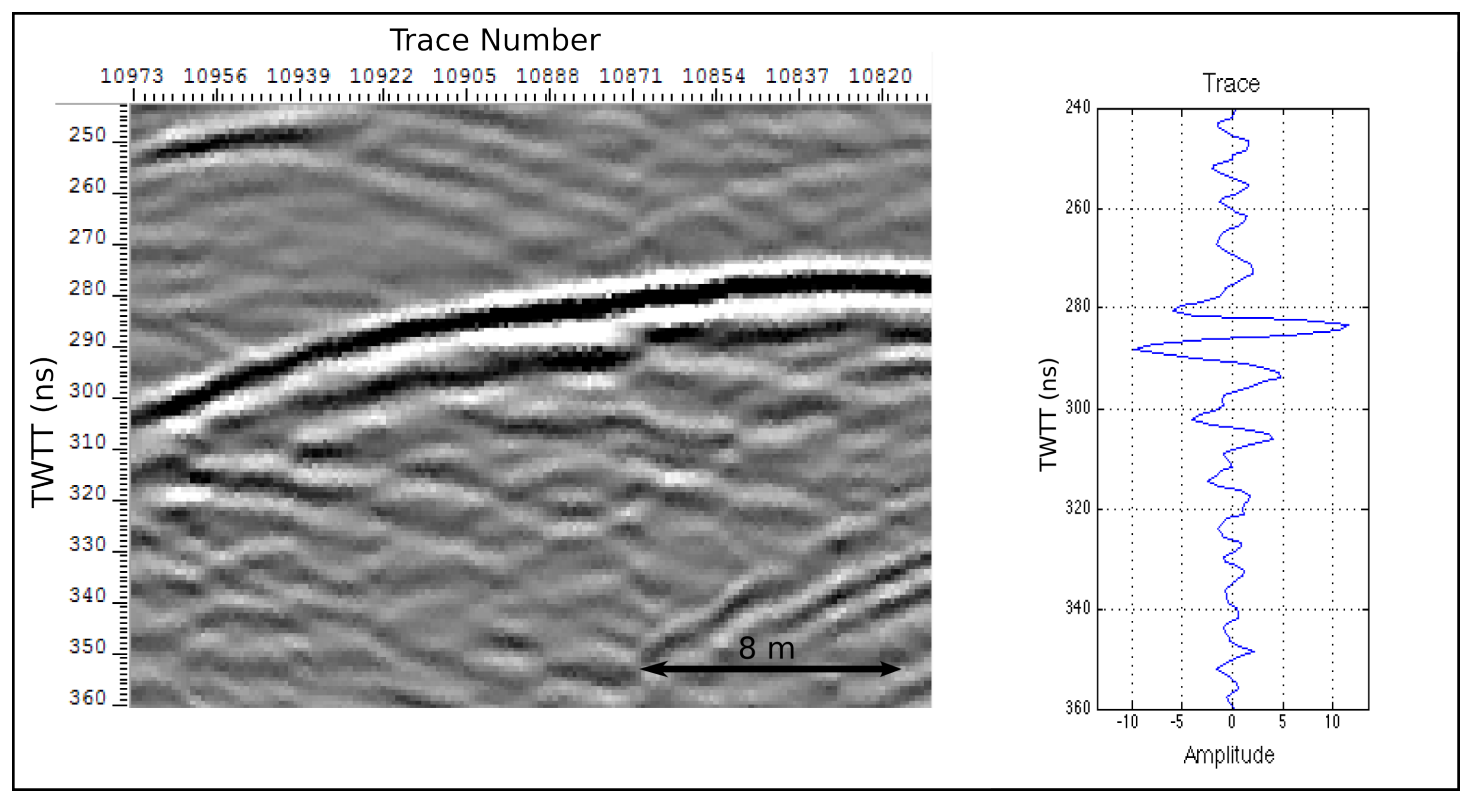

Figure 3.4: Bed reflection from upper glacier profile Sept1077.

in Figure 3.5. The spatial distribution of bed picks from both surveys is shown in Figures 3.6, 3.7, 3.8, 3.9, 3.10 and 3.11. Overall the bed is well defined in the upper profiles and becomes less distinct further down-glacier. This is possibly due to increasing ice depth and water content down-glacier, causing a greater amount of radar attenuation (Jol, 2009).

The bed topography of the upper profiles on the western side show a high angle, poorly defined, bed reflection. The eastern side undulates at a low-angle and is well defined. The western side of the glacier bed remains less defined and at a higher angle than the eastern side until $220 \mathrm{~m}$ down-glacier. At this point the classic $U$ shaped glacier bedrock topography is evident. It is thought the western side of the glacier is less defined due to the high dip angle. The bed topography on the eastern side of the glacier begins with a shallow dip, which steepens down-glacier, and is constant by $200 \mathrm{~m}$ down-glacier.

The mid to lower section of the surveyed area shows well defined bed topography until $600 \mathrm{~ns}(50 \mathrm{~m})$, below which the bed horizon is less defined, although few sections were inferred based on less defined bed reflections. The longitu- 
dinal profiles surveyed in a down-glacier direction, north to south, reflect what is seen in the cross profiles; however increased definition is evident from bed reflections up to $1300 \mathrm{~ns}$ (125 m) (Appendix profile Dec1211). This anisotropic penetration is not uncommon in glaciers and ice sheets (Dowdeswell and Evans, 2004). Below $420 \mathrm{~m}$ down-glacier the bed shows a slight over deepening however this is not well constrained due to the lack of cross-glacier profiles in this area.

Histogram data, from Figures 3.6, 3.7, 3.8, 3.9, 3.10 and 3.11, shows that bed horizons were typically distributed between 50 - $400 \mathrm{~ns}(4.2-33.4 \mathrm{~m})$. The bed inferred picks are distributed between $200-1200 \mathrm{~ns}$ (16.7 - $100.2 \mathrm{~m})$. Overall the largest distribution is found between $50-350 \mathrm{~ns}(4.2-29.2 \mathrm{~m})$, with a small evenly spread distribution between 350 - $1400 \mathrm{~ns}(29.2$ - $116.9 \mathrm{~m})$; these results are expected as bed definition is typically better at lower ice depths. 


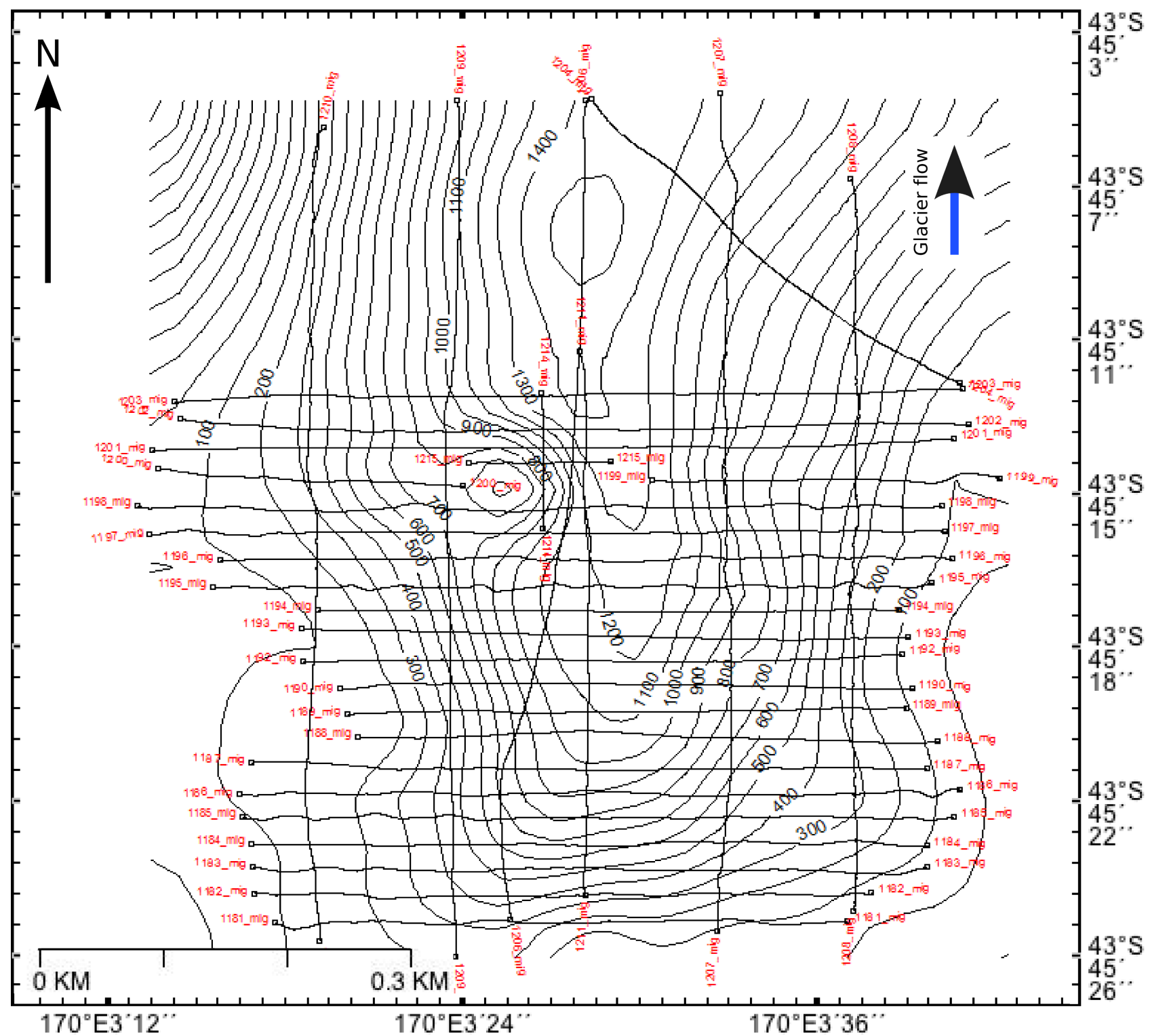

Figure 3.5: Annette Plateau bed topography determined by bed picks from December survey. Contours displayed in TWTT. Note contours $500 \mathrm{~ns}(41.8 \mathrm{~m})$ and $1000 \mathrm{~ns}(83.5 \mathrm{~m})$. Surveyed profiles also shown. 


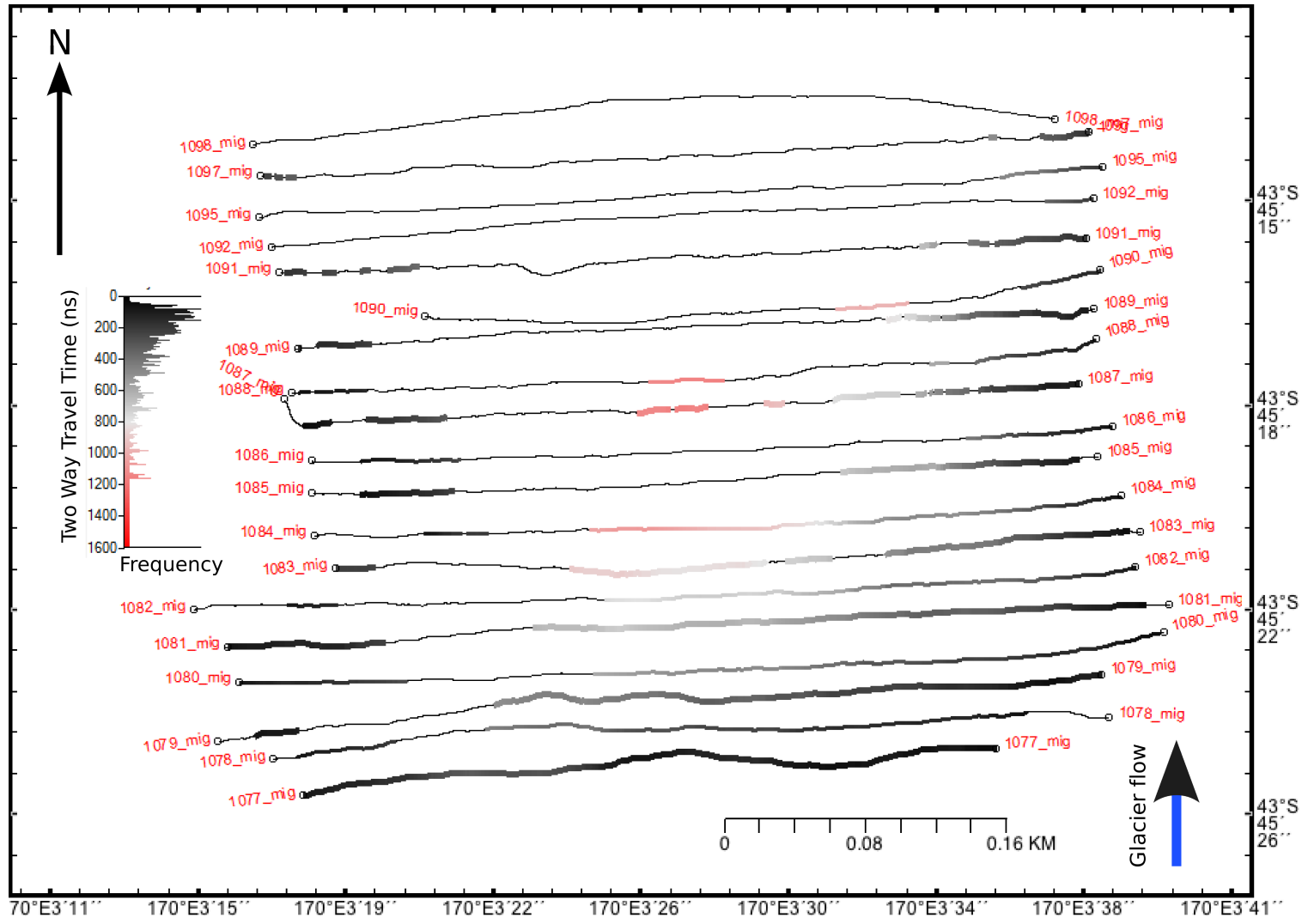

Figure 3.6: September survey spatial distribution of bed picks. Histogram on left shows distribution of picks in TWTT (ns) and also acts as a colour scale.

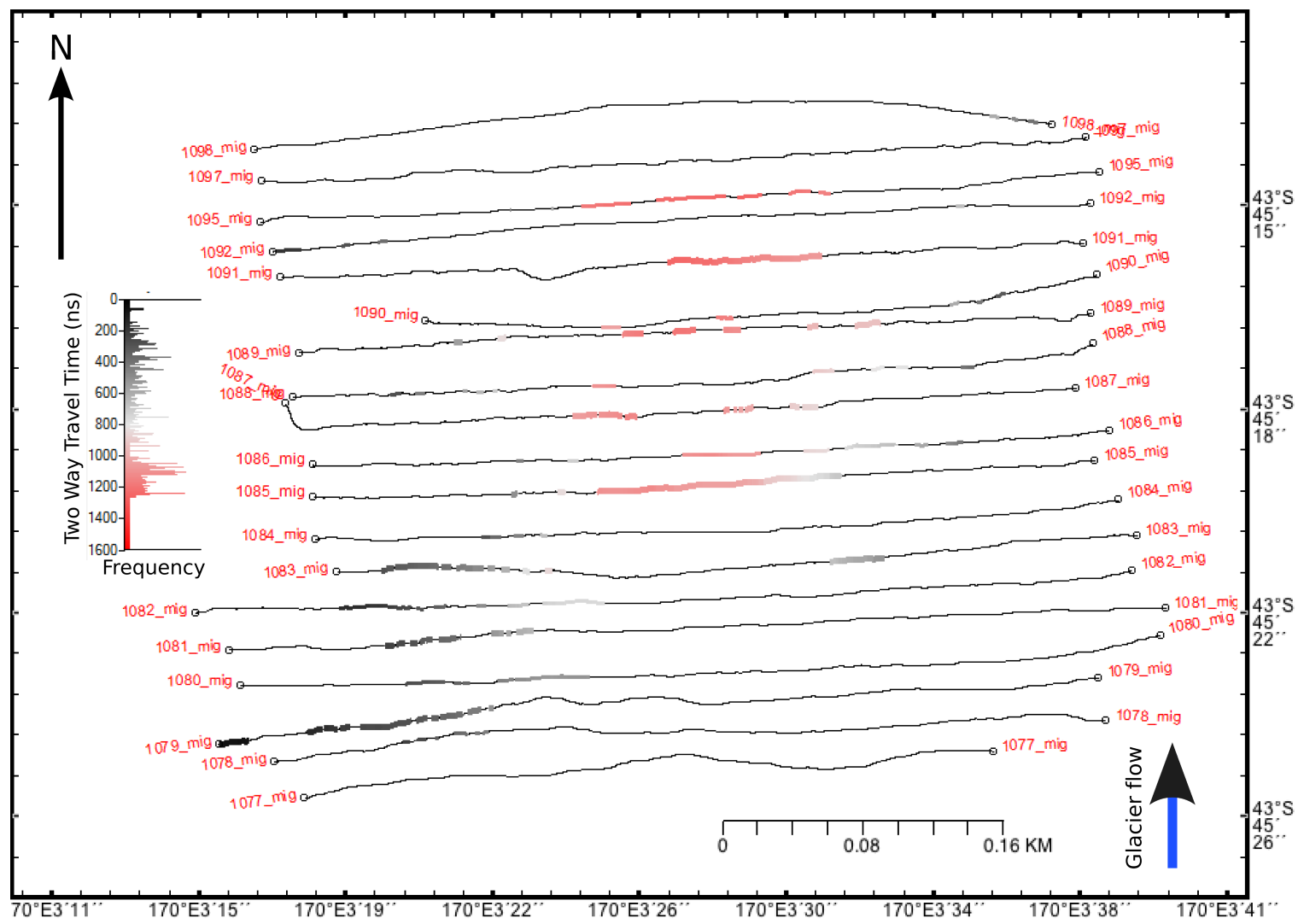

Figure 3.7: September survey spatial distribution of inferred bed picks. Histogram on left shows distribution of picks. 


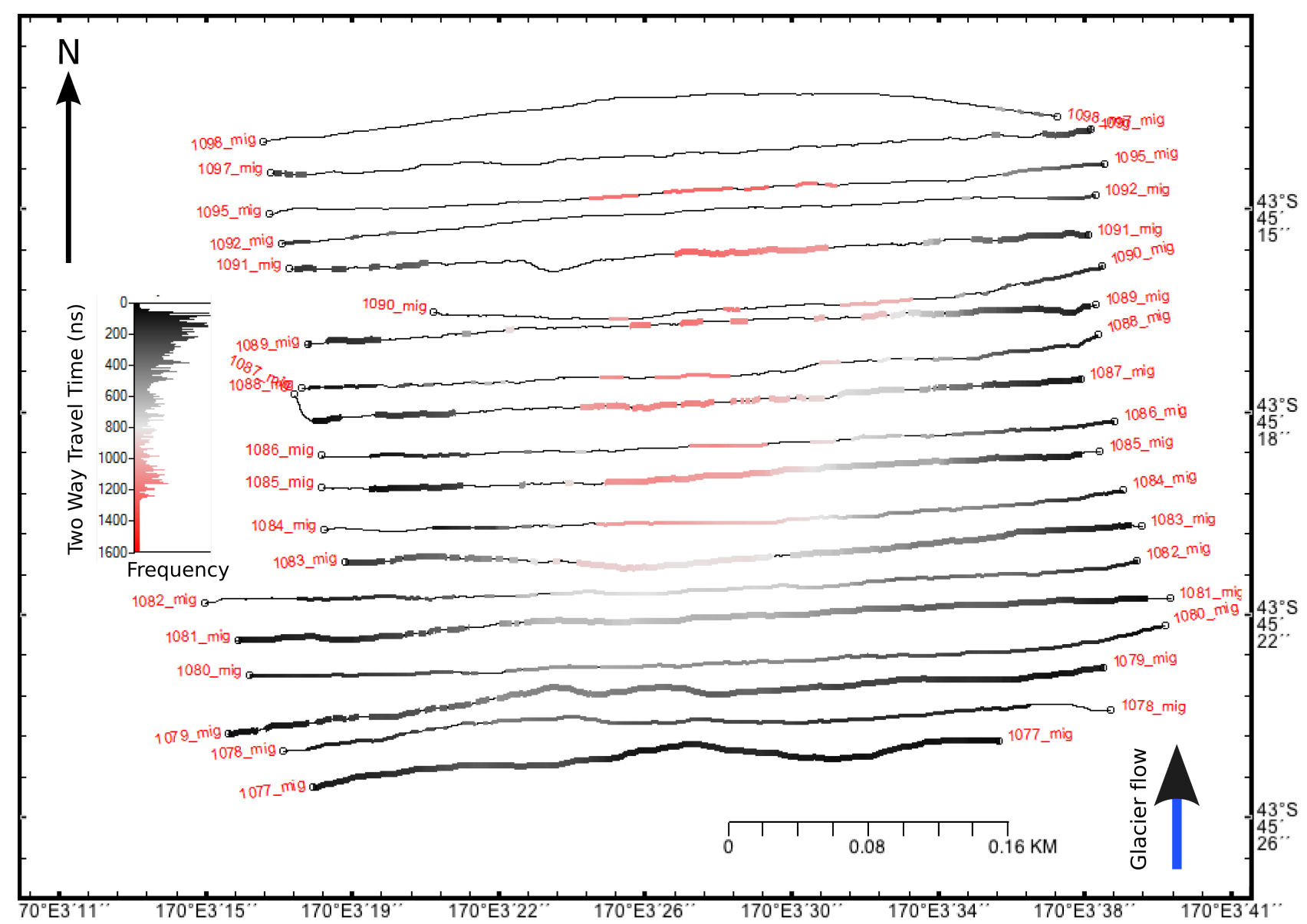

Figure 3.8: September survey spatial distribution of all bed picks. Histogram on left shows the relative distribution of picks. 


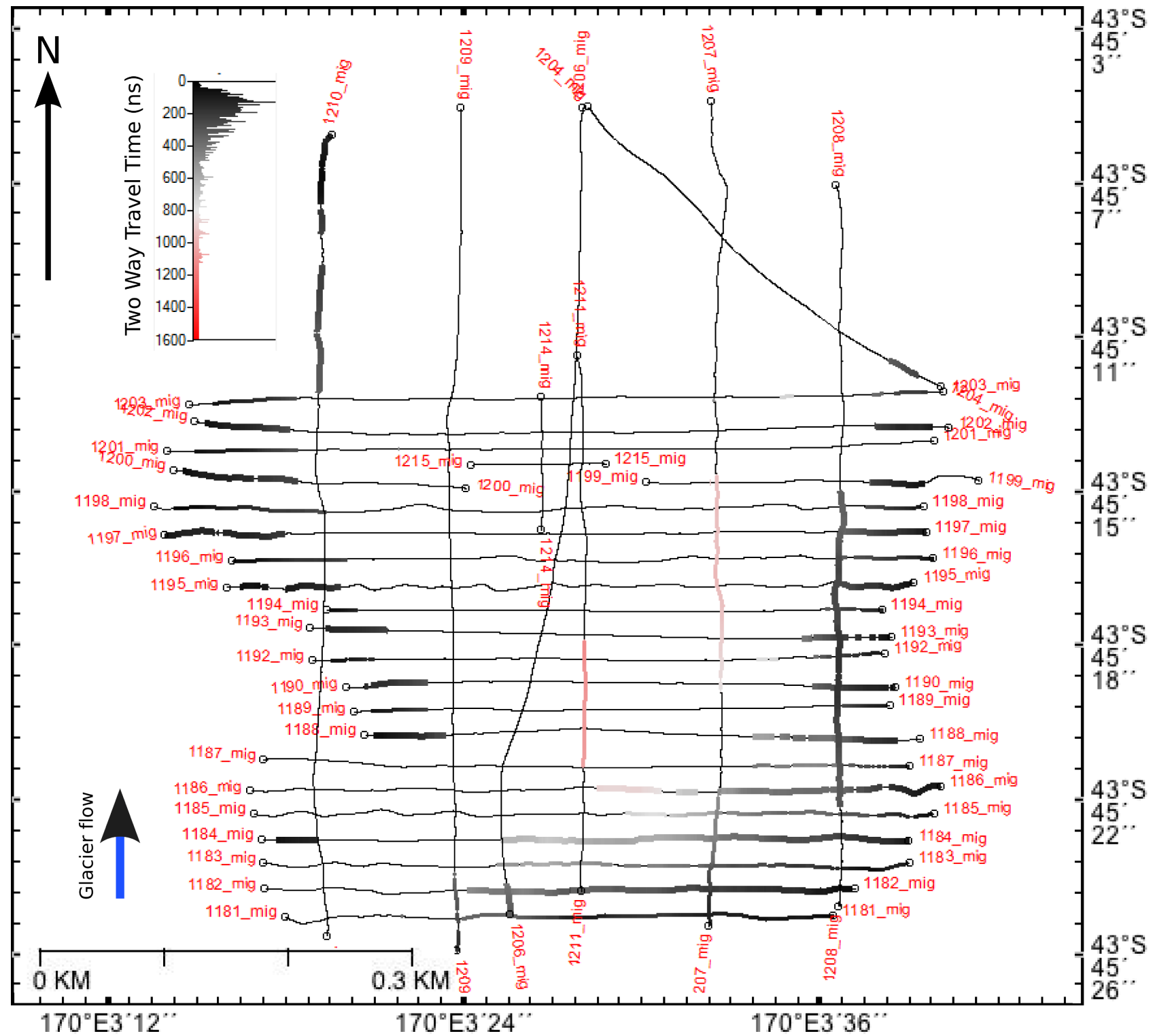

Figure 3.9: December survey spatial distribution of bed picks. Histogram on left shows the relative distribution of picks. 


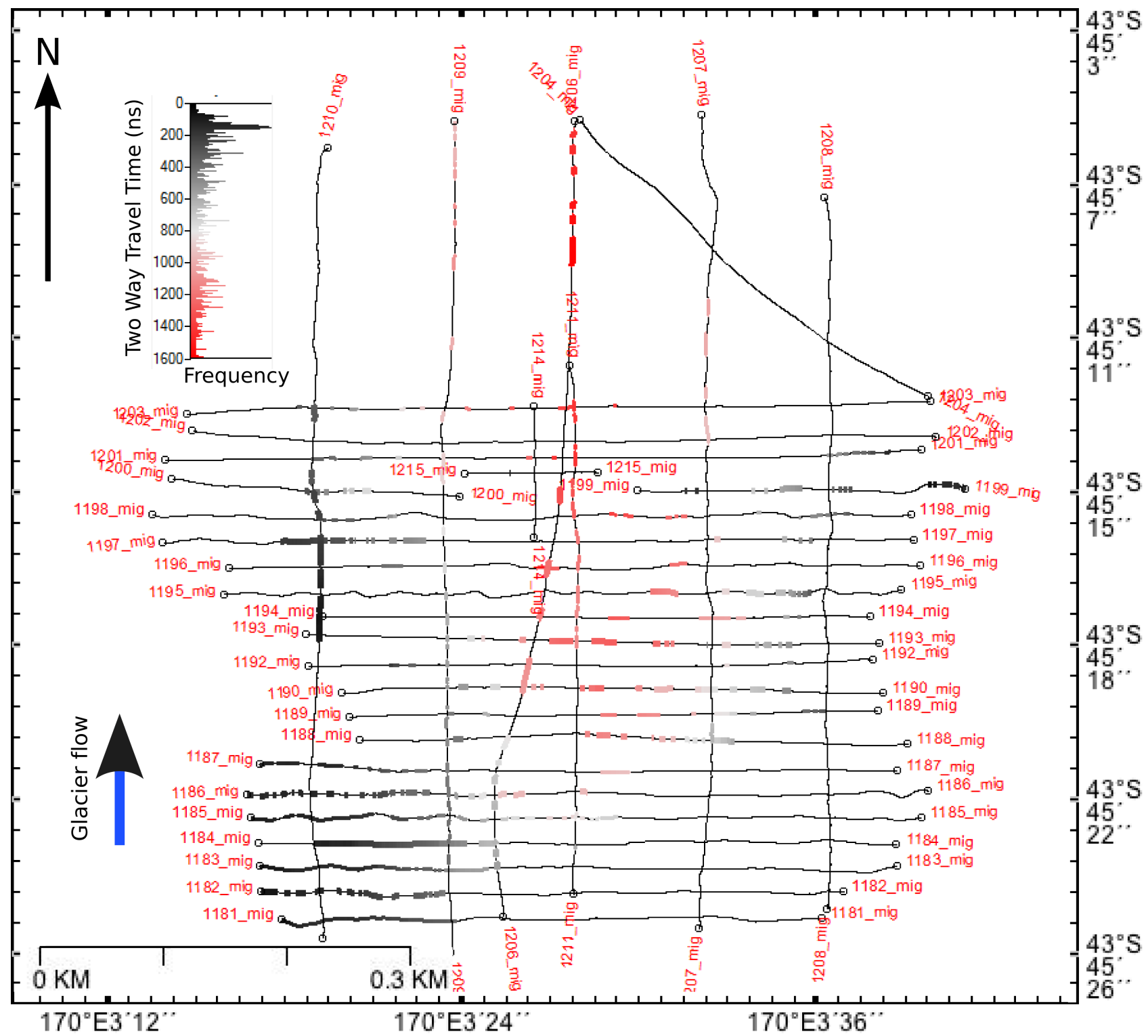

Figure 3.10: December survey spatial distribution of inferred bed picks. Histogram on left shows the relative distribution of picks. 


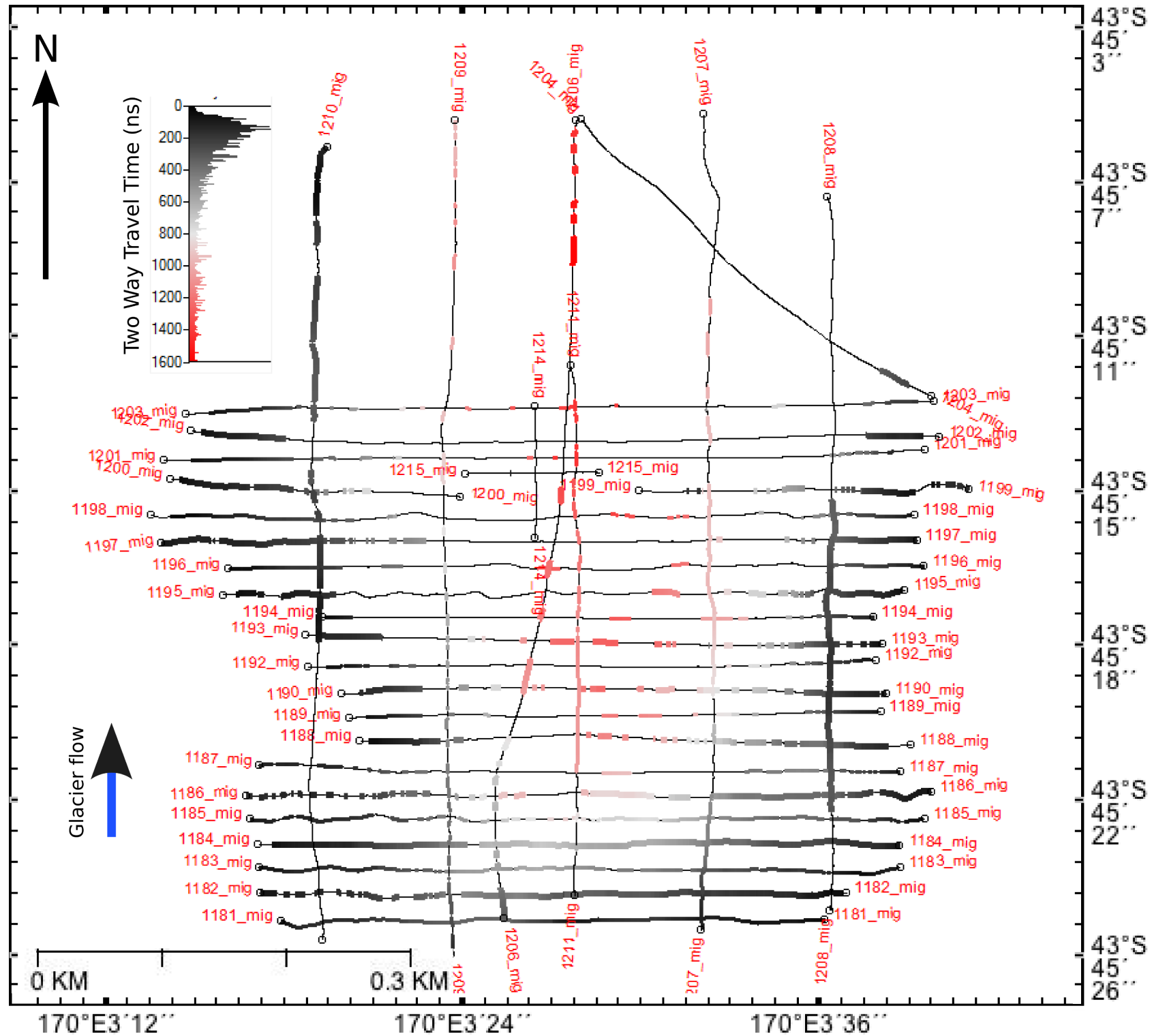

Figure 3.11: December survey spatial distribution of all bed picks. Histogram on left shows the relative distribution of picks. 


\subsubsection{Englacial reflectors}

This section will describe the englacial reflectors which are observed in the radar surveys from both September and December 2011. The englacial reflectors will be described in terms of their spatial distribution, size, continuity of features through neighbouring profiles, definition and clarity of reflections and the profiles as a whole. The September and December surveys will be described interchangeably, to enable a direct comparison between both surveys.

The englacial point reflectors (conduits or cavities) which were picked as isolated point reflectors within the radar profiles will be described. These features will be referred to as 'point-reflectors' for ease of description within this section. Within non-migrated data, which were also used during feature identification, the point-reflectors appear as hyperbolic reflections. The semi continuous reflective horizon (water table surface) will also be described and referred to as the 'reflective horizon'. Vertical banded reflectors that extend downward from the near-surface (crevasses or melt water percolation) will be described and will be referred to as 'banded surface reflectors'.

Englacial reflections were identified in all profiles in both September and December surveys. In general the upper section of the glacier showed a smaller number of well defined point-reflectors, which increase in number down-glacier and become less defined. The reflective horizon (water table) which is typically found between 120 - $180 \mathrm{~ns}(10-15 \mathrm{~m})$ becomes a prominent feature $100 \mathrm{~m}$ down-glacier below, which there is an increase in the frequency of chaotic returns. Chaotic returns imply noisy scattered reflection events which are typically difficult or not able to be interpreted. The reflective horizon is better defined in the September survey than the December survey. Banded surface reflectors were evident throughout the majority of profiles, but are increasingly prominent in the December survey. The December survey shows a higher content of chaotic returns in comparison to the September survey. 


\subsubsection{Point reflectors}

Point reflectors were identified in all profiles in both radar surveys. In general the upper section of the glacier showed a low amount of well defined pointreflectors which increase in number down-glacier and become less defined. This may be caused by an increase in water content down-glacier causing radar attenuation and less defined reflections. Point reflectors were typically better defined in the profiles collected in the early spring (September) survey in comparison to the early summer (December survey). This loss of definition is most likely due to an increase in water content within the early summer survey causing increased radar attenuation. Point reflector examples can be seen in Figure 3.12. Example (a) shows two well defined englacial point reflectors from the uppermost profile (Sept1077); (b) shows two poorly defined point reflectors at $300 \mathrm{~m}$ down-glacier (Sept1091); (c) shows a well defined point reflector from the uppermost profile (Dec1081); (d) shows three poorly defined point reflectors at $100 \mathrm{~m}$ (Dec1186). Figure 3.12 shows that the definition and structure of point reflectors varied spatially, and caused difficulty when picking and defining point reflectors.

Figures 3.13 and 3.14 show the spatial distribution and two way travel time as a histogram of point reflectors picked in both surveys. The majority of point reflectors picked are distributed between 130 - $200 \mathrm{~ns}(8.4$ - $16.7 \mathrm{~m})$ in the September and 130 - $250 \mathrm{~ns}$ (10.9 - $20.9 \mathrm{~m}$ ) December. The frequency of point reflectors is similar between both surveys. In the upper profiles there are between $6-20$ point reflectors, which increase in number down-glacier, and becomes stable by $80 \mathrm{~m}$ where approximately 30 point reflectors are observed each profile. The majority of point reflectors are found in the thickest areas of the glacier's cross profile (see Sept and Dec radargrams in appendix 7.1). 

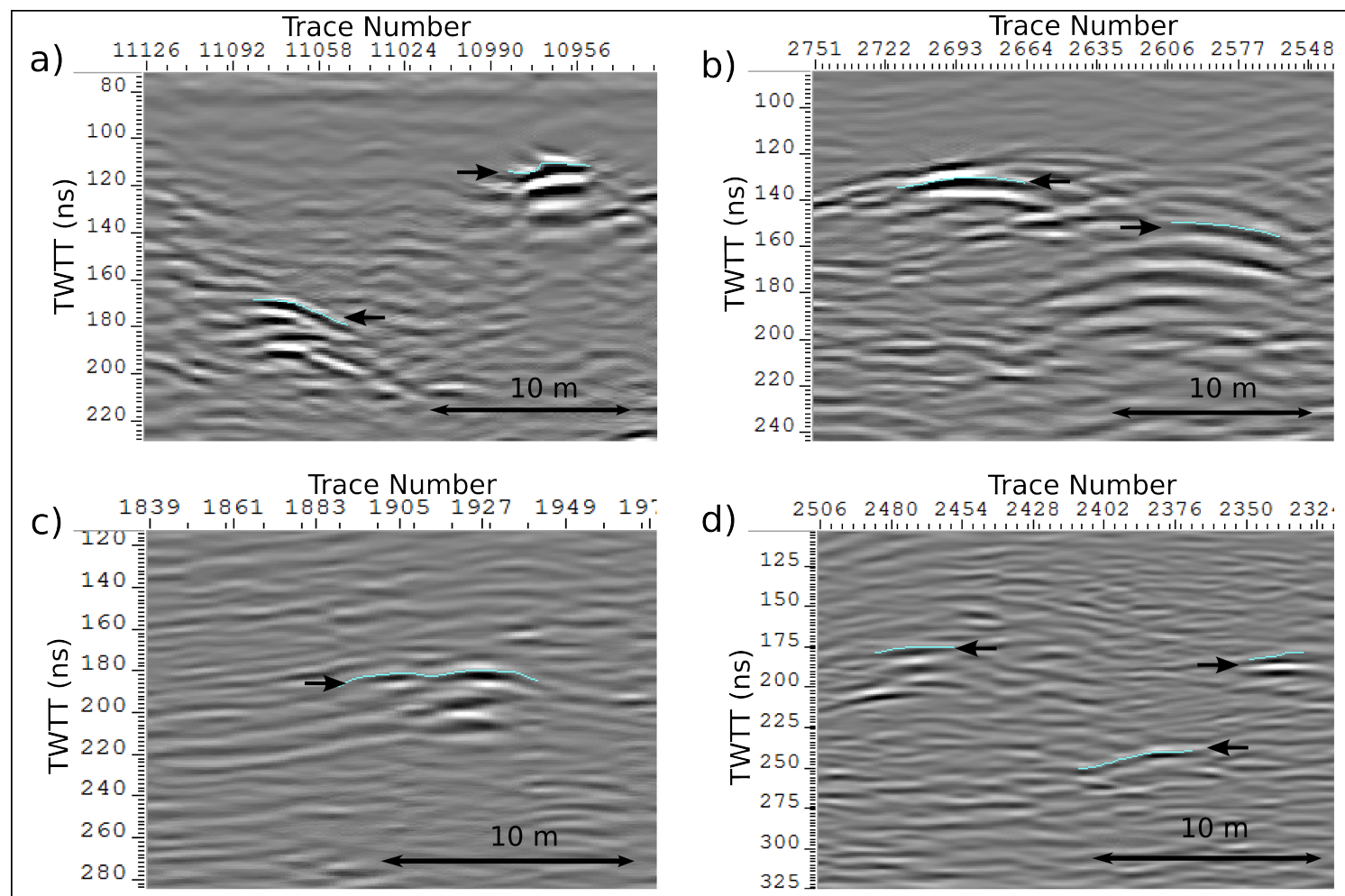

Figure 3.12: Radar examples of point reflectors from September and December surveys. Examples are from following profiles: a) Sept1077; b) Sept1091; c) Dec1081; d) Dec1186. Upper limit of reflections are marked with blue line also indicated with arrows.

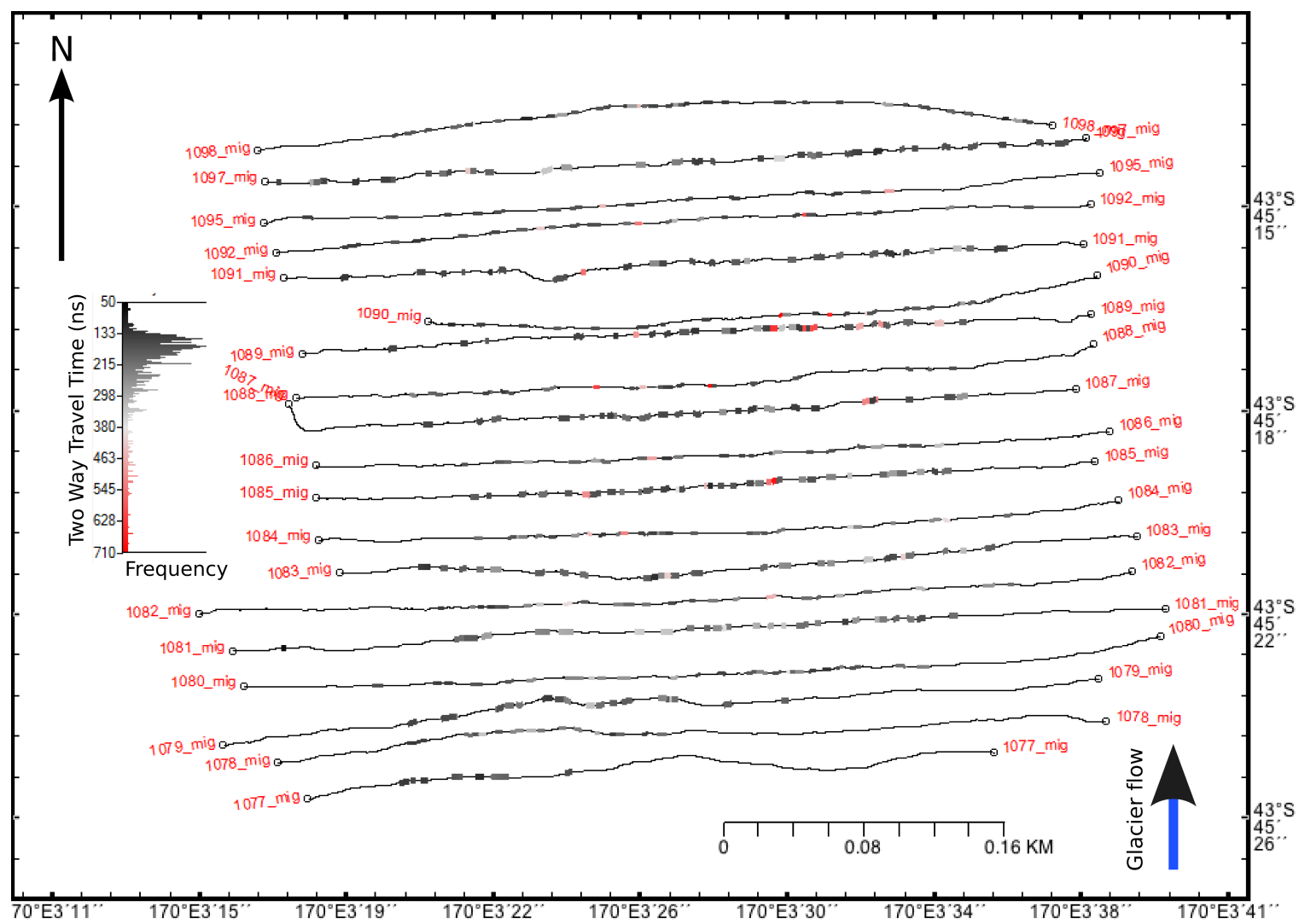

Figure 3.13: September survey spatial distribution of point reflectors. Histogram on left shows the relative distribution of picks. The sum of point reflector picks is 373 . 


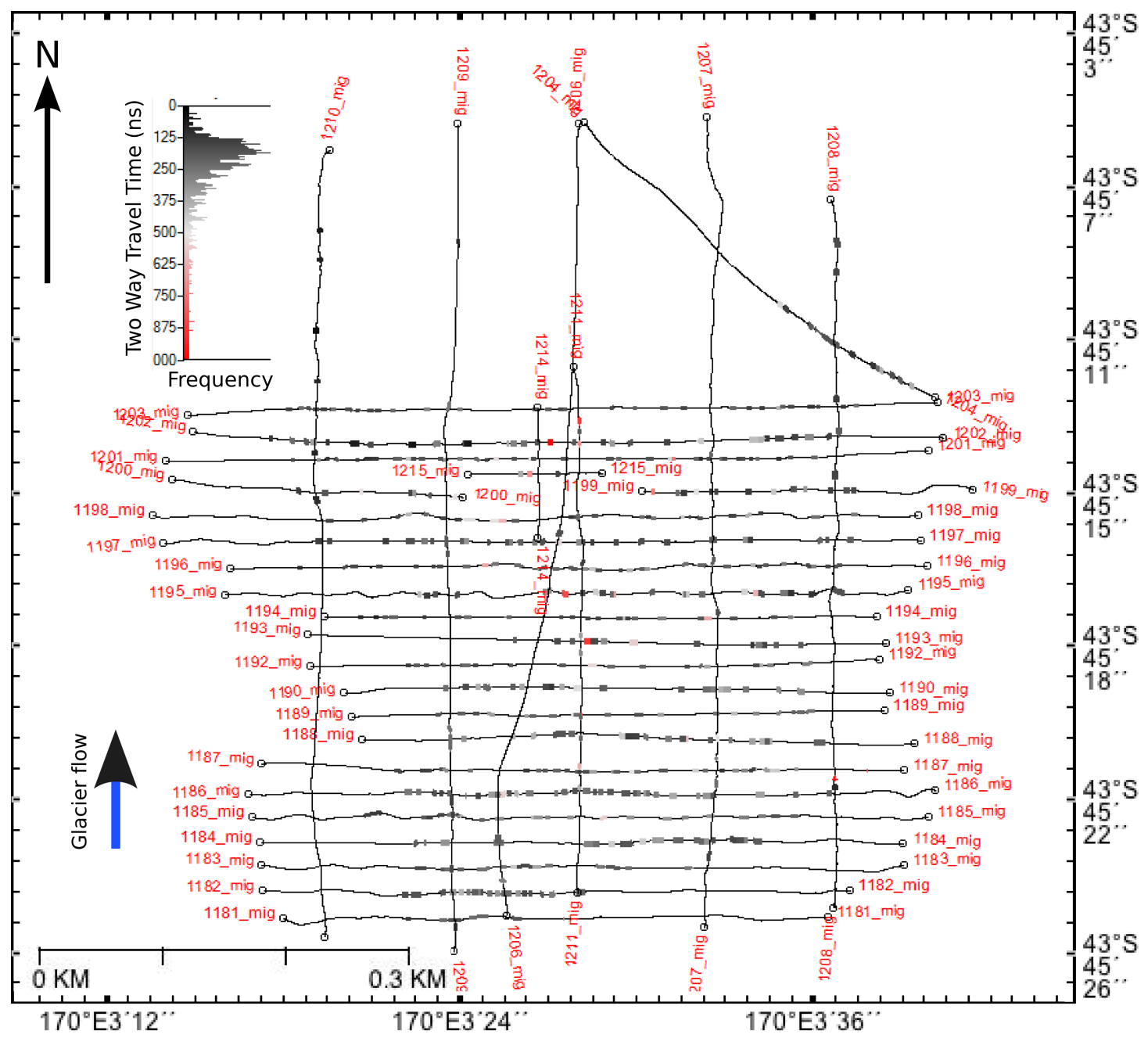

Figure 3.14: December survey spatial distribution of point reflectors. Histogram on left shows the relative distribution of picks. The sum of point reflector picks is 435 .

\subsubsection{Banded Surface reflectors}

Banded surface reflectors occur in both September and December although there are more in the December survey. This is thought to be caused by an increase in water at the glacier's near-surface in the December survey.

Examples of banded surface reflectors can be seen in Figure 3.15. The Figure shows four examples from both September and December surveys. Example (a) from profile Sept1081 shows two well defined banded surface reflectors which 
begin at $100 \mathrm{~ns}$ and extend to $225 \mathrm{~ns}$; (b) profile Sept1085 shows a moderately defined reflector which begins at $80 \mathrm{~ns}$ and extends to $160 \mathrm{~ns}$, where a point reflector occurs; (c) profile Dec1182 shows a moderately defined banded surface reflector, which begins at $40 \mathrm{~ns}$ and extends to $110 \mathrm{~ns}$; (d) profile Dec1195 shows a poorly defined reflector which begins at $80 \mathrm{~ns}$ and extends to $170 \mathrm{~ns}$. The definition and structure of banded surface reflectors varies spatially, which causes difficulty when picking and defining reflections.

The distribution of banded surface reflectors is seen in Figure 3.16 for the September survey and 3.17 for the December survey. The distribution of reflectors in the September survey is concentrated from the head to $140 \mathrm{~m}$ down-glacier and shows between 0 - 5 reflectors per profile. The distribution of reflectors in the upper section of the glacier in the December survey is very similar to the September survey. The mid and lower sections of the glacier show a higher frequency of banded surface reflectors in December, with between 5 - 10 reflections per profile. 


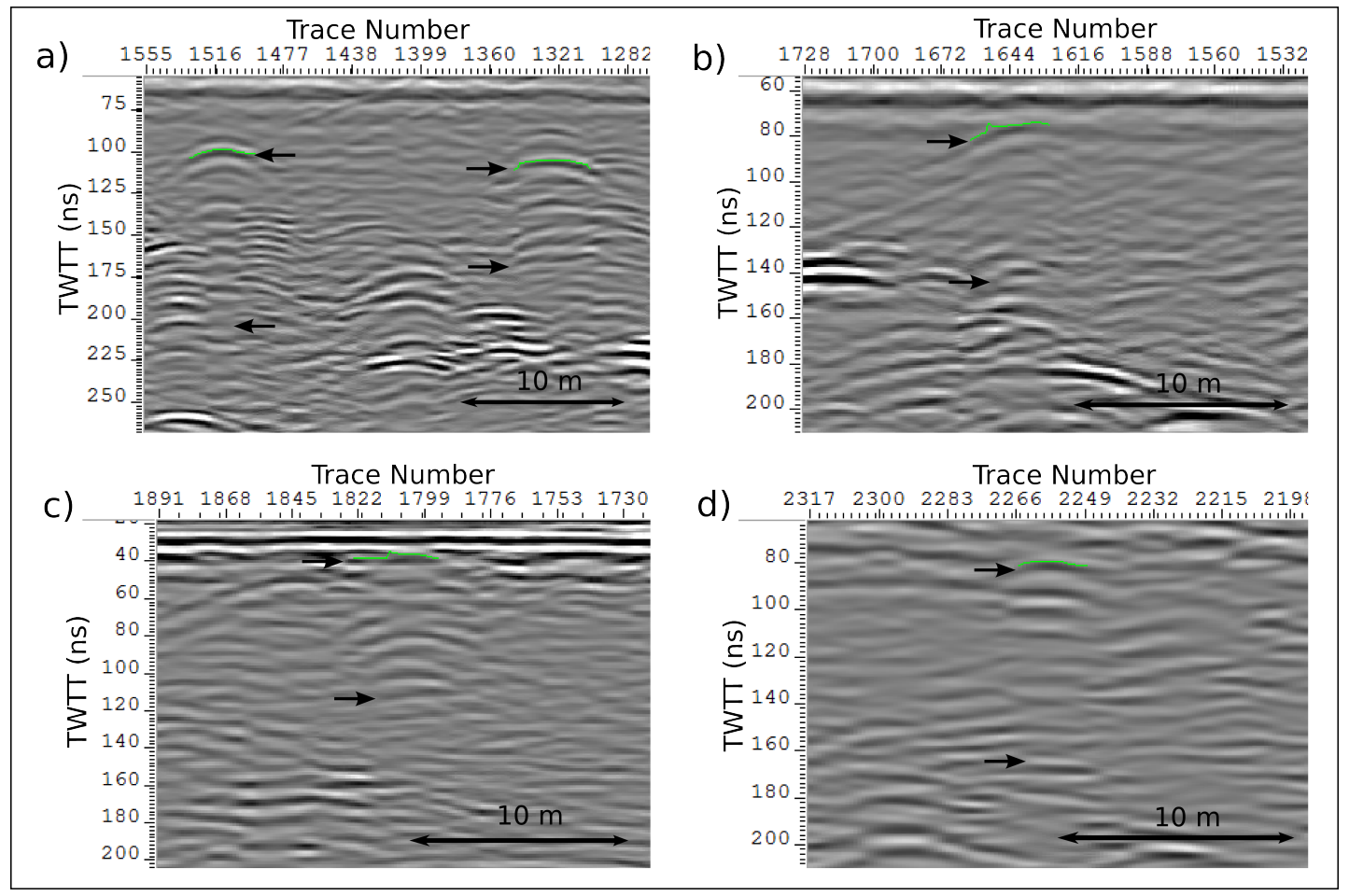

Figure 3.15: Radar examples of banded surface reflectors from September and December surveys. Examples are from following profiles: a) Sept1081; b) Sept1085; c) Dec1182; d) Dec1195. Upper limit of reflections marked with green line also indicated with arrows which show upper and lower limit of reflections.

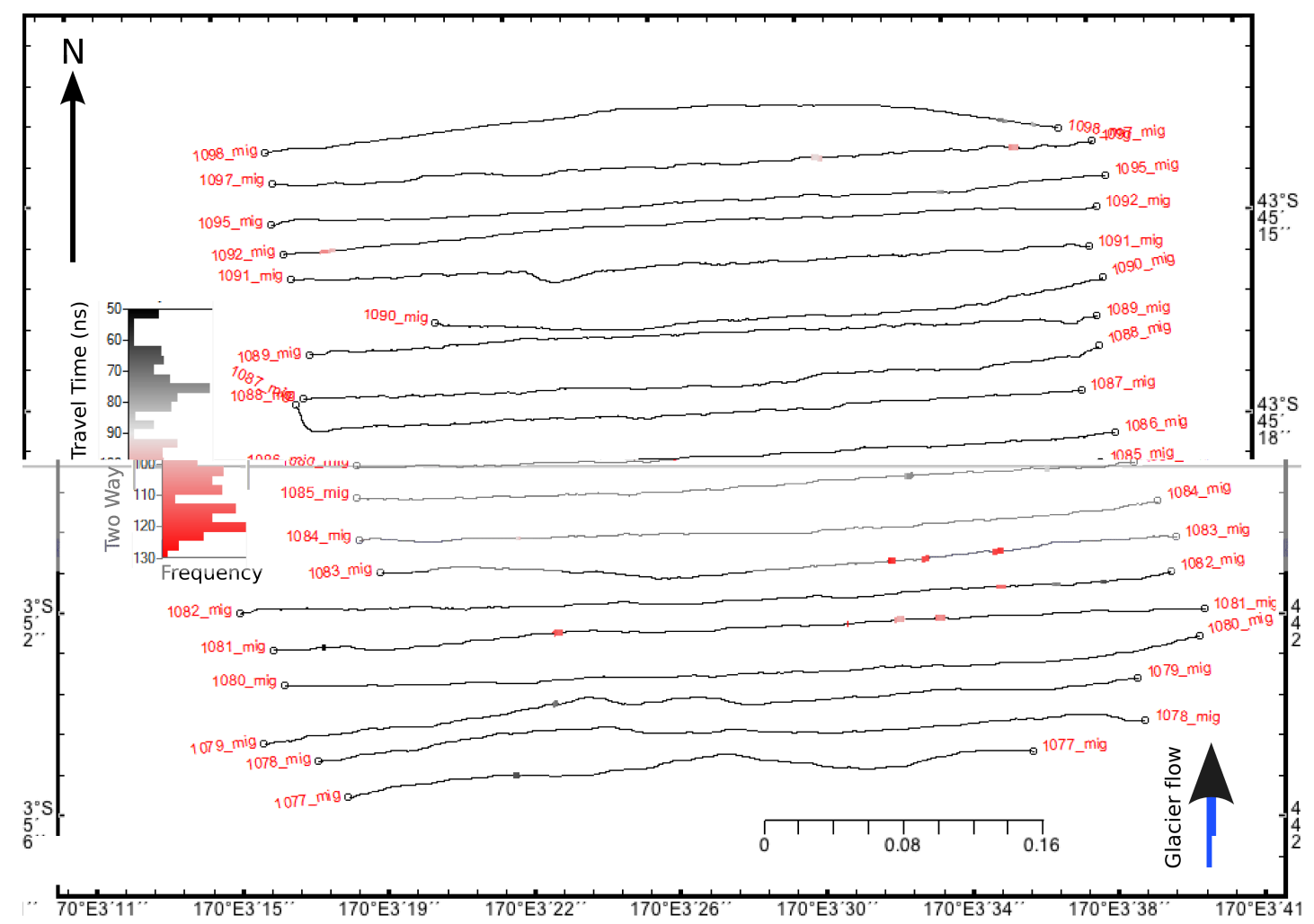

Figure 3.16: September survey spatial distribution of banded surface reflectors. Histogram on left shows the relative distribution of picks. The sum of banded surface reflector picks is 15 . 


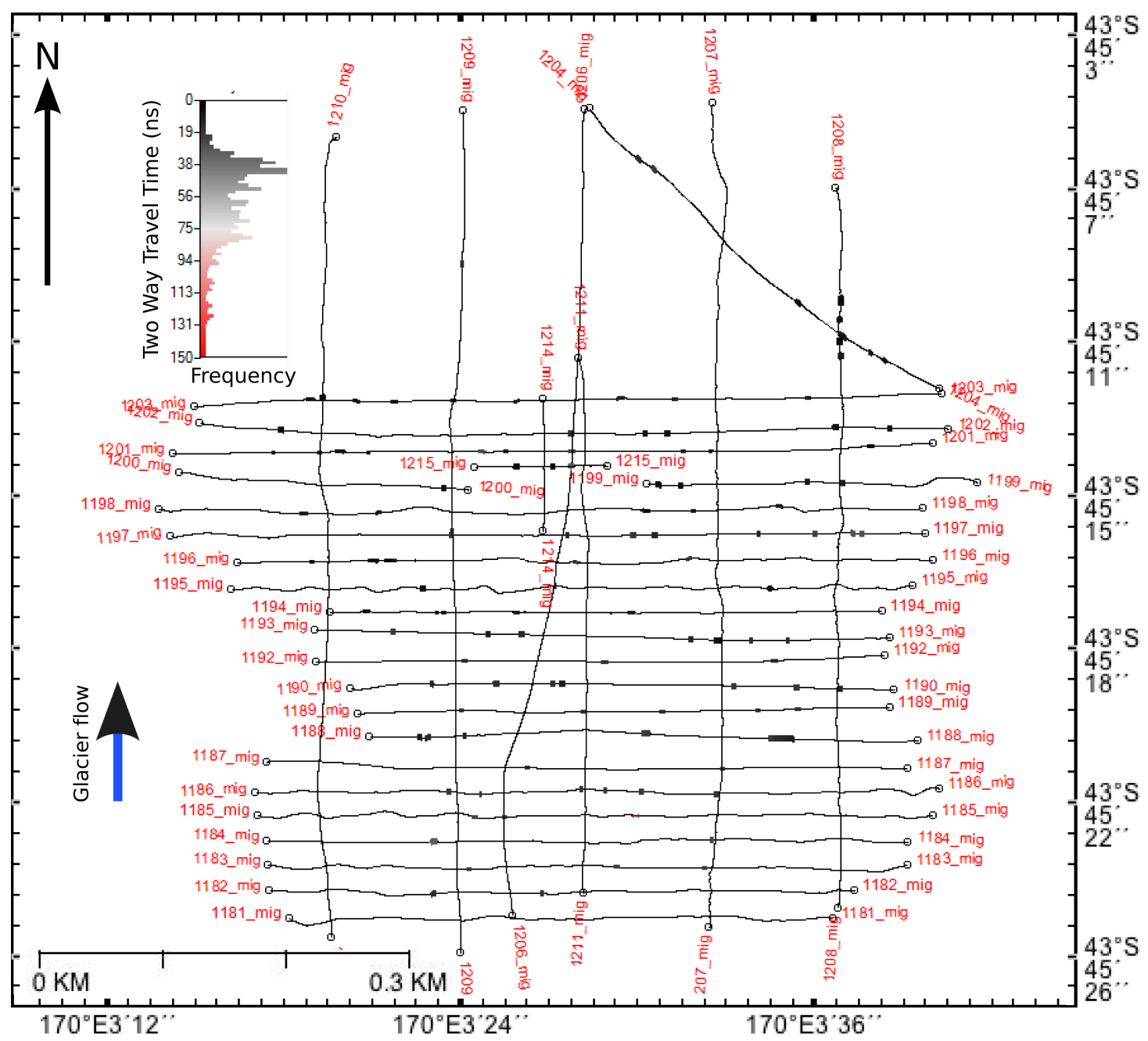

Figure 3.17: December survey spatial distribution of banded surface reflectors. Histogram on left shows the relative distribution of picks. The sum of banded surface reflector picks is 117.

\subsubsection{Reflection horizon}

The reflection horizon is defined as a semi continuous horizon and was observed in both radar surveys (Figures 3.19 and 3.20) and was typically between 100 - 200 ns (8.4 - 16.7 m). The horizon shows increased definition in the September data in comparison to the December data. The horizon is more confined in the September data between 120 - $150 \mathrm{~ns}(10$ - $12.5 \mathrm{~m})$, whereas the December data shows a greater spread between 100 - $190 \mathrm{~ns}(8.4-15.9 \mathrm{~m})$. The horizon also shallows down-glacier in both surveys with a depth of approximately 150 
ns $(12.5 \mathrm{~m})$ on the upper glacier (profile 1083) and $100 \mathrm{~ns}(8.4 \mathrm{~m})$ down-glacier (profile 1095). The horizon becomes evident $100 \mathrm{~m}$ down-glacier and was not picked in the upper profiles. The December data shows a higher amount of reflectivity above the reflective horizon. The horizon generally is evident in the center of the profile on the upper glacier and has a greater cross profile extent on the lower glacier.

Examples of the picked reflection horizon can be seen in Figure 3.18, where horizons are shown in pink. Above the horizon the data typically show a zone of few reflections which increase in number and become more chaotic with depth. Figure 3.18 (a) profile Sept1085 shows zone few reflections between 70 - 150 ns (5.8 - $12.5 \mathrm{~m})$ with four picked reflectors below $150 \mathrm{~ns}(15.5 \mathrm{~m})$ which are picked as the horizon; (b) profile Sept1097 shows the picked reflective horizon at 120 ns $(10 \mathrm{~m})$ and a zone of few reflections above the horizon; (c) profile Dec1190 shows a moderately defined reflection horizon at $200 \mathrm{~ns}(16.7 \mathrm{~m})$; d) profile Dec1195 shows moderately defined reflection horizon at $170 \mathrm{~ns}(14.2 \mathrm{~m})$. 

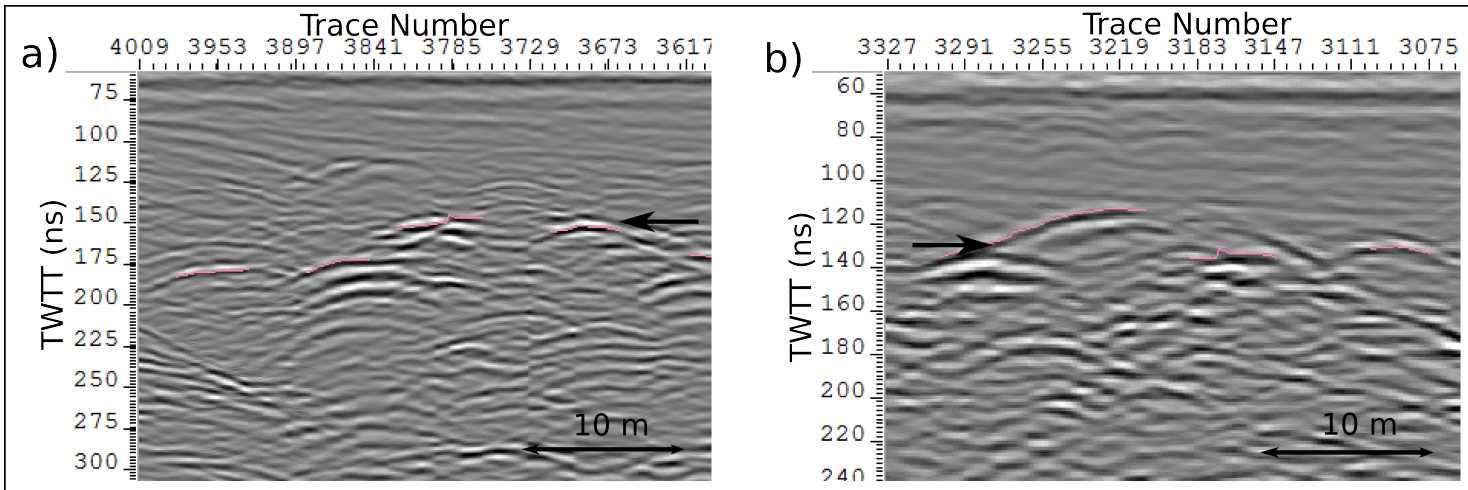

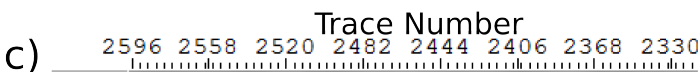

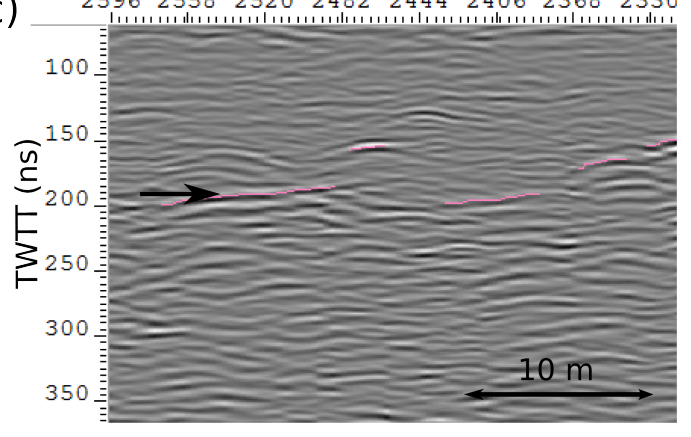

\begin{tabular}{c} 
Trace Number \\
d) $\quad 3950,3905,3860,3815,37703725,36803635$ \\
\hline
\end{tabular}

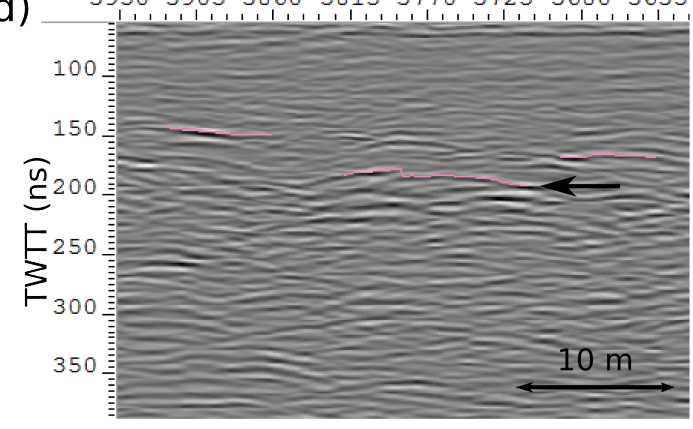

Figure 3.18: Radar examples of reflective horizons (water table) from September and December surveys. Examples are from following profiles: a) Sept1085; b) Sept1097; c) Dec1190; d) Dec1195. Upper limit of reflections marked with pink line also indicated with arrows.

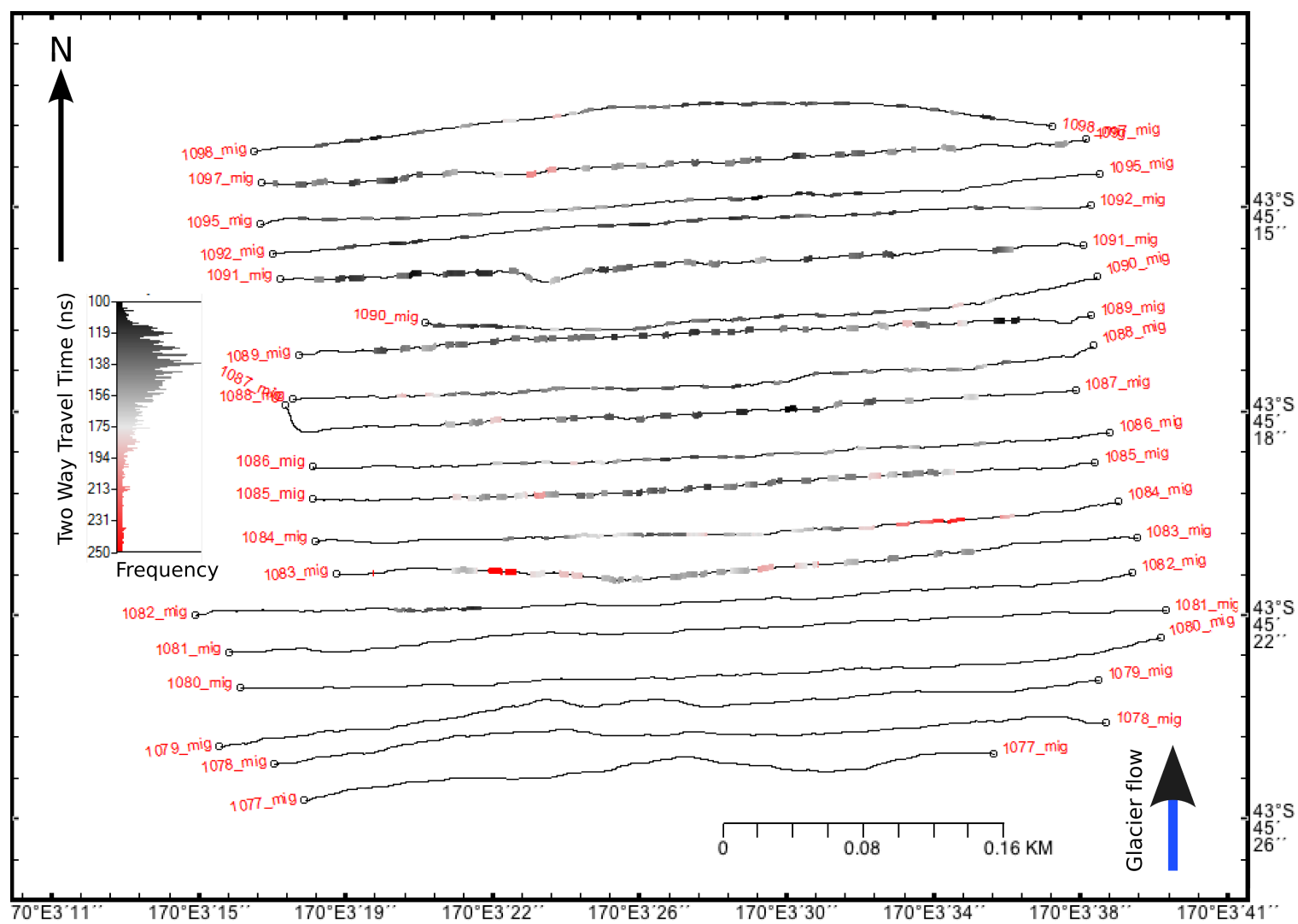

Figure 3.19: September survey spatial distribution of reflective horizon. Histogram on left shows the relative distribution of picks. 


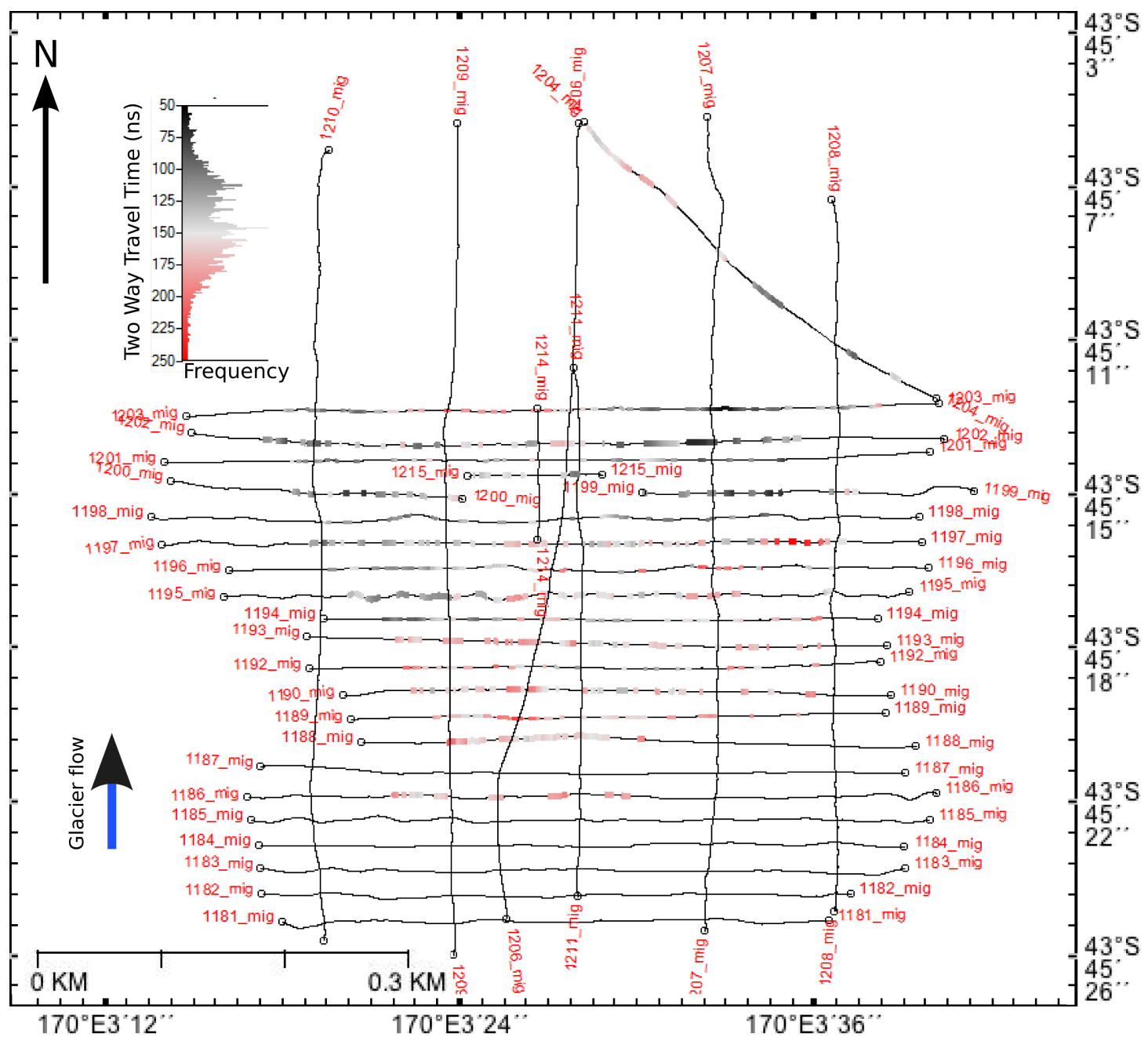

Figure 3.20: December survey spatial distribution of reflective horizon. Histogram on left shows the relative distribution of picks. 


\subsubsection{Initial reflection horizon}

The initial reflection horizon is determined by the continuous reflector typically between approximately $50-70 \mathrm{~ns}(4.2-5.8 \mathrm{~m})$. The horizon is evident in all profiles typically across the whole profile and shallows down-glacier. Picks for the initial reflection horizon can be viewed in the appendix. The horizon is visible in both surveys and is found between $70-80 \mathrm{~ns}(5.8-6.7 \mathrm{~m})$ in the September survey and between 40 - $60 \mathrm{~ns}$ (3.3 - $5 \mathrm{~m}$ ) in the December survey (Figures 3.21 and 3.22). A reduction in snow cover is expected to occur between the two surveys as the September survey took place at the end of the winter season and the December survey in early summer.

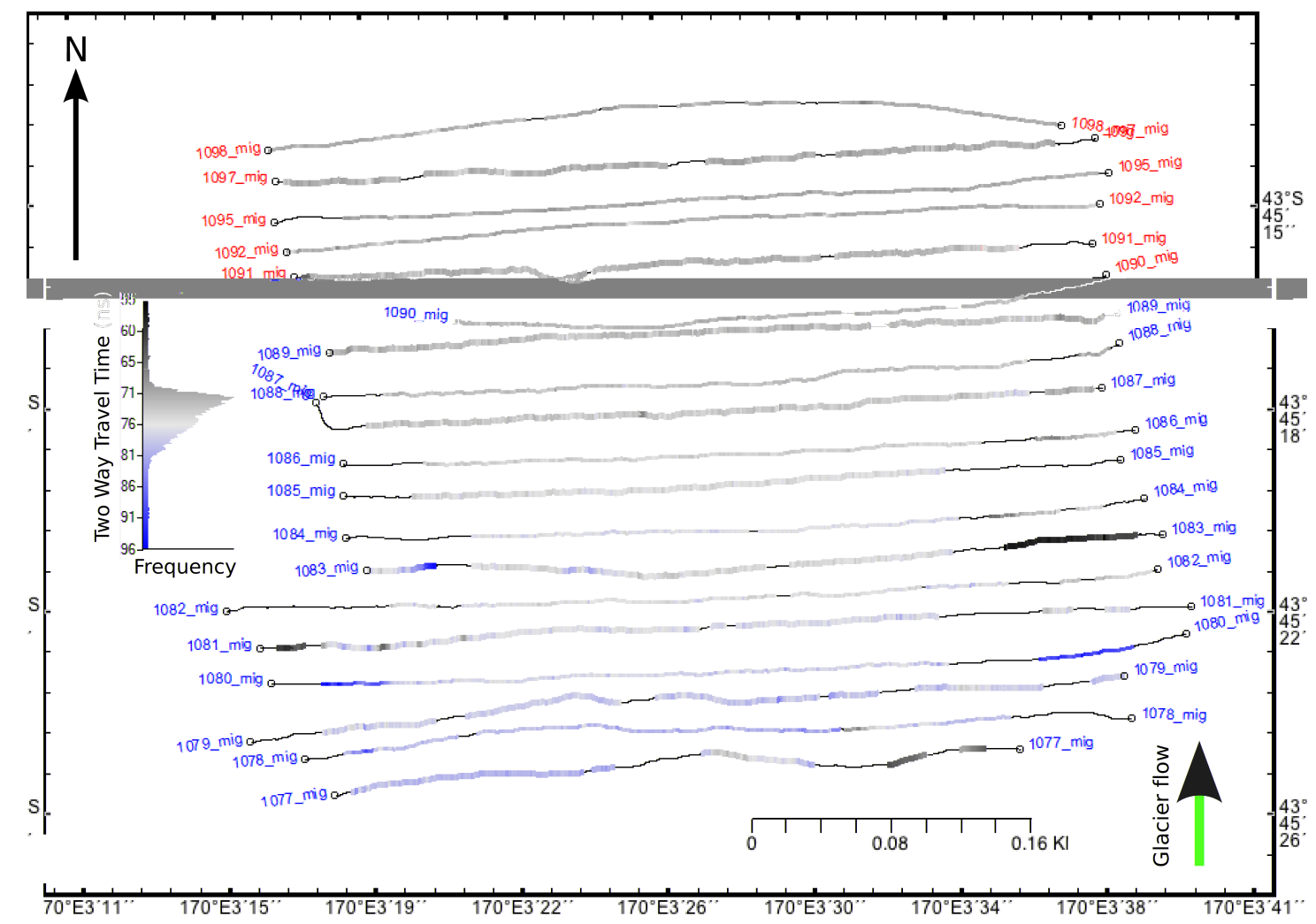

Figure 3.21: September survey spatial distribution of initial reflection horizon. Histogram on left shows the relative distribution of picks. 


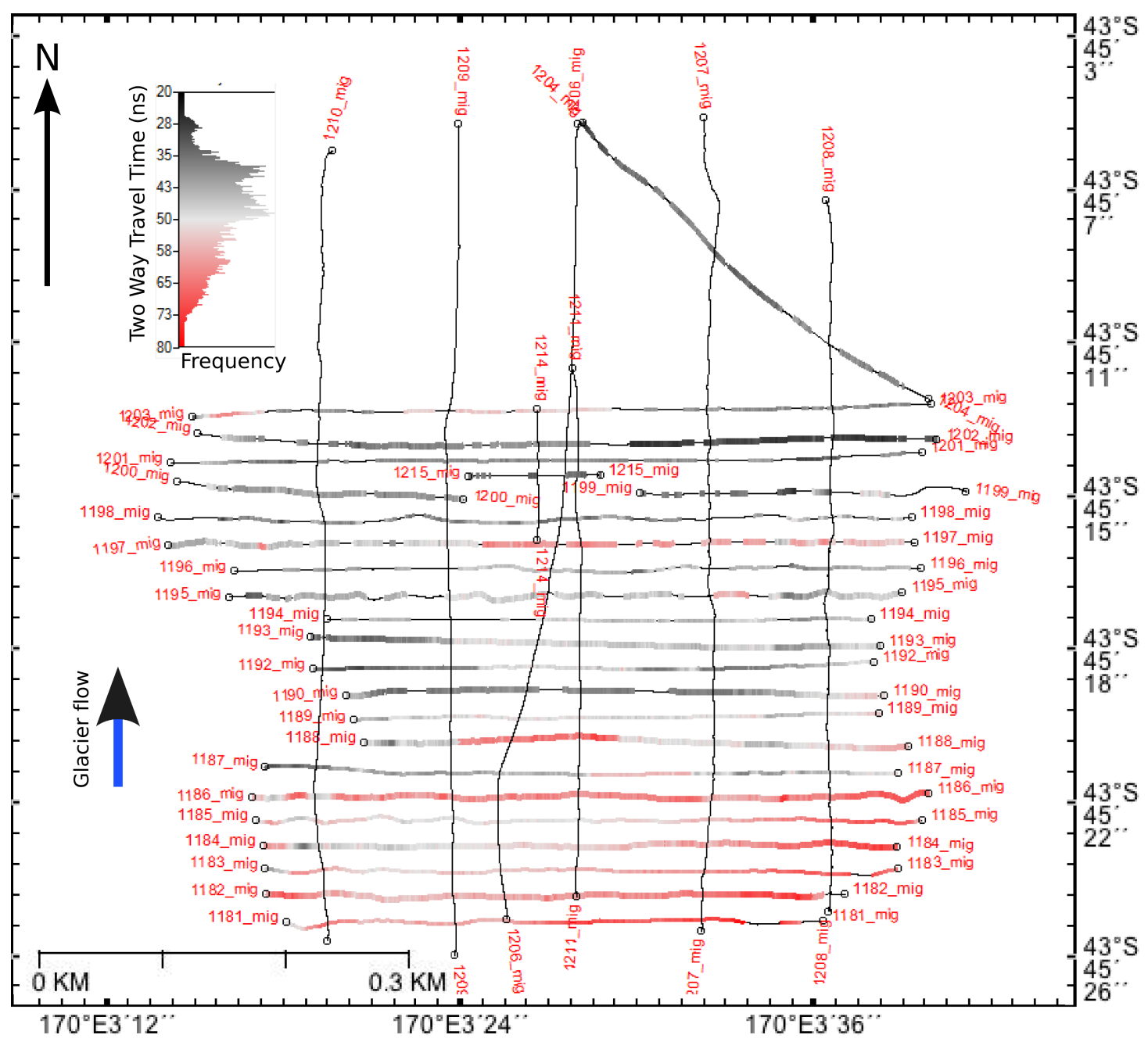

Figure 3.22: December survey spatial distribution of initial reflection horizon. Histogram on left shows the relative distribution of picks.

\subsubsection{Tracking of englacial reflectors}

Point reflectors in the six uppermost profiles show evidence for continuity of englacial conduits over $60 \mathrm{~m}$ and may extend up to $100 \mathrm{~m}$ down-glacier (Figures $3.23,3.24)$. The Figures show a series of radar data approximately $200 \mathrm{~m}$ in width which track point reflectors through six profiles from 0 - $100 \mathrm{~m}$ downglacier. Point reflectors have been circled using various colours to indicate possible continuity down-glacier. Down glacier profiles are used as reference sites as they are perpendicular to the cross-glacier profiles. 
An example of this is seen in the point reflectors circled yellow in Figure 3.23: (a) shows a point reflector at $120 \mathrm{~ns}(10 \mathrm{~m})$; (b) shows another reflector in a similar position in the profile at $150 \mathrm{~ns}(12.5 \mathrm{~m})$; (c) shows a point reflector again at a similar position $12 \mathrm{~m}$ westward at $150 \mathrm{~ns}(12.5 \mathrm{~m})$; (d) shows a point reflector at $170 \mathrm{~ns}(14.2 \mathrm{~m}) 13.2$ eastward; (e) shows a point reflector at $210 \mathrm{~ns}(17.5 \mathrm{~m})$ $10.8 \mathrm{~m}$ to the west; (f) shows a point reflector at $220 \mathrm{~ns}(18.4 \mathrm{~m}) 7.2 \mathrm{~m}$ eastward.

Another example is seen in the December survey (Figure 3.24), tracking the point reflector circled blue; insert (a) shows a point reflector at $190 \mathrm{~ns}(15.9 \mathrm{~m})$; (b) shows a point reflector $6 \mathrm{~m}$ westward in the profile at $250 \mathrm{~ns}(20.9 \mathrm{~m})$; (c) shows a point reflector at $250 \mathrm{~ns}(20.9 \mathrm{~m}) 13.2 \mathrm{~m}$ eastward; (d) shows a point reflector at $250 \mathrm{~ns}(20.9 \mathrm{~m}) 10.8 \mathrm{~m}$ westward; (e) shows a point reflector at 310 ns $(25.9 \mathrm{~m})$ in the same cross profile position and (f) shows a point reflector at $350 \mathrm{~ns}(29.2 \mathrm{~m}) 2.4 \mathrm{~m}$ westward.

Tracking point reflectors shows a meandering pattern which gradually deepens down-glacier and in some cases deepens in a step like pattern. The other examples seen in Figures 3.23 and 3.24 show similar patterns. Point reflectors from both radar surveys show a similar distribution. The three most prominent reflectors observed in the uppermost profile of the September survey are also found in the December survey at similar positions. As the radar profiles from September and December do not directly overlie each other it can not be determined if the point reflectors in the December survey have moved deeper into the glacier. This is observed in examples (a) when comparing circled point reflectors from both Figure 3.23 and 3.24. The point reflectors circled yellow orange and blue all show a similar distribution in both surveys. The pattern is also observed through sequential profiles down-glacier, but it is not as pronounced. 


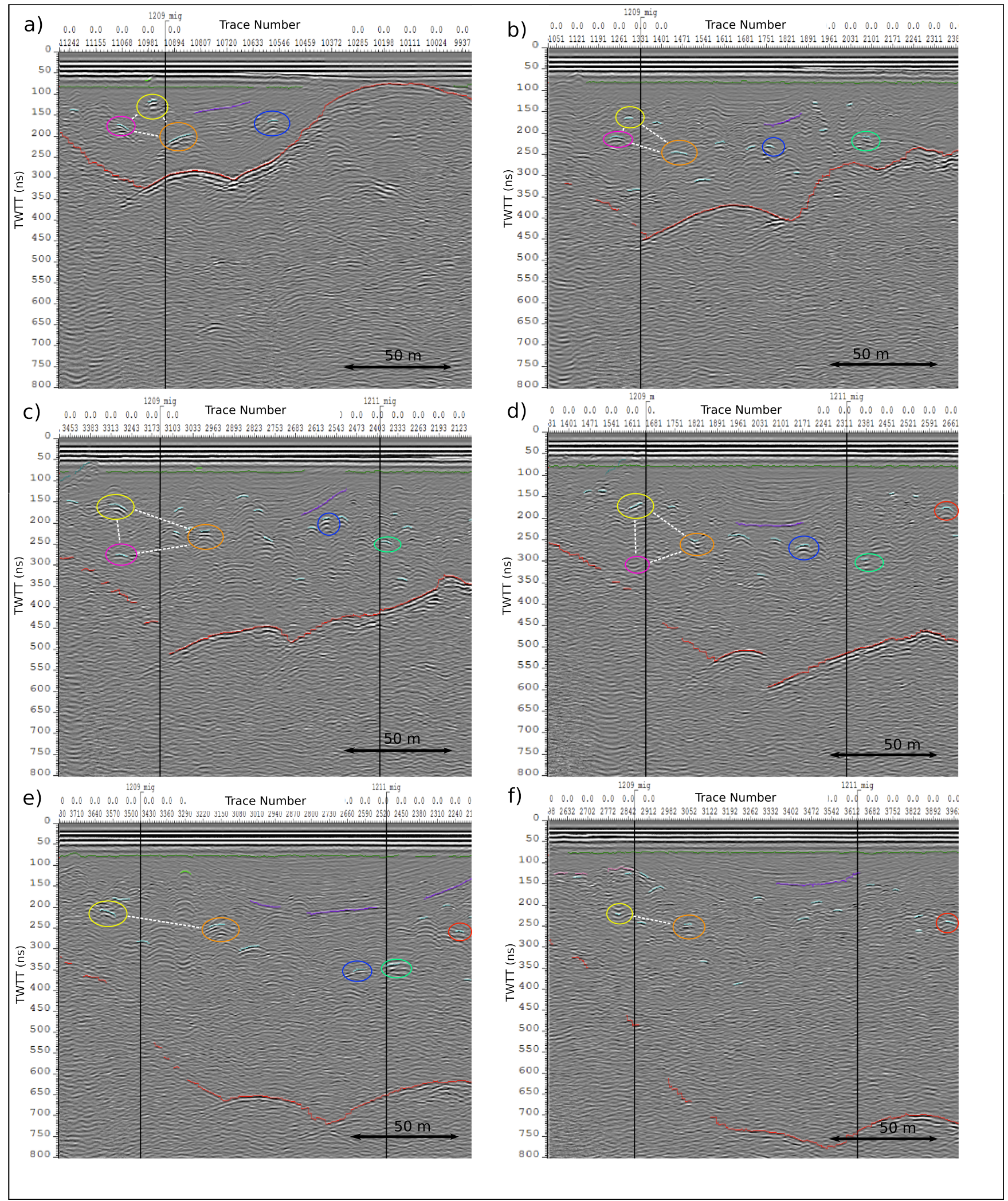

Figure 3.23: Figure shows a series of radar profiles which track point reflectors from the September survey from 0 - 100 $\mathrm{m}$ down-glacier. Bed picks are shown in red. Radar data is labelled from uppermost profile through successive radar profiles down-glacier, respectively (a) $0 \mathrm{~m}$ (profile 1077), (b) $20 \mathrm{~m}$ (profile 1078), (c) $40 \mathrm{~m}$ (profile 1079), (d) $60 \mathrm{~m}$ (profile 1080), (e) $80 \mathrm{~m}$ (profile 1081) and (f) $100 \mathrm{~m}$ (profile 1082). Point reflectors have been circled using various colours to indicate possible continuity down-glacier. White dashed lines connect reflectors as a visual aid. Profiles 1209 and 1211 are used as reference sites as they are perpendicular to the cross-glacier profiles. The tracked point reflectors show a deepening trend down-glacier. The point reflector circled orange shows a good correlation to down-glacier profiles 


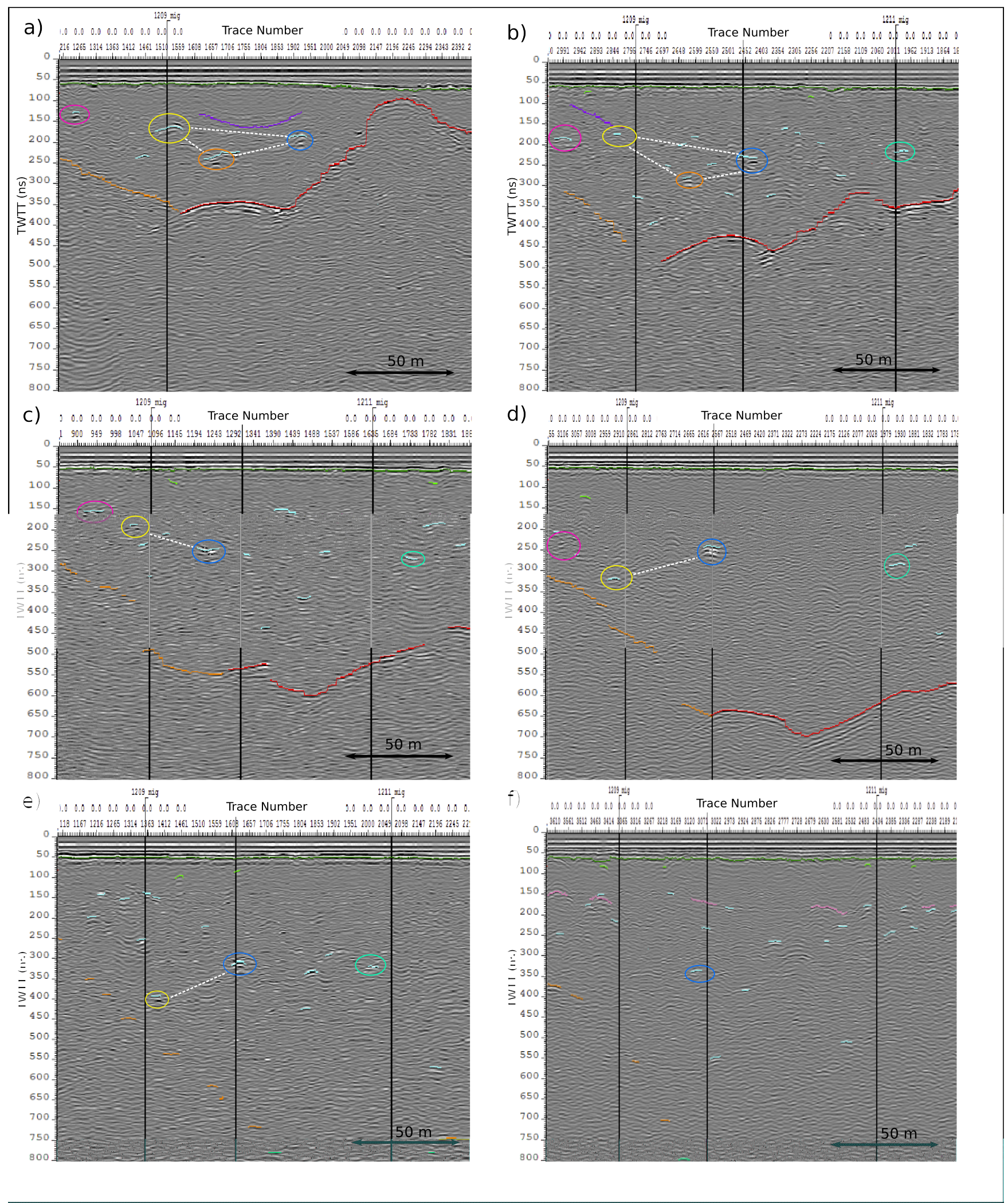

Figure 3.24: Figure shows a series of radar profiles from the December survey which track point reflectors from 0 - 100 $\mathrm{m}$ down-glacier. Bed picks are shown in red. Radar data is labelled from uppermost profile through successive radar profiles down-glacier, respectively (a) $0 \mathrm{~m}$ (profile 1181), (b) $20 \mathrm{~m}$ (profile 1082), (c) $40 \mathrm{~m}$ (profile 1083), (d) $60 \mathrm{~m}$ (profile 1084), (e) $80 \mathrm{~m}$ (profile 1085) and (f) $100 \mathrm{~m}$ (profile 1086). Point reflectors have been circled using various colours to indicate possible continuity down-glacier. White dashed lines connect reflectors as a visual aid. Profiles 1209, 1206, 1211 are used as a reference sites as they are perpendicular to the cross-glacier profiles. The tracked point reflectors show a deepening trend down-glacier. The point reflector circled blue shows a good correlation to down-glacier profiles 


\subsection{Synthetic radargrams}

This section will describe the synthetic radargrams produced from models built to simulate features likely to be formed in temperate englacial environments. As previously described in the Methods chapter, the models were constructed and run in MATGPR using the relative electrical properties (Table 2.1). Model and conduit dimensions are given in the Methods section. All models were run at $100 \mathrm{MHz}$ and results are shown in Figures 3.25, 3.27, 3.30 and 3.28. The figures are set out with the model (left), synthetic radargram (middle) and the center trace from relative synthetic (right). The colour scale used for the synthetics is consistent throughout figures, however, the center trace amplitude scale varies in order to resolve a range of amplitudes. Caution should be taken when comparing trace amplitudes. Results for individual synthetics are described in captions below figures. 


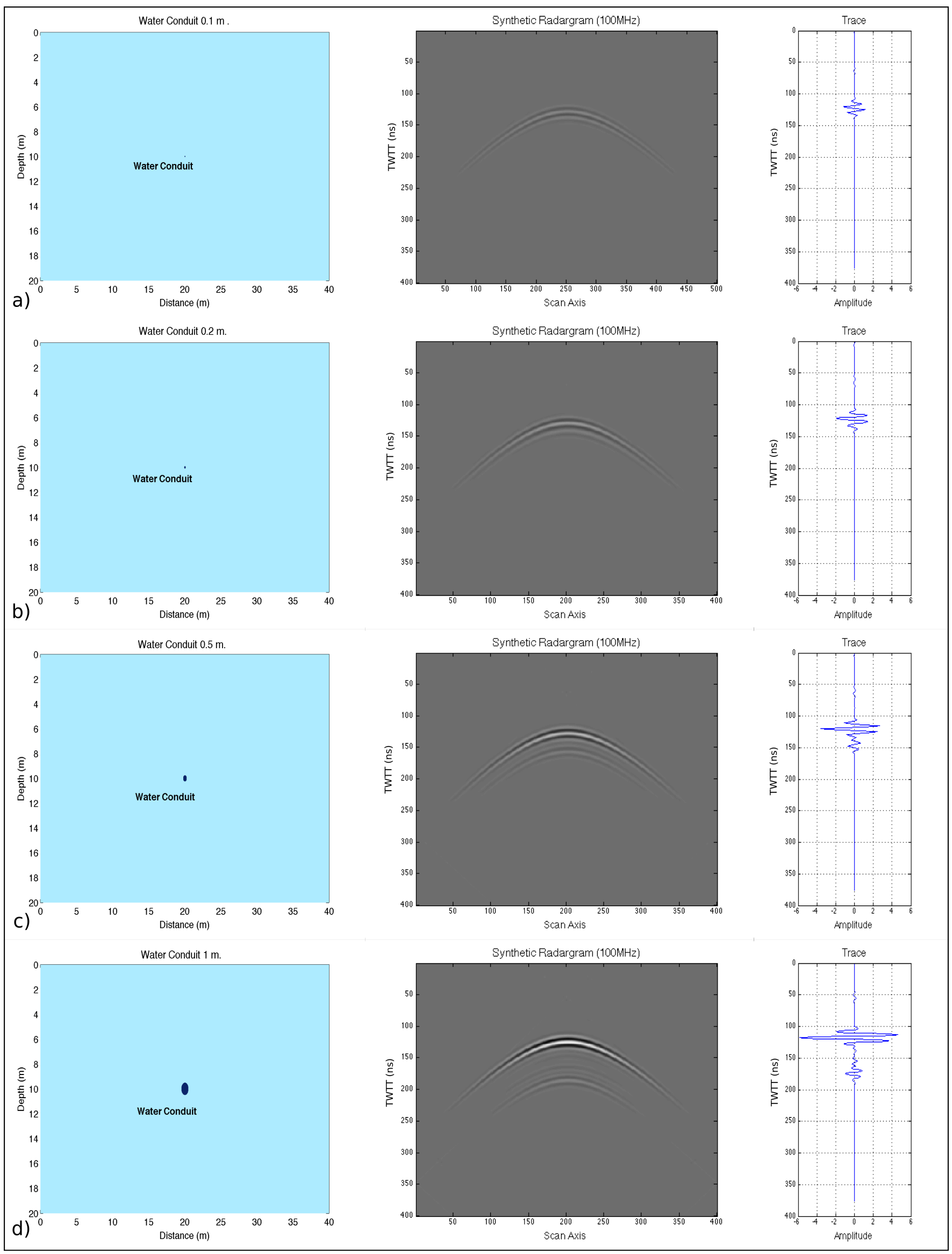

Figure 3.25: Figure showing water conduit models in a range of diameters; model synthetic (100 MHz); and center trace of the relative synthetic. Models were constructed and run in MATGPR using relative electrical properties, see Table 2.1. (a) $0.1 \mathrm{~m}$ wide water conduit, (b) $0.2 \mathrm{~m}$ wide water conduit, (c) $0.5 \mathrm{~m}$ wide water conduit and (d) $1 \mathrm{~m}$ wide water conduit. All radar synthetics show a +-+ wave phase which increases in amplitude with diameter of conduit. 


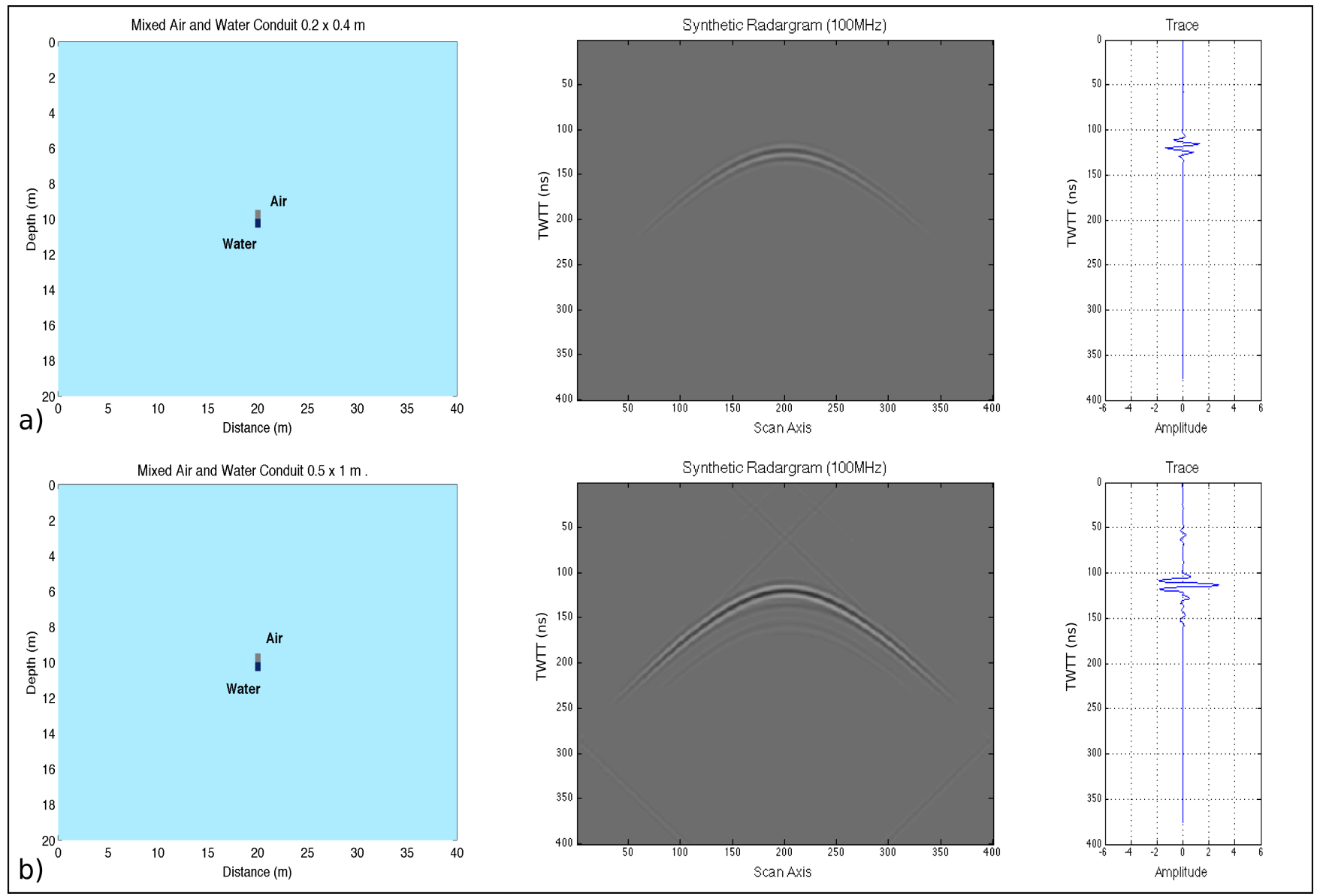

Figure 3.26: Figure showing mixed air and water conduit models; model synthetic (100 MHz); and center trace of the relative synthetic. Models were constructed and run in MATGPR using relative electrical properties, see Table 2.1. Model and conduit dimensions are given in the methods section. Model dimensions (a) air $(0.2 \mathrm{~m} \times 0.2 \mathrm{~m})$ above water $(0.2 \mathrm{~m} \times 0.2 \mathrm{~m})$; (b) air $(0.5 \mathrm{~m} \times 0.5 \mathrm{~m})$ above water $(0.5 \mathrm{~m} \times 0.5 \mathrm{~m})$. Both synthetics show a - + - phase polarity which increases in amplitude with larger size conduit. 


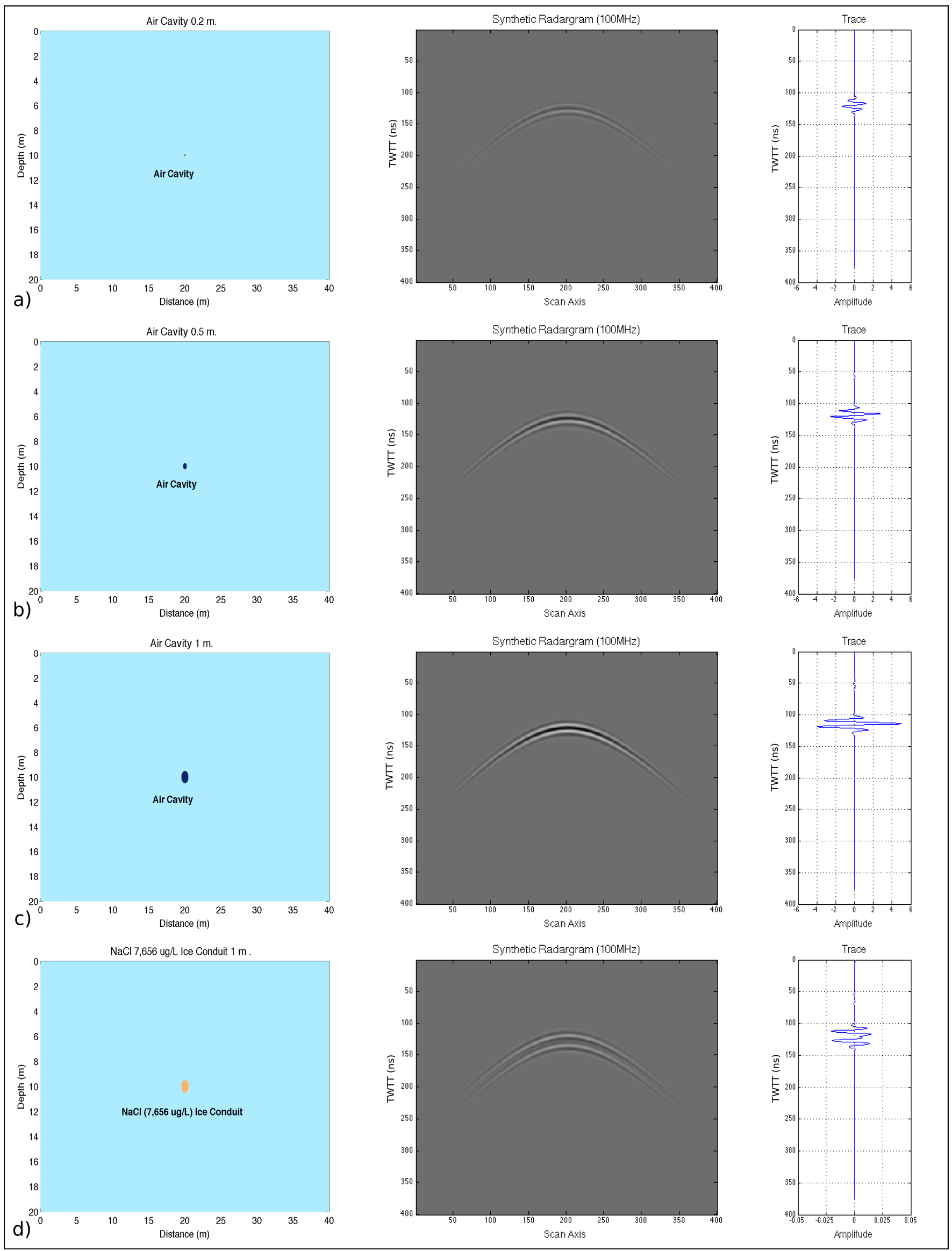

Figure 3.27: Figure showing air cavity and ice impurity models; model synthetic (100 MHz); and center trace of the relative synthetic. Models are as follows; (a) $0.2 \mathrm{~m}$ wide air cavity, (b) $0.5 \mathrm{~m}$ wide air cavity, (c) $1 \mathrm{~m}$ wide air cavity and (d) $1 \mathrm{~m}$ wide ice conduit containing sodium-chloride $(\mathrm{NaCl})$ at $7,656 \mathrm{ug} / \mathrm{L}$. The amplitude scale is adjusted from $(-0.05,0.05)$ allowing visualisation of the trace. 


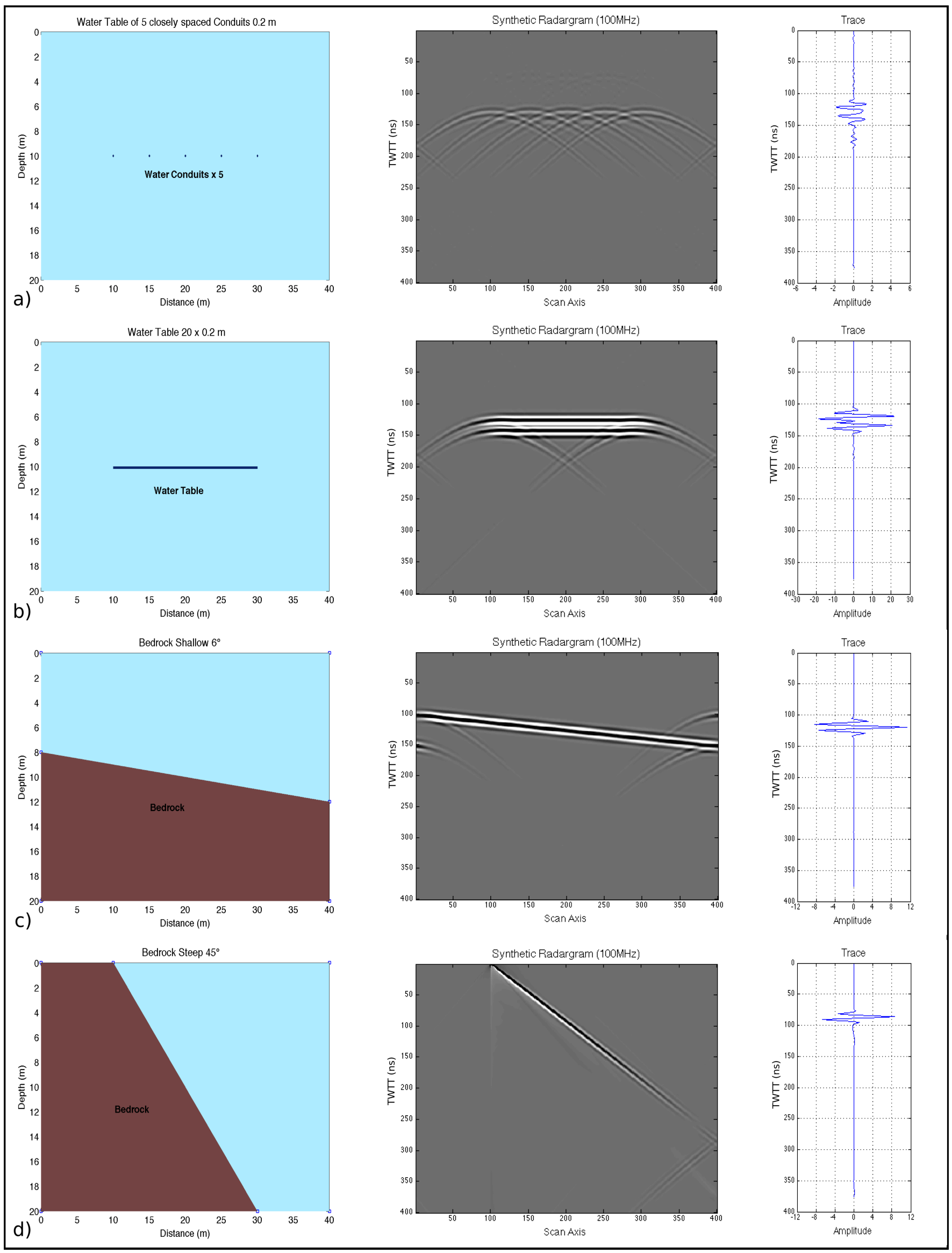

Figure 3.28: Figure showing water table and crevasse models, model synthetic (100 MHz); and center trace of the relative synthetic. Watertable dimensions are as follows; (a) watertable of conduits with $0.2 \mathrm{~m}$ diameter spaced $5 \mathrm{~m}$ apart; (b) watertable $20 \mathrm{~m} \times 0.2 \mathrm{~m}$; (c) bedrock at angle of $6^{\circ}$; and (d) bedrock at angle of $45^{\circ}$. Water table synthetic; (a) shows the integration of five hyperbolic reflections forming a semi-continuous horizontal horizon which all have a + - + phase polarity; (b) shows a high amplitude flat surface that have hyperbolic point reflectors from both ends of the feature. Bedrock synthetics (c) and (d) shows a flat surface with a dip shallower then model. Synthetic (d) shows an increased shallowing effect in comparison to (c). Both bedrock synthetics have a +- + phase polarity. 


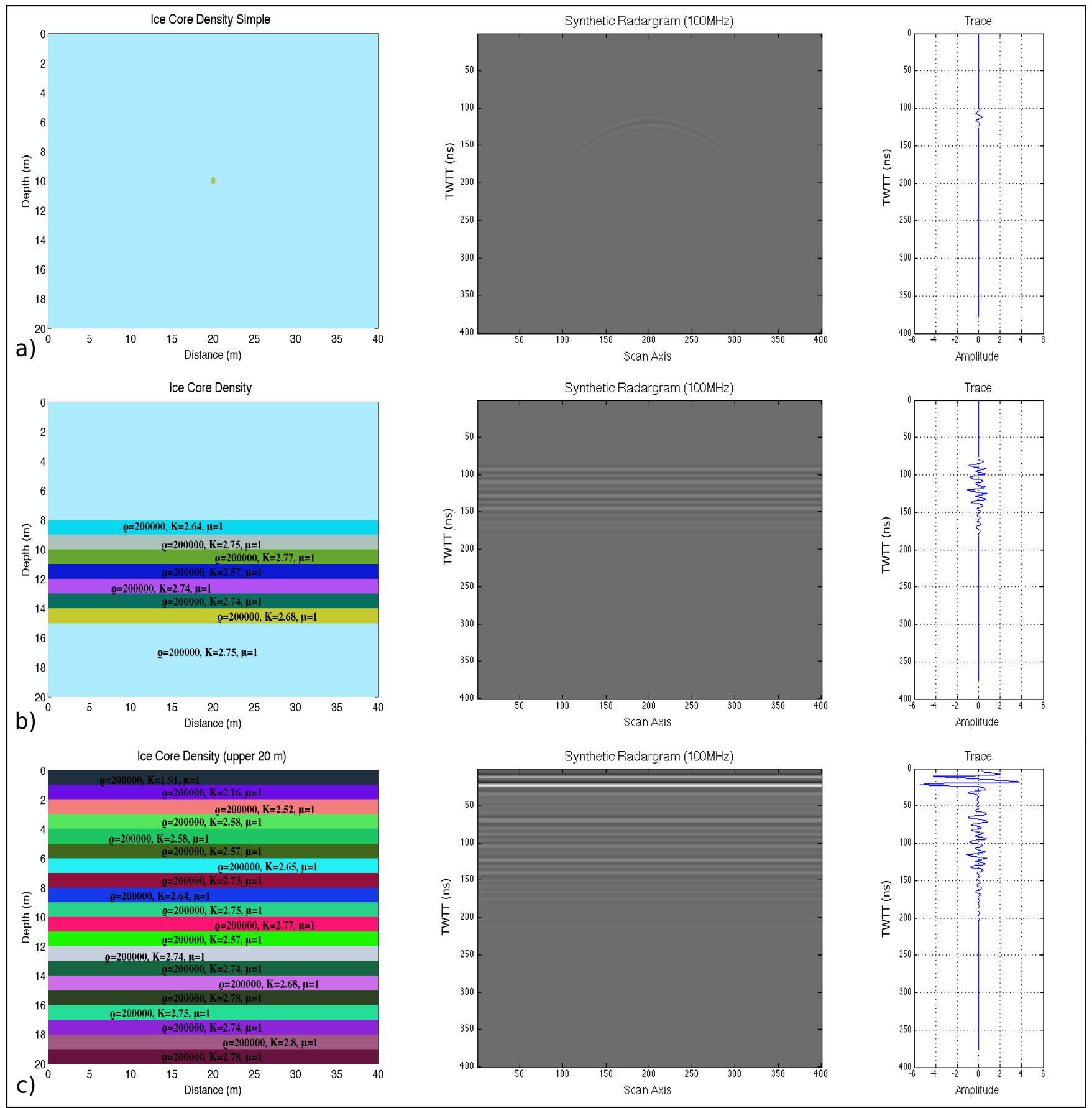

Figure 3.29: Figure showing ice core density models; model synthetic (100 MHz); and center trace of the relative synthetic. Model (a) change in relative permittivity between $9.9 \mathrm{~m}$ and $11.9 \mathrm{~m}$ due to ice density changes; (b) change in relative permittivity between $8 \mathrm{~m}$ and $15 \mathrm{~m}$ due to ice density changes; (c) change in relative permittivity between $0 \mathrm{~m}$ and $20 \mathrm{~m}$ due to ice density changes. Details of changes in relative permittivity are shown within the models and in Table 2.2. 


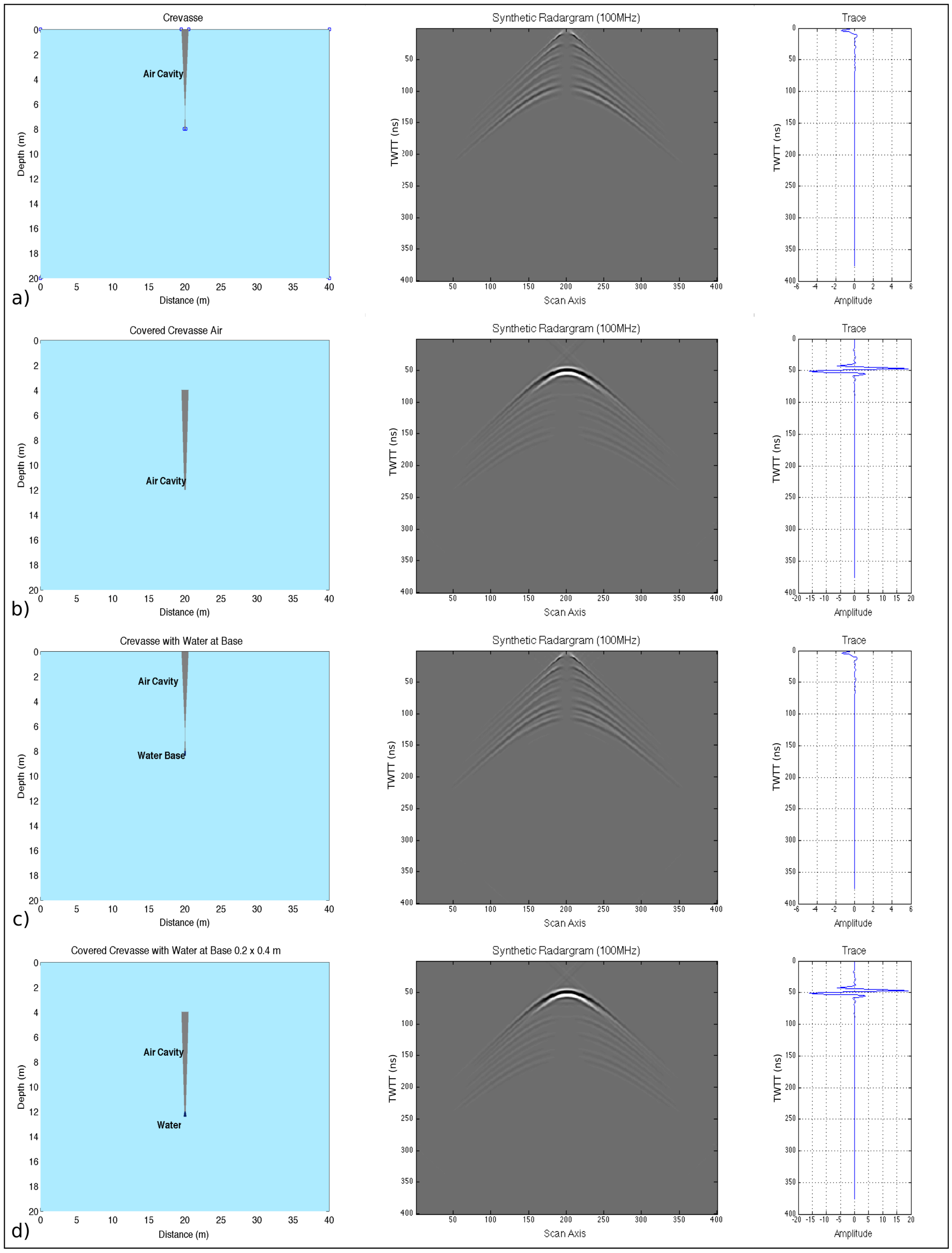

Figure 3.30: Figure showing crevasse models, model synthetic (100 MHz); and center trace of the relative synthetic. Crevasse dimensions are as follows; (a) $8 \mathrm{~m}$ crevasse; (b) $8 \mathrm{~m}$ buried crevasse; (c) $8 \mathrm{~m}$ crevasse with water at base; and (d) $8 \mathrm{~m}$ buried crevasse with water at base. Crevasse (a) and (c) show hyperbolic reflections which become progressively wider angle down trace and show a reflective free zone through the center of the reflection. Buried crevasse (b) and (d) show a hyperbolic reflections with reflective free zones through the center below the initial reflection. The buried crevasses have a - + - phase polarity. 
The ice density models use data from the ice core results and are shown in Figure 3.29. These are as follows: (a) $0.5 \mathrm{~m}$ point reflector at $10 \mathrm{~m}$, with decreased ice core density; (b) ice core density changes in one meter bands between $8 \mathrm{~m}$ and $15 \mathrm{~m}$; (c) ice core density changes in one meter bands between $0 \mathrm{~m}$ and 20 $\mathrm{m}$. Details of relative permittivity are given in Table 2.2. Ice core density example (a) shows a hyperbolic reflection and the phase polarity is positive; (b) shows banded reflections and a trace which shows increased negative phase amplitudes at $90 \mathrm{~ns}(7.5 \mathrm{~m}), 100 \mathrm{~ns}(8.4 \mathrm{~m}), 120 \mathrm{~ns}(10 \mathrm{~m}), 140 \mathrm{~ns}(11.7 \mathrm{~m})$ and (c) shows banded reflectors and a trace which shows increased amplitudes at $20 \mathrm{~ns}$ $(1.7 \mathrm{~m})$ with a high amplitude positive phase, at $60 \mathrm{~ns}(5 \mathrm{~m}), 100 \mathrm{~ns}(8.4 \mathrm{~m}), 120$ $\mathrm{ns}(10 \mathrm{~m})$ and at $140 \mathrm{~ns}(11.7 \mathrm{~m})$.

\subsection{Observed and synthetic radar comparison}

The synthetic radargrams presented earlier in the results are compared to observed englacial radar reflections to create a basis for radar interpretation. Overall the structure and wave phase of the synthetic and observed data compare well, although there are differences in the wave phases of observed data. It should be noted that the radar data presented in these results are unmigrated in order to compare to the synthetic radargrams.

Figures 3.31, 3.32 and 3.33 show the observed radar reflection event and trace (upper insert), and synthetic radar data and trace (lower insert). Radar data showing a hyperbolic reflection event from observed data and a synthetic radargram produced by a $0.2 \mathrm{~m}$ diameter water-filled conduit are shown in Figure 3.31. Both the observed and synthetic data show a negative phase polarity and have a similar structure. The amplitudes vary significantly between the observed and synthetic data. This research does not aim to recover wave amplitude therefore the mismatch of amplitudes is not an issue. The observed reflective horizon interface and synthetic are shown in Figure 3.32. The synthetic radargram was produced by five, $0.2 \mathrm{~m}$ diameter, water-filled conduits, 
spaced $5 \mathrm{~m}$ apart. The spatial structure of the hyperbolic reflections is comparable between the observed and synthetic data. The observed and synthetic trace do not match well. The synthetic trace shows a negative phase. Figure 3.33 shows a bed reflection event and the synthetic radargram produced by bedrock interface dipping at $16^{\circ}$. Both the observed and synthetic show a similar structure as solid continuous reflections with positive phase trace amplitudes.

Englacial air cavities or empty conduits also produce hyperbolic reflection events, as shown earlier in the synthetic radargrams section. The wave phase of hyperbolic reflections differs within the observed data. Determining the medium which causes the hyperbolic point reflection events is difficult, although it can be assumed with some confidence that they are caused by water, air or possibly both. 


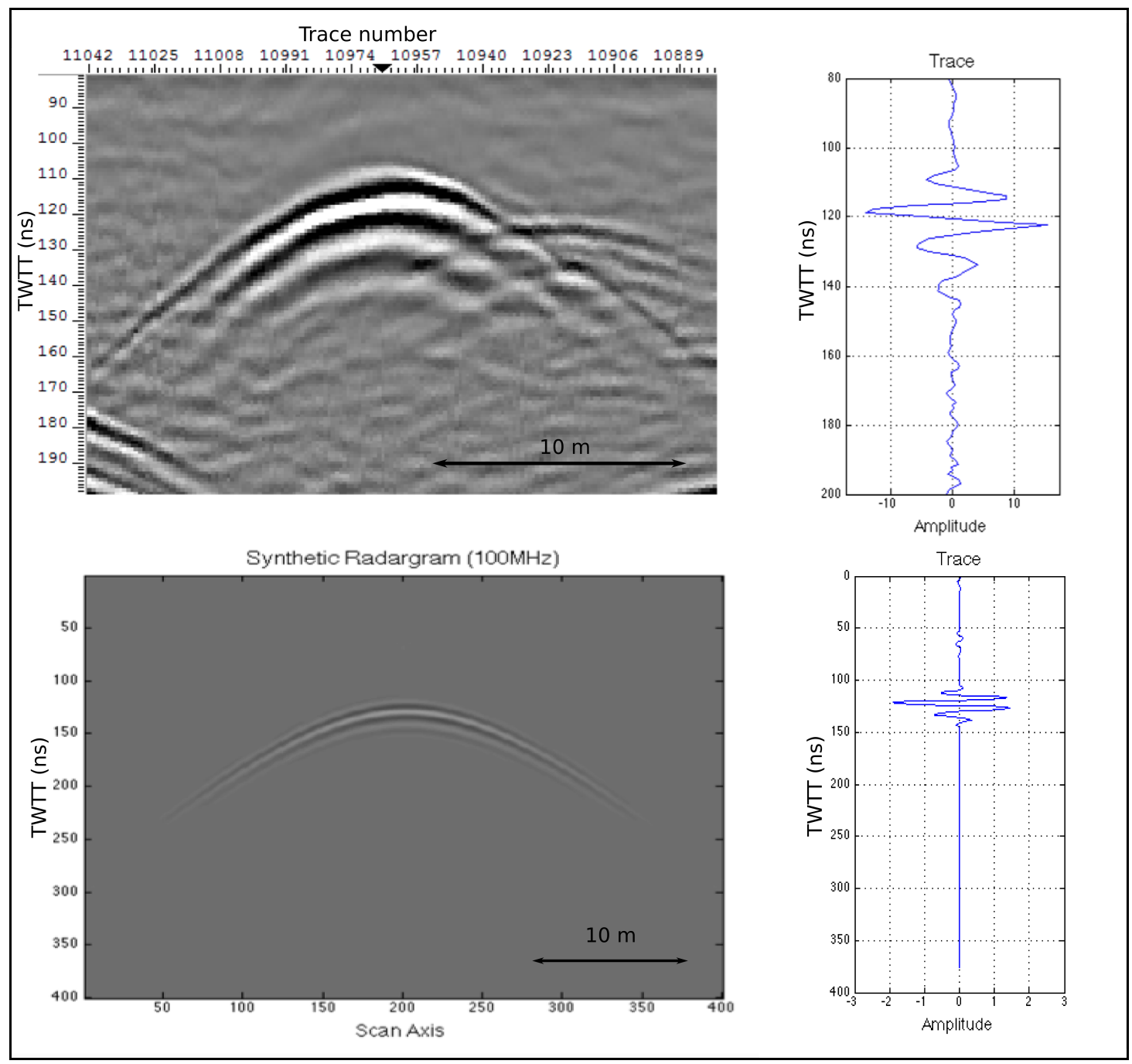

Figure 3.31: Upper insert shows observed hyperbolic reflection event from profile Sept 1077 with trace (taken below black triangle). Below shows synthetic radargram and center trace produced by a $0.2 \mathrm{~m}$ wide water conduit. Note the similar structure and phase polarity 


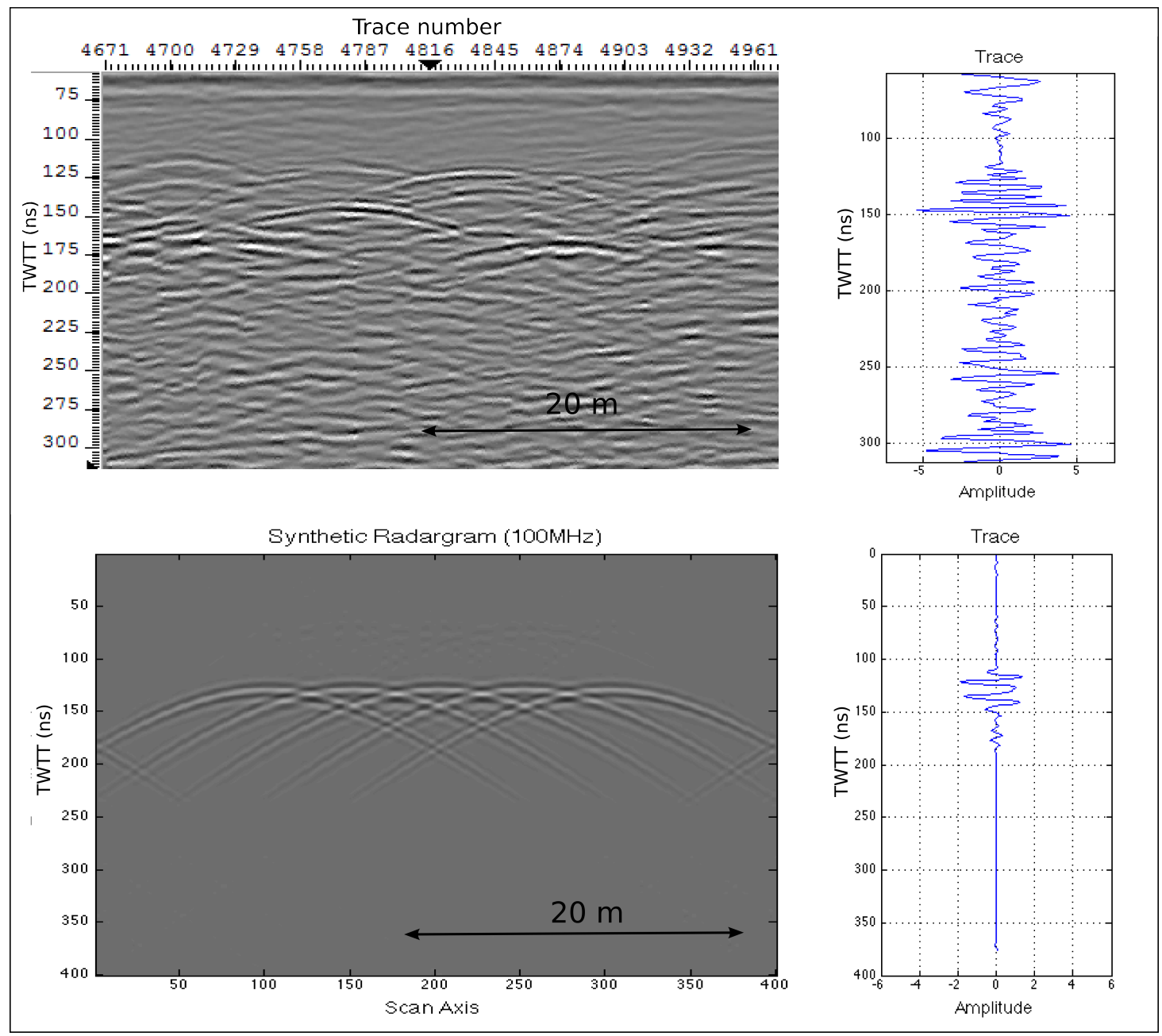

Figure 3.32: Upper insert shows observed reflective horizon (water table) hyperbolic reflection events from profile Sept 1088 with trace (taken below black triangle). Below shows water table synthetic radargram and center trace produced by five $0.2 \mathrm{~m}$ wide water conduits spaced at $5 \mathrm{~m}$ intervals. Note the similar reflection structure 


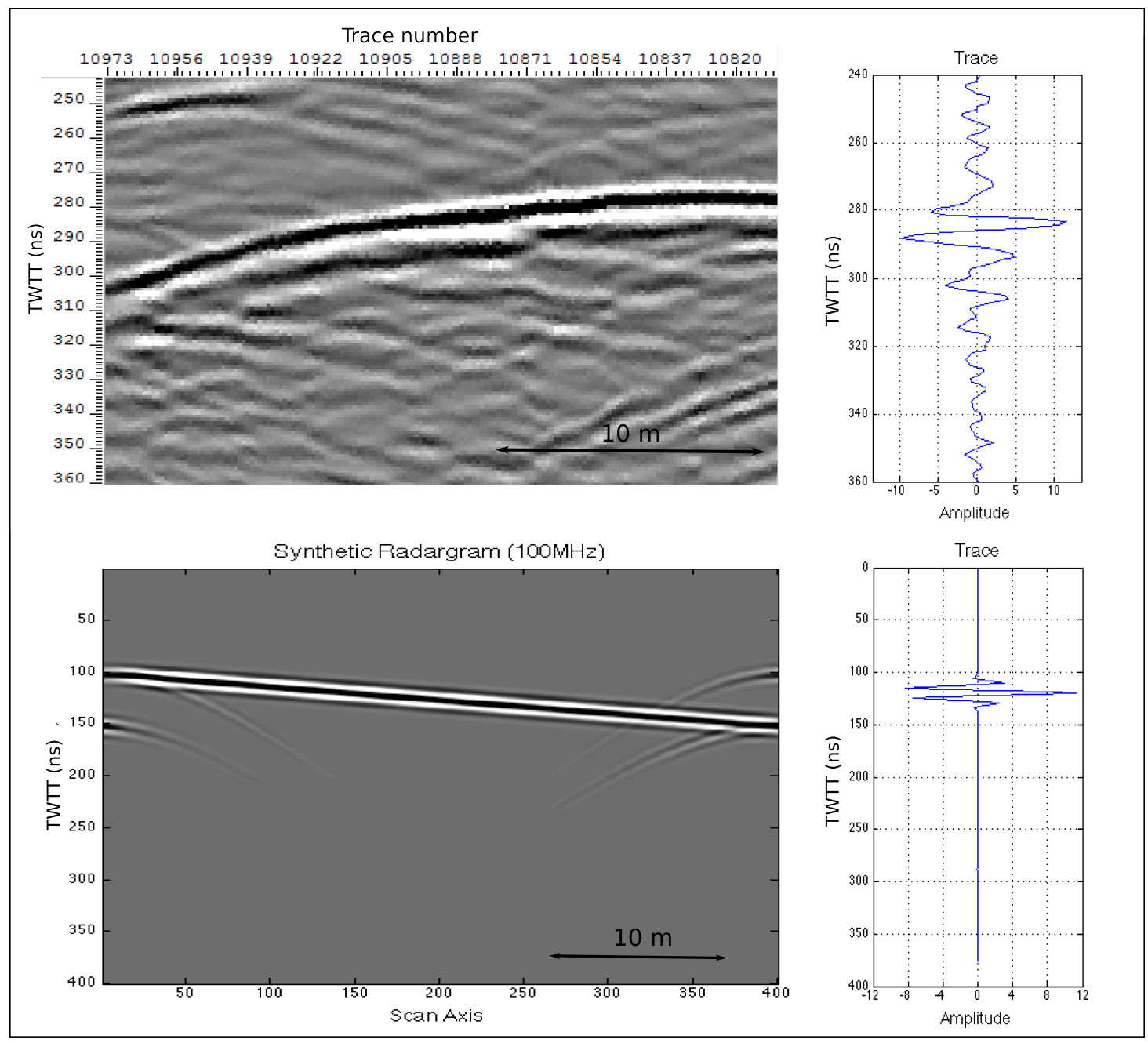

Figure 3.33: Upper insert shows observed reflection event from profile 1077 and trace (taken below trace number 10888). Below shows synthetic radargram and center trace produced by bedrock interface dipping at $16^{\circ}$ in opposite direction to observed reflection.

\subsection{Hydropotential surfaces}

Hydropotential surfaces were created using the glacier's surface topography from the December survey and horizon picks for the bed and the reflective horizon (see Figures 3.34, 3.35), as described in the methodology. The figures show the glacier surface elevation, hydropotential surfaces and surveyed profiles. Water flows perpendicular to the hydropotential surface contours from high hydropotential to low hydropotential. 
Figure 3.34 shows the hydropotential at the bed of the glacier. It shows that water flows in a down-glacier direction and towards the center of the glacier. Figure 3.35 shows the hydropotential at the reflective horizon which may possibly be a water table feature. The hydropotential shows a zone of lower hydropotential through the center of the glacier, which increases near the margin. 


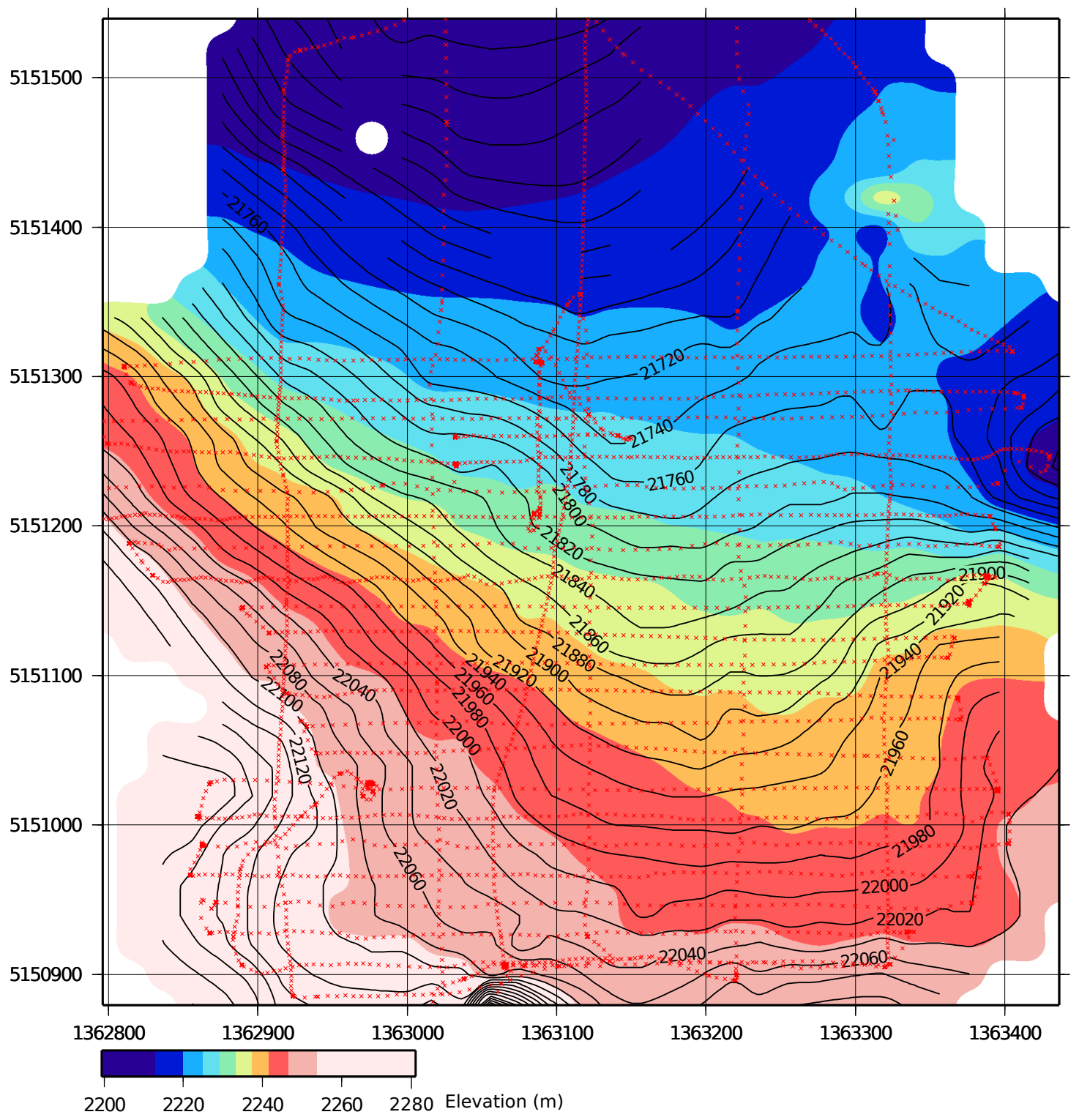

Figure 3.34: Hydropotential map of glacier bed at Annette Plateau for the December survey data. The coloured contours show surface elevation; the red crosses show the surveyed profiles and the black contours indicate hydropotential and are spaced every $20 \mathrm{hPa}$. Co-ordinate system is NZTM and units in $\mathrm{m}$. 


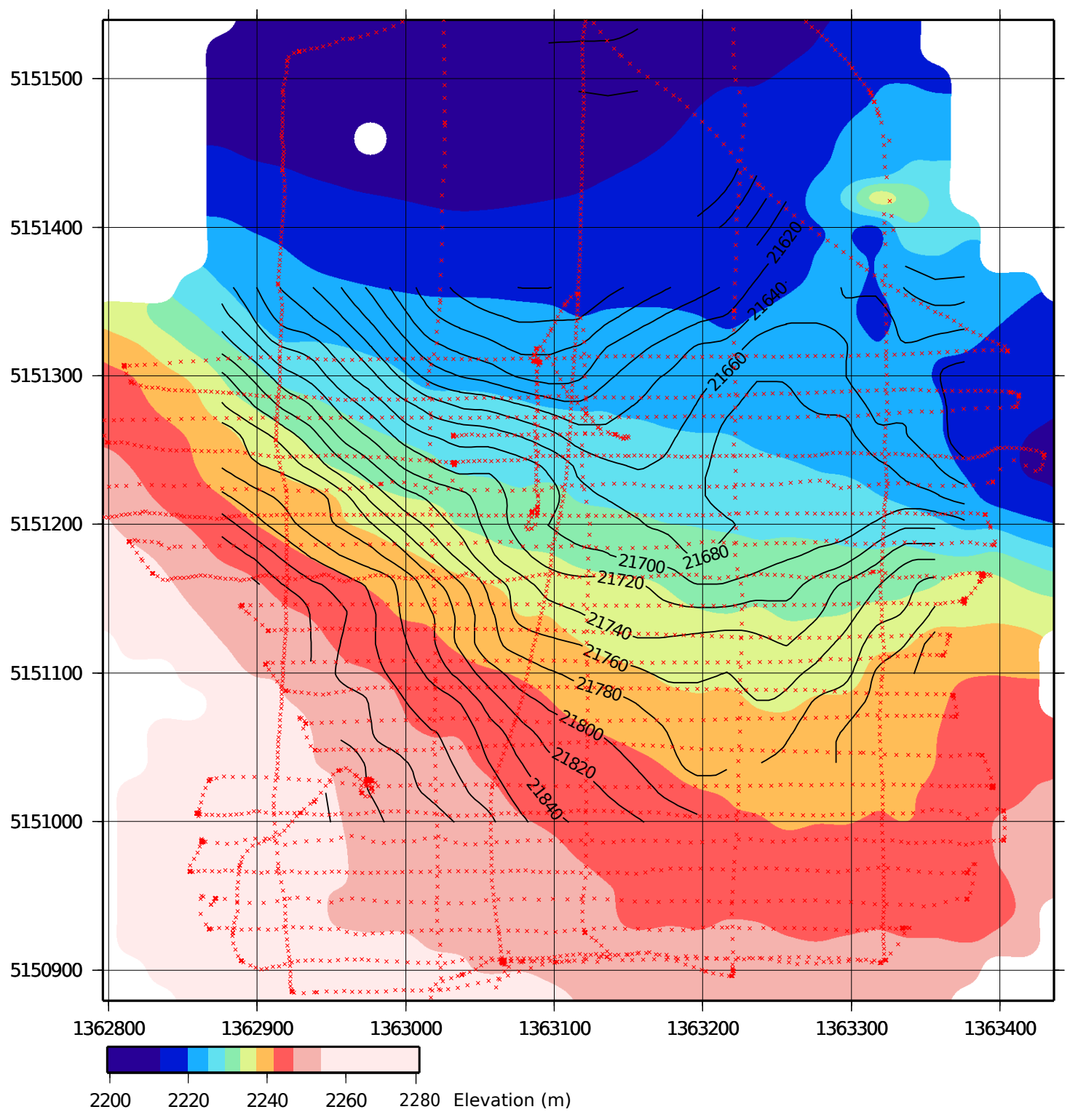

Figure 3.35: Hydropotential map of reflective horizon (water table) at Annette Plateau for the December survey data. The coloured contours show surface elevation; the red crosses show the surveyed profiles and the black contours indicate hydropotential and are spaced every $20 \mathrm{hPa}$. Co-ordinate system is NZTM and units $\mathrm{m}$.

\subsection{Ice core and radar data comparison}

The ice core which was drilled to 45 m on Annette Plateau in 2009 was analysed for a range of chemical properties including tritium, lead, silicon and others 
(Morgenstern, 2009). The tritium which is used to date ice shows that the upper $14 \mathrm{~m}$ of the glacier has a continuously decreasing age over the past $18 \mathrm{yrs}$, after which the ice jumps to approximately 100 yrs old. This shows that there is a significant amount of ice missing from the record indicating a hiatus. The age jump is also recorded by $210 \mathrm{~Pb}$ (lead). The tritium record also jumps at 24 $\mathrm{m}$ and $32 \mathrm{~m}$ which may represent other sections of missing ice (Morgenstern, 2009).

The density of the ice core was also taken. Field measurements of ice core density were recorded by weighing each section of core, which were typically $1 \mathrm{~m}$ long assuming a perfect cylinder to calculate density (Morgenstern, 2009).

The radar data show a significant horizon 'picked as the reflective horizon' between approximately $10-15 \mathrm{~m}$, which is evident from $100 \mathrm{~m}$ down-glacier (Figure 3.19 and 3.20. At the site of the ice core the depth to the reflective horizon was $12.5 \mathrm{~m}$ (150 ns) in the December survey and $14.2 \mathrm{~m}$ (170 ns) in the September survey. This horizon corresponds well to the depth at which the age jump in the tritium record appears at $14 \mathrm{~m}$. The field measured density record shows a decrease in the density from $0.78 \mathrm{~g} \mathrm{~cm}^{-3}$ to $0.71 \mathrm{~g} \mathrm{~cm}^{-3}$ and back to $0.78 \mathrm{~g} \mathrm{~cm}^{-3}$, between 9.9 and $11.9 \mathrm{~m}$ depth. The density corresponds well with the radar data which show a reflective horizon between $10-16 \mathrm{~m}$. The ice firn transition is reached between $0.81-0.84 \mathrm{~g} \mathrm{~cm}^{-3}$ at which the ice becomes impermeable (Bender et al., 1997). Therefore, there is a possibility that the decrease in density allows for an increase in water content, which forms the reflective horizon (water table) across the glacier. 


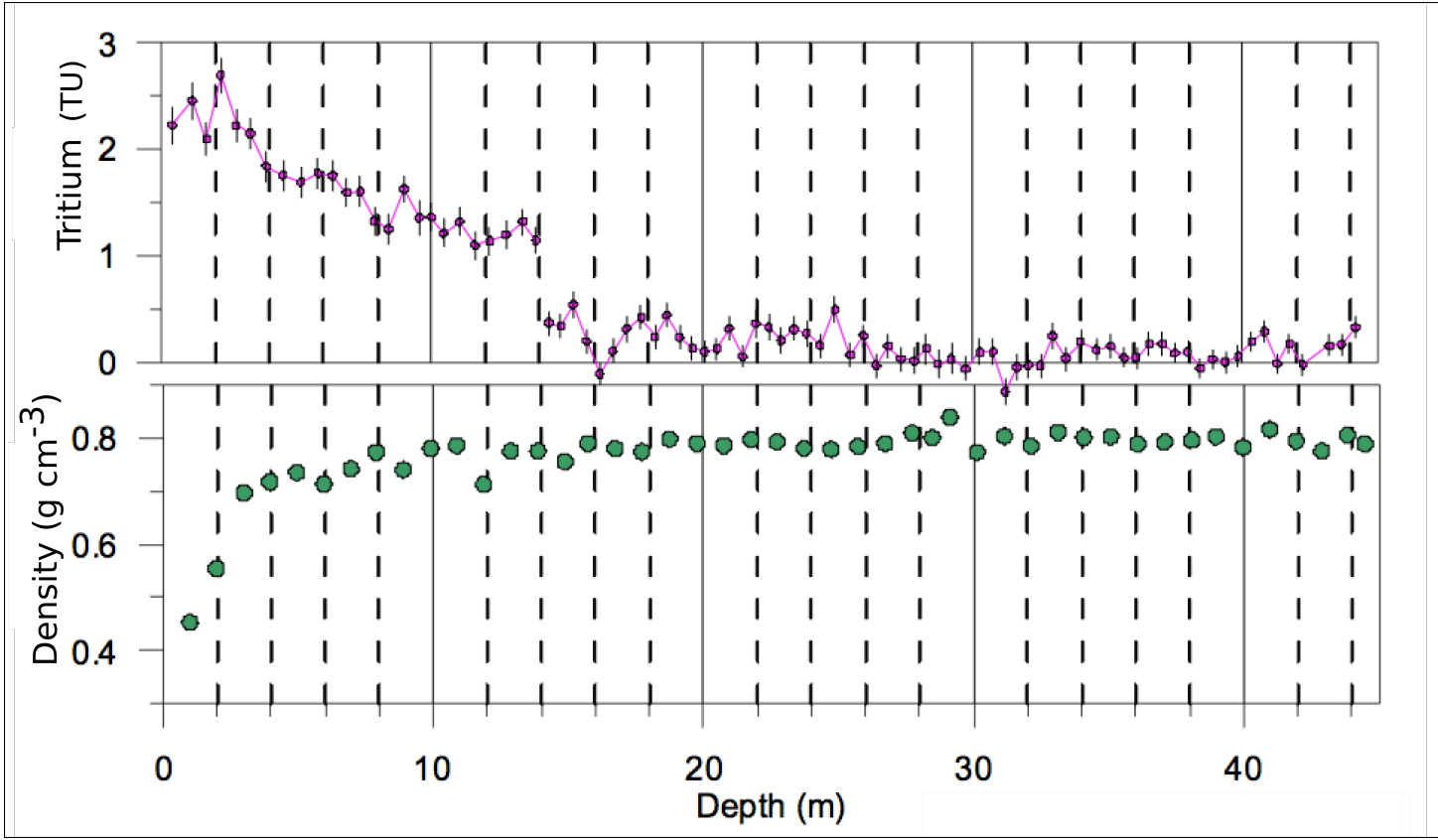

Figure 3.36: Tritium and density record from Annette Plateau ice core from Morgenstern (2009). Tritium record (upper insert) and density record (lower insert). 


\section{Chapter 4}

\section{Discussion}

This chapter describes the englacial hydrology of Annette Plateau as inferred from the combination of radar and ice core results.

\subsection{Englacial hydrology of Annette Plateau glacier}

Observed radar data, modelled englacial features and ice core studies indicate that there is a significant amount of englacial water within Annette Plateau. The radar data shows the presence of englacial reflections including (a) concentrated point reflectors, (b) the formation of a semi continuous horizon 100 $m$ down-glacier and (c) banded surface reflectors (Section 3.1.2). Englacial reflections show temporal and spatial differences in distribution. Synthetic radargrams of modelled englacial features show similar structure and wave phase to observed radar data (Section 3.3). Ice coring attempts at Annette Plateau in 2009 intercepted water at $5 \mathrm{~m}, 10 \mathrm{~m}$ and $45 \mathrm{~m}$ depth at different sites across the glacier (Morgenstern, 2009). These findings emphasize the prevalence of water within Annette Plateau. The radar data will now be discussed to show the existence of englacial conduits as water pathways at Annette Plateau.

\subsubsection{Englacial conduits}

Point reflectors were observed in all profiles in both radar surveys at Annette Plateau (Figures 3.13 and 3.14). The profiles from the head to $100 \mathrm{~m}$ down- 
glacier show less chaotic reflections and better defined point reflections. These reflections were tracked between profiles (20 m spacing) to determine if reflectors were continuous. Point reflectors on the upper section of Annette Plateau show evidence for continuity over a distance of $60 \mathrm{~m}$ and possibly up to $100 \mathrm{~m}$ (Figures 3.23 and 3.24). Tracked point reflectors deepen down-glacier, in some cases step and tend to meander. The link between point reflectors in adjacent profiles provides further evidence for the existence of englacial conduits at Annette Plateau.

Studies by Rothlisberger (1972) and Shreve (1972) show that meltwater flowing within a glacier will follow the hydrological equipotential, which is governed by the gradient of the total potential energy, gravity and ice pressure. This has been the prevailing hypothesis for englacial water pathways. However, field evidence shows that conduit paths are not limited to this pattern (Fountain, 1993; Gulley et al., 2009). Research by Gulley et al. (2009) of meterscale englacial conduits using caving techniques found that the existence and direction of englacial conduits corresponds to the orientation of the glacier's principle stresses or pre-existing hydraulic conductivity. These results suggest that the englacial drainage suggested by Shreve (1972) does not always dominate.

Hydrological equipotential shows that conduit paths are expected to be near horizontal on the upper glacier but steepen quickly further down-glacier (see Figure 1.3, Hooke 1989). This pattern is seen on the upper section of Annette Plateau. Near horizontal point reflectors show a deepening of approximately $10-15 \mathrm{~m}$ over $100 \mathrm{~m}$, reflecting an inferred conduit slope of approximately 5.8 $-8.6^{\circ}$ relative to the surface. The shallow gradient englacial conduits inferred from these point reflectors agrees with the near-horizontal englacial conduits observed by Copland et al. (1997) and Pohjola (1994) using borehole video analysis. Point reflectors were not able to be tracked further than $100 \mathrm{~m}$ downglacier at Annette plateau. This may be caused by either; (1) a steepening in conduit dip (steep conduit dips may not be resolvable at $20 \mathrm{~m}$ profile spacing) or (2) the increase in near-surface englacial reflectivity (causing an increase 
of radar attenuation at depth making the interpretation of reflectors difficult). Radar data of the glacier bed shows that it deepens from $100 \mathrm{~ns}(8.4 \mathrm{~m})$ to 900 $\mathrm{ns}(75 \mathrm{~m})$ over the upper $100 \mathrm{~m}$ of the glacier. Therefore conduits follow the surface slope much more than the bed slope.

The low gradient meandering pattern of englacial conduits at Annette Plateau are similar to those found in other studies (Gulley et al., 2009; Gulley and Benn, 2007; Stuart et al., 2003; Arcone and Yankielun, 2000). Studies by Gulley et al. (2009) of the temperate Matanuska glacier in Alaska found low-angle meandering conduits between 1 - $4 \mathrm{~m}$ in diameter. A study by Stuart et al. (2003) using radar and caving techniques to study englacial channels in a poly-thermal glacier in Svalbard, Norway, found that conduits stepped down-glacier, flowed at a low gradient and were up to $6 \mathrm{~m}$ in diameter. Findings from the study by Stuart et al. (2003) compare well to the conduit pattern found at Annette Plateau, however, it is thought these conduits have a smaller diameter, more comparable to studies by Copland et al. (1997) and Pohjola (1994) of temperate glaciers where conduit diameters of $0.2 \mathrm{~m}$ were found.

Radar data collected at Annette Plateau show an increase in englacial point reflectors down-glacier, suggesting an increasingly complex drainage network distribution (Section 3.1.2.1). From the head of the glacier to $100 \mathrm{~m}$ downglacier the least amount of point reflections are observed after which, approximately 20 point reflections are observed in each profile. This pattern of point reflectors does not align with research by Shreve (1972), which shows englacial drainage should be most complex up-glacier and simplify as drainage pathways merge down-glacier, forming an upward branching tree like network. The lack of increasing simplicity down glacier within the englacial system is likely to be related to the glaciers low elevation and overall glacier morphology. Annette Plateau has a low surface slope $\left(2^{\circ}\right)$ and is largely crevasse free. Shreve (1972) notes that surface morphology is a main determinant of water movement. Radar data shows the majority of water entering the englacial system is likely to be through melt water percolation across the glaciers surface. Therefore increased complexities are expected with distance down-glacier due to a 
higher number of meltwater input sites and decreased elevation causing higher melt rates.

Convergent flow between conduit pathways is assumed to occur although it is not observed in this study. Studies have found that englacial conduits do not typically link or merge with other englacial conduits down-glacier (Gulley et al., 2009; Stuart et al., 2003; Gulley and Benn, 2007). Arcone and Yankielun (2000) used radar to study englacial pathways within the Black Rapids Glacier, Alaska and interpreted two horizons on the upper section of the glacier as meandering drainage channels. Closer to the ablation zone a more complex branching drainage structure was interpreted, which is thought to be supplied by nearsurface melt. Radar data of Annette Plateau agrees with these studies, suggesting that englacial drainage becomes increasingly complex down-glacier as a result of glacier surface morphology and low elevation of glacier.

Synthetic radargrams show that water-filled conduits produce hyperbolic structures with a negative phase reflection, and air-filled conduits produce similar structures but a positive phase reflection. The observed radar data show point reflections with both negative and positive reflection phases. It can therefore be assumed that at the time of the radar survey both water and air-filled conduits were present within the glacier. Analysis of the number and distribution of point reflector wave phase is out of the scope of this project. Additionally during three attempts to drill an ice core to the bed of Annette Plateau glacier englacial water was intercepted at 5, 10 and $45 \mathrm{~m}$. Air cavities were not once intercepted during coring attempts which highlights the prevalence of water within Annette Plateau.

Copland et al. (1997) studied 11 boreholes on the Haut Glacier d'Arolla, Switzerland and found that the englacial channels accounted for $0.1 \%$ of vertical ice thickness. A study by Pohjola (1994) on Storglaciaren, Sweden, found englacial channels to account for $1.3 \%$ of the observed ice column, suggestive of a more extensive englacial system. The englacial hydrology at Annette Plateau is more similar to the study by Pohjola (1994), as the radar data suggests water passages are extensive throughout the glacier. 
The englacial conduit system at Annette Plateau may be described as follows: (1) the upper glacier is made up of few low gradient conduits which tend to meander down-glacier; (2) conduits are continuous up to $60 \mathrm{~m}$ and may extend to $100 \mathrm{~m}$; (3) conduits may dip steeply into the glacier body near $100 \mathrm{~m}$ downglacier and; (4) from $100 \mathrm{~m}$ down-glacier the majority of point reflectors form a horizon, possibly a water table feature, between 10 - $15 \mathrm{~m}$ and are not able to be tracked between profiles.

\subsubsection{Water table}

The radar data shows the development of a reflective horizon from $100 \mathrm{~m}$ downglacier suggesting the existence of a water table feature. The horizon forms a semi continuous reflective horizon above which a reflection-free zone exists extending from the glacier surface. It is typically found between $10-15 \mathrm{~m}$ deep across the width of the glacier and shallows down-glacier. The horizon is visible in both surveys and shows better definition in the September survey.

Water tables are common within temperate glacier environments. Water saturated zones typically form at the interface between the glacier's near impermeable ice body and the wet firn (Schneider, 1999). The firn is porous and permeable and is therefore able to store and buffer water inputs into the glacier. The rate of water movement into the glacier depends on the permeability and saturation of the firn (Ambach et al., 1981). Water table features typically deepen up-glacier as snow accumulation increases with elevation (Fountain, 1989). At a small temperate glacier in Iceland Murray et al. (2000a) found that the water content changed from $0.23-0.34 \%$ near the surface to $3.0-4.1 \%$ at $28 \mathrm{~m}$ depth. The sharp rise in water content was interpreted to be a water table. Below this surface until the bed of the glacier, near $100 \mathrm{~m}$, the water content gradually dropped to $0.09-0.14 \%$.

The formation of a water table is typically caused by the densification of snow into ice (approximately $0.81-0.84 \mathrm{~g} \mathrm{~cm}^{-3}$ ) at the firn ice interface which is com- 
monly found near $20 \mathrm{~m}$ depth (Bender et al., 1997). This is noticeably deeper than the water table feature at Annette Plateau which is found between approximately 10 - $15 \mathrm{~m}$ depth. However, the depth of the firn-ice transition is similar to the transition determined by temperature and accumulation rates by Herron and Langway Jr (1980).

The ice core data may provide an explanation for this shallow water table. The tritium and $210 \mathrm{~Pb}$ show continuously decreasing age for the past 18 yrs until $14 \mathrm{~m}$ in the record at which point the ice is much older $(100 \mathrm{yrs}+)$ signifying a hiatus in the record (Figure 3.36). The old ice was most likely buried beneath younger ice, caused by snow accumulation in the past, enabling it to densify. The field measured density record shows a decrease in the density from $0.78 \mathrm{~g} \mathrm{~cm}^{-3}$ to $0.71 \mathrm{~g} \mathrm{~cm}^{-3}$ and back to $0.78 \mathrm{~g} \mathrm{~cm}^{-3}$ between 9.9 and 11.9 $m$ depth (Figure 3.36). The density corresponds well with the radar data which show a reflective horizon near $12 \mathrm{~m}$ at the ice coring site. The decrease in density may allow for an increase in water content forming the water table across the glacier. As stated above ice become impermeable between approximately $0.81-0.84 \mathrm{~g} \mathrm{~cm}^{-3}$ but the water table observed here is found above lower density ice which is unexpected. It is likely that the density measurements made were underestimating the actual ice density.

Synthetic radargrams which model ice core density show it is unlikely that the reflective horizon can be attributed solely to density changes (Figure 3.30). The major reflections in the density record appear between 5 - $11 \mathrm{~m}$ (see Figure 3.29 in results) whereas the reflective horizon is typically found between $10-15 \mathrm{~m}$ depth. The density reflection pattern does not reflect what is seen in the radar data. The radar data typically show a reflection free zone above the reflective horizon at which the greatest amplitude reflector is found. It is also thought that density changes would be homogeneous across the glacier and therefore appear as continuous reflective horizons. However, this is not observed.

The structure of water tables in temperate glaciers is largely unknown. The synthetic radargrams may provide an explanation. The synthetic radargram 
model which uses 5 water conduits, $0.2 \mathrm{~m}$ in diameter, spaced $5 \mathrm{~m}$ apart, creates a reflection pattern which is similar to the reflective horizon seen in the observed data (Figure 3.32). This indicates that the water table may be made up of conduit pathways which have formed on or near the reflective horizon. The horizontal water table, $0.2 \mathrm{~m}$ in thickness, was also modelled and resulted in a reflection pattern which is not observed in the data.

Englacial water was intercepted during all ice coring attempts at Annette Plateau at 5, 10 and $45 \mathrm{~m}$ depth. Englacial water intercepted at $45 \mathrm{~m}$ flooded the ice coring site to $13 \mathrm{~m}$ depth in the drill hole. The $13 \mathrm{~m}$ mark corresponds well with the depth of the observed reflective horizon (water table). This suggests that: (1) the water drained through the permeable water table surface; or (2) the pressure in the englacial conduit forced the water to rise to $13 \mathrm{~m}$. The water table observed is most likely formed on an old melt surface as shown by the tritium record and caused by a combination of (1) increased water content due to a lowering in ice density above the horizon, (2) the increase in ice density below the water table and (3) the concentration of chemical elements on the old melt surface.

\subsection{Temporal changes in hydrology}

In temperate glacier environments water inputs into the glaciers surface vary seasonally and daily. Water entering the glacier can range from no inputs during winter to tens of millimetres and likely much more per day in summer (Oerter and Moser, 1982). The observed radar data from Annette plateau show significant differences in the spatial distribution and number of internal reflectors when comparing surveys (Section 3.1.2). The changes in reflectivity may be attributed to changes in the glacier's water content and hydrological processes. Overall the December data shows a greater distribution of internal reflections and an increase in chaotic returns. Differences in internal reflectivity are well illustrated by the comparison of banded surface reflectors from both surveys (Figure 3.16 and 3.17). 
Banded surface reflectors are found between the glacier's near-surface and $8 \mathrm{~m}$ depth and extend vertically downward (Figure 3.15). Approximately 15 banded surface reflectors are found in the September survey and 115 in the December survey. As the glacier surface is predominantly crevasse free the reflections are thought to be caused by an increase in near-surface water. It is also unlikely that approximately 100 new crevasse features formed between September and December and show no surface expression.

The reflective horizon (water table feature) also shows differences in spatial distribution of englacial reflectors between surveys. Water table features are known to change thickness depending on water inputs which vary greatly seasonally (Lang et al., 1977; Oerter and Moser, 1982). Increased reflectivity is observed above and below the horizon in the December survey suggesting an increase in the water content above and below the water table horizon. If the reflective horizon is caused by density changes it would be expected that the same reflection horizons would be evident in both surveys. As this was not the case, differences in the characteristics of the glacier's reflective horizon are most likely caused by changes in water content, distribution and inputs.

Changes in distribution of englacial reflectors may be explained by increased temperatures and higher frequency rain events in early summer (Sturman et al., 1996). Higher meltwater contents are expected to enter the glacier's surface during warmer months (Hodgkins, 2001). The increase in banded surface reflectors may represent an increase of water at the glacier's surface that drains through the firn to the water table. The excess water possibly drains from the water table through passages into the glaciers body. This may explain the increase of englacial reflectors below the water table in the December survey.

Point reflectors from the head of the glacier to $100 \mathrm{~m}$ down-glacier show a similar distribution in both surveys although this is most prominent in the upper 3 profiles (Figures 3.23 and 3.24). Similarities in distribution suggests that the englacial system on the upper glacier is semi steady state. Steady state 


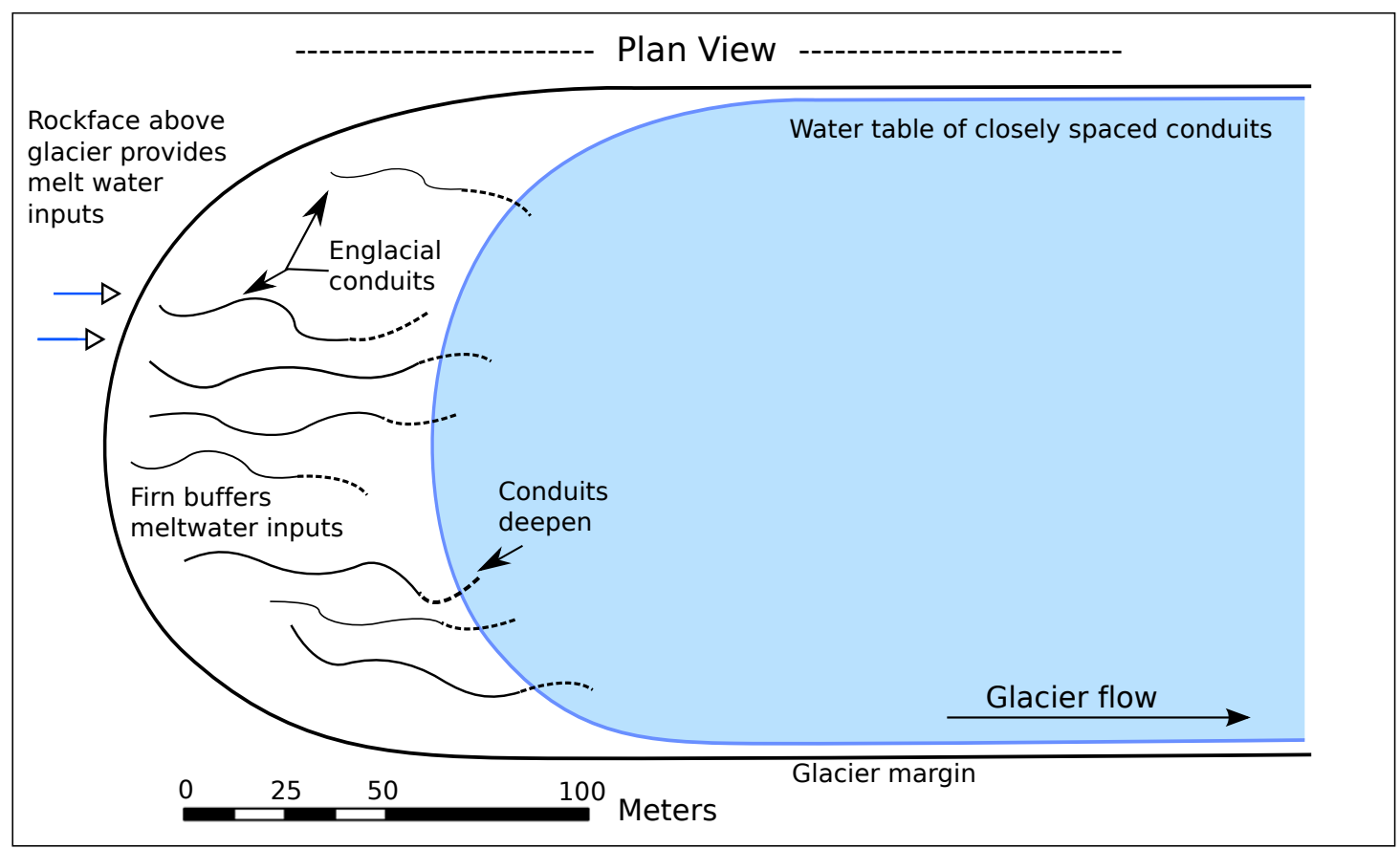

Figure 4.1: Schematic illustration showing plan view of hydrological features at Annette Plateau. Dashed black line indicating inferred conduit.

englacial conditions only occur under consistent or slightly varied hydraulic inputs, which requires a storage mechanism (Fountain, 1989). The firn layer on a glacier is able to act as a storage reservoir and filter daily variations in water inputs (Fountain, 1989). It is thought that inputs solely through the firn may not be sufficient to supply steady inputs. The upper glacier may also be supplied by local meltwater inputs from the rock face above the upper extent of the glacier. It is suggested that the combination of firn drainage and meltwater inputs from the rock face form a semi steady state conduit system observed on the upper glacier.

\subsection{Conceptual model for englacial hydrology}

Schematic illustrations showing plan and profile views of hydrological features at Annette Plateau can be seen in Figures 4.1 and 4.2. Below the conceptual hydrological features at Annette Plateau are described. 


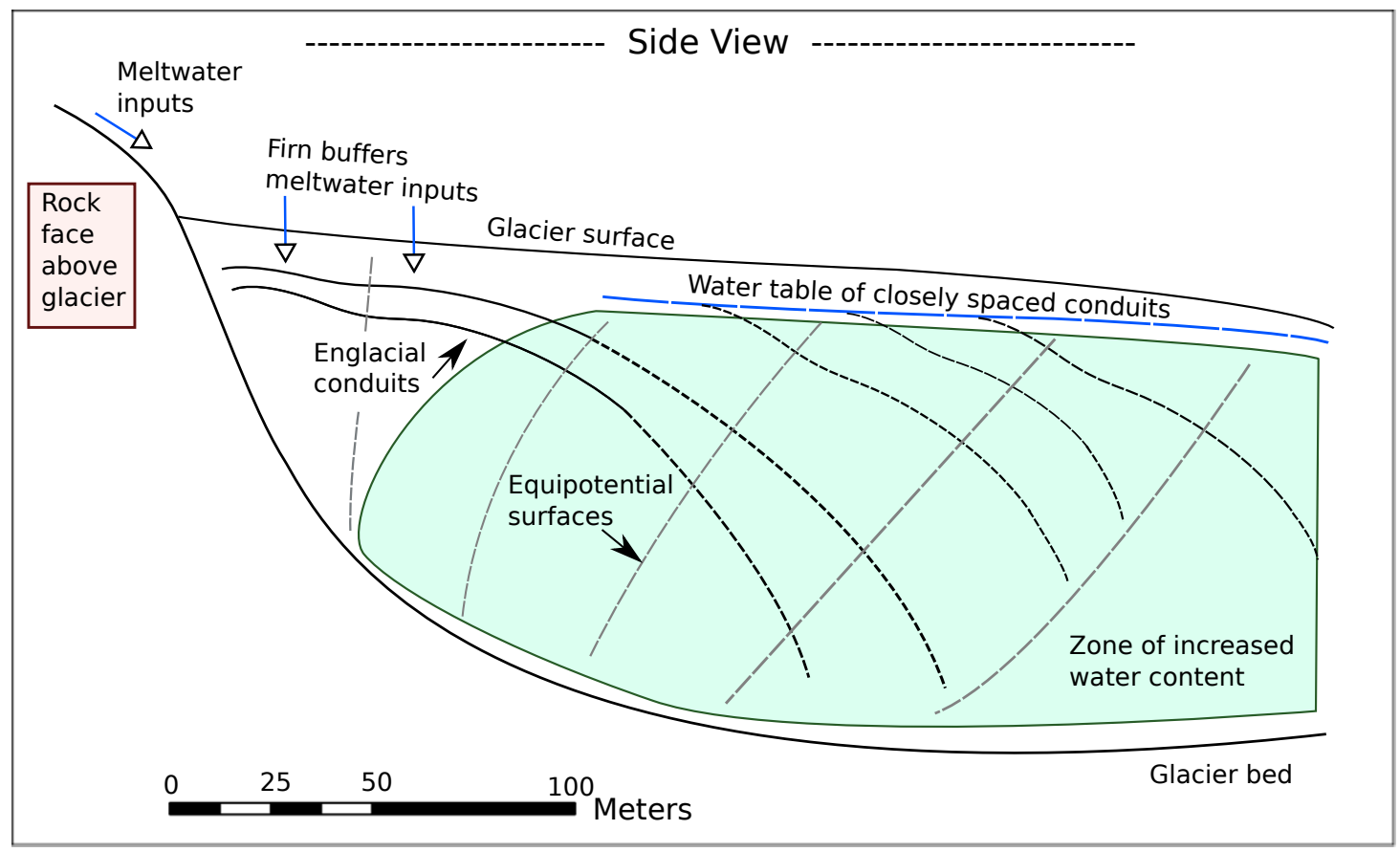

Figure 4.2: Schematic illustration showing profile view of hydrological features at Annette Plateau.Dashed black line indicating inferred conduit. Dashed grey lines indicate equipotential surfaces, from (Hooke, 1989)

\section{Englacial hydrology}

The upper glacier consists of a semi-stable hydraulic englacial system containing few conduits which may be continuous over $60 \mathrm{~m}$ or more in length. Conduits meander and tend to deepen with distance down-glacier. The upper glacier's hydraulic system is possibly supplied by localised inputs such as firn drainage and snow melting from rock surfaces above Annette Plateau producing a semi-stable conduit system.

From the upper to mid glacier englacial reflectors become concentrated along the reflective horizon surface suggesting the development of a semi-impermeable horizon on which water flows (water table) through small conduit pathways. Reflectors are also seen below the water table horizon inferring that there is water or air-filled conduits or cavities at depth. Englacial conduits may initiate from the water table horizon and extend deep within the glacier. Tracking 
of englacial reflectors at depths below the water table is not possible due to chaotic internal reflections.

Water filled conduits within the glacier were encountered at $45 \mathrm{~m}$ when drilling the ice core in 2009 (Morgenstern, 2009). The drill hole flooded up to the $13 \mathrm{~m}$ level within the core which is a similar height to the water table observed within the radar data. It is possible that at $13 \mathrm{~m}$ depth the up-welling water reached the water table and drained.

The mid glacier shows a fully developed water table which shallows downglacier. The increase in chaotic internal reflections down-glacier may imply all or a combination of the following: (1) increased water contents; (2) a greater spatial distribution of water through glacier profile and (3) an increasingly complex hydraulic system supplied by surface melt and up-glacier inputs as suggested by Arcone and Yankielun (2000). The lower glacier is similar to the mid glacier although the water table rises closer to the glacier surface.

\section{Temporal changes in hydrology}

Increased temperatures and higher frequency rain events in summer cause an increase of water at the glacier's surface which drains through firn to the water table. This is evident in the increase of banded surface reflectors which are visible within the December survey. Water drains from the water table through new or existing passages as the water content within glacier increases.

\subsection{Ice core and radar data comparison}

Ice core data from Annette Plateau shows changes in chemistry, density and the prevalence of englacial water. The ice core data are compared to radar data to aid the understanding of englacial reflections, as done by Murray et al. (2000a) and Eichler et al. (2001) in previous studies. Radar data from Annette Plateau reported here were collected 2 yrs after the ice core was drilled. Radar data 
collected at the time of ice coring is optimum in terms of comparing between data sets. It is expected that the general hydrological system within the glacier remained similar over this period. However, it is expected that single features such as englacial water pathways encountered during ice coring will most likely have changed.

During three ice coring attempts at Annette Plateau englacial water was intercepted at 5, 10 and $45 \mathrm{~m}$. Analysis of the radar data at the site of the deepest ice core shows that there is no significant englacial reflector at or near $45 \mathrm{~m}$. The data shows chaotic reflections throughout the profile which are not any different to other profiles. These results suggest that some of the chaotic reflections observed at depth throughout the profiles may be englacial water pathways. It also suggests that detecting a single englacial conduit, at depth is not possible using $100 \mathrm{MHz}$ radar.

As mentioned in the discussion on the water table, the reflective horizon observed in the data may be explained by a decrease in density between 9.9 and $11.9 \mathrm{~m}$. The density decrease may allow water to pool on the surface forming the water table horizon. The area corresponds well with radar data which show a reflective horizon at $150 \mathrm{~ns}(12.5 \mathrm{~m})$ at the site of the ice core. Synthetic radargrams which model ice core density show that it is unlikely that the reflective horizon can be attributed solely to density changes. The major reflections in the density record appear between 5 - $11 \mathrm{~m}$ whereas the reflective horizon is typically found between 10 - $15 \mathrm{~m}$ depth. Furthermore the density reflection pattern does not compare well with what is seen in the radar data. The radar data typically shows a reflection-free zone up until the reflective horizon, at which the greatest amplitude reflector is found (typically near $10 \mathrm{~m}$ ). It is also thought that density changes in the ice would be more homogeneous across the glacier therefore appear as continuous reflective horizons.

The water table feature at Annette Plateau also correlates to the hiatus in accumulation inferred from the tritium record. The tritium record from the ice core shows that the upper $14 \mathrm{~m}$ of the glacier has a continuously decreasing age 
over the past 18 yrs after which the tritium jumps to older ice possibly from the 1930s. This indicates that there is a significant amount of ice missing from the record and that the older ice represents an old melt surface. The water table observed in the radar data may have formed on this old melt surface.

Changes in ice chemistry are known to cause englacial reflections and are a major contributor to reflections in the polar regions (Jol, 2009). Synthetic models were used to test if reflections observed in the radar data could be attributed to changes in ice core chemistry. A model was made which uses sodium-chloride $(\mathrm{NaCl})$ at a concentration of $7,656 \mathrm{ug} / \mathrm{L}$, which is likely in temperate marine environments (Matsuoka et al., 1997) although the highest concentration of sodium observed in the ice core was only $300 \mathrm{ug} / \mathrm{L}$. The synthetic showed a weak reflection indicating that the changes in ice core chemistry could not solely attribute for the observed englacial reflections. The water table reflection is most likely caused by a combination of chemistry, density and increased water content, the last of which is thought to have the greatest contribution to the observed reflective horizon.

\subsection{Ice cores from the Southern Alps of New Zealand}

High resolution radar profiles of Annette Plateau combined with the ice core data show that water is pervasive throughout the englacial system. The data suggests that other glaciated sites which experience similar climates to Annette Plateau, within the Southern Alps, may also be affected by englacial water. Therefore Annette Plateau and other similar or lower elevation sites are not recommended for retrieving ice cores unless a drill is used that is able to penetrate through water.

Other glaciated sites in the Southern Alps were also drilled to gain ice core data as part of the New Zealand Ice Coring Project. Baker Glacier is positioned at $2360 \mathrm{~m}$ a.s.1. and was drilled in June 2009. An ice core of $30.7 \mathrm{~m}$ in length was retrieved at which point englacial water was intercepted (Morgenstern, 2009). 
Ice core analysis shows the core dates back approximately $12 \mathrm{yrs}$ and that melt water is present within the record (Morgenstern, 2009). Hutton glacier was the highest elevation site positioned at $2760 \mathrm{~m}$ a.s.l. and was drilled in June 2009. An ice core of $33.3 \mathrm{~m}$ in length was retrieved at which point the bed was reached. The ice core analysis shows the top of the core is older than $100 \mathrm{yrs}$ as it is beyond the tritium dating range. Meltwater impacts are seen within the record in the upper $26 \mathrm{~m}$ of the core (Morgenstern, 2009). These results show that ice cores from the Southern Alps are impacted by meltwater from at least until 2760 m a.s.l. 


\section{Chapter 5}

\section{Conclusions}

This study combines: (1) two high resolution radar surveys, (2) synthetic radar models, and (3) ice core data to investigate the englacial hydrology at Annette Plateau. A range of internal reflections are evident in the radar data which have aided in the understanding of water presence and pathways within Annette Plateau. Synthetic radargrams were produced to model a range of englacial features which were used to better understand observed radar data. The results of the ice core demonstrate the presence of water within the glacier and provide chemistry and density data to aid the understanding of the radar data. This study shows that the temperate englacial hydrology is a result of the combination of physical processes defined by Rothlisberger (1972) and Shreve (1972), and the inherent physical properties and internal structures that exist within a glacier.

\subsubsection{Completed research objectives}

Results from this study show that the following research objectives are now able to be addressed:

1. Use high resolution GPR survey to understand water presence and pathways within Annette Plateau and create a conceptual model of englacial hydrology. 
Radar was used as a tool to image where englacial water and conduits exist within Annette Plateau. Previous ice core data show that water exists between 5 - $45 \mathrm{~m}$ within the glacier. Radar shows evidence of conduits on the upper glacier which are $60 \mathrm{~m}$ and possibly up to $100 \mathrm{~m}$ in length after which they likely dip steeply into the glacier. Conduits tend to dip gently and meander down-glacier. The conduits are thought to be fed by drainage through firn and snow melt from rock slopes above Annette Plateau. Radar shows the development of a semi continuous horizon from $100 \mathrm{~m}$ down-glacier, which appears to be a water table. The horizon is typically found between 10 - $15 \mathrm{~m}$ shallowing down-glacier. Synthetic radargrams indicate that the water table is possibly made up of closely spaced conduits which form the reflective horizon. The ice core density decreases near $12 \mathrm{~m}$ which may explain the presence of the water table. The water table feature has likely formed on an old melt surface as indicted by the hiatus in the tritium record near $14 \mathrm{~m}$. Point reflections at depth may indicate water-filled conduits as ice core data shows water down to $45 \mathrm{~m}$.

\section{To compare two GPR surveys in order to understand seasonal changes in water distribution/glacier hydrology over a four-month period (Sept-Dec).}

The radar data show differences in the spatial distribution and number of internal reflectors when comparing surveys. The changes in reflectivity may be attributed to changes in the glacier's water content and hydrological processes. Radar data from December shows a greater distribution of internal reflections and an increase in chaotic returns indicating increased water content throughout the glacier's profile. The increase in banded surface reflectors shows evidence for higher water contents from the glacier's surface to approximately 10 $m$ depth in the December survey. The water table is less defined in the December survey with increased reflectivity above and below the horizon. Excess surface water may flood the surface and drain through new or existing passages. This may explain increased amounts of englacial reflectors found below the water table in the December survey.

\section{To compare existing ice core stratigraphy with GPR profiles to better un-}




\section{derstand radar data.}

The ice core from Annette Plateau has indicated the chemistry and density through the core and highlights the prevalence of englacial water. Englacial water was intercepted at 5, 10 and $45 \mathrm{~m}$ at Annette Plateau. Radar data at the site of the deepest ice core shows that there is no significant englacial reflector at or near $45 \mathrm{~m}$ suggesting that deep englacial point reflectors may be attributed to water conduits. The ice core has a density decrease between 9.9 and $11.9 \mathrm{~m}$ which may account for the reflective horizon (water table feature). Synthetic radargrams that model ice core density show it is unlikely that the reflective horizon can be attributed solely to density changes. The synthetics also show that changes in ice core chemistry could not attribute solely for the observed englacial reflections. The water table reflection is most likely a result of the combination of chemistry, density and increased water content. Of these, the final factor is thought to have the greatest contribution to the observed reflective horizon.

4. To assess Annette Plateau for potential ice coring sites and indicate the degree to which ice cores from South Island glaciers are adversely affected by melt-water.

High resolution radar profiles of Annette Plateau combined with the ice core data show that water is pervasive throughout the englacial system. Therefore Annette Plateau and other similar or lower elevation sites are not recommended for retrieving ice cores unless a drill is used that is able to penetrate through water. Ice core results from Annette Plateau and other glaciated sites in the Southern Alps show that ice is impacted by meltwater from at least $2760 \mathrm{~m}$ a.s.l. and below.

\section{Effectiveness of GPR in understanding englacial environments}

This study shows that GPR is an effective tool in analysing englacial water in a temperate setting. Ground Penetrating Radar was used to determine water 
pathways, glacier thickness and map out an extensive water table. The application of GPR to other englacial environments would further our understanding of englacial environments.

\subsubsection{Future work}

This study of englacial hydrology at Annette Plateau, a temperate alpine glacier, has shown some interesting hydrological features. In order to better constrain and understand the englacial hydrology at Annette Plateau several avenues for future research are given below:

1. Map hydrological features on the surface of the glacier in summer and use high resolution GPR profiles to track features down-glacier. This would help constrain different types of englacial features.

2. Use dye tracing methods to examine the rate of discharge through the glacier's hydrological system.

3. Use higher frequency radar survey to image near-surface features at a higher resolution.

4. Use borehole and camera techniques to verify conduit properties.

5. Repeat radar surveys at higher frequency during the year would constrain changes in englacial reflectivity and determine if conduits are steady state. 


\section{Chapter 6}

\section{Bibliography}

Ambach, W., Blumthaler, M., and Kirchlechner, P. (1981). Application of the gravity flow theory to the percolation of melt water through firn. Journal of Glaciology, 27(95):67-75.

Anderson, B., Kees, L., and Mackintosh, A. (2010a). Potential sites for ice-core recovery, southern alps, new zealand. unpublished report prepared for GNS.

Anderson, B., Mackintosh, A., Stumm, D., George, L., Kerr, T., WinterBillington, A., and Fitzsimons, S. (2010b). Climate sensitivity of a highprecipitation glacier in new zealand. Journal of Glaciology, 56(195):114-128.

Anderson, R., Anderson, S., MacGregor, K., Waddington, E., O'Neel, S., Riihimaki, C., and Loso, M. (2004). Strong feedbacks between hydrology and sliding of a small alpine glacier. Journal of Geophysical Research-Earth Surface, 109(F3).

Annan, A. P. (2004). Ground Penetrating Radar: principles, procedures \& applications. Sensors \& Softwares Incorporated.

Arcone, S. (2002). Airborne-radar stratigraphy and electrical structure of temperate firn: Bagley Ice Field, Alaska, USA. Journal of Glaciology, 48(161):317334.

Arcone, S., Lawson, D., and Delaney, A. (1995). Short-pulse radar wavelet re- 
covery and resolution of dielectric contrasts within englacial and basal ice of Matanuska Glacier, Alaska, USA. Journal of Glaciology, 41(137):68-86.

Arcone, S. and Yankielun, N. (2000). $1.4 \mathrm{GHz}$ radar penetration and evidence of drainage structures in temperate ice: Black Rapids Glacier, Alaska, USA. Journal of Glaciology, 46(154):477-490.

Arcone, S. A. and Kreutz, K. (2009). GPR reflection profiles of Clark and Commonwealth Glaciers, Dry Valleys, Antarctica. Annals of Glaciology, 50(51):121129.

Aristarain, A. J. and Delmas, R. J. (1993). Firn-core study from the Southern Patagonia ice cap, South-America. Journal of Glaciology, 39(132):249-254.

Baelum, K. and Benn, D. I. (2011). Thermal structure and drainage system of a small valley glacier (Tellbreen, Svalbard), investigated by ground penetrating radar. Cryosphere, 5(1):139-149.

Bender, M., Sowers, T., and Brook, E. (1997). Gases in ice cores. Proceedings of the National Academy of Sciences, 94(16):8343-8349.

Benn, D. I. and Evans, D. J. A. (1998). Glacier and Glaciation. Arnold, London.

Bjornsson, H., Gjessing, Y., Hamran, S., Hagen, J., Liestol, O., Palsson, F., and Erlingsson, B. (1996). The thermal regime of sub-polar glaciers mapped by multi-frequency radio-echo sounding. Journal of Glaciology, 42(140):23-32.

Campbell, S., Kreutz, K., Osterberg, E., Arcone, S., Wake, C., Introne, D., Volkening, K., and Winski, D. (2012). Melt regimes, stratigraphy, flow dynamics and glaciochemistry of three glaciers in the Alaska Range. Journal of Glaciology, 58(207):99-109.

Catania, G. A., Neumann, T. A., and Price, S. F. (2008). Characterizing englacial drainage in the ablation zone of the greenland ice sheet. Journal of Glaciology, 54(187):567-578. 
Copland, L., Harbor, J., Gordon, S., and Sharp, M. (1997). The use of borehole video in investigating the hydrology of a temperate glacier. Hydrological Processes, 11(2):211-224.

Davis, J. and Annan, A. (1989). Ground-penetrating radar for high-resolution mapping of soil and rock stratigraphy. Geophysical Prospecting, 37(5):531-551.

Dowdeswell, J. and Evans, S. (2004). Investigations of the form and flow of ice sheets and glaciers using radio-echo sounding. Reports on Progress in Physics, 67(10):1821-1861.

Eichler, A., Schwikowski, M., and Gaggeler, H. (2001). Meltwater-induced relocation of chemical species in Alpine firn. Tellus Series B-Chemical And Physical Meteorology, 53(2):192-203.

Eichler, A., Schwikowski, M., Gaggeler, H., Furrer, V., Synal, H., Beer, J., Saurer, M., and Funk, M. (2000). Glaciochemical dating of an ice core from upper Grenzgletscher (4200 m a.s.1.). Journal of Glaciology, 46(154):507-515.

Flowers, G. and Clarke, G. (1999). Surface and bed topography of Trapridge Glacier, Yukon Territory, Canada: digital elevation models and derived hydraulic geometry. Journal of Glaciology, 45(149):165-174.

Fountain, A. and Jacobel, R. (1997). Advances in ice radar studies of a temperate alpine glacier, South Cascade Glacier, Washington, USA. Annals of Glaciology, 24:303-308. International Symposium on Changing Glaciers, Fjaerland, Norway, Jun 24-27, 1996.

Fountain, A., Jacobel, R., Schlichting, R., and Jansson, P. (2005). Fractures as the main pathways of water flow in temperate glaciers. Nature, 433(7026):618621.

Fountain, A. and Walder, J. (1998). Water flow through temperate glaciers. Reviews of Geophysics, 36(3):299-328.

Fountain, A. G. (1989). The storage of water in, and hydraulic characteristics of, the firn of south cascade glacier, washington state, USA. Annals of Glaciology, 13:69-75. 
Fountain, A. G. (1993). Geometry and flow conditions of subglacial water at South Cascade Glacier, Washington-State, USA - an analysis of tracer injections. Journal of Glaciology, 39(131):143-156.

Fujita, S., Matsuoka, T., Ishida, T., Matsuoka, K., and Mae, S. (2000). A summary of the complex dielectric permittivity of ice in the megahertz range and its applications for radar sounding of polar ice sheets. Physics of Ice Core Records, pages 185-212.

Glover, J. M. and Rees, H. V. (1992). Radar investigations of firn structures and crevasses. Ground Penetrating Radar, Geological Survey of Canada, Paper, pages 90-4.

Gruber, S., Ludwig, F., and Moore, J. C. (1996). Application of ground penetrating radar in glaciology and permafrost prospecting. Study paper for the Arctic studies programme at the Arctic centre, Rovaniemi, Finland.

Gulley, J. (2009). Structural control of englacial conduits in the temperate Matanuska Glacier, Alaska, USA. Journal of Glaciology, 55(192):681-690.

Gulley, J. and Benn, D. I. (2007). Structural control of englacial drainage systems in himalayan debris-covered glaciers. Journal of Glaciology, 53(182):399-412.

Gulley, J. D., Benn, D. I., Screaton, E., and Martin, J. (2009). Mechanisms of englacial conduit formation and their implications for subglacial recharge. Quaternary Science Reviews, 28(19-20):1984-1999.

Hambrey, M. and Alean, J. (2004). Glaciers. Cambridge University Press, 2nd edition.

Hamran, S., Aarholt, E., Hagen, J., and Mo, P. (1996). Estimation of relative water content in a sub-polar glacier using surface-penetration radar. Journal of Glaciology, 42(142):533-537.

Harper, J. T. and Humphrey, N. F. (1995). Borehole video analysis of a temperate glaciers englacial and subglacial structure - implications for glacier flow models. Geology, 23(10):901-904. 
Hart, J. K., Rose, K. C., and Martinez, K. (2011). Temporal englacial water content variability associated with a rapidly retreating glacier. Earth Surface Processes and Landforms, 36(9):1230-1239.

Herron, M. M. and Langway Jr, C. C. (1980). Firn densification: an empirical model. Journal of Glaciology, 25:373-385.

Hock, R. (2005). Glacier melt: a review of processes and their modelling. Progress in Physical Geography, 29(3):362-391.

Hodgkins, R. (2001). Seasonal evolution of meltwater generation, storage and discharge at a non-temperate glacier in Svalbard. Hydrological Processes, 15(3):441-460.

Hooke, R. L. (1984). On the role of mechanical energy in maintaining subglacial water conduits at atmospheric-pressure. Journal of Glaciology, 30(105):180-187.

Hooke, R. L. (1989). Englacial and subglacial hydrology - a qualitative review. Arctic and Alpine Research, 21(3):221-233.

Hooke, R. L. and Pohjola, V. A. (1994). Hydrology of a segment of a glacier situated in an overdeening, Storglaciaren, Sweden. Journal of Glaciology, 40(134):140-148.

Hooke, R. L., S. B. M. and Kohler., J. (1988.). Character of the englacial and subglacial drainage system in the upper part of the ablation area of storglaciaren, sweden. Journal of Glaciology, (117):87-92.

Hubbard, B. and Nienow, P. (1997). Alpine subglacial hydrology. Quaternary Science Reviews, 16(9):939-955.

Irvine-Fynn, T. D. L. (2004). A non-invasive investigation of polythermal glacial hydrology: Stagnation glacier, bylot island, nunavut, canada. Master's thesis, University of Calgary.

Irvine-Fynn, T. D. L., Moorman, B. J., Williams, J. L. M., and Walter, F. S. A. (2006). Seasonal changes in ground-penetrating radar signature observed at 
a polythermal glacier, Bylot Island, Canada. Earth Surface Processes and Landforms, 31(7):892-909.

Jaccard, C. (2006). Mechanism of the Electrical Conductivity in Ice. Annals of the New York Academy of Sciences, 125(2):390-400.

Jacobel, R. and Raymond, C. (1984). Radio echo-sounding studies of englacial water-movement in variegated glacier, Alaska. Journal of Glaciology, 30(104):22-29.

Jol, H. M. (2009). Ground penetrating radar: theory and applications. Elsevier Science Ltd.

Kaser, G., Hardy, D., Molg, T., Bradley, R., and Hyera, T. (2004). Modern glacier retreat on Kilimanjaro as evidence of climate change: Observations and facts. International Journal of Climatology, 24(3):329-339.

Kees, L. J. (2011). Assessment of a snow storage gradient across a maritime mountain environment; a ground penetrating radar investigation. Master's thesis, Victoria University of Wellington.

Kovacs, A., Gow, A. J., and Morey, R. M. (1995). The in-situ dielectric constant of polar firn revisited. Cold Regions Science and Technology, 23(3):245-256.

Lang, H., Schädler, B., and Davidson, G. (1977). Hydroglaciological investigations on the ewigschneefeld-grosser aletschgletscher. Zeitschrift für Gletscherkunde und Glazialgeologie, 12(2):109-124.

Laumann, T. and Reeh, N. (1993). Sensitivity to climate change of the massbalance of glaciers in southern Norway. Journal of Glaciology, 39(133):656-665.

Letreguilly, A. (1988). Relation between the mass balance of western Canadian mountain glaciers and meteorological data. Journal of Glaciology, 34(116):1118.

Lillie, A. R. and Gunn, B. M. (1964). Steeply plunging folds in the sealy range, southern alps. New Zealand Journal of Geology and Geophysics, 7(3):403-423. 
LINZ (2011). Linz topographic maps, (www.nztopomaps.com).

Liu, S., Sun, W., Shen, Y., and Li, G. (2003). Glacier changes since the Little Ice Age maximum in the western Qilian Shan, northwest China, and consequences of glacier runoff for water supply. Journal of Glaciology, 49(164):117124.

Lliboutry, L. (1997). "Temperate ice permeability, stability of water veins and percolation of internal meltwater" - Reply. Journal of Glaciology, 43(144):372373.

Martinez, A. and Byrnes, A. P. (2001). Modeling dielectric-constant values of geologic materials: An aid to ground-penetrating radar data collection and interpretation. Kansas Geological Survey, University of Kansas.

Masson-Delmotte, V., Dreyfus, G., Braconnot, P., Johnsen, S., Jouzel, J., Kageyama, M., Landais, A., Loutre, M. F., Nouet, J., Parrenin, F., Raynaud, D., Stenni, B., and Tuenter, E. (2006). Past temperature reconstructions from deep ice cores: Relevance for future climate change. Climate of the Past, 2(2):145165.

Matsuoka, K. and Naruse, R. (1999). Mass balance features derived from a firn core at Hielo Patagonico Norte, South America. Arctic Antarctic and Alpine Research, 31(4):333-340.

Matsuoka, T., Fujita, S., and Mae, S. (1997). Dielectric properties of ice containing ionic impurities at microwave frequencies. The Journal of Physical Chemistry B, 101(32):6219-6222.

Menzies, J. (1995). Hydrology of glaciers. Modern Glacial Environments: Processes, Dynamics and Sediments, Glacial Environments, 1:197-240.

Moore, J., Palli, A., Ludwig, F., Blatter, H., Jania, J., Gadek, B., Glowacki, P., Mochnacki, D., and Isaksson, E. (1999). High-resolution hydrothermal structure of Hansbreen, Spitsbergen, mapped by ground-penetrating radar. Journal of Glaciology, 45(151):524-532. 
Moore, J., Paren, J., and Oerter, H. (1992). Sea salt dependent electrical conduction in polar ice. Journal of Geophysical Research, 97(B13):19803-19.

Moore, J. C. (1988). Dielectric variability of a $130 \mathrm{~m}$ antarctic ice core: Implications for radar sounding. Annals of Glaciology, 11:95-99.

Moorman, B. and Michel, F. (2000). Glacial hydrological system characterization using ground-penetrating radar. Hydrological Processes, 14(15):2645-2667.

Moran, M., Greenfield, R., and Arcone, S. (2003). Modeling GPR radiation and reflection characteristics for a complex temperate glacier bed. Geophysics, 68(2):559-565.

Morgenstern, U. (2004). Tritium dating of water and ice. New Zealand Science Review, 61:42-44.

Morgenstern, U. (2009). Dating of southern alps glacier ice, mount cook national park, new zealand. poster.

Munro, D. (2005). A revised Canadian perspective: progress in glacier hydrology. Hydrological Processes, 19(1, SI):231-245. Annual Hydrology Session Meeting of the Canadian-Geophysical-Union, Banff, CANADA, MAY, 2003.

Murray, T., Gooch, D., and Stuart, G. (1997). Structures within the surge front at Bakaninbreen, Svalbard, using ground-penetrating radar. 24:122-129. International Symposium on Changing Glaciers, FJAERLAND, NORWAY, JUN 24-27, 1996.

Murray, T., Stuart, G., Fry, M., Gamble, N., and Crabtree, M. (2000a). Englacial water distribution in a temperate glacier from surface and borehole radar velocity analysis. Journal of Glaciology, 46(154):389-398.

Murray, T., Stuart, G., Miller, P., Woodward, J., Smith, A., Porter, P., and Jiskoot, H. (2000b). Glacier surge propagation by thermal evolution at the bed. Journal of Geophysical Research-Solid Earth, 105(B6):13491-13507. 
Nye, J. F. and Frank, F. C. (1973). Hydrology of the intergranular veins in a temperate glacier. In Symposium on the Hydrology of Glaciers, volume 95, pages 157-161.

Odegard, R., Hagen, J., and Hamran, S. (1997). Comparison of radio-echo sounding (30-1000 MHz) and high-resolution borehole-temperature measurements at Finsterwalderbreen, southern Spitsbergen, Svalbard. Annals of Glaciology, 24:262-267. International Symposium on Changing Glaciers, Fjaerland, Norway, Jun 24-27, 1996.

Oerlemans, J. (1994). Quantifying global warming from the retreat of glaciers. Science, 264(5156):243-245.

Oerlemans, J. (2005). Extracting a climate signal from 169 glacier records. Science, 308(5722):675-677.

Oerlemans, J. and Klok, E. (2002). Energy balance of a glacier surface: Analysis of automatic weather station data from the Morteratschgletscher, Switzerland. Arctic Antarctic and Alpine Research, 34(4):477-485.

Oerter, H. and Moser, H. (1982). Water storage and drainage within the firn of a temperate glacier (vernagtferner, oetztal alps, austria). Hydrological Aspects of Alpine and High-Mountain Areas, IAHS Publ.,, 138:71-81.

Pälli, A. (2003). Polythermal glacier studies in svalbard determined by ground penetrating radar. Master's thesis, Oulu University.

Paterson, W. S. B. (1994). The physics of glaciers. Pergamon, Oxford, 3rd edition.

Pawar, S. D., Murugavel, P., and Lal, D. M. (2009). Effect of relative humidity and sea level pressure on electrical conductivity of air over indian ocean. Journal of Geophysical Research (Atmospheres), 114:02205.

Petit, J., Jouzel, J., Raynaud, D., Barkov, N., Barnola, J., Basile, I., Bender, M., Chappellaz, J., Davis, M., Delaygue, G., Delmotte, M., Kotlyakov, V., Legrand, M., Lipenkov, V., Lorius, C., Pepin, L., Ritz, C., Saltzman, E., and Stievenard, M. (1999). Climate and atmospheric history of the past 420,000 years from the Vostok ice core, Antarctica. Nature, 399(6735):429-436. 
Plewes, L. and Hubbard, B. (2001). A review of the use of radio-echo sounding in glaciology. Progress in Physical Geography, 25(2):203-236.

Pohjola, V. A. (1994). TV-video observations of englacial voids in Storglaciaren, Sweden. Journal of Glaciology, 40(135):231-240.

Purdie, H., Mackintosh, A., Lawson, W., Anderson, B., Morgenstern, U., Chinn, T., and Mayewski, P. (2011). Interannual variability in net accumulation on Tasman Glacier and its relationship with climate. Global and Planetary Change, 77(3-4):142-152.

Raymond, C. F., Benedict, R. J., Harrison, W. D., Echelmeyer, K. A., and Sturm, M. (1995). Hydrological discharges and motion of Fels and Black-Rapids glaciers, Alaska, USA - Implications for the structure of their drainage systems. Journal of Glaciology, 41(138):290-304.

Reynolds, J. M. (2011). An introduction to applied and environmental geophysics. Wiley. com.

Rothlisberger, H. (1972). Water pressure in intra and subglacial channels. Journal of Glaciology, 11:177-203.

Ruddell, A. and Budd, W. (1990). An investigation into the feasibility of using a new zealand ice core for paleo-climate interpretation. Technical report, A report to the Australia/New Zealand/United Kingdom Tripartite Climate Change Committee. Department of Meteorology, University of Melbourne, Australia.

Schneider, T. (1999). Water movement in the firn of Storglaciaren, Sweden. Journal of Glaciology, 45(150):286-294.

Schneider, T. and Jansson, P. (2004). Internal accumulation in firn and its significance for the mass balance of Storglaciaren, Sweden. Journal of Glaciology, 50(168):25-34.

Schommer, P. (1977). Wasserspiegelmessungen im firn des ewigschneefeldes (Schweizer alpen) 1976. Z. Gletscherkd. Glazialgeol, 12(2):125-141. 
Schwikowski, M., Bruetsch, S., Casassa, G., and Rivera, A. (2006). A potential high-elevation ice-core site at hielo patagonico sur. Annals of Glaciology, 43:8-13. International Symposium on High-Elevation Glaciers and Climate Records, Lanzhou, PEOPLES R CHINA, SEP 05-09, 2005.

Sharp, M., Richards, K., Willis, I., Arnold, N., Nienow, P., Lawson, W., and Tison, j. (1993). Geometry, bed topography and drainage system structure of the Haut Glacier Darolla, Switzerland. Earth Surface Processes and Landforms, 18(6):557-571.

Sheriff, R. E. and Geldart, L. P. (1982). Exploration seismology: History, theory, and data acquisition, vol. 1. Cambridge University Press.

Shreve, R. L. (1972). Movement of water in glaciers. Journal of Glaciology, (11):205-214.

Solomon, S. (2007). Climate change 2007: the physical science basis: contribution of Working Group I to the Fourth Assessment Report of the Intergovernmental Panel on Climate Change. Cambridge University Press.

Stuart, G., Murray, T., Gamble, N., Hayes, K., and Hodson, A. (2003). Characterization of englacial channels by ground-penetrating radar: An example from austre Broggerbreen, Svalbard. Journal of Geophysical Research-Solid Earth, 108(B11).

Sturman, A. P., Tapper, N. J., Sturman, A., and Sturman, A. P. (1996). The weather and climate of Australia and New Zealand. Oxford University Press Melbourne.

Sugden, D. E. and John, B. S. (1976). Glaciers and Landscape. Edward Arnold, London.

Takeuchi, N., Miyake, T., Nakazawa, F., Narita, H., Fujita, K., Sakai, A., Nakawo, M., Fujii, Y., Duan, K., and Yao, T. (2009). A shallow ice core redrilled on the Dunde Ice Cap, western China: recent changes in the Asian high mountains. Environmental Research Letters, 4(4). 
Thompson, L., Davis, M., Mosley-Thompson, E., Sowers, T., Henderson, K., Zagorodnov, V., Lin, P., Mikhalenko, V., Campen, R., Bolzan, J., Cole-Dai, J., and Francou, B. (1998). A 25,000-year tropical climate history from Bolivian ice cores. Science, 282(5395):1858-1864.

Thompson, L. G. (1992). Interpretation of short-pulse radar soundings from low latitude, high altitude glaciers of peru and china. Ground penetrating radar: Geological Survey of Canada, Paper, pages 90-4.

Thompson, L. G., Mosleythompson, E., Dansgaard, W., and Grootes, P. M. (1986). The little ice-age as recorded in the stratigraphy of the tropical Quelccaya ice cap. Science, 234(4774):361-364.

Tzanis, A. and Kafetsis, G. (2004). A freeware package for the analysis and interpretation of common-offset ground probing radar data, based on general purpose computing engines. Bulletin of the Geological Society of Greece, 36.

Villalba, R., Grosjean, M., and Kiefer, T. (2009). Long-term multi-proxy climate reconstructions and dynamics in South America (LOTRED-SA): State of the art and perspectives Preface. Palaeogeography Palaeoclimatology Palaeoecology, 281(3-4):175-179.

Waite, A. H. and Schmidt, S. J. (1961). Gross errors in height indication from pulsed radar altimeters operating over thick ice or snow. Institute of Radio Engineers, International Convention Record, Part 5:pp. 38-53.

Walford, M. and Kennett, M. (1989). A synthetic-aperture radio-echo experiment at Storglaciaren, Sweden. Journal of Glaciology, 35(119):43-47.

Wang, P., Li, Z., and Gao, W. (2011). Rapid shrinking of glaciers in the middle Qilian mountain region of northwest China during the last similar to 50 years. Journal of Earth Science, 22(4):539-548.

Willis, I., Lawson, W., Owens, I., Jacobel, B., and Autridge, J. (2009). Subglacial drainage system structure and morphology of Brewster Glacier, New Zealand. Hydrological Processes, 23(3):384-396. 
Willis, I. C. (1995). Intra-annual variations in glacier motion: a review. Progress in Physical Geography, 19(1):61-106.

Woodward, J. and Burke, M. J. (2007). Applications of ground-penetrating radar to glacial and frozen materials. Journal of Environmental and Engineering Geophysics, 12(1):69-85.

Woodward, J., Murray, T., Clark, R., and Stuart, G. (2003). Glacier surge mechanisms inferred from ground-penetrating radar: Kongsvegen, Svalbard. Journal of Glaciology, 49(167):473-480.

Yamada, T. (1987). Glaciological characteristics revealed by $37.6 \mathrm{~m}$ deep core drilled at the accumulation area of san rafael glacier, the north patagonianicefield. Bulletin of Glacier Re-search, 4(59-67). 


\section{Chapter 7}

\section{Appendix}

Radar profiles an picks from 2011 GPR surveys at Annette Plateau are shown below. September data is shown first followed by December. Profiles are shown sequentially down glacier beginning at the upper most profile and longitudinal profiles are shown last. All radar profiles are fully processed and migrated. Profiles show picked englacial reflections as follows: (1) red - bed; (2) orange bed inferred; (3) green - initial reflection horizon; (4) pink - reflective horizon; (5) blue - point reflector; (6) light-green - banded surface reflector. 


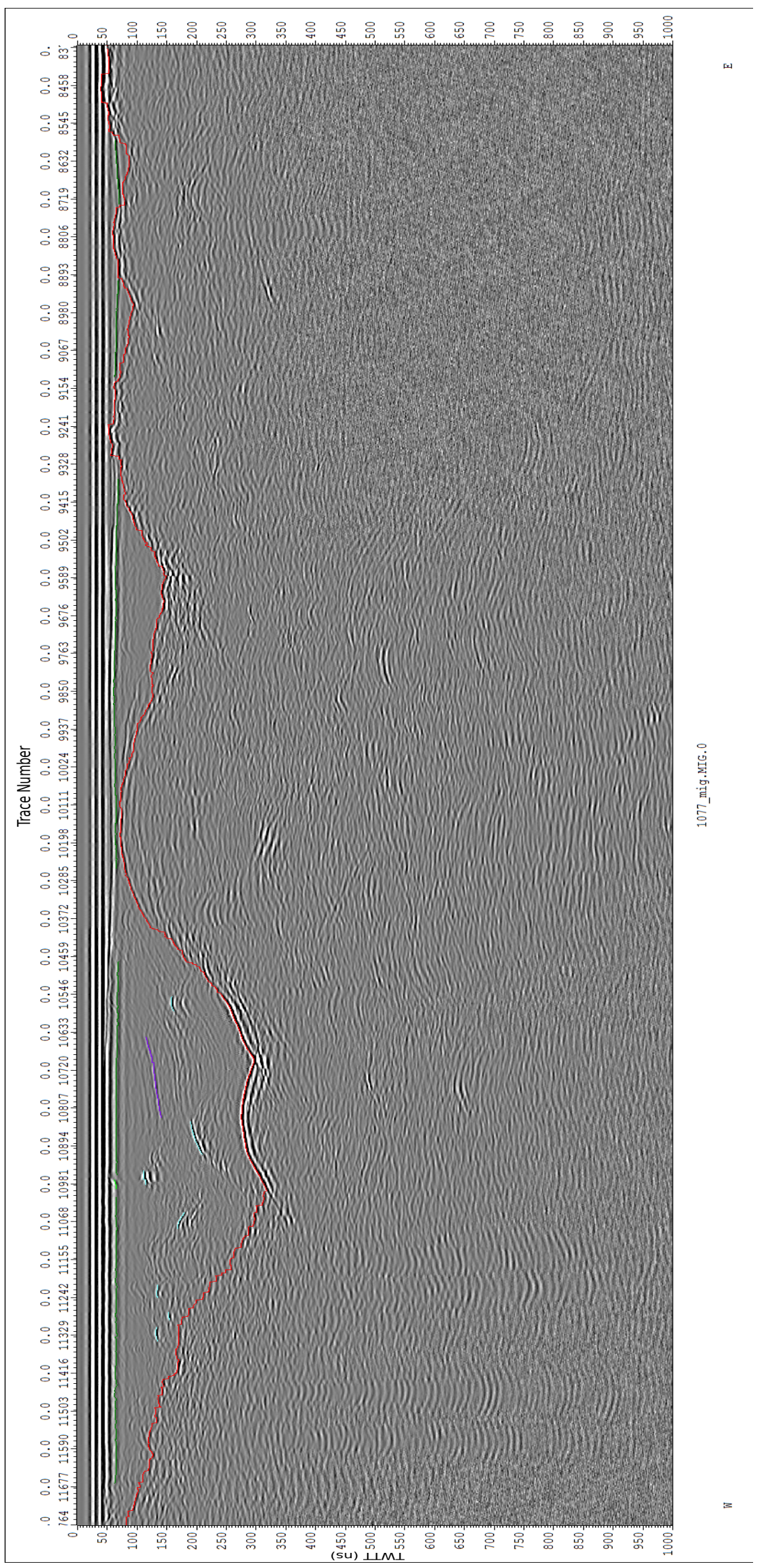

Figure 7.1: Profile 1077 September, showing picked englacial reflections as follows: (1) red - bed; (2) orange - bed inferred; (3) green - initial reflection horizon; (4) pink - reflective horizon (5) blue - point reflector; (6) light-green - banded surface reflector. 


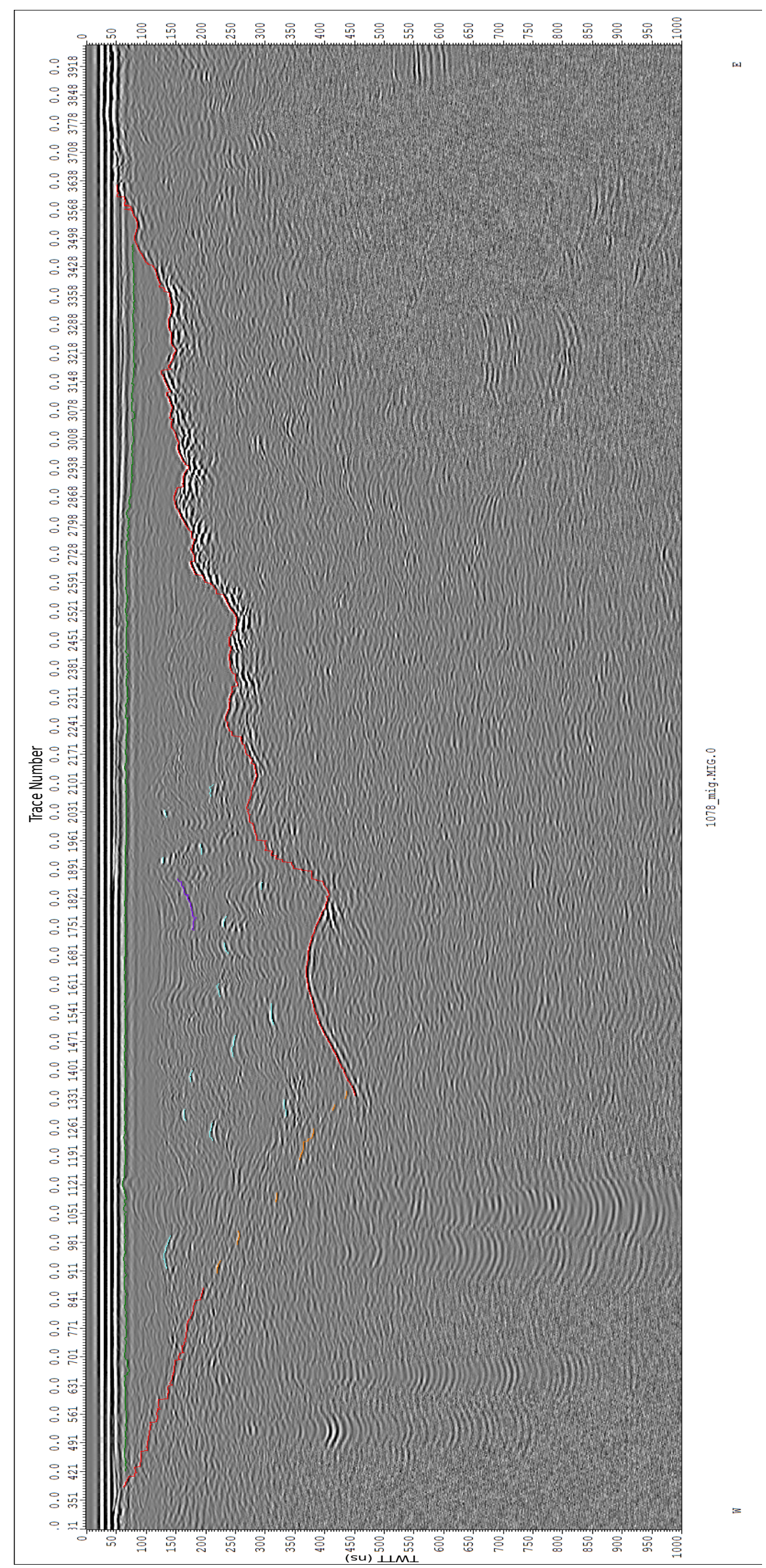

Figure 7.2: Profile 1078 September, showing picked englacial reflections as follows: (1) red - bed; (2) orange - bed inferred; (3) green - initial reflection horizon; (4) pink - reflective horizon (5) blue - point reflector; (6) light-green - banded surface reflector. 


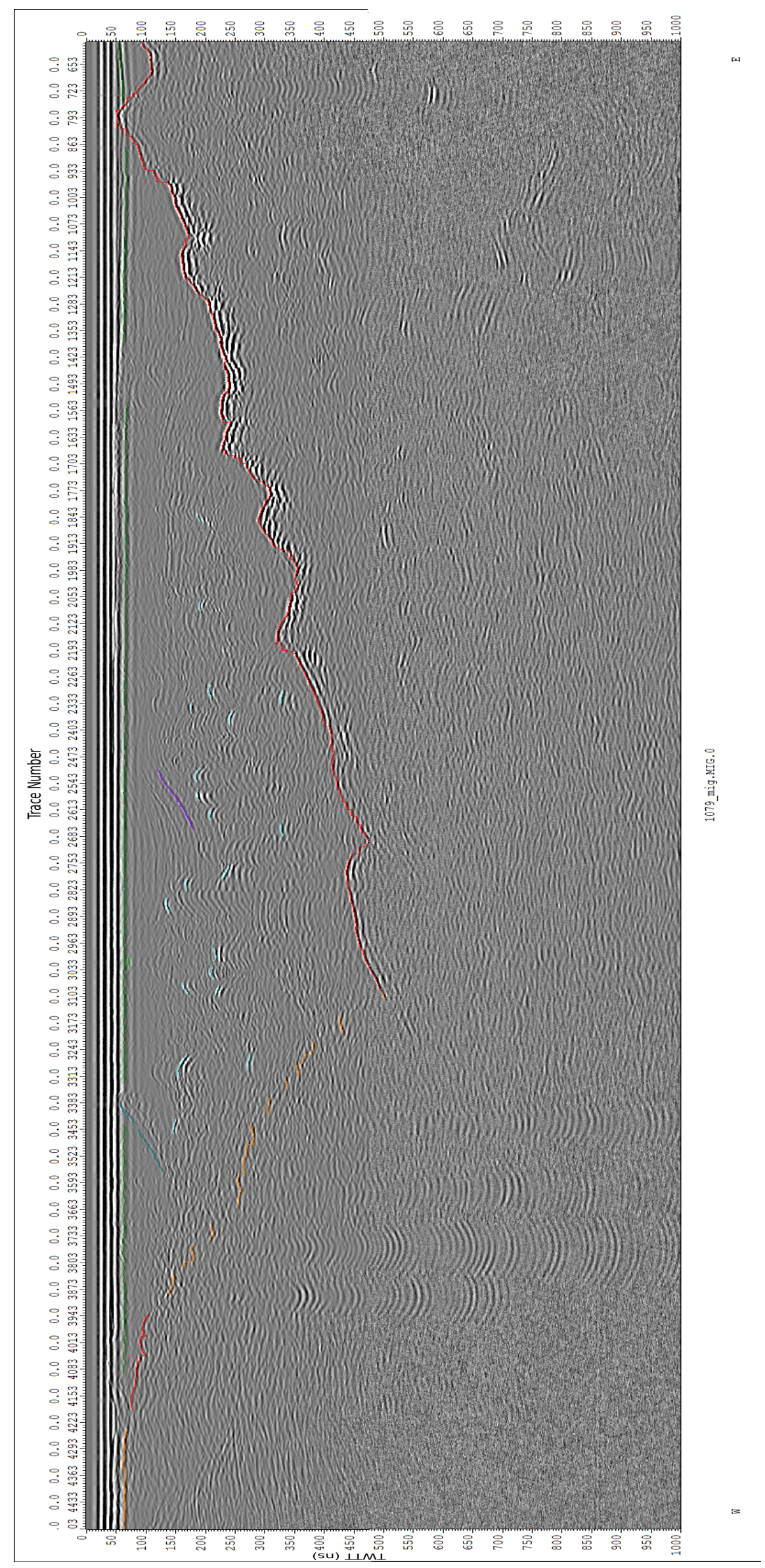

Figure 7.3: Profile 1079 September, showing picked englacial reflections as follows: (1) red - bed; (2) orange - bed inferred; (3) green - initial reflection horizon; (4) pink - reflective horizon (5) blue - point reflector; (6) light-green - banded surface reflector. 


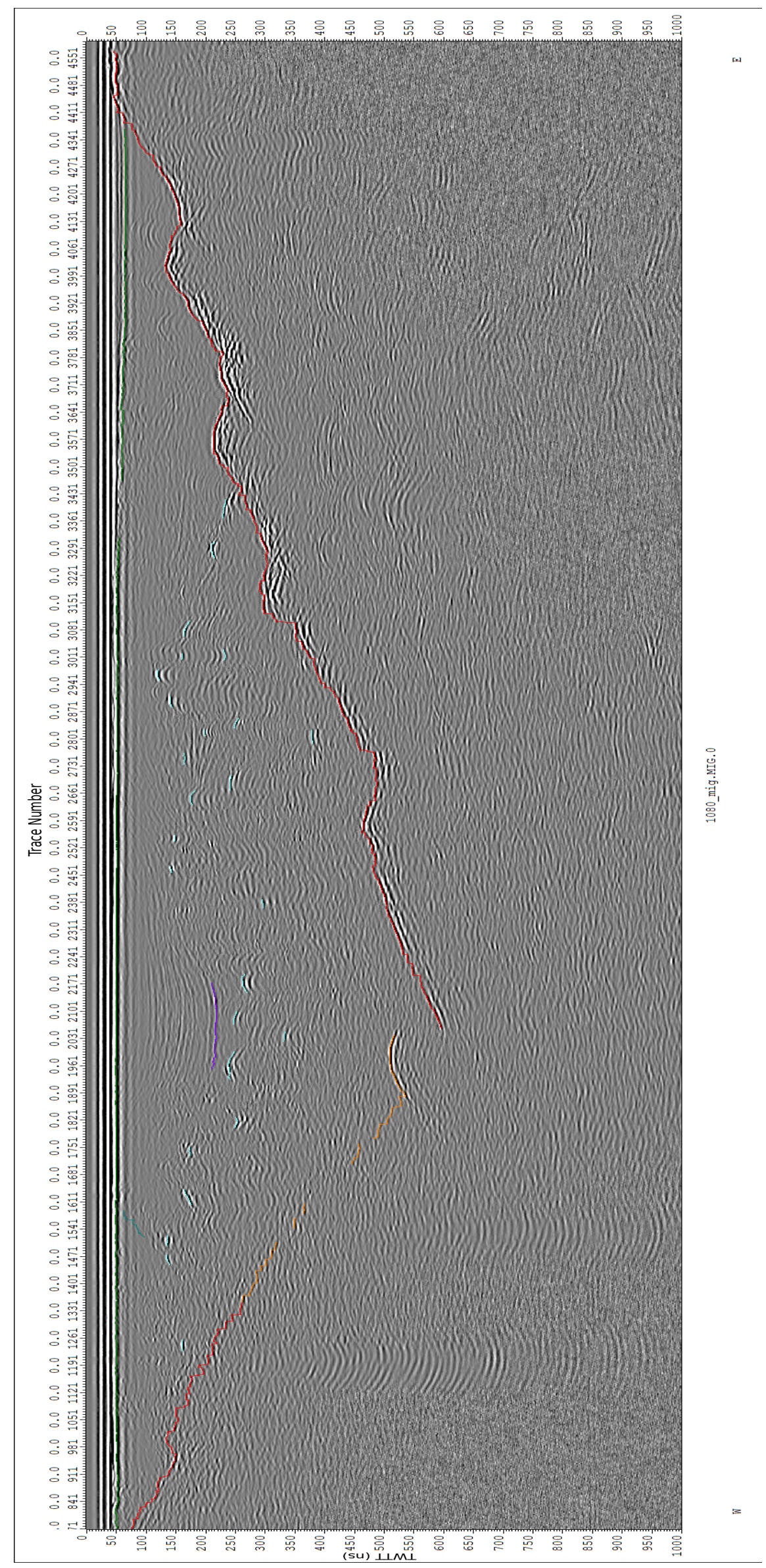

Figure 7.4: Profile 1080 September, showing picked englacial reflections as follows: (1) red - bed; (2) orange - bed inferred; (3) green - initial reflection horizon; (4) pink - reflective horizon (5) blue - point reflector; (6) light-green - banded surface reflector. 


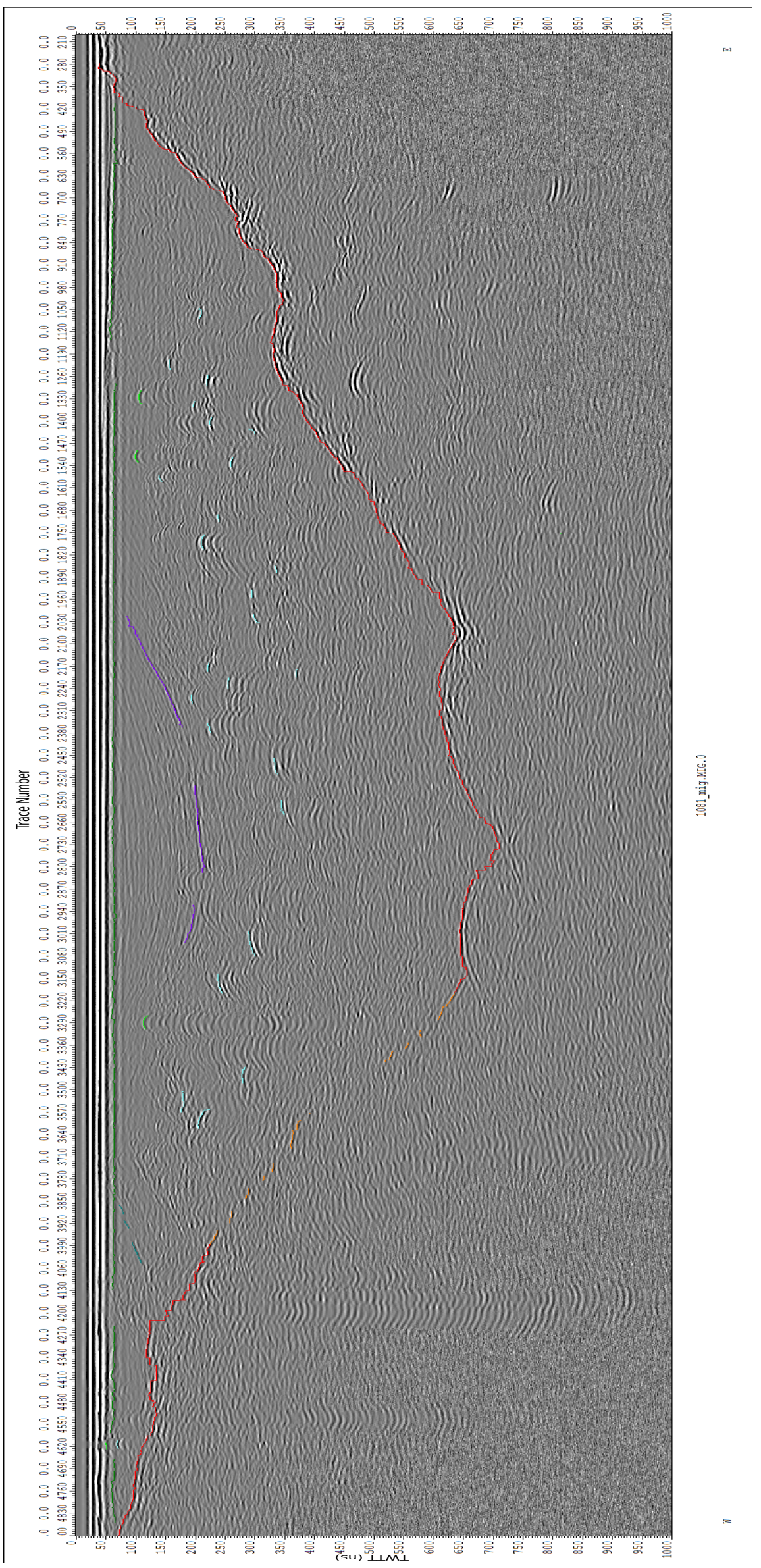

Figure 7.5: Profile 1081 September, showing picked englacial reflections as follows: (1) red - bed; (2) orange - bed inferred; (3) green - initial reflection horizon; (4) pink - reflective horizon (5) blue - point reflector; (6) light-green - banded surface reflector. 


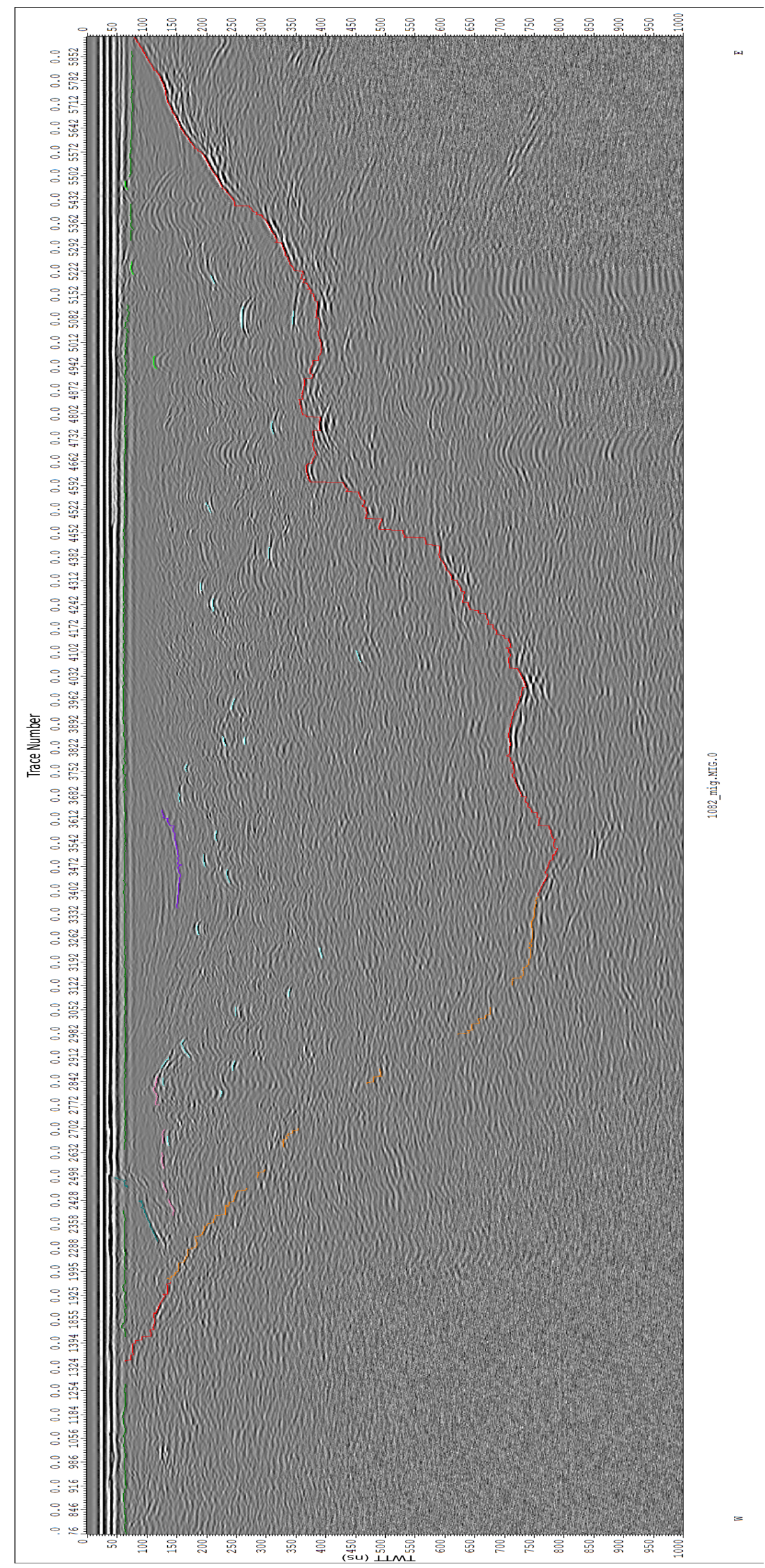

Figure 7.6: Profile 1082 September, showing picked englacial reflections as follows: (1) red - bed; (2) orange - bed inferred; (3) green - initial reflection horizon; (4) pink - reflective horizon (5) blue - point reflector; (6) light-green - banded surface reflector. 


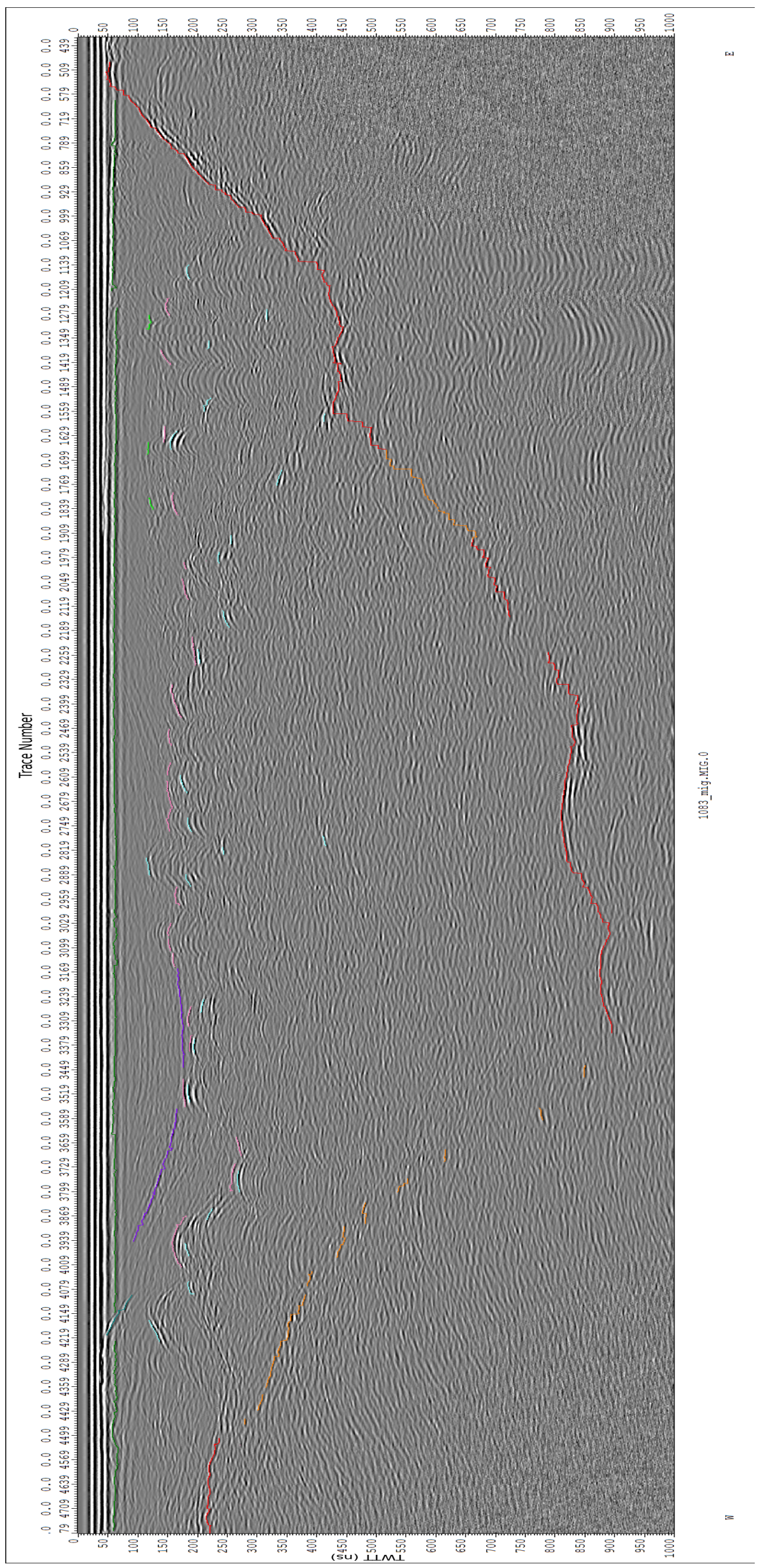

Figure 7.7: Profile 1083 September, showing picked englacial reflections as follows: (1) red - bed; (2) orange - bed inferred; (3) green - initial reflection horizon; (4) pink - reflective horizon (5) blue - point reflector; (6) light-green - banded surface reflector. 


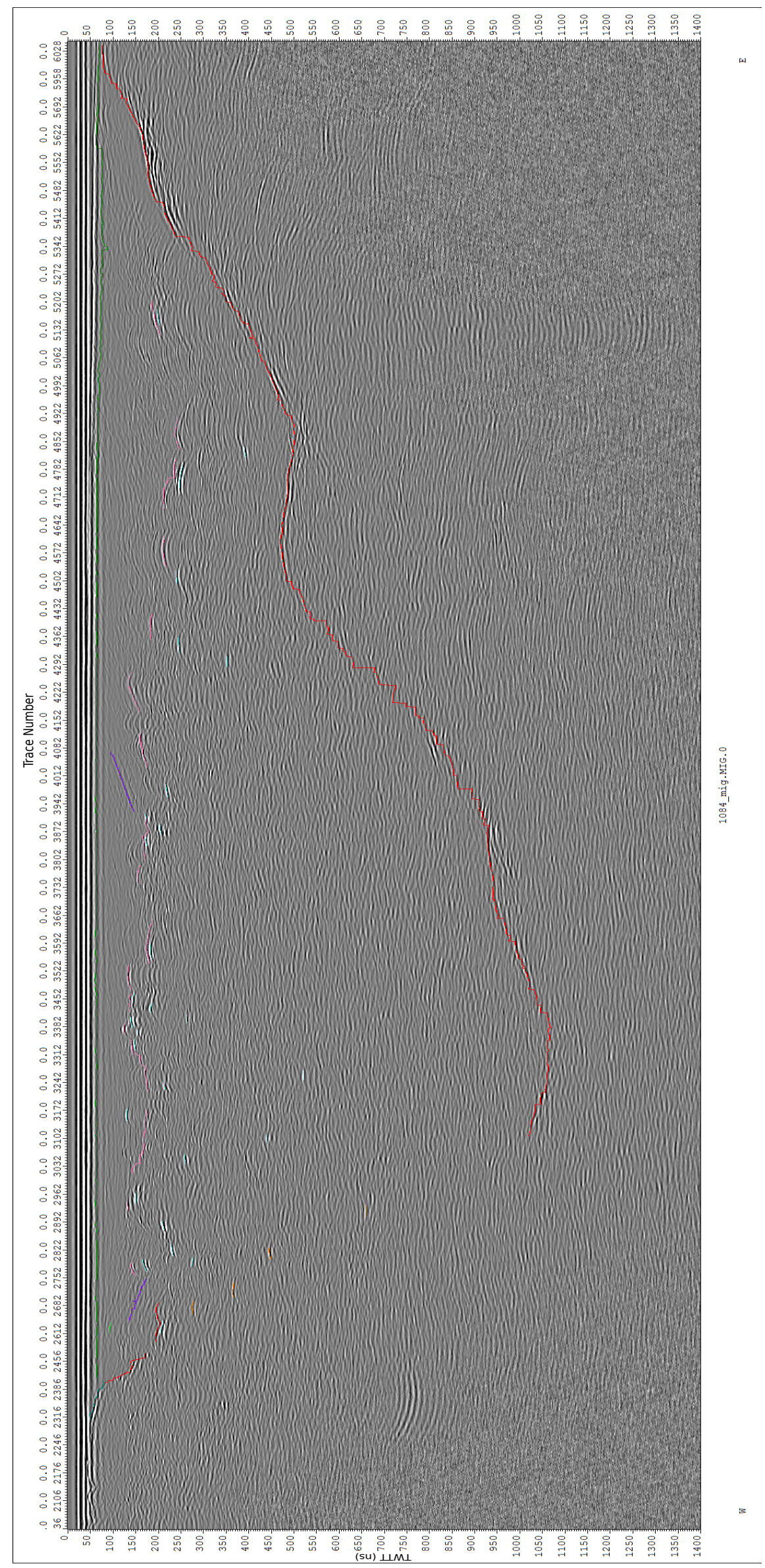

Figure 7.8: Profile 1084 September, showing picked englacial reflections as follows: (1) red - bed; (2) orange - bed inferred; (3) green - initial reflection horizon; (4) pink - reflective horizon (5) blue - point reflector; (6) light-green - banded surface reflector. 


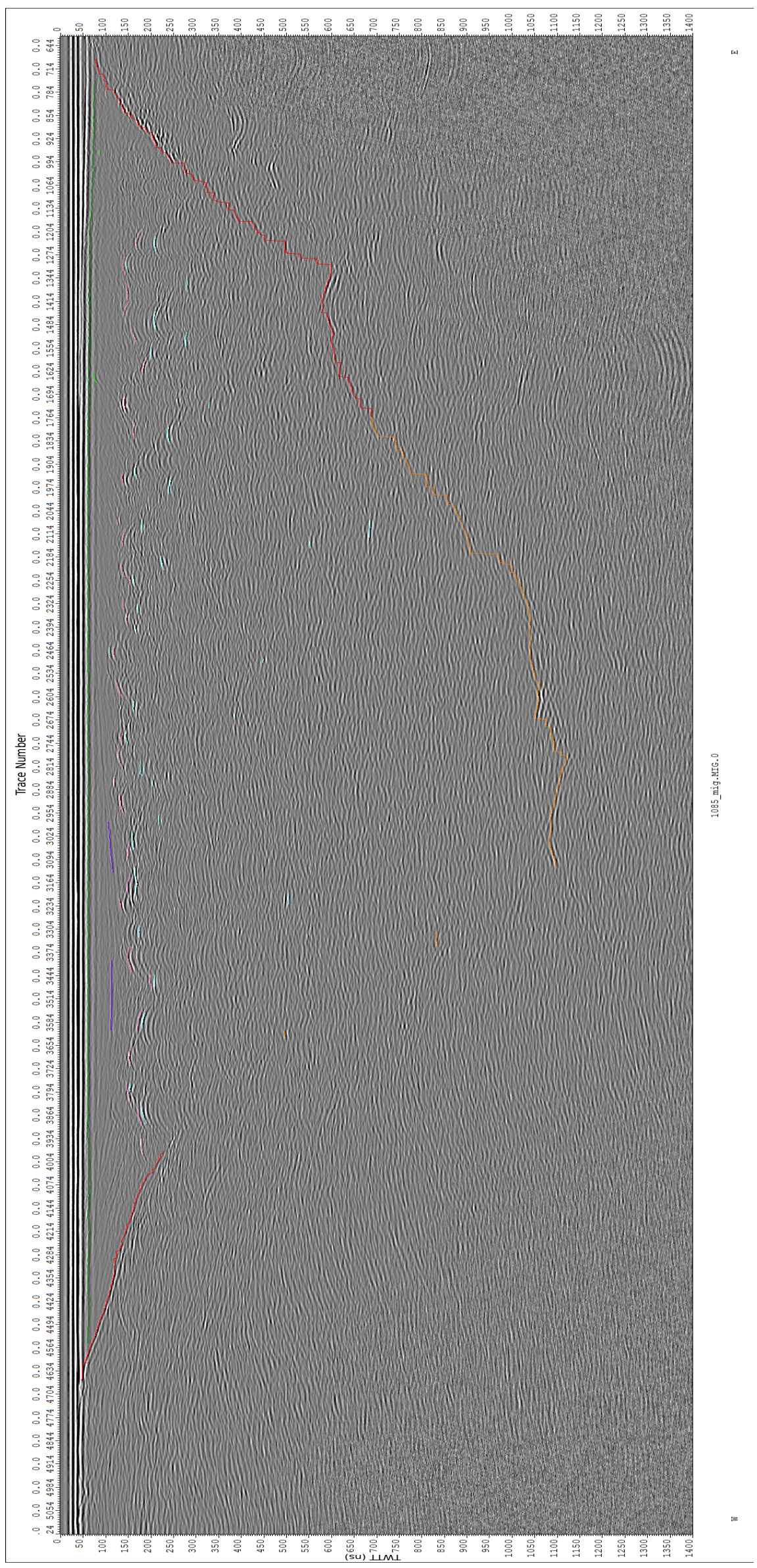

Figure 7.9: Profile 1085 September, showing picked englacial reflections as follows: (1) red - bed; (2) orange - bed inferred; (3) green - initial reflection horizon; (4) pink - reflective horizon (5) blue - point reflector; (6) light-green - banded surface reflector. 


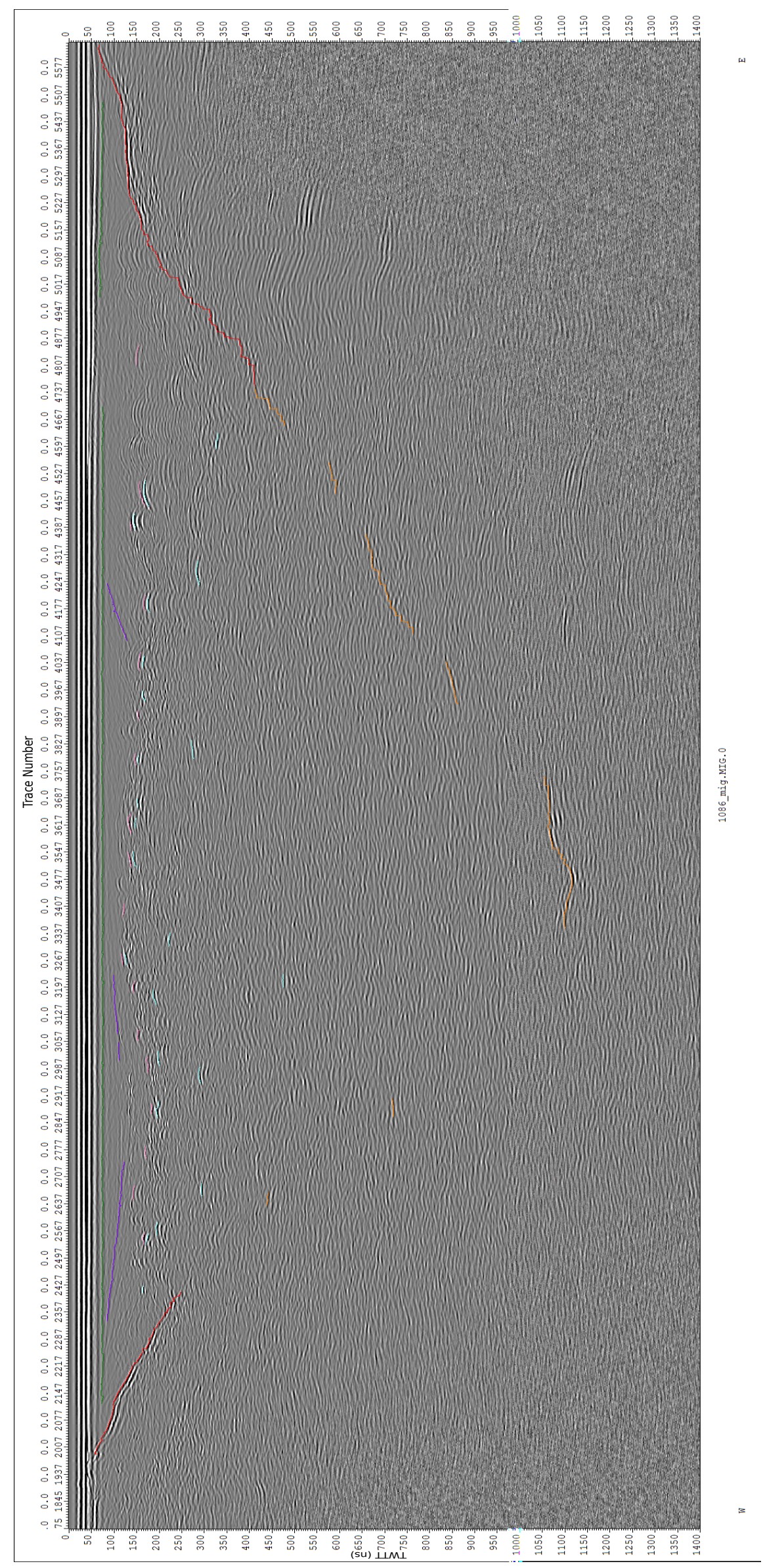

Figure 7.10: Profile 1086 September, showing picked englacial reflections as follows: (1) red - bed; (2) orange - bed inferred; (3) green - initial reflection horizon; (4) pink - reflective horizon (5) blue - point reflector; (6) light-green - banded surface reflector. 


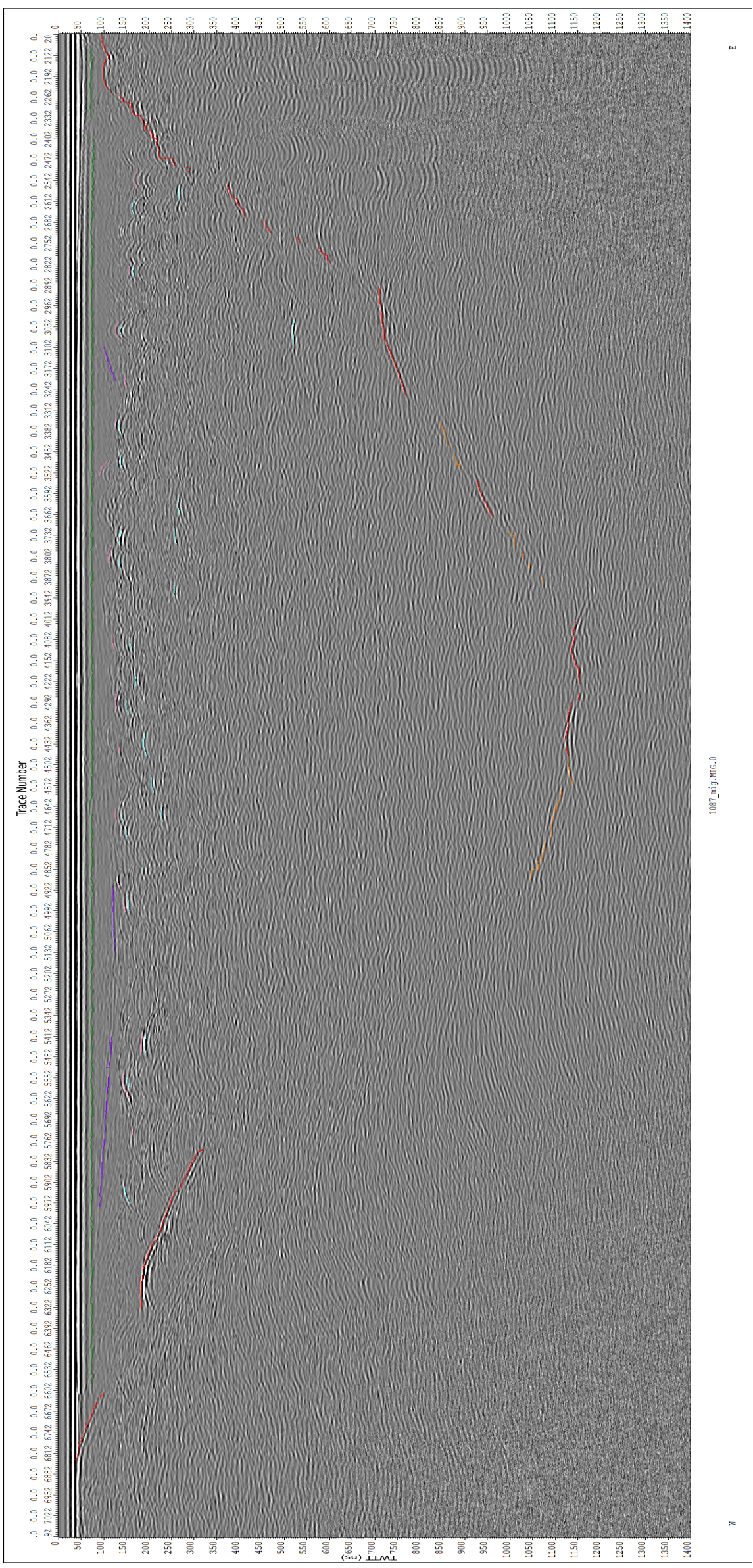

Figure 7.11: Profile 1087 September, showing picked englacial reflections as follows: (1) red - bed; (2) orange - bed inferred; (3) green - initial reflection horizon; (4) pink - reflective horizon (5) blue - point reflector; (6) light-green - banded surface reflector. 


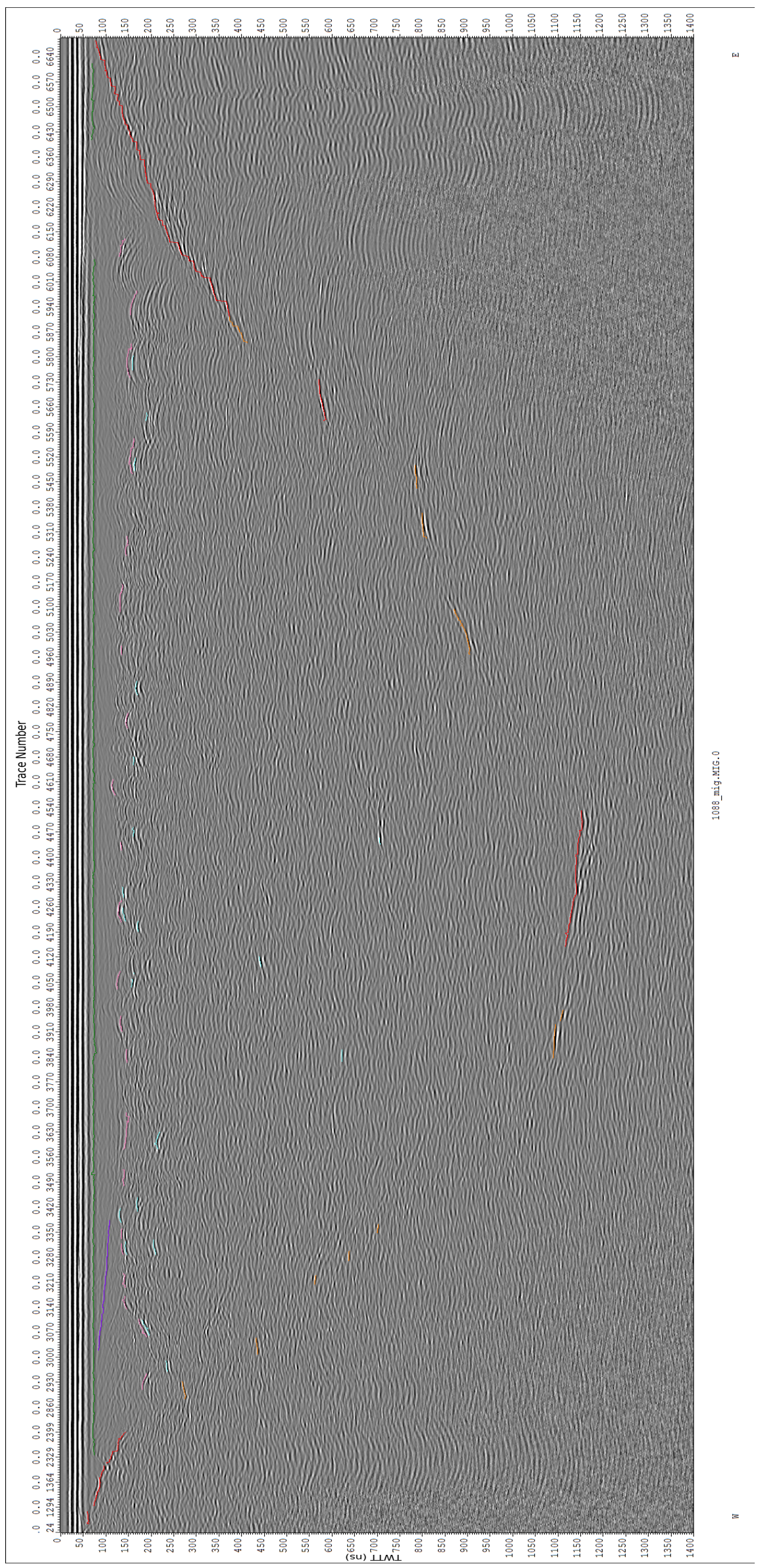

Figure 7.12: Profile 1088 September, showing picked englacial reflections as follows: (1) red - bed; (2) orange - bed inferred; (3) green - initial reflection horizon; (4) pink - reflective horizon (5) blue - point reflector; (6) light-green - banded surface reflector. 


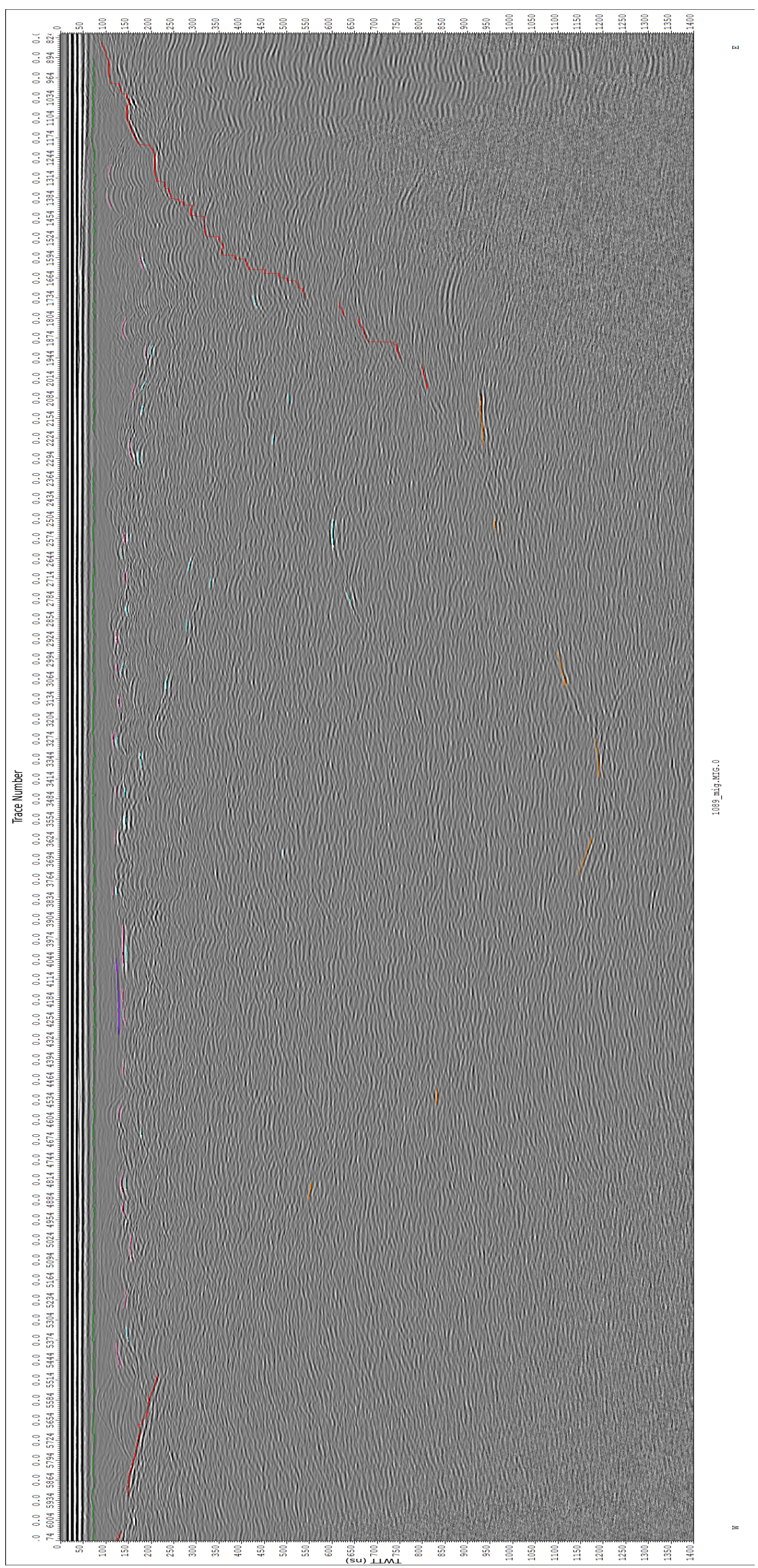

Figure 7.13: Profile 1089 September, showing picked englacial reflections as follows: (1) red - bed; (2) orange - bed inferred; (3) green - initial reflection horizon; (4) pink - reflective horizon (5) blue - point reflector; (6) light-green - banded surface reflector. 


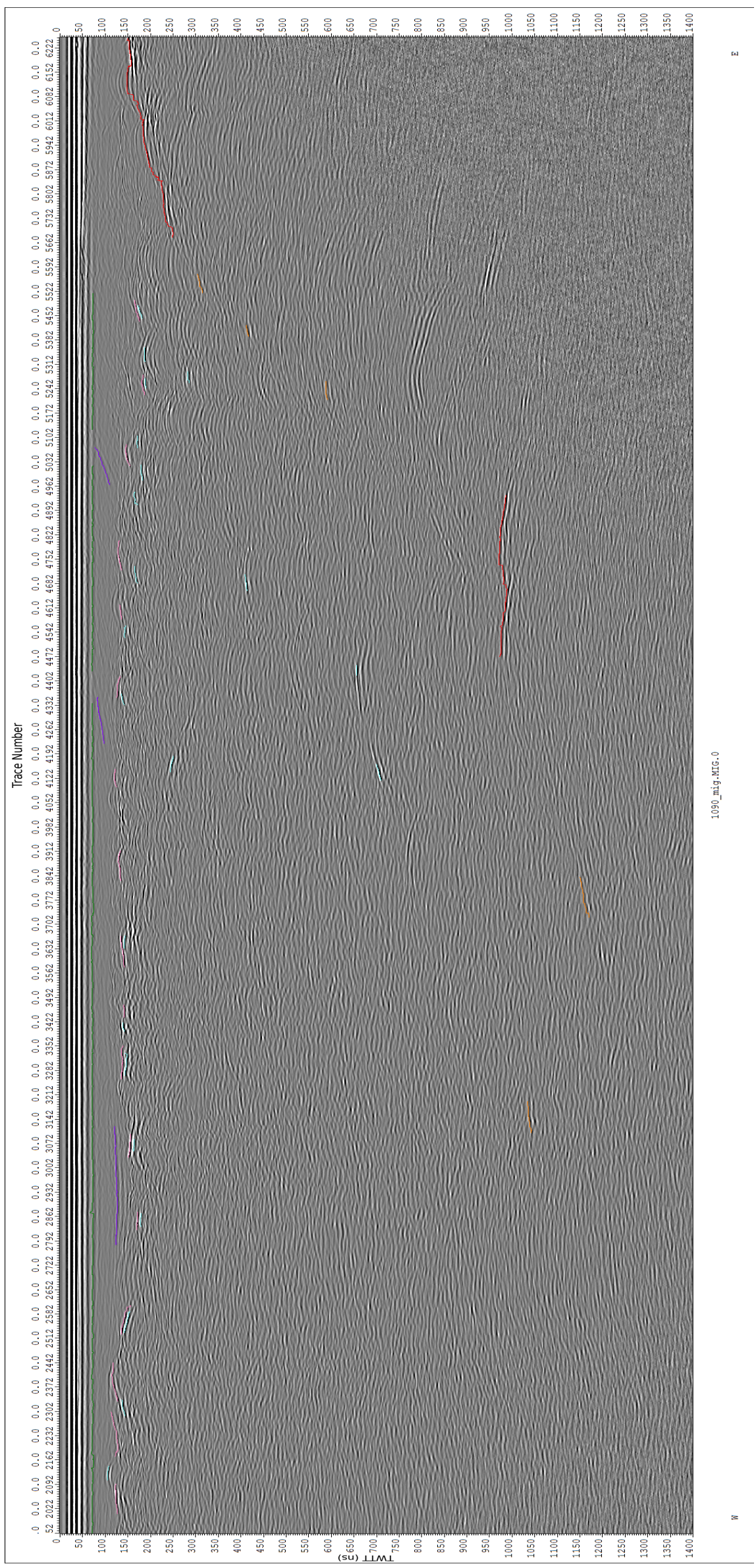

Figure 7.14: Profile 1090 September, showing picked englacial reflections as follows: (1) red - bed; (2) orange - bed inferred; (3) green - initial reflection horizon; (4) pink - reflective horizon (5) blue - point reflector; (6) light-green - banded surface reflector. 


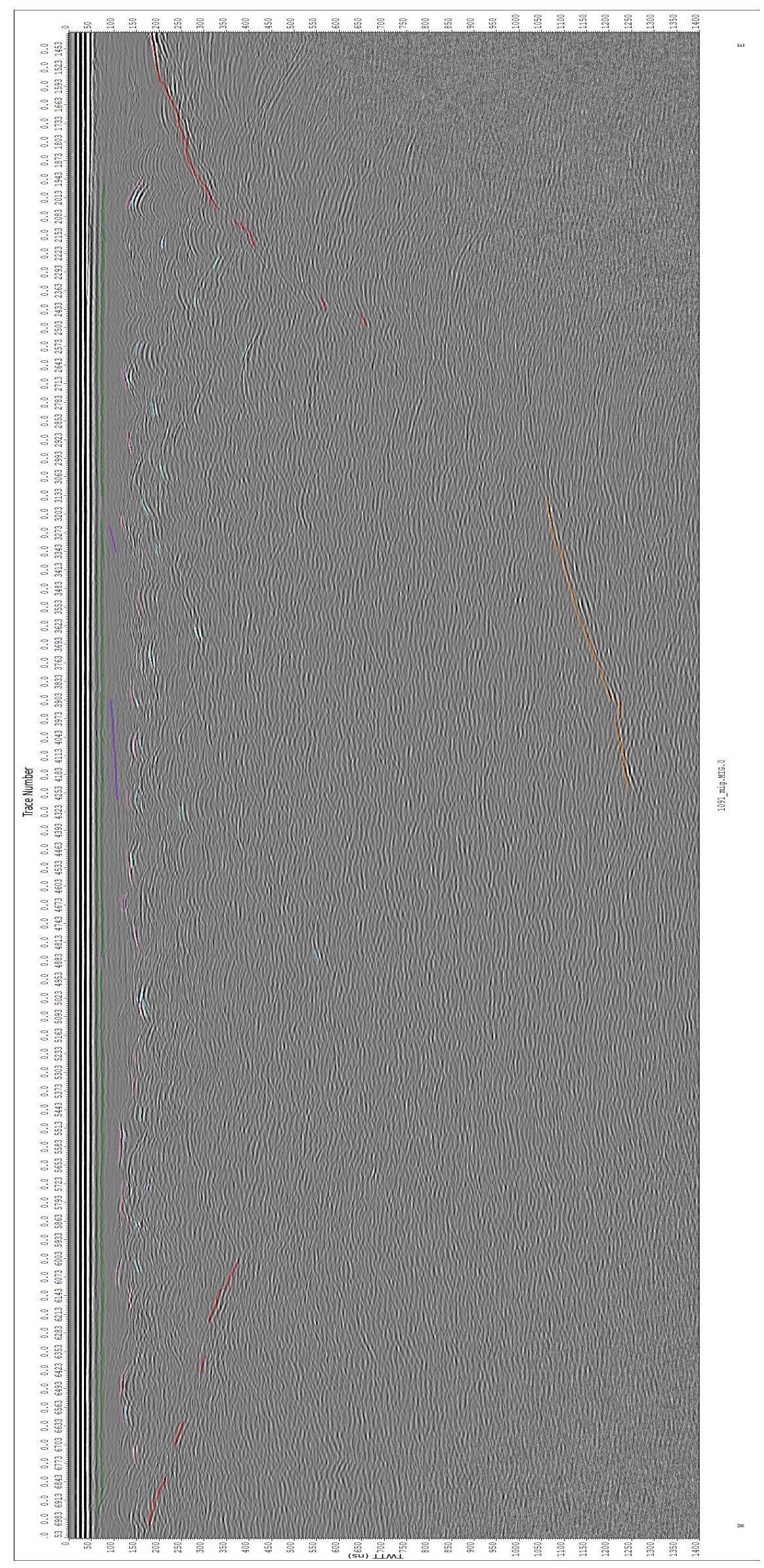

Figure 7.15: Profile 1091 September, showing picked englacial reflections as follows: (1) red - bed; (2) orange - bed inferred; (3) green - initial reflection horizon; (4) pink - reflective horizon (5) blue - point reflector; (6) light-green - banded surface reflector. 


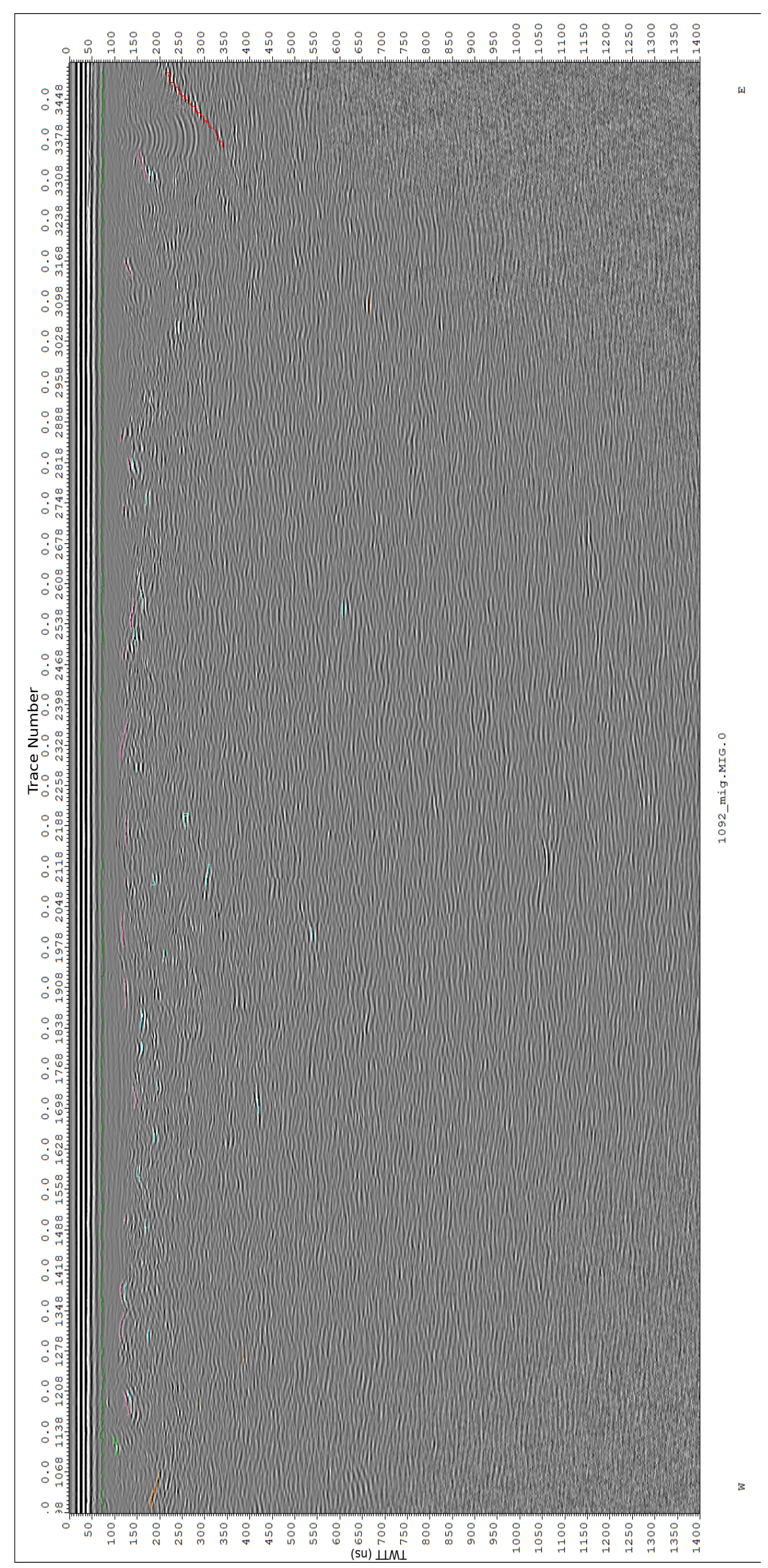

Figure 7.16: Profile 1092 September, showing picked englacial reflections as follows: (1) red - bed; (2) orange - bed inferred; (3) green - initial reflection horizon; (4) pink - reflective horizon (5) blue - point reflector; (6) light-green - banded surface reflector. 


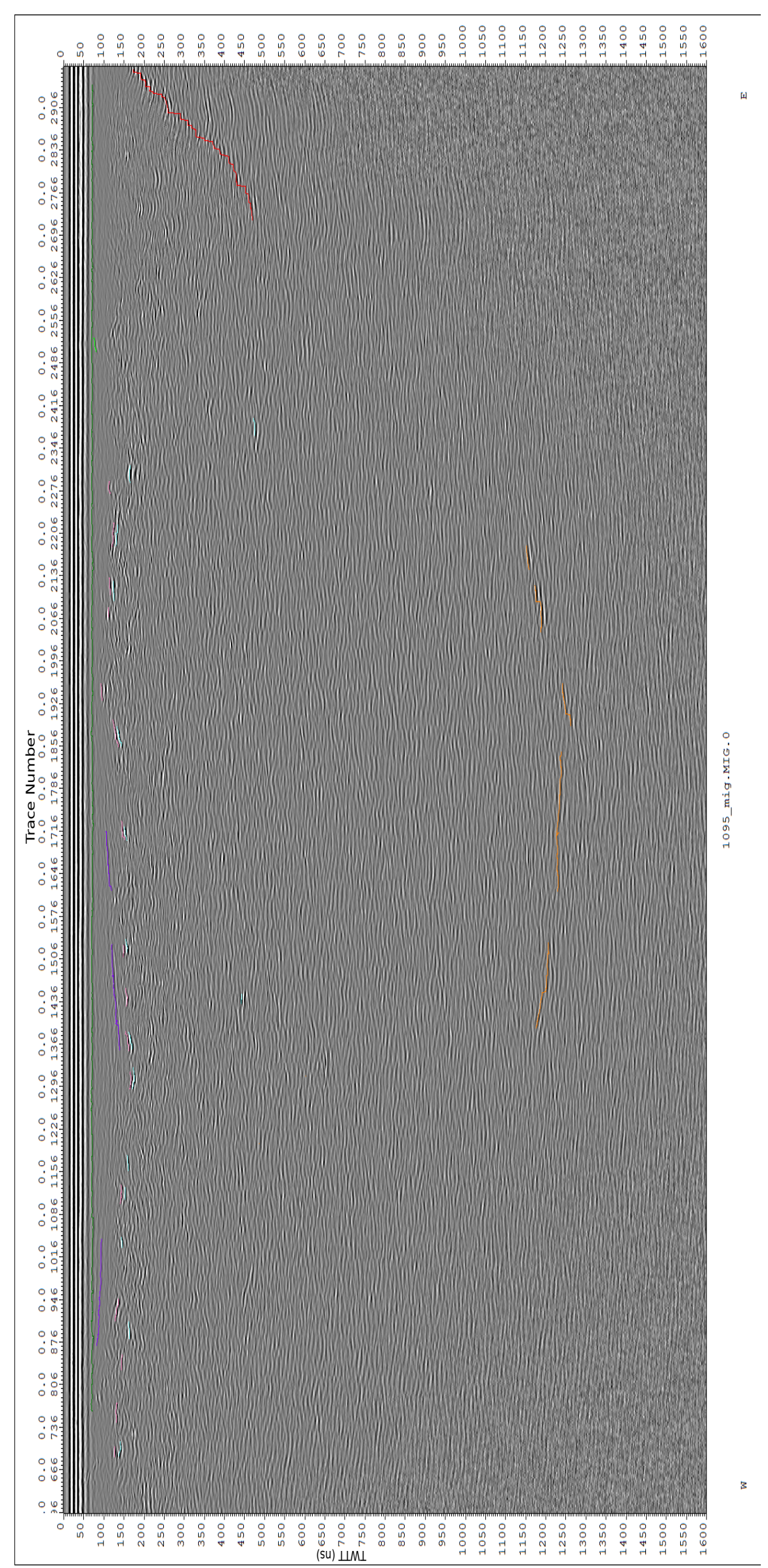

Figure 7.17: Profile 1095 September, showing picked englacial reflections as follows: (1) red - bed; (2) orange - bed inferred; (3) green - initial reflection horizon; (4) pink - reflective horizon (5) blue - point reflector; (6) light-green - banded surface reflector. 


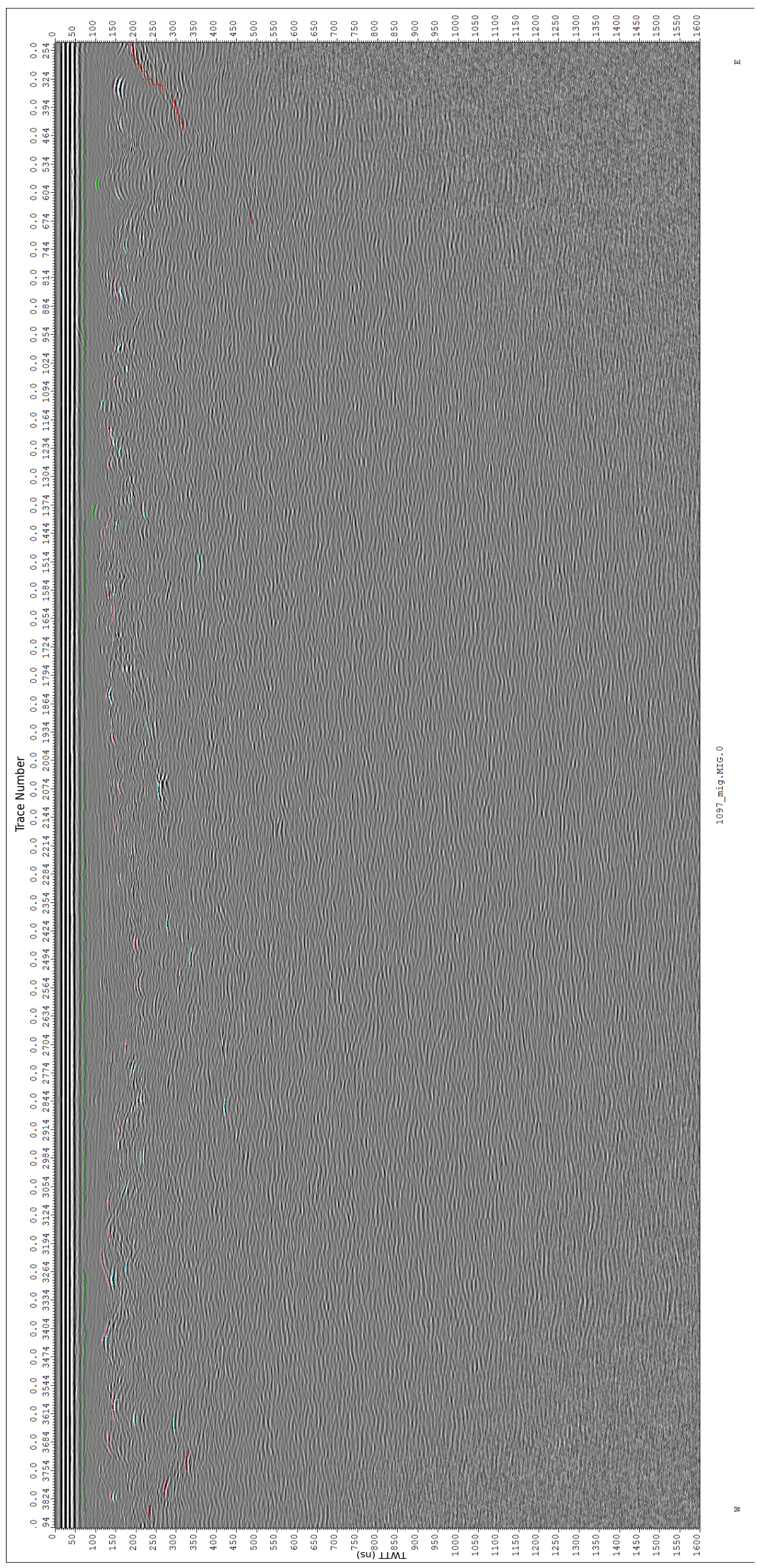

Figure 7.18: Profile 1097 September, showing picked englacial reflections as follows: (1) red - bed; (2) orange - bed inferred; (3) green - initial reflection horizon; (4) pink - reflective horizon (5) blue - point reflector; (6) light-green - banded surface reflector. 


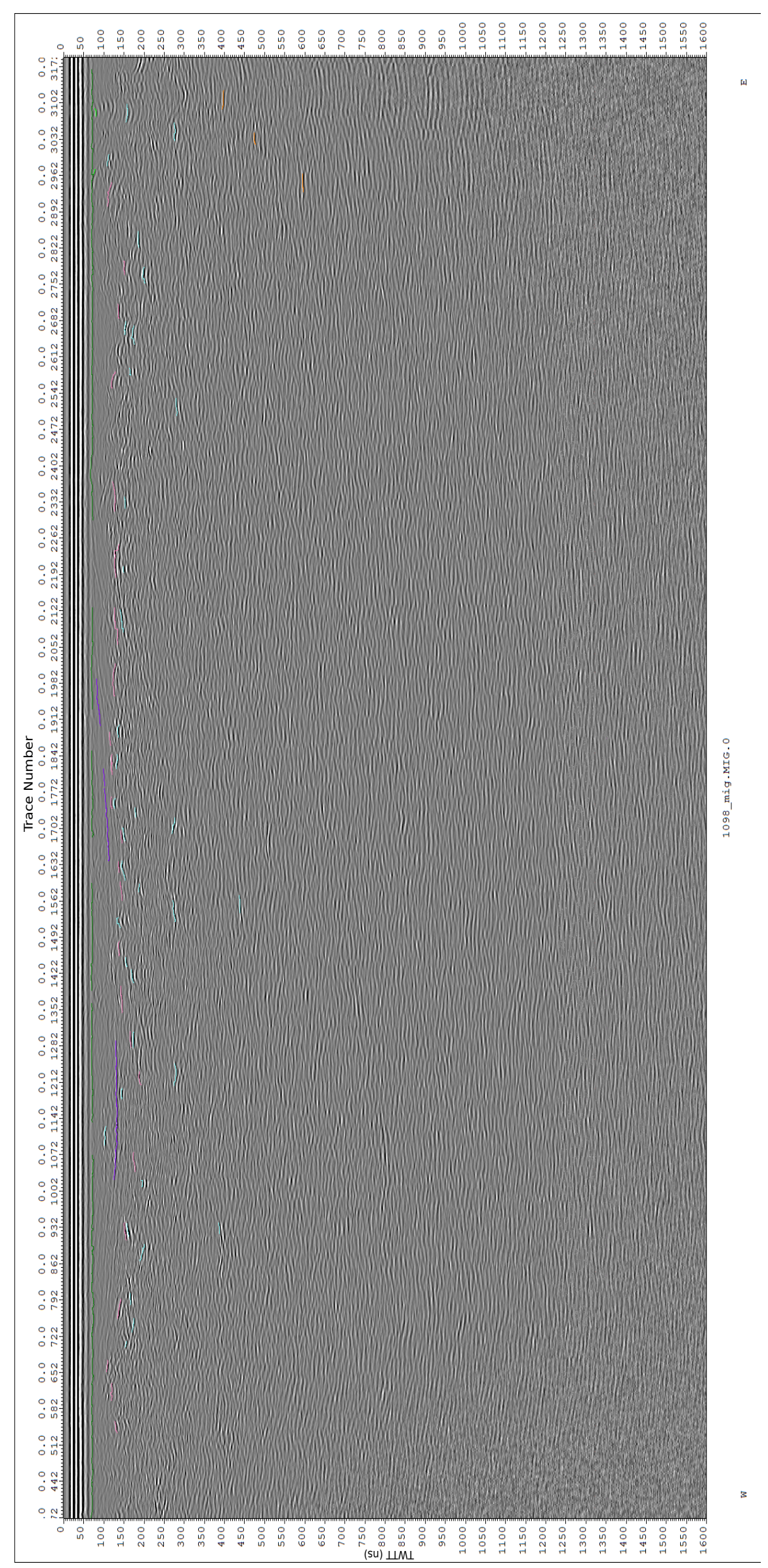

Figure 7.19: Profile 1098 September, showing picked englacial reflections as follows: (1) red - bed; (2) orange - bed inferred; (3) green - initial reflection horizon; (4) pink - reflective horizon (5) blue - point reflector; (6) light-green - banded surface reflector. 


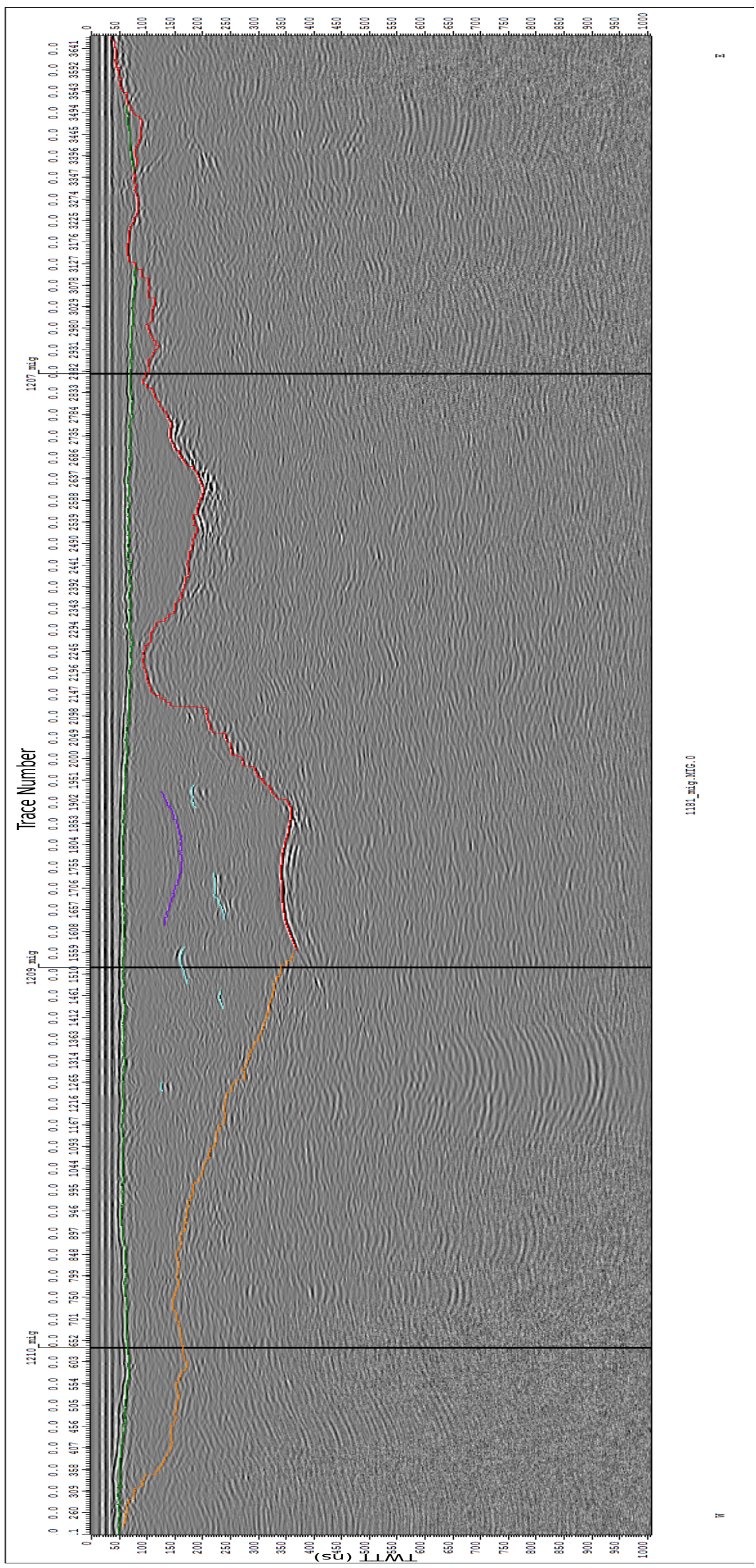

Figure 7.20: Profile 1181 December, showing picked englacial reflections as follows: (1) red - bed; (2) orange - bed inferred; (3) green - initial reflection horizon; (4) pink - reflective horizon (5) blue - point reflector; (6) light-green - banded surface reflector. 


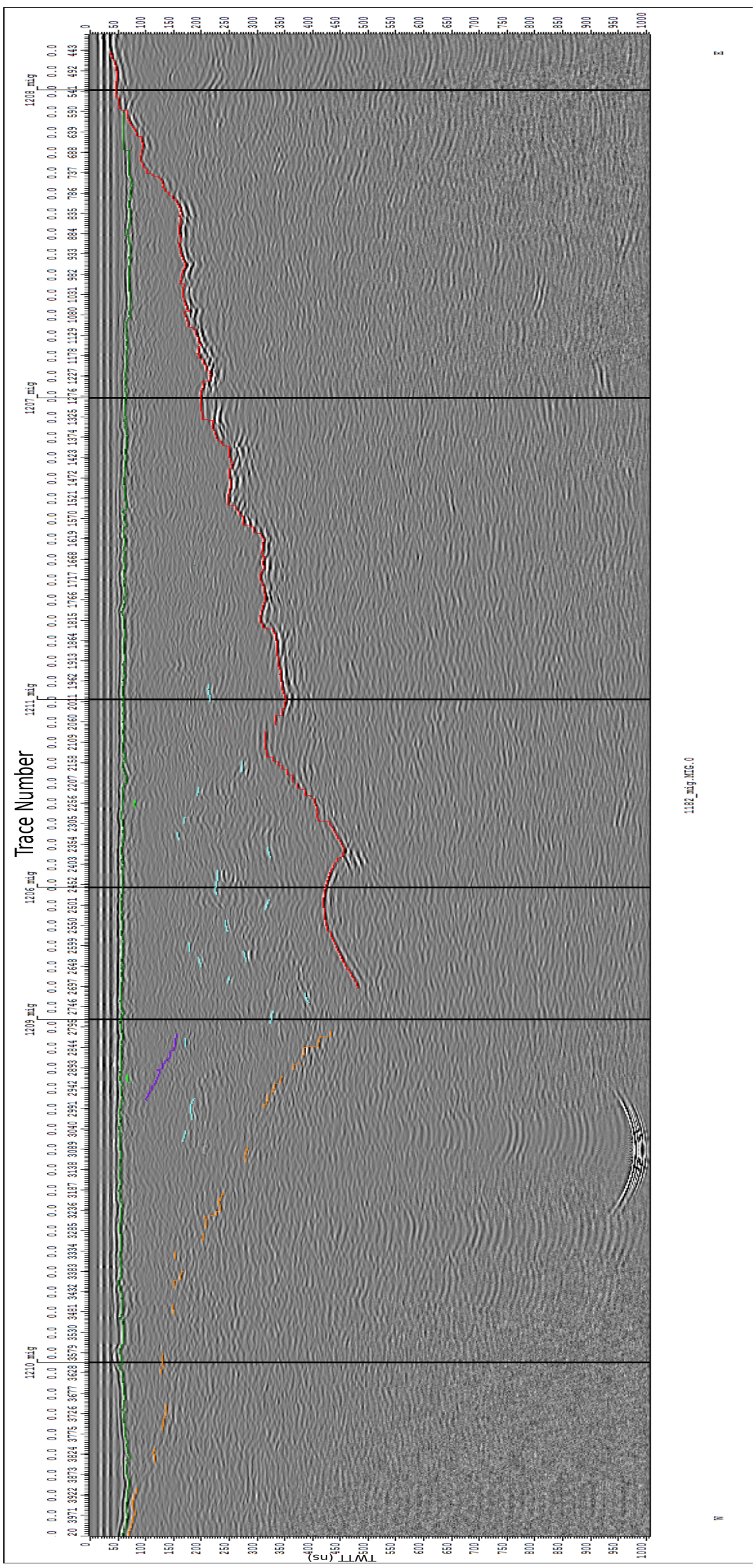

Figure 7.21: Profile 1182 December, showing picked englacial reflections as follows: (1) red - bed; (2) orange - bed inferred; (3) green - initial reflection horizon; (4) pink - reflective horizon (5) blue - point reflector; (6) light-green - banded surface reflector. 


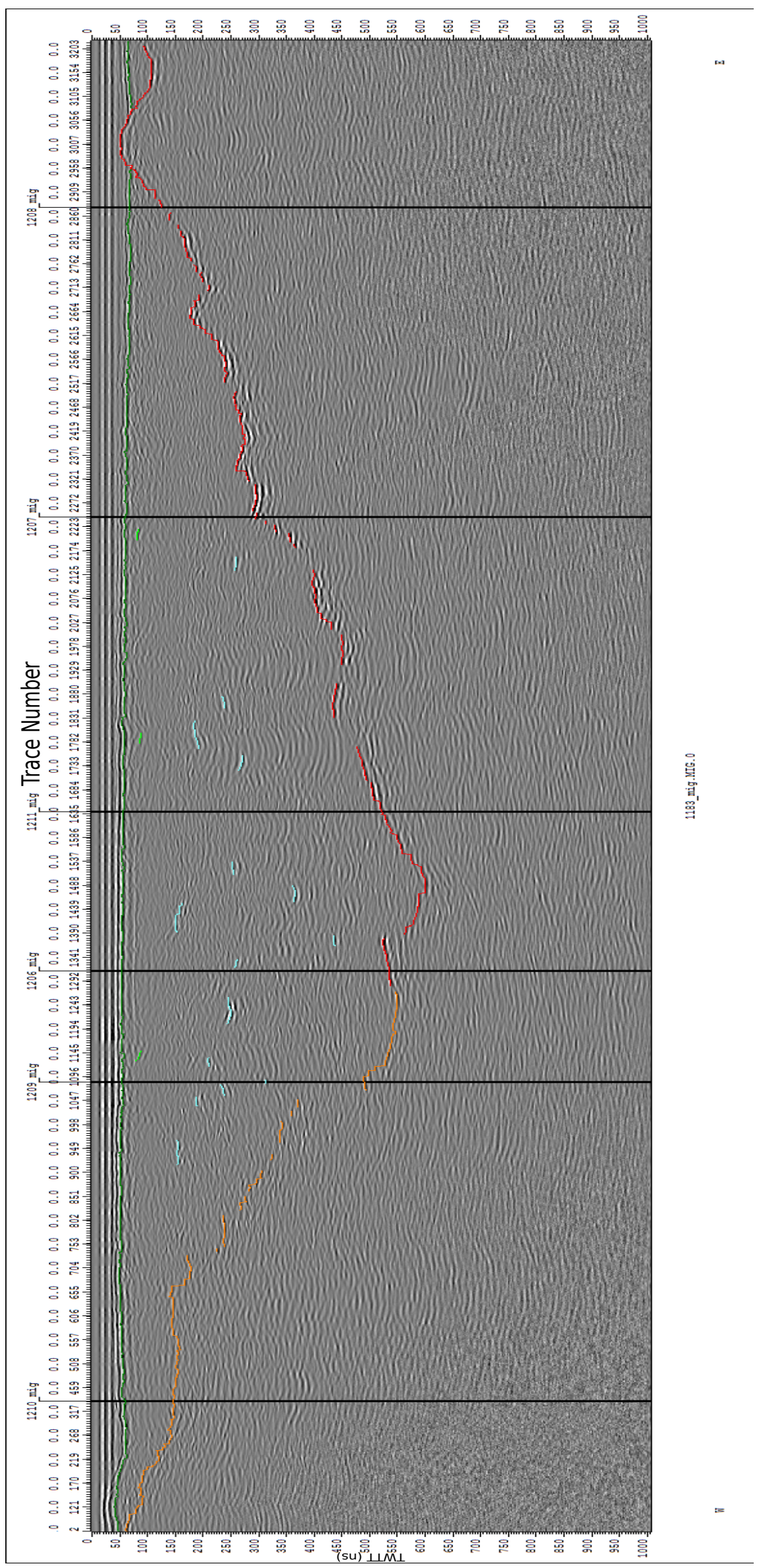

Figure 7.22: Profile 1183 December, showing picked englacial reflections as follows: (1) red - bed; (2) orange - bed inferred; (3) green - initial reflection horizon; (4) pink - reflective horizon (5) blue - point reflector; (6) light-green - banded surface reflector. 


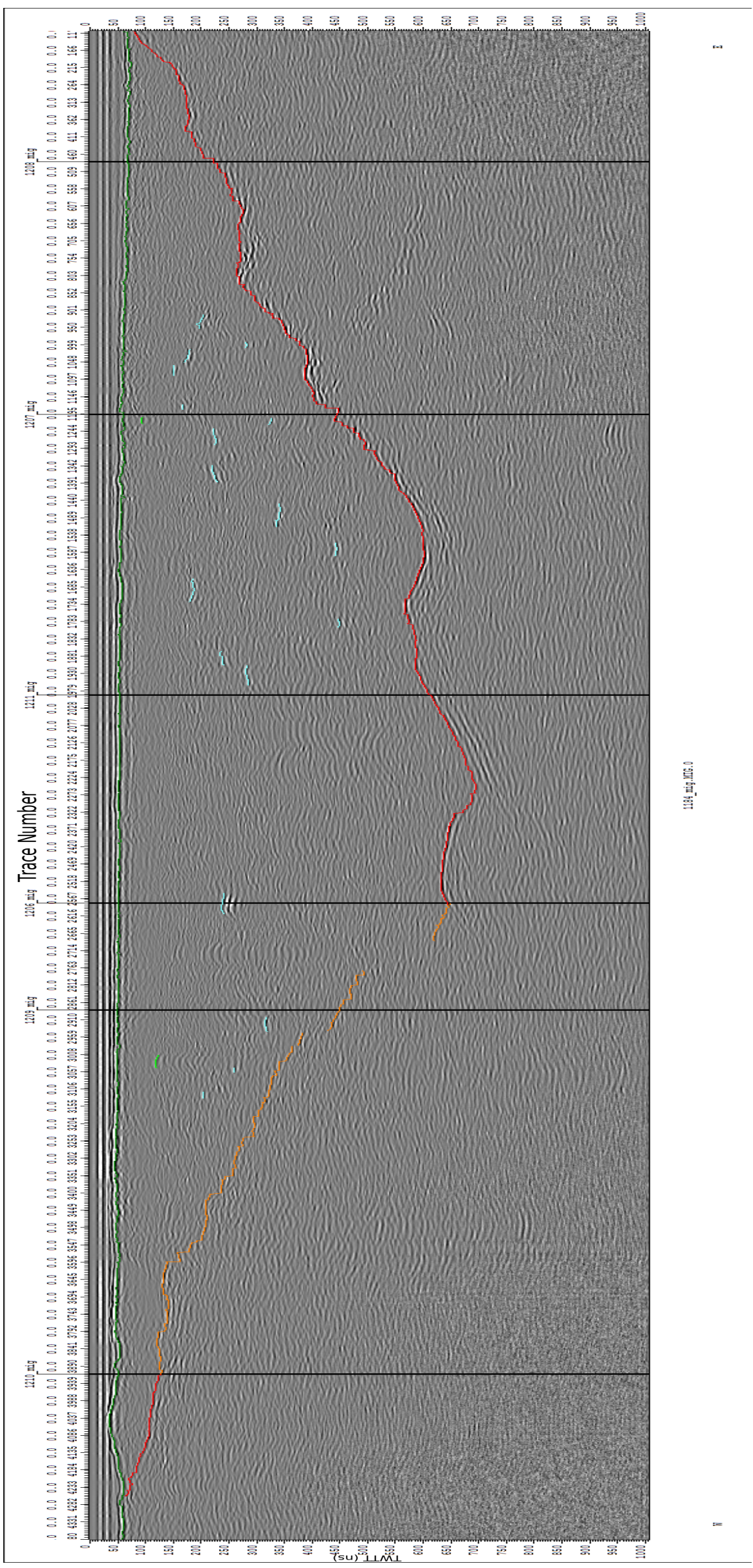

Figure 7.23: Profile 1184 December, showing picked englacial reflections as follows: (1) red - bed; (2) orange - bed inferred; (3) green - initial reflection horizon; (4) pink - reflective horizon (5) blue - point reflector; (6) light-green - banded surface reflector. 


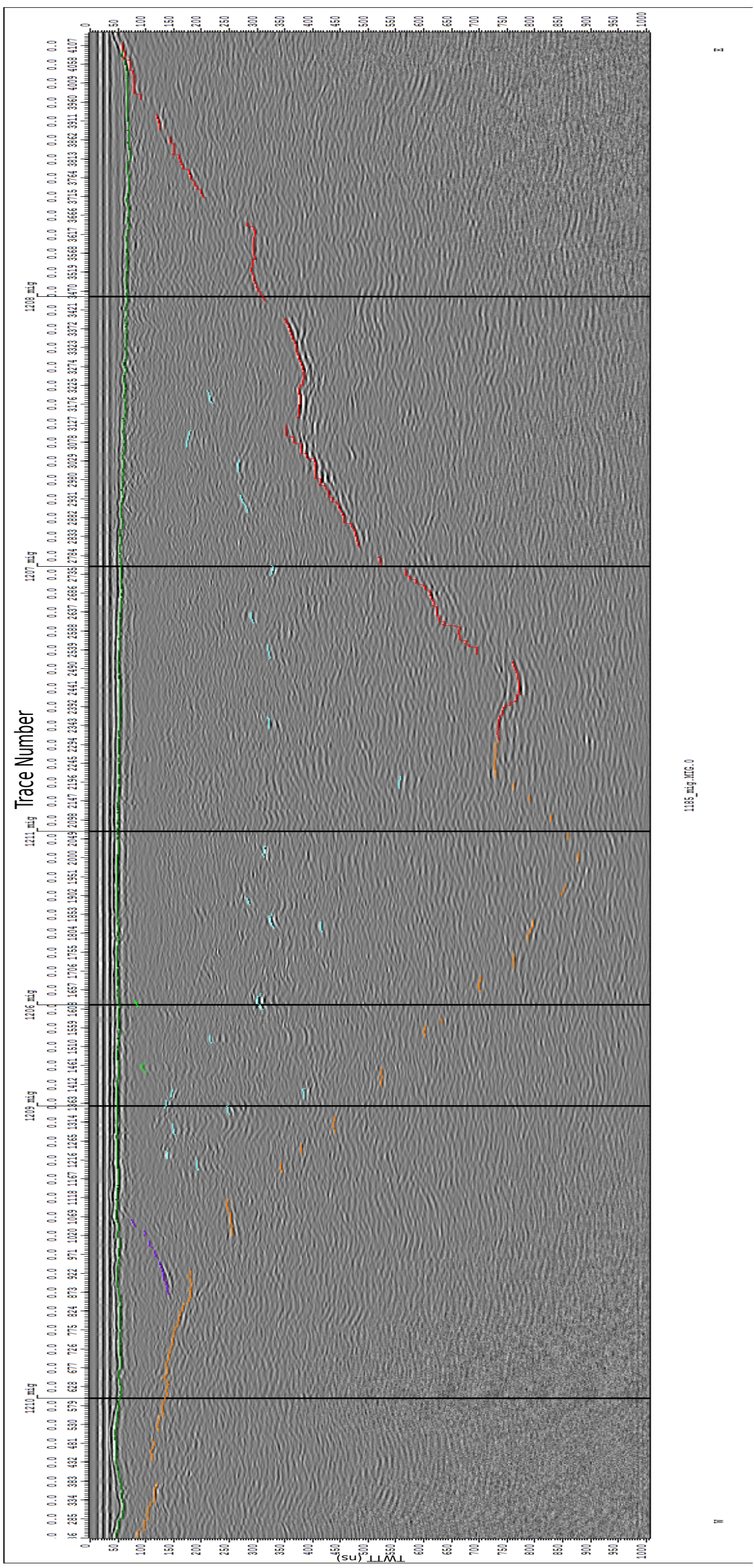

Figure 7.24: Profile 1185 December, showing picked englacial reflections as follows: (1) red - bed; (2) orange - bed inferred; (3) green - initial reflection horizon; (4) pink - reflective horizon (5) blue - point reflector; (6) light-green - banded surface reflector. 


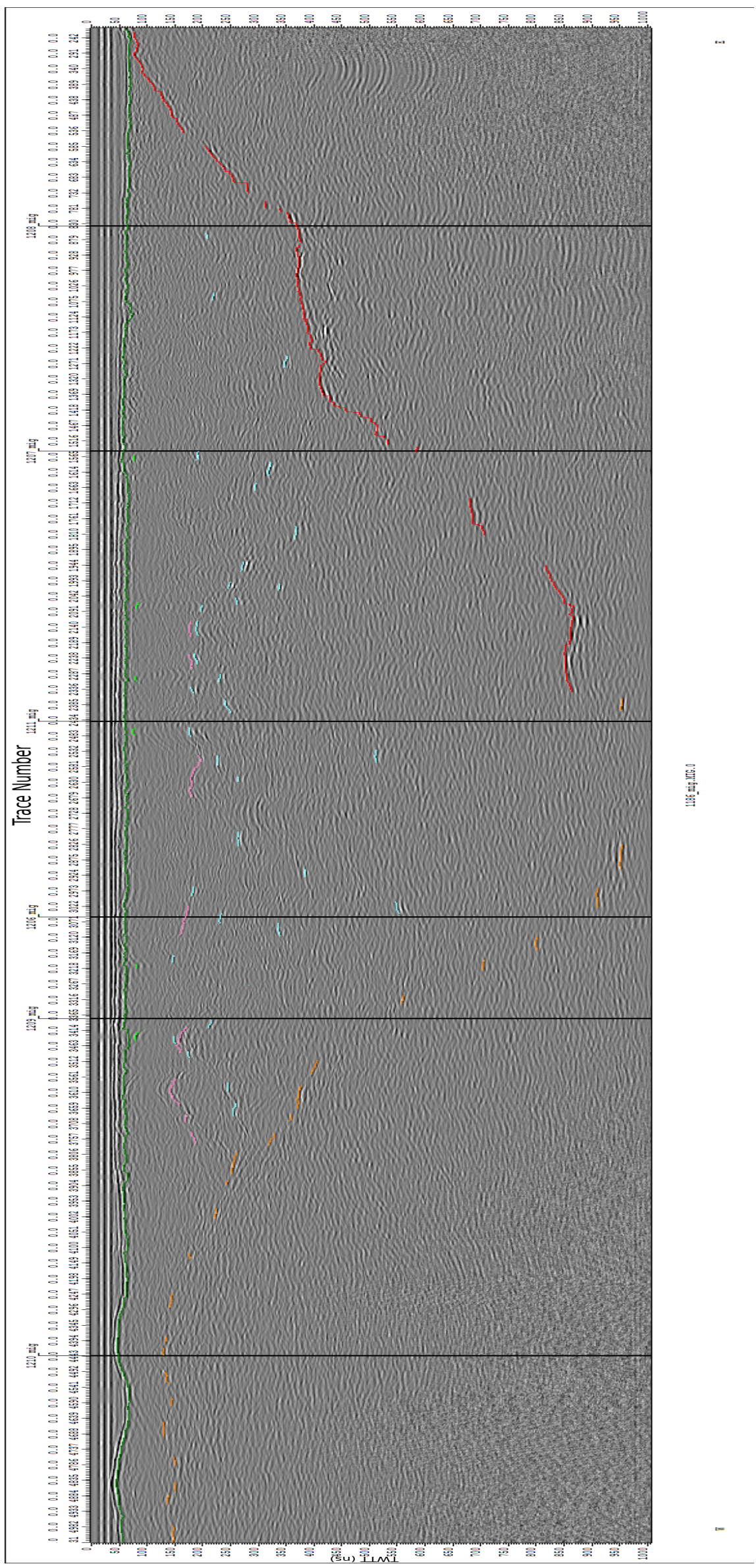

Figure 7.25: Profile 1186 December, showing picked englacial reflections as follows: (1) red - bed; (2) orange - bed inferred; (3) green - initial reflection horizon; (4) pink - reflective horizon (5) blue - point reflector; (6) light-green - banded surface reflector. 


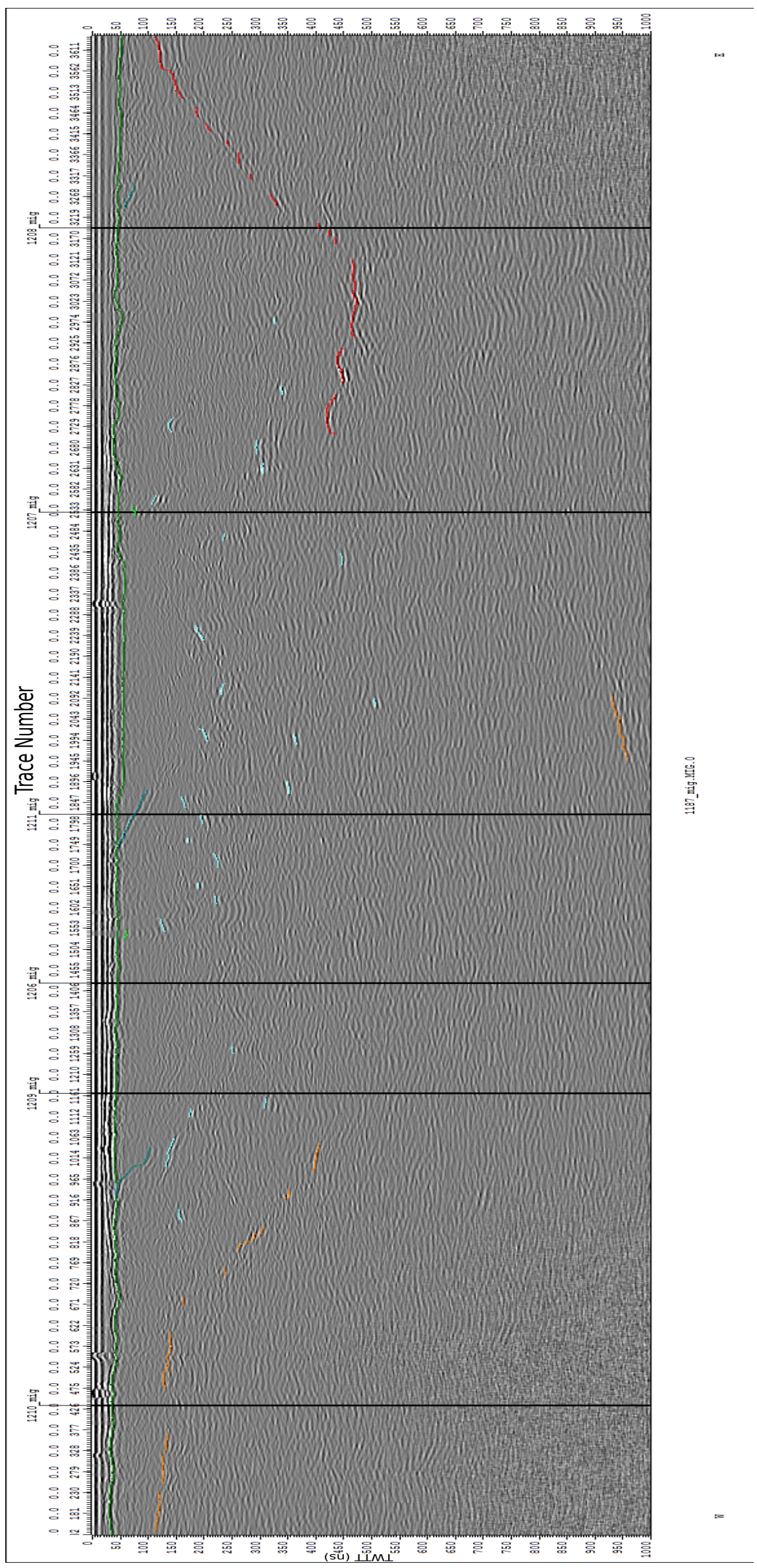

Figure 7.26: Profile 1187 December, showing picked englacial reflections as follows: (1) red - bed; (2) orange - bed inferred; (3) green - initial reflection horizon; (4) pink - reflective horizon (5) blue - point reflector; (6) light-green - banded surface reflector. 


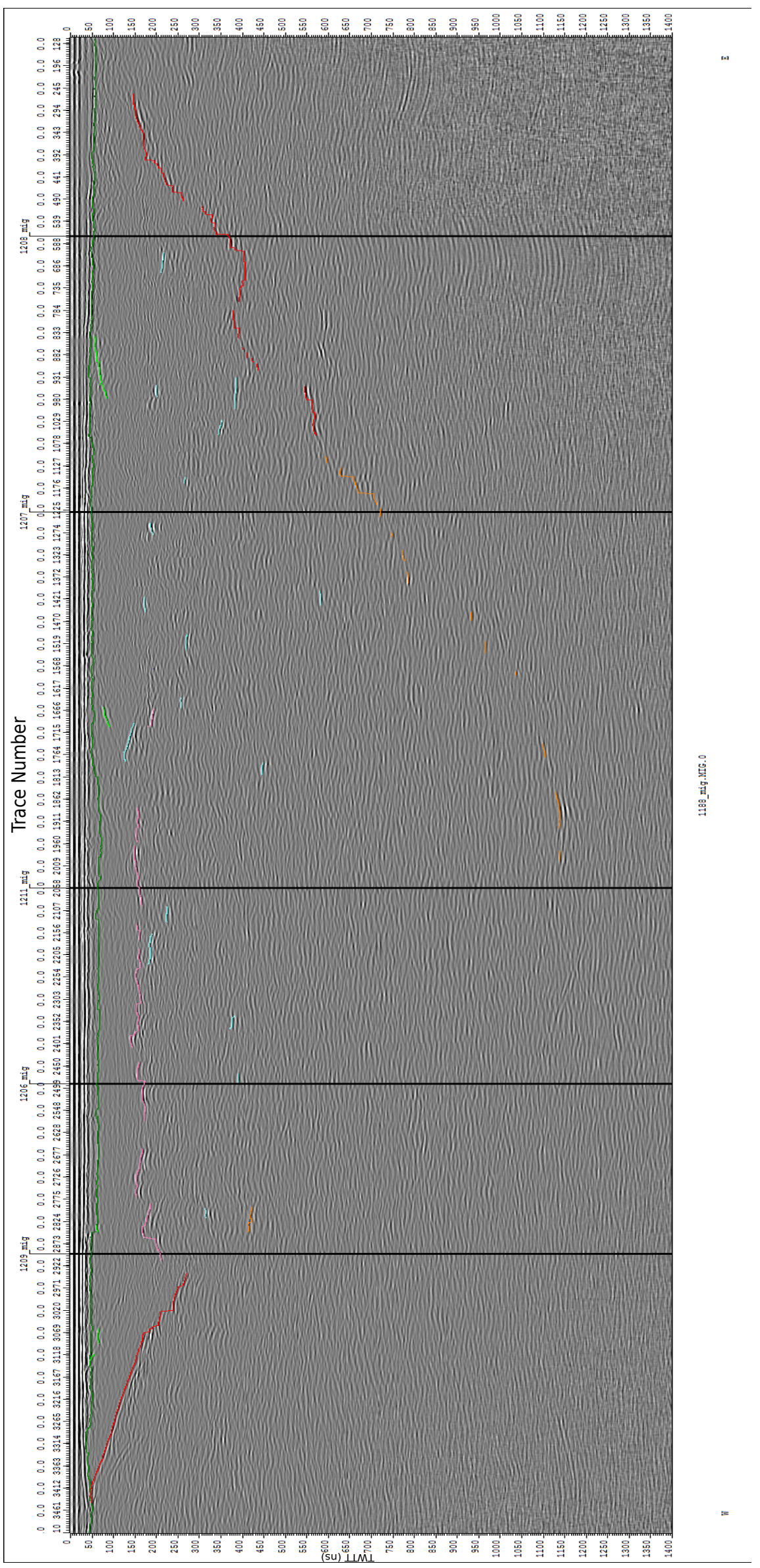

Figure 7.27: Profile 1188 December, showing picked englacial reflections as follows: (1) red - bed; (2) orange - bed inferred; (3) green - initial reflection horizon; (4) pink - reflective horizon (5) blue - point reflector; (6) light-green - banded surface reflector. 


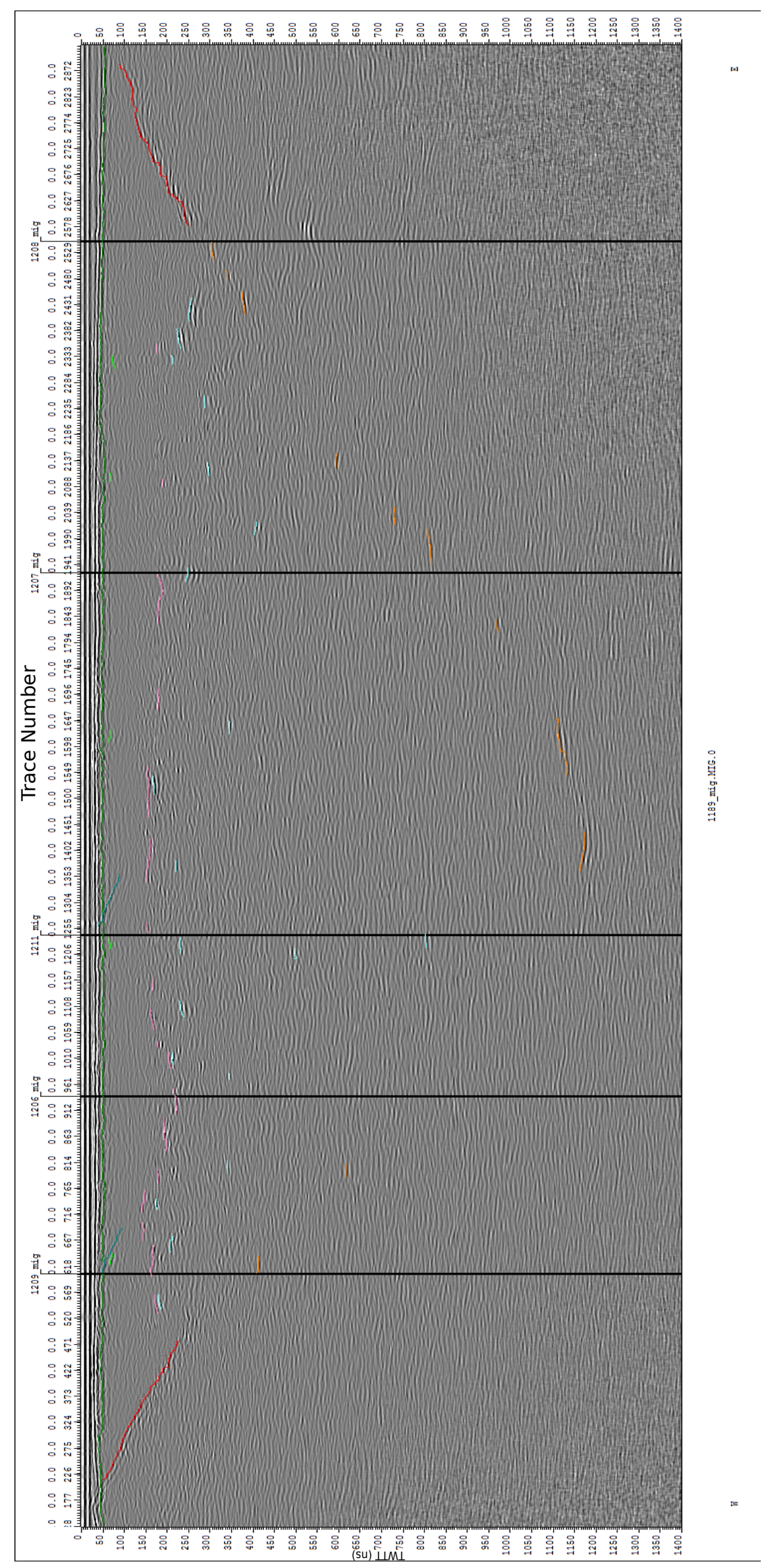

Figure 7.28: Profile 1189 December, showing picked englacial reflections as follows: (1) red - bed; (2) orange - bed inferred; (3) green - initial reflection horizon; (4) pink - reflective horizon (5) blue - point reflector; (6) light-green - banded surface reflector. 


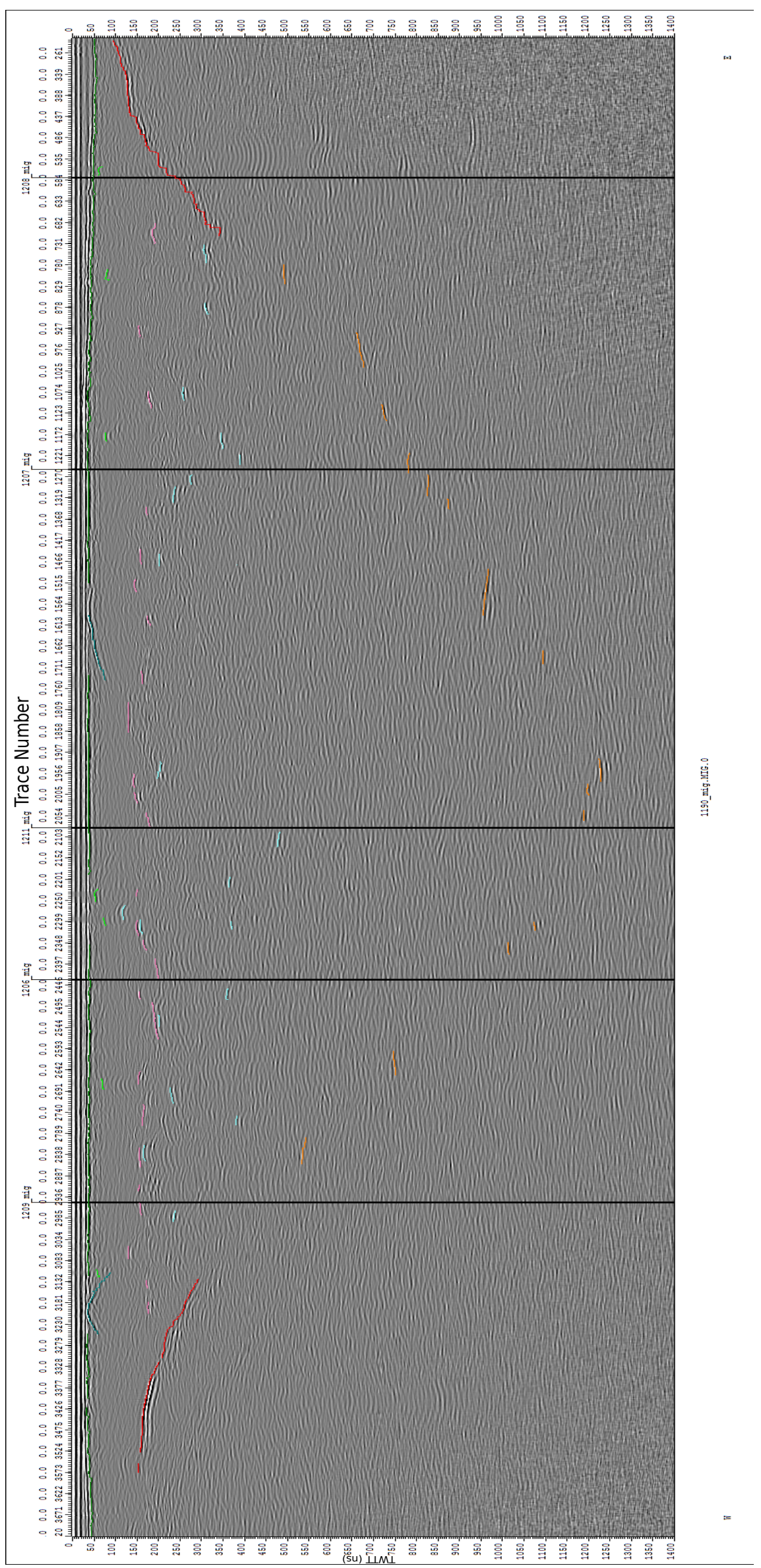

Figure 7.29: Profile 1190 December, showing picked englacial reflections as follows: (1) red - bed; (2) orange - bed inferred; (3) green - initial reflection horizon; (4) pink - reflective horizon (5) blue - point reflector; (6) light-green - banded surface reflector. 


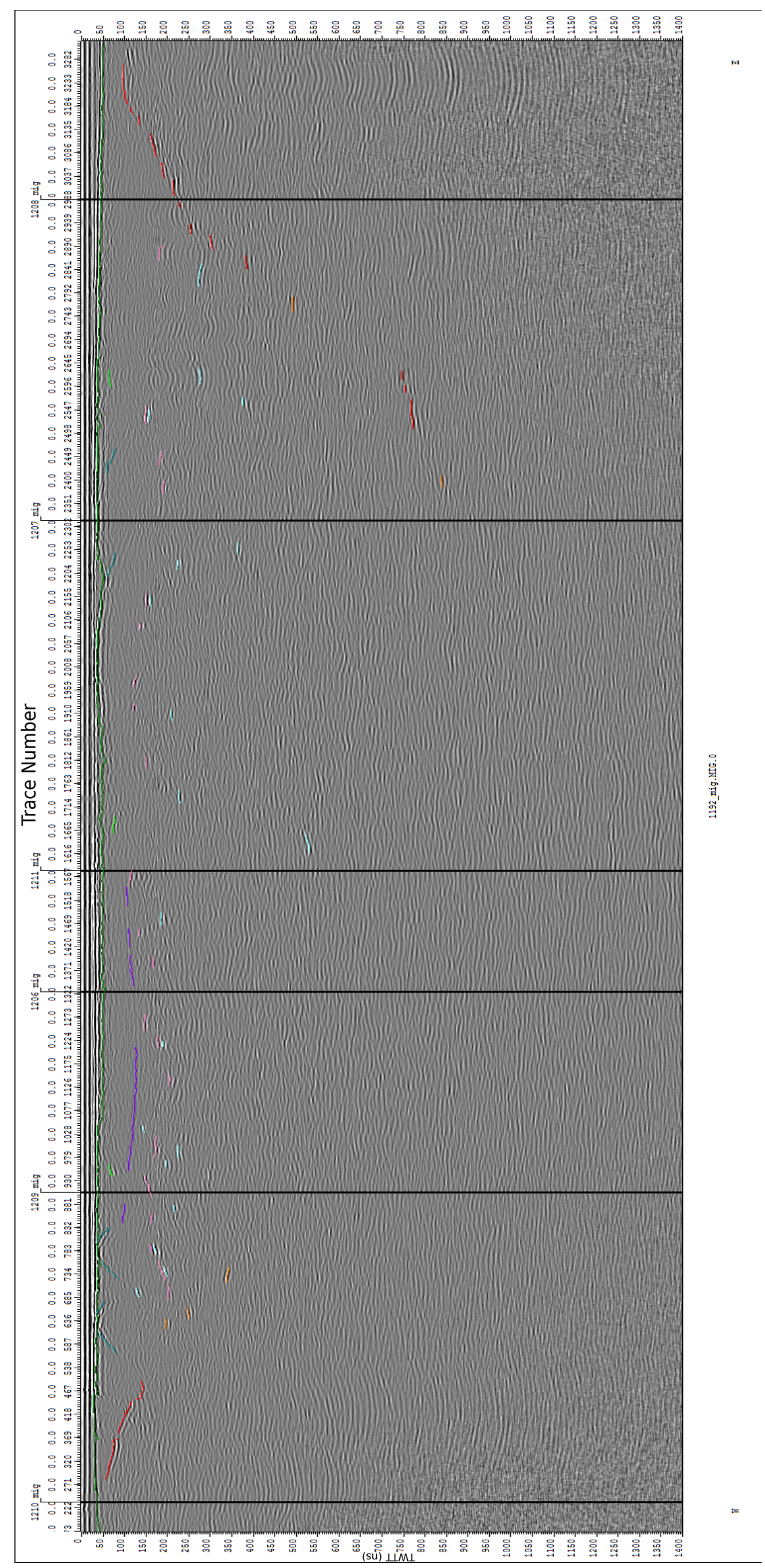

Figure 7.30: Profile 1192 December, showing picked englacial reflections as follows: (1) red - bed; (2) orange - bed inferred; (3) green - initial reflection horizon; (4) pink - reflective horizon (5) blue - point reflector; (6) light-green - banded surface reflector. 


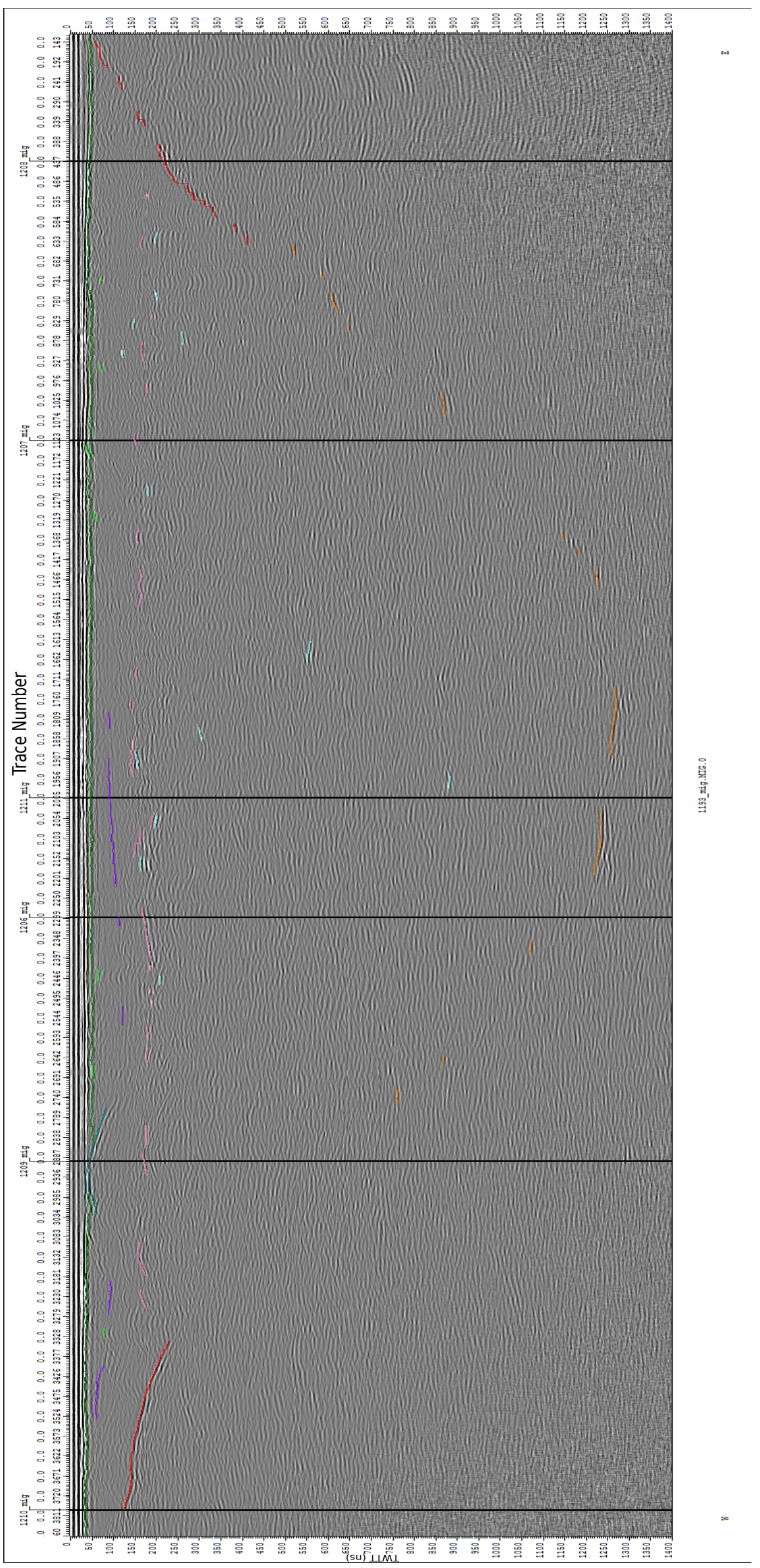

Figure 7.31: Profile 1193 December, showing picked englacial reflections as follows: (1) red - bed; (2) orange - bed inferred; (3) green - initial reflection horizon; (4) pink - reflective horizon (5) blue - point reflector; (6) light-green - banded surface reflector. 


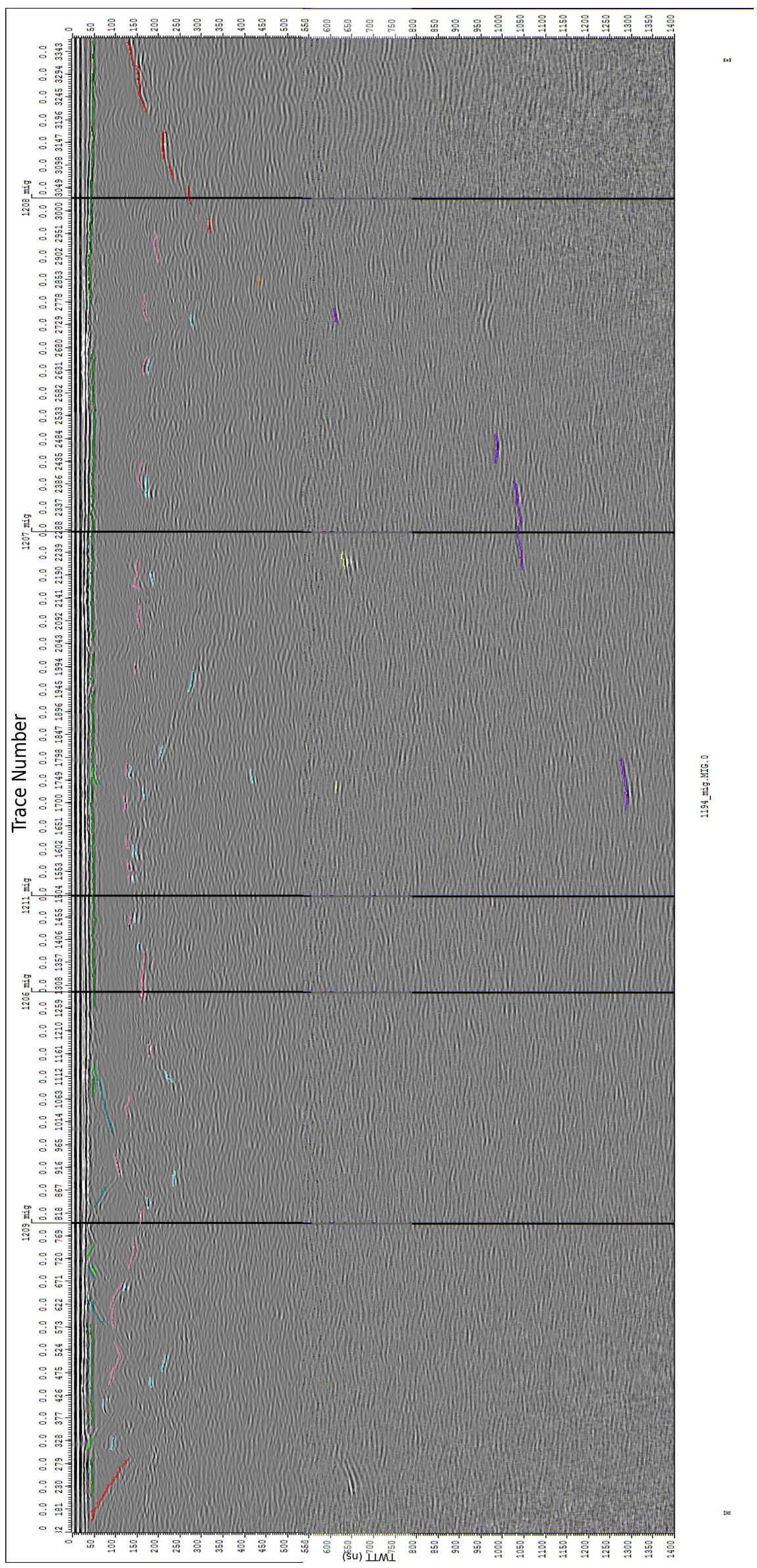

Figure 7.32: Profile 1194 December, showing picked englacial reflections as follows: (1) red - bed; (2) orange - bed inferred; (3) green - initial reflection horizon; (4) pink - reflective horizon (5) blue - point reflector; (6) light-green - banded surface reflector. 


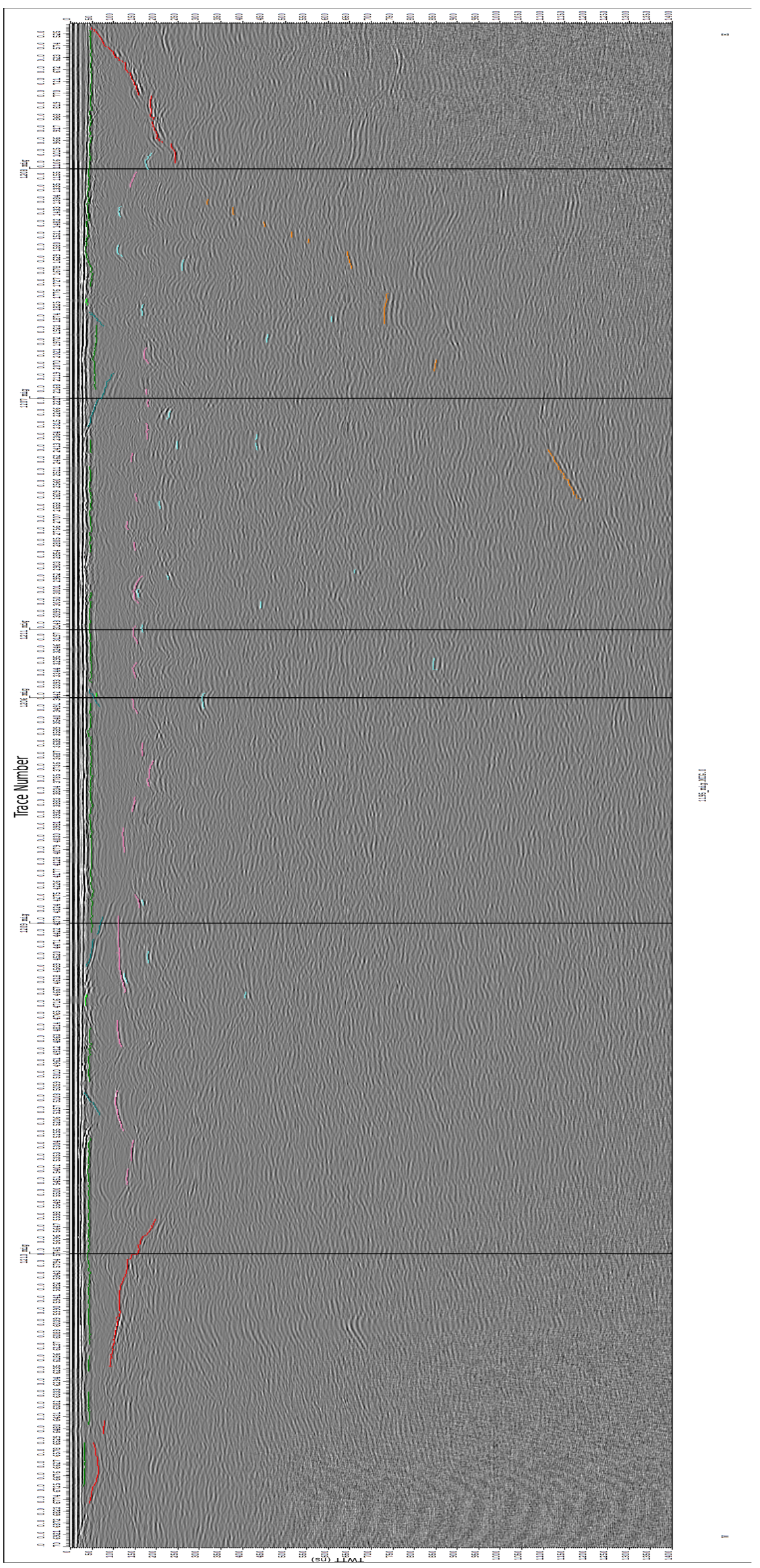

Figure 7.33: Profile 1195 December, showing picked englacial reflections as follows: (1) red - bed; (2) orange - bed inferred; (3) green - initial reflection horizon; (4) pink - reflective horizon (5) blue - point reflector; (6) light-green - banded surface reflector. 


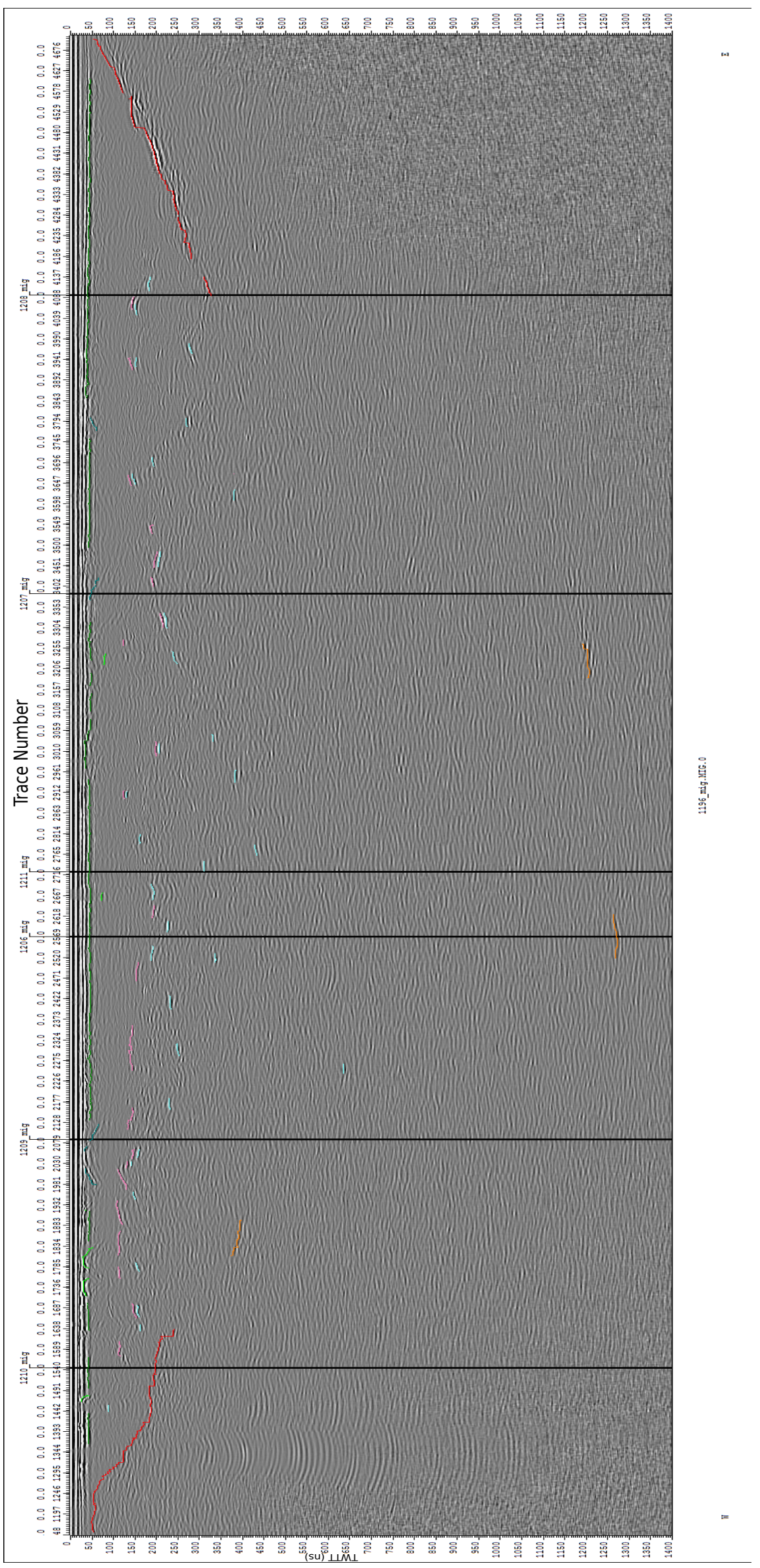

Figure 7.34: Profile 1196 December, showing picked englacial reflections as follows: (1) red - bed; (2) orange - bed inferred; (3) green - initial reflection horizon; (4) pink - reflective horizon (5) blue - point reflector; (6) light-green - banded surface reflector. 


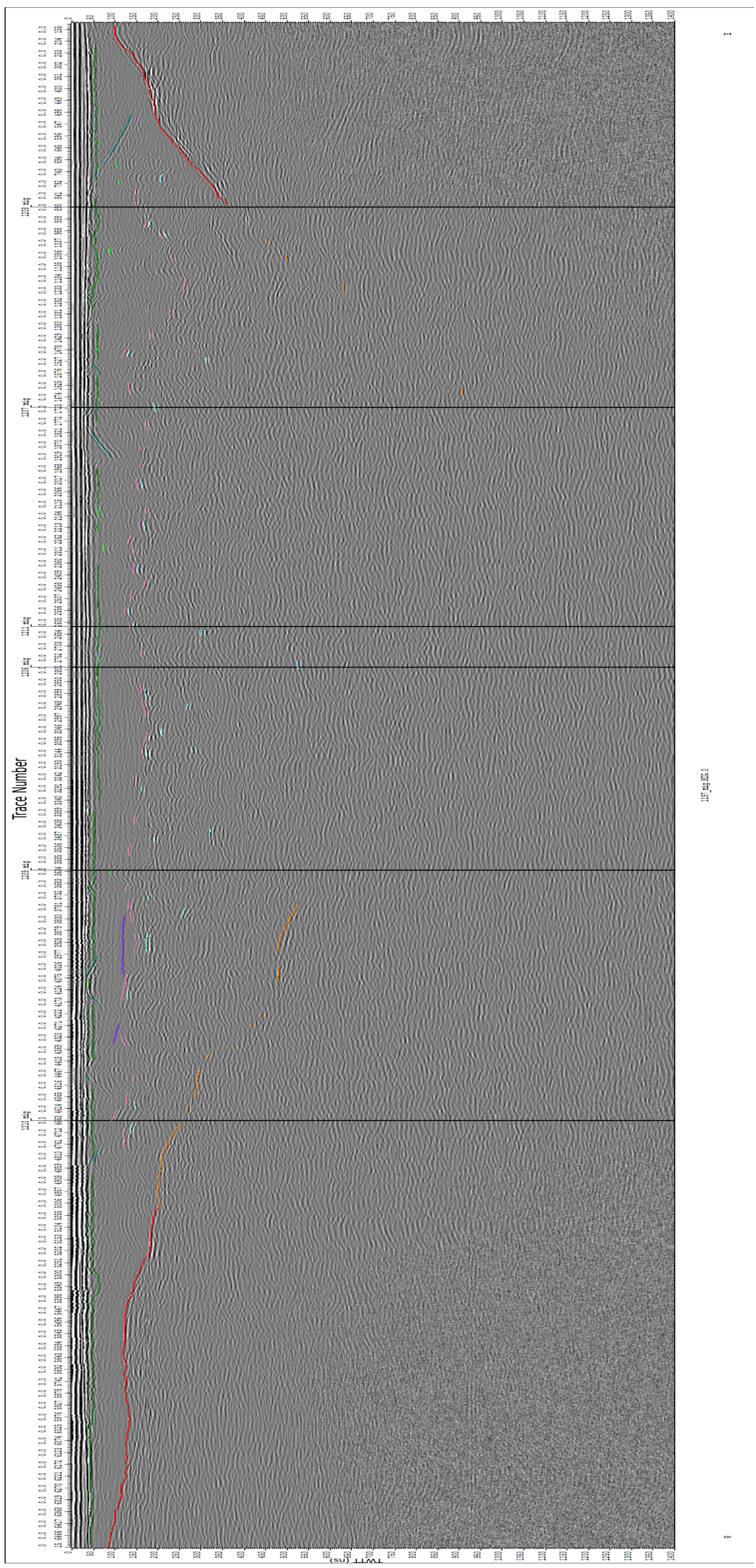

Figure 7.35: Profile 1197 December, showing picked englacial reflections as follows: (1) red - bed; (2) orange - bed inferred; (3) green - initial reflection horizon; (4) pink - reflective horizon (5) blue - point reflector; (6) light-green - banded surface reflector. 


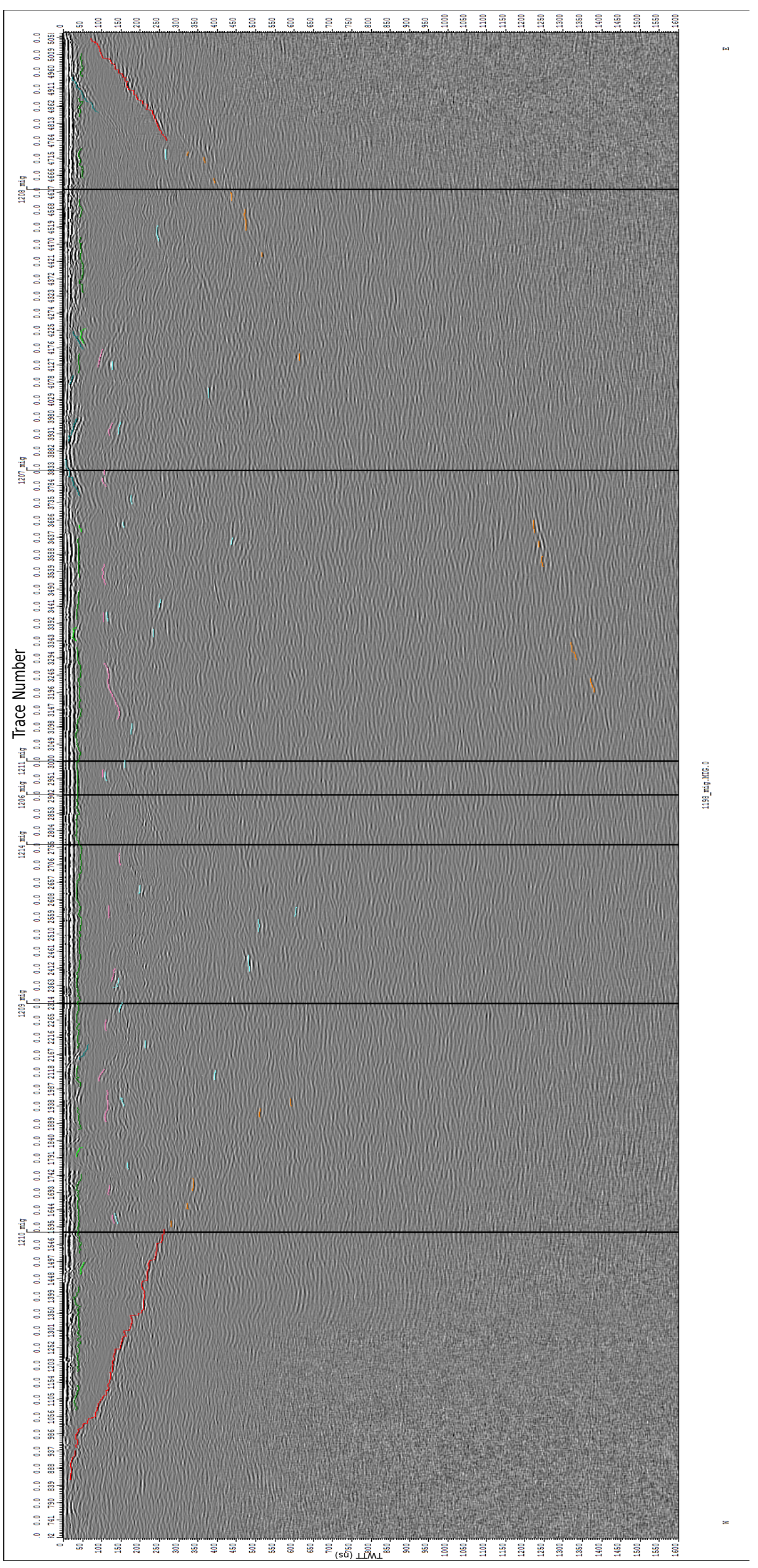

Figure 7.36: Profile 1198 December, showing picked englacial reflections as follows: (1) red - bed; (2) orange - bed inferred; (3) green - initial reflection horizon; (4) pink - reflective horizon (5) blue - point reflector; (6) light-green - banded surface reflector. 


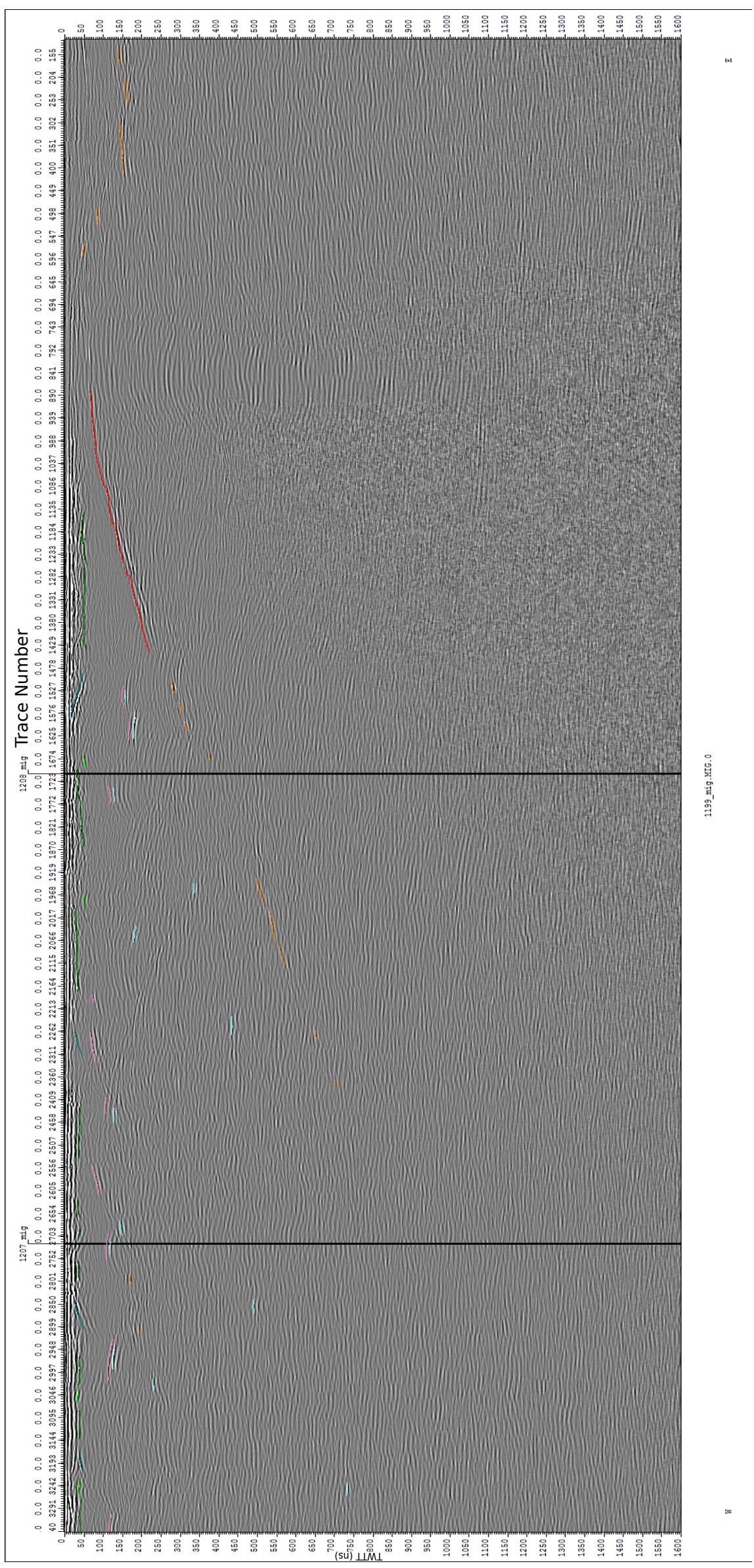

Figure 7.37: Profile 1199 December, showing picked englacial reflections as follows: (1) red - bed; (2) orange - bed inferred; (3) green - initial reflection horizon; (4) pink - reflective horizon (5) blue - point reflector; (6) light-green - banded surface reflector. 


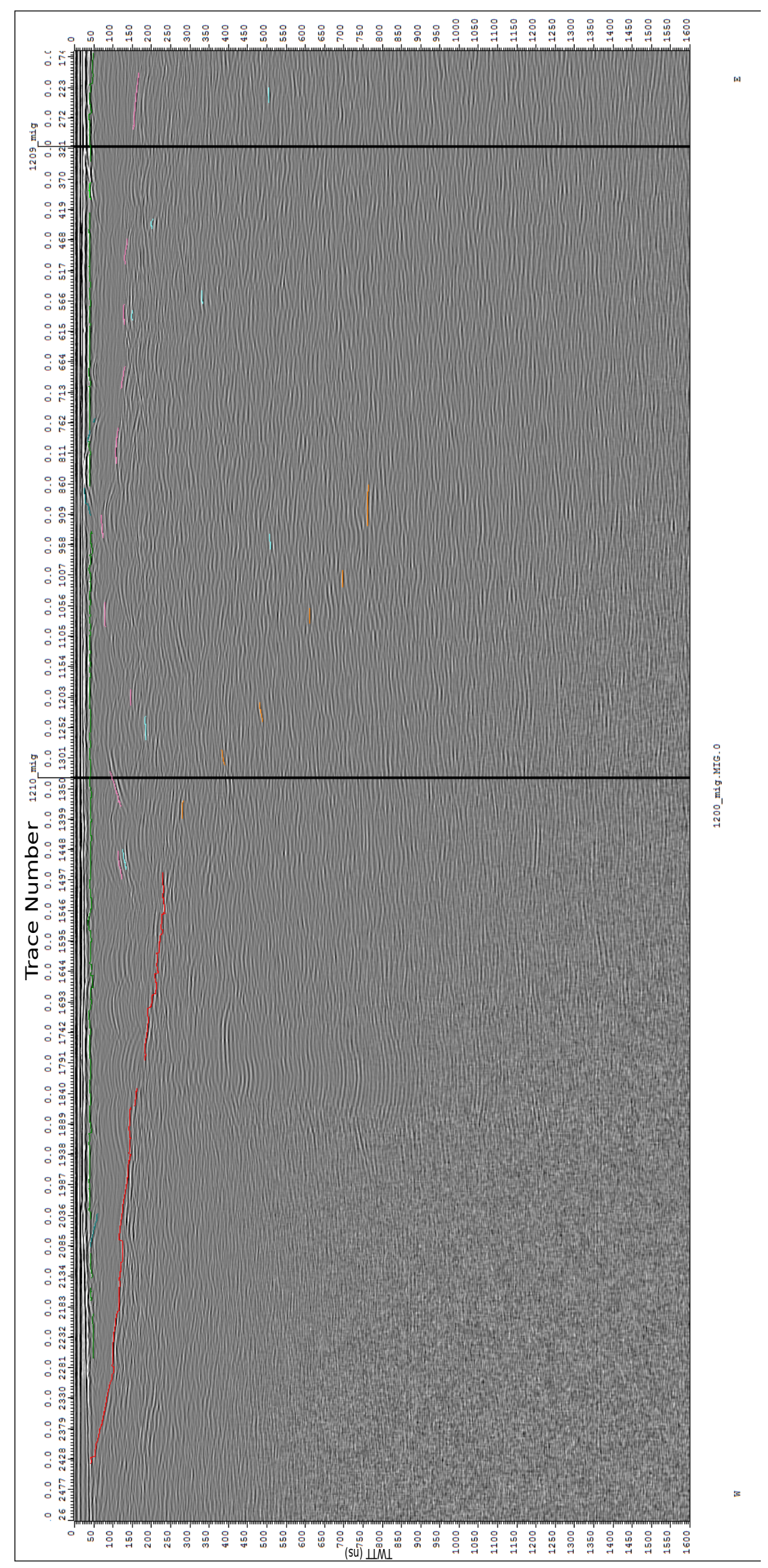

Figure 7.38: Profile 1200 December, showing picked englacial reflections as follows: (1) red - bed; (2) orange - bed inferred; (3) green - initial reflection horizon; (4) pink - reflective horizon (5) blue - point reflector; (6) light-green - banded surface reflector. 


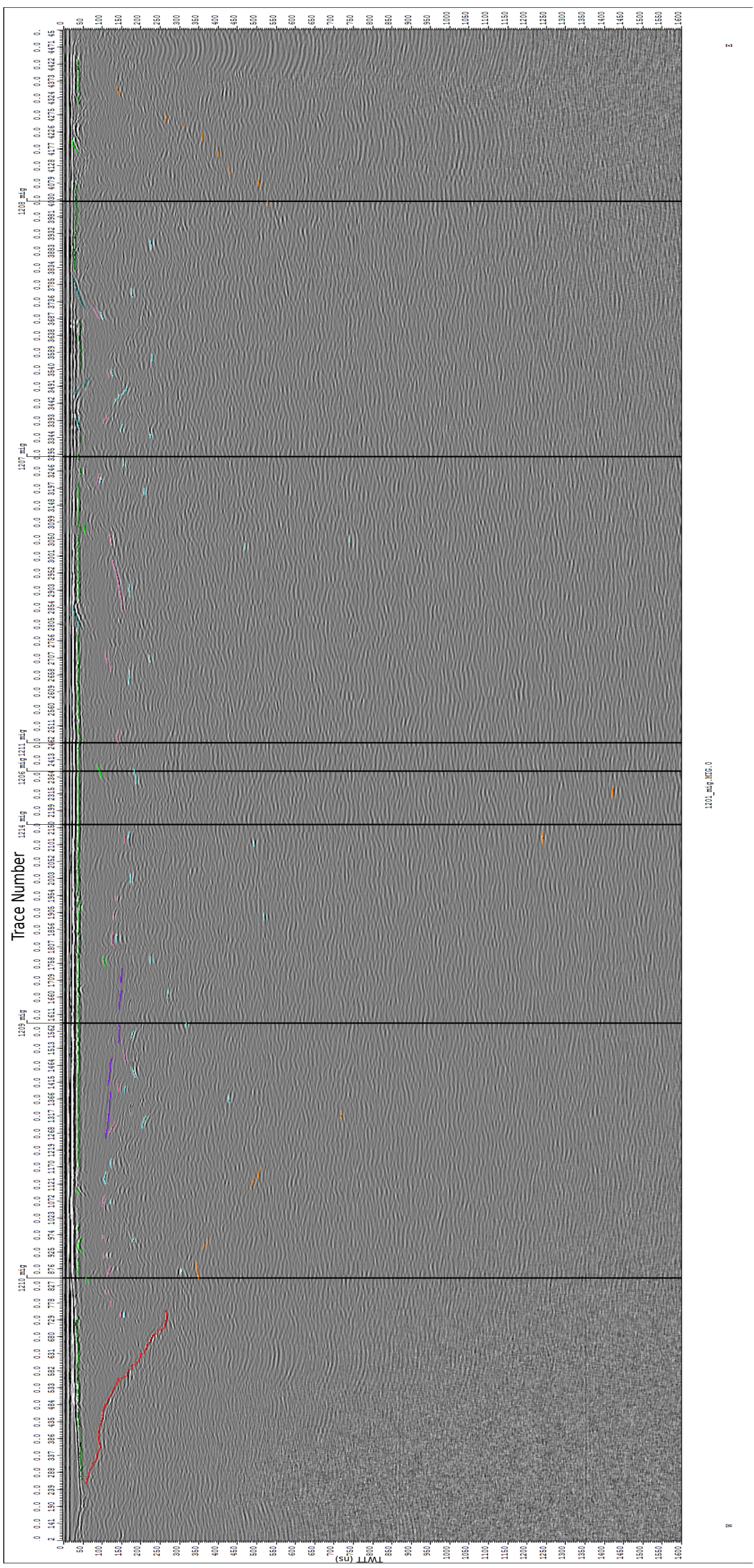

Figure 7.39: Profile 1201 December, showing picked englacial reflections as follows: (1) red - bed; (2) orange - bed inferred; (3) green - initial reflection horizon; (4) pink - reflective horizon (5) blue - point reflector; (6) light-green - banded surface reflector. 


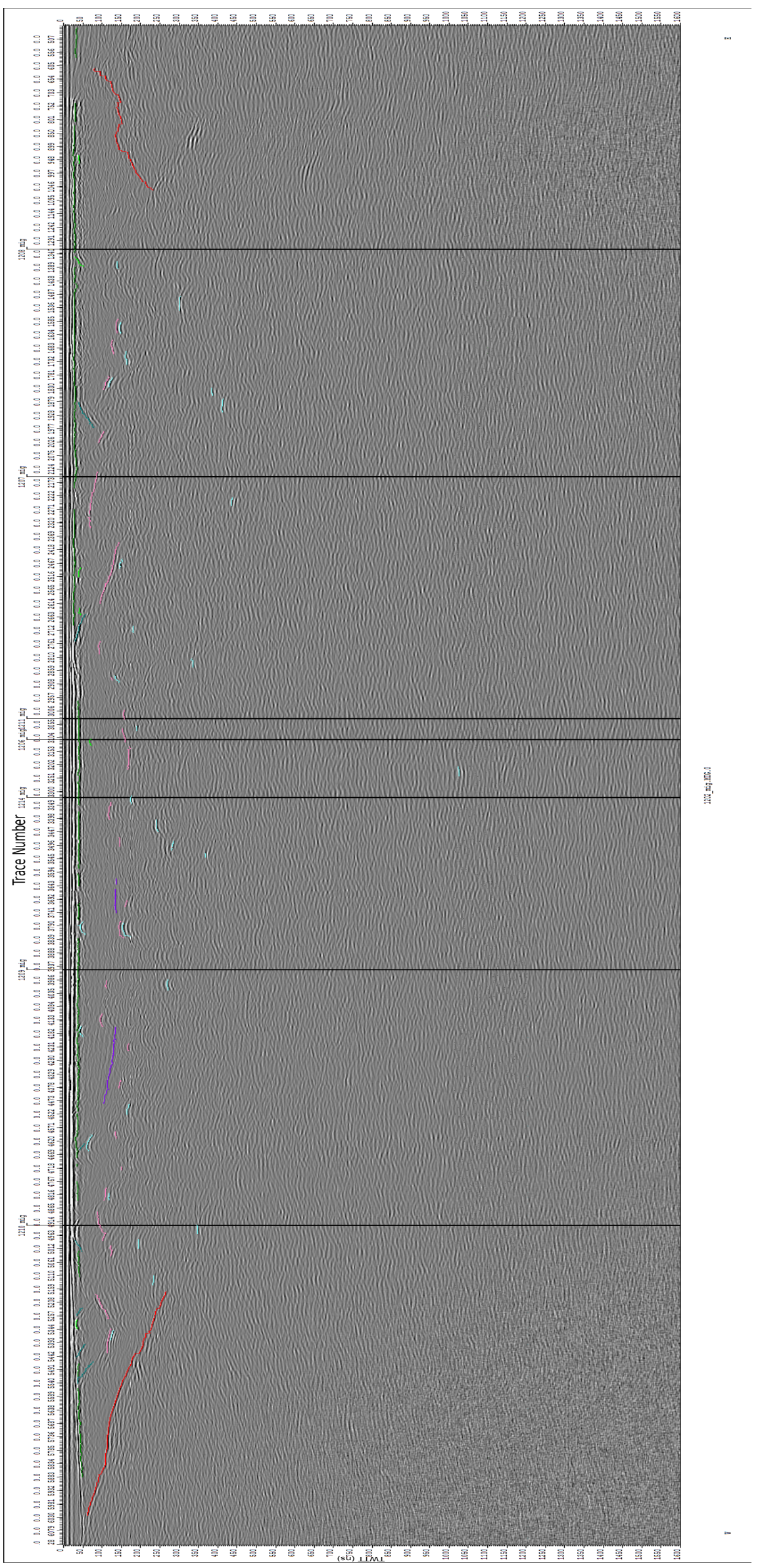

Figure 7.40: Profile 1202 December, showing picked englacial reflections as follows: (1) red - bed; (2) orange - bed inferred; (3) green - initial reflection horizon; (4) pink - reflective horizon (5) blue - point reflector; (6) light-green - banded surface reflector. 


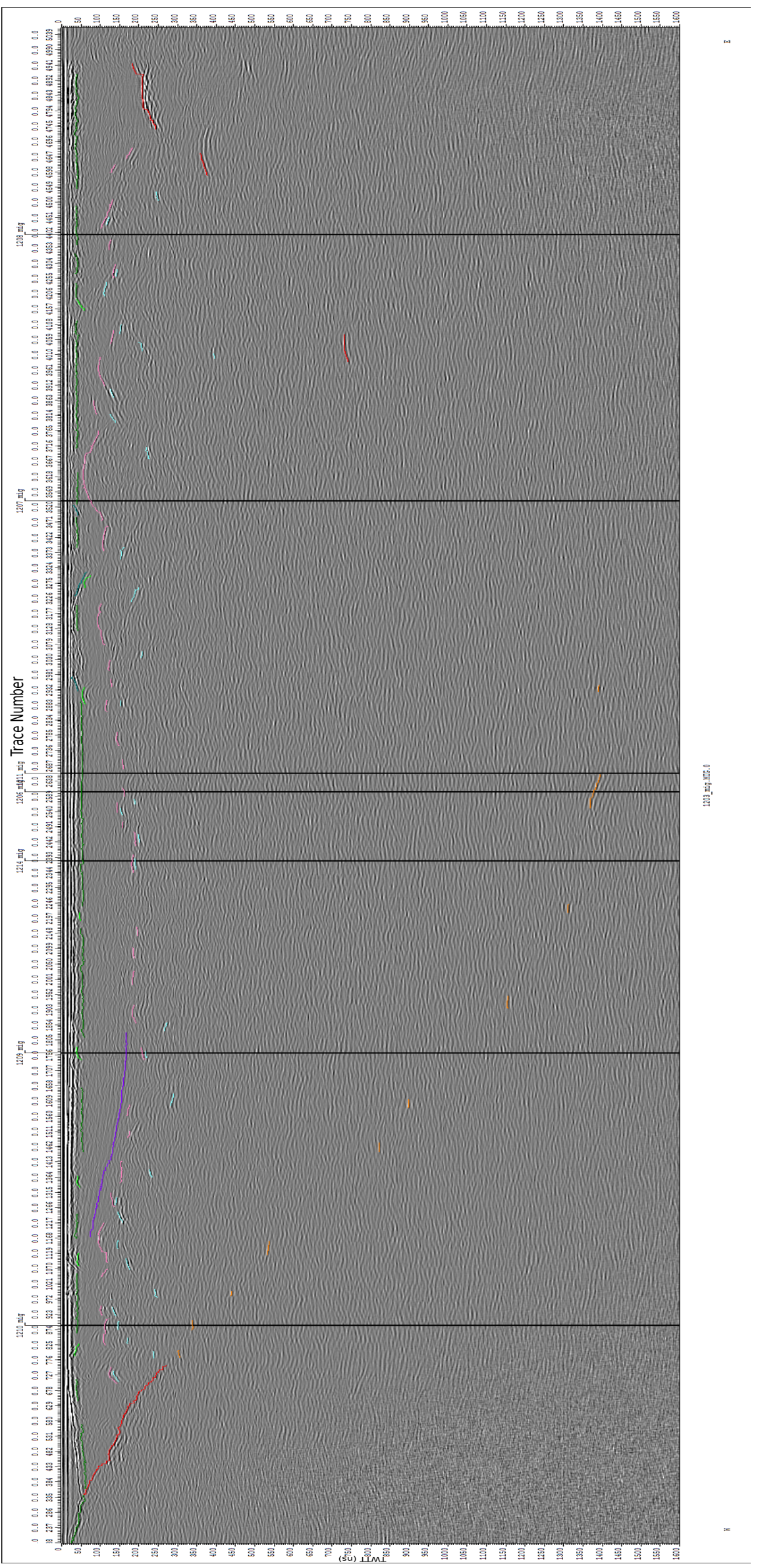

Figure 7.41: Profile 1203 December, showing picked englacial reflections as follows: (1) red - bed; (2) orange - bed inferred; (3) green - initial reflection horizon; (4) pink - reflective horizon (5) blue - point reflector; (6) light-green - banded surface reflector. 


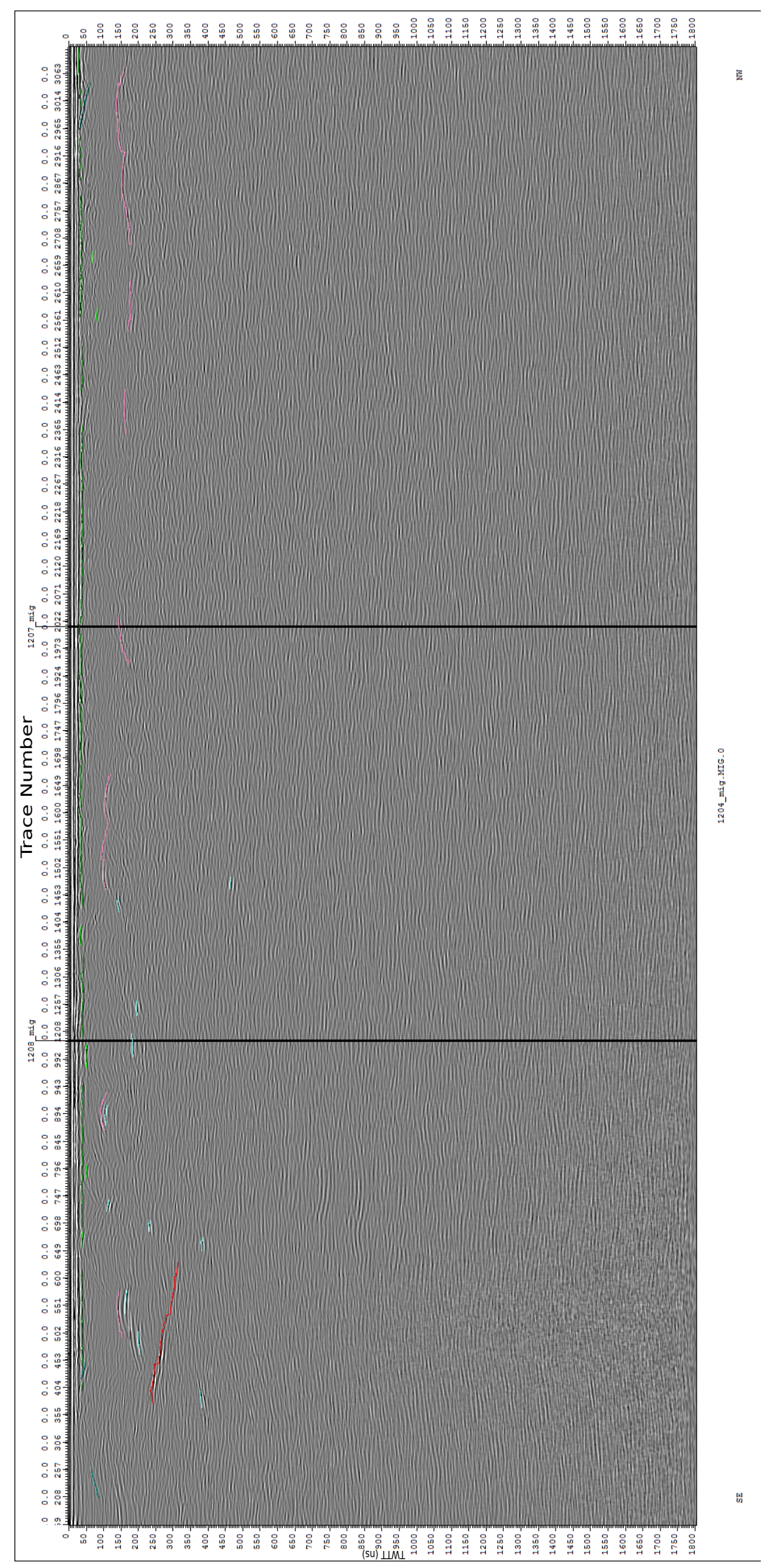

Figure 7.42: Profile 1204 December, showing picked englacial reflections as follows: (1) red - bed; (2) orange - bed inferred; (3) green - initial reflection horizon; (4) pink - reflective horizon (5) blue - point reflector; (6) light-green - banded surface reflector. 


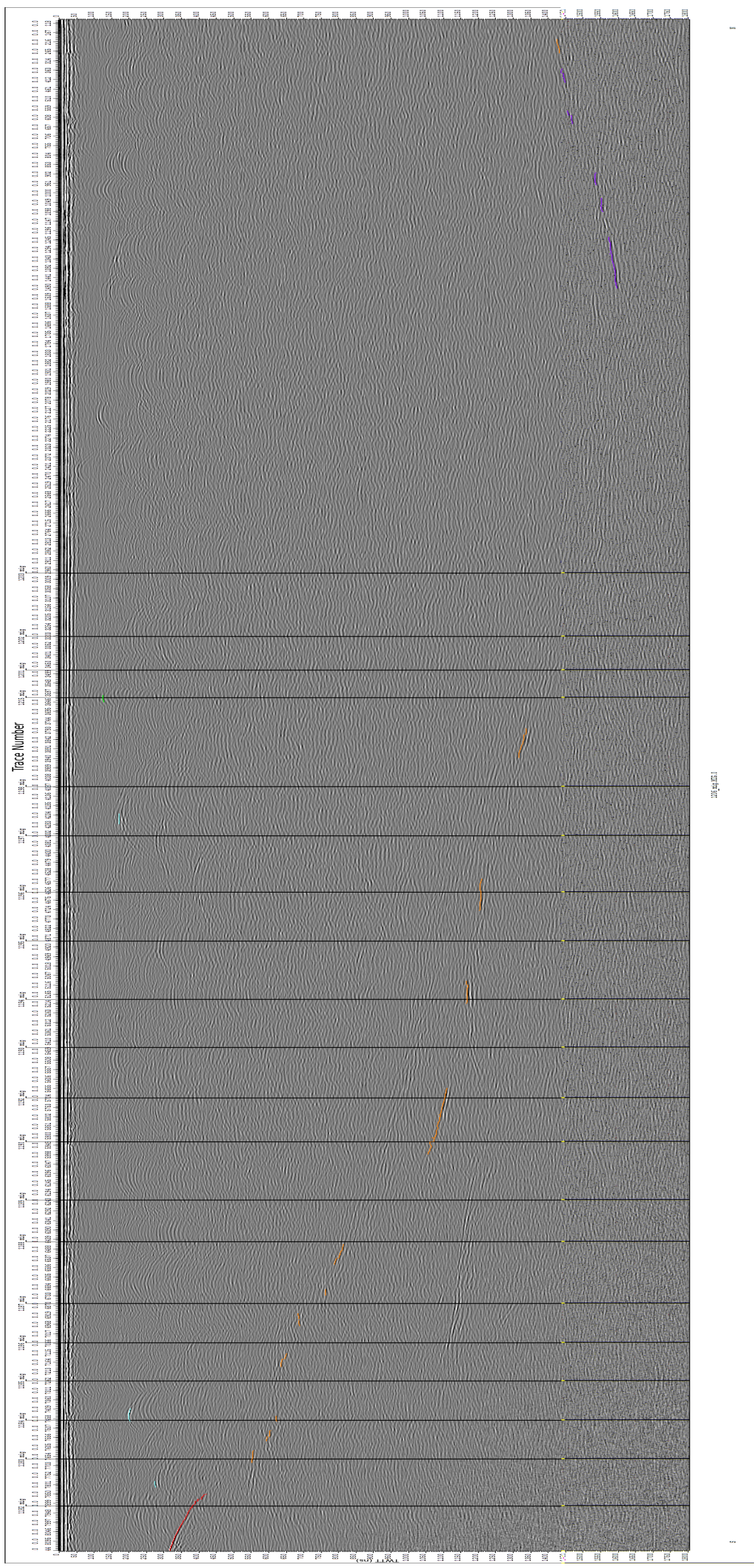

Figure 7.43: Profile 1206 December, showing picked englacial reflections as follows: (1) red - bed; (2) orange - bed inferred; (3) green - initial reflection horizon; (4) pink - reflective horizon (5) blue - point reflector; (6) light-green - banded surface reflector. 


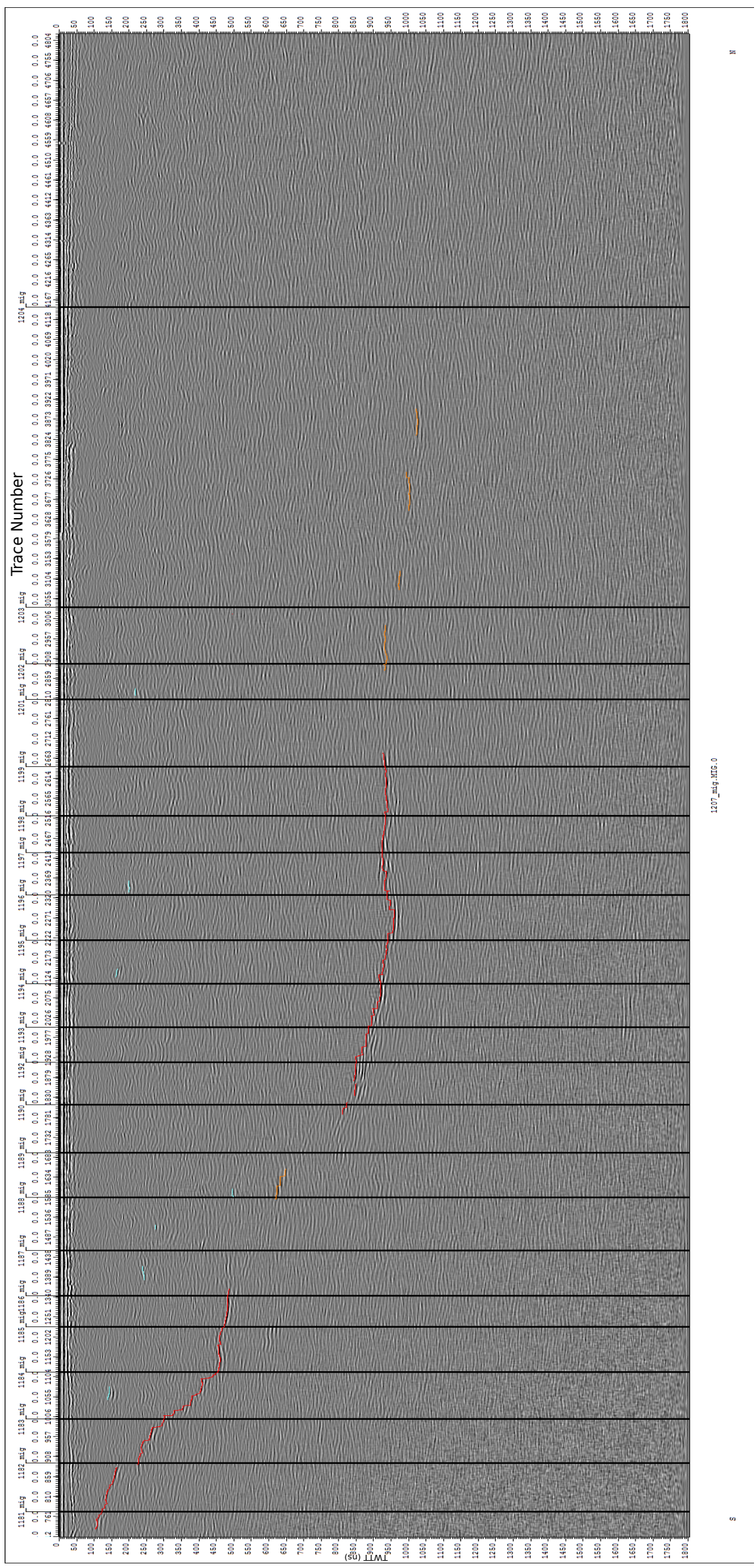

Figure 7.44: Profile 1207 December, showing picked englacial reflections as follows: (1) red - bed; (2) orange - bed inferred; (3) green - initial reflection horizon; (4) pink - reflective horizon (5) blue - point reflector; (6) light-green - banded surface reflector. 


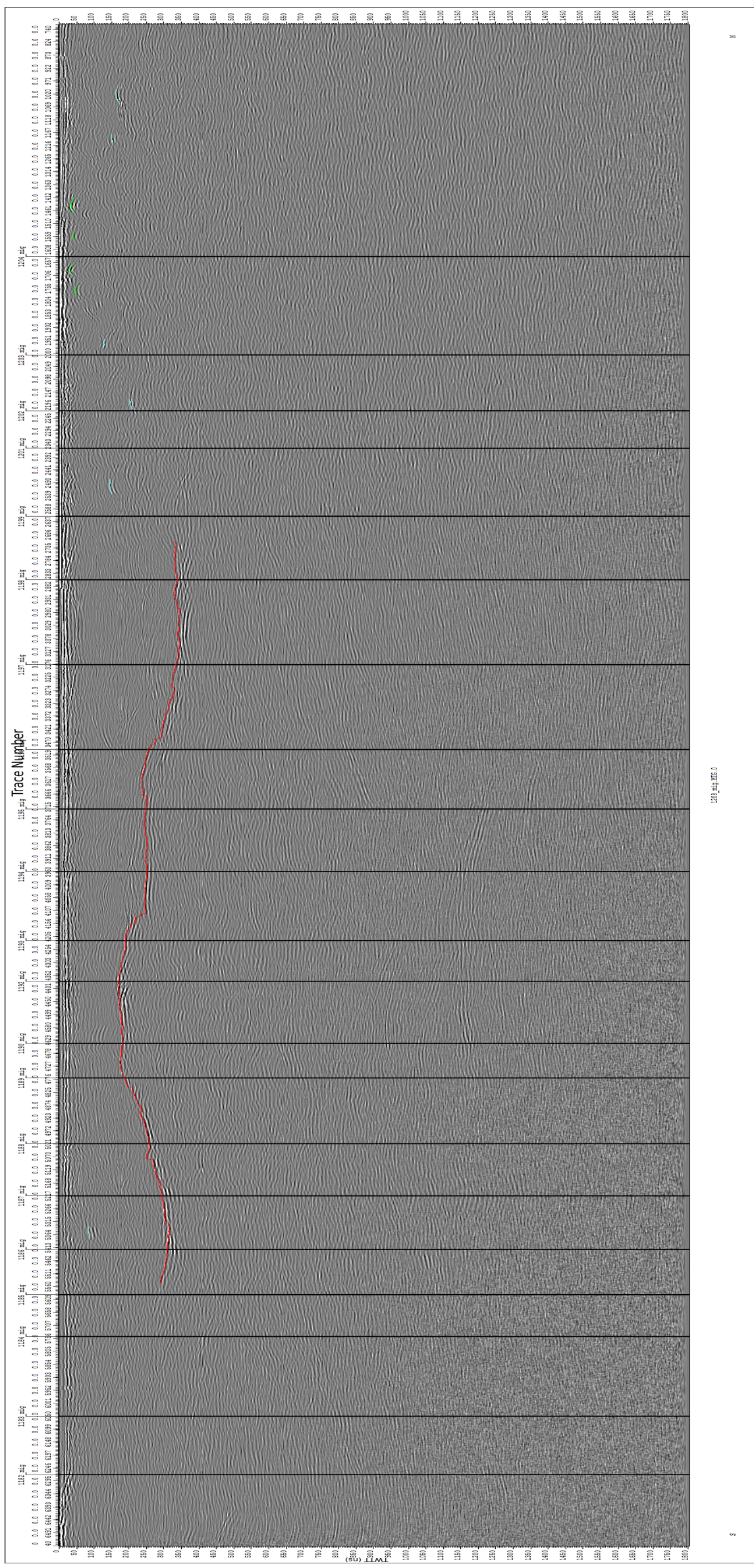

Figure 7.45: Profile 1208 December, showing picked englacial reflections as follows: (1) red - bed; (2) orange - bed inferred; (3) green - initial reflection horizon; (4) pink - reflective horizon (5) blue - point reflector; (6) light-green - banded surface reflector. 


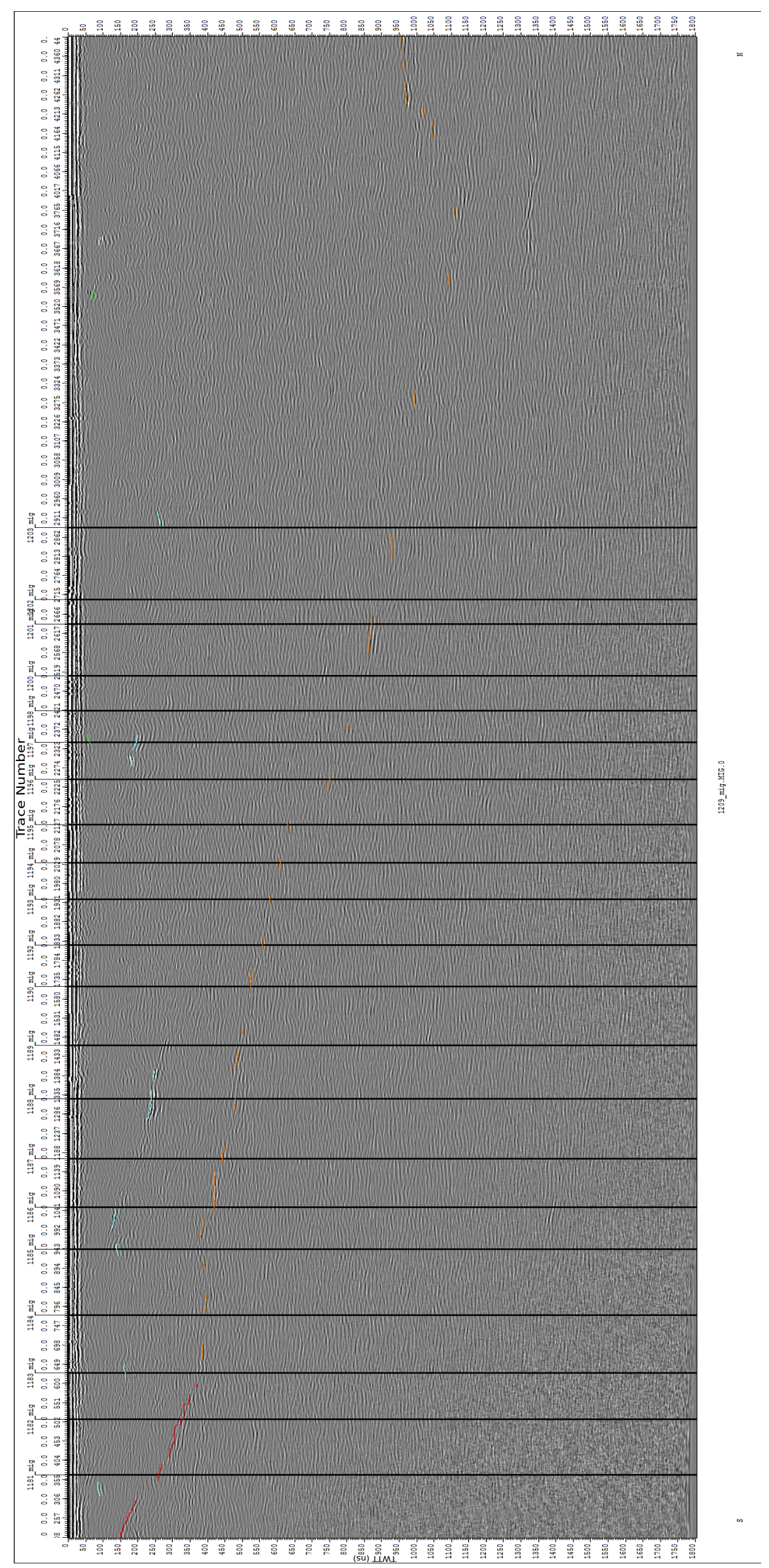

Figure 7.46: Profile 1209 December, showing picked englacial reflections as follows: (1) red - bed; (2) orange - bed inferred; (3) green - initial reflection horizon; (4) pink - reflective horizon (5) blue - point reflector; (6) light-green - banded surface reflector. 


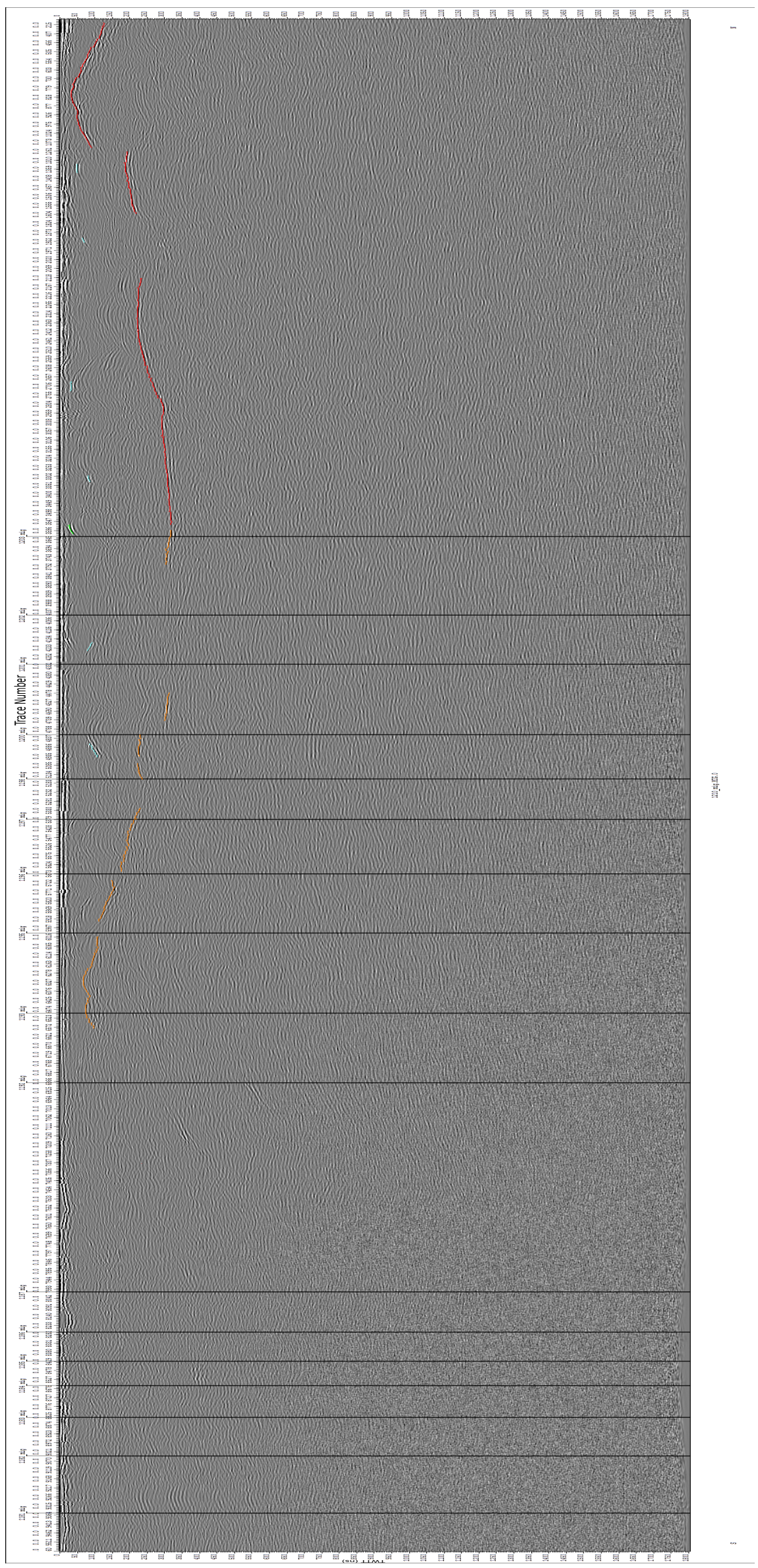

Figure 7.47: Profile 1210 December, showing picked englacial reflections as follows: (1) red - bed; (2) orange - bed inferred; (3) green - initial reflection horizon; (4) pink - reflective horizon (5) blue - point reflector; (6) light-green - banded surface reflector. 


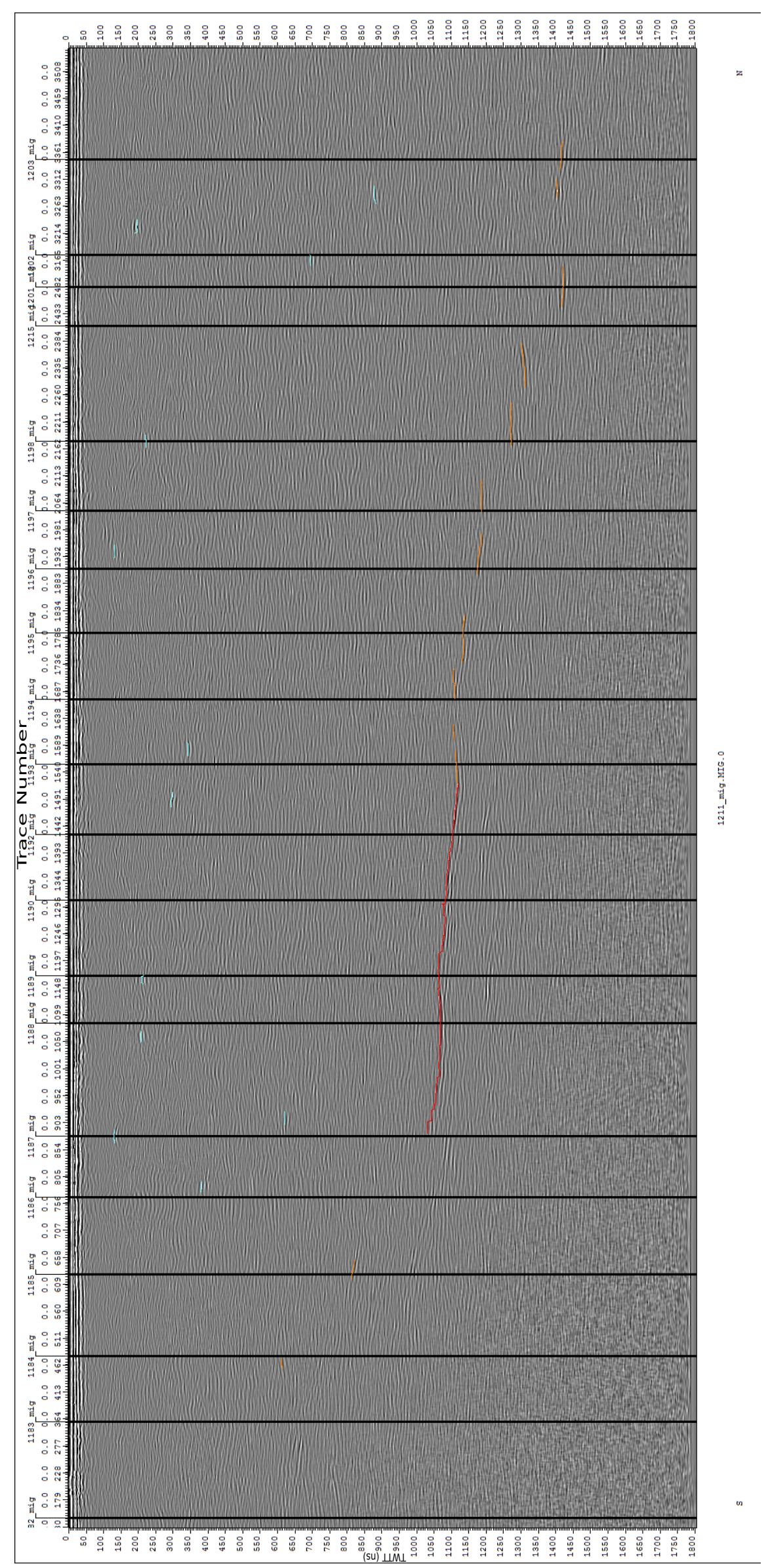

Figure 7.48: Profile 1211 December, showing picked englacial reflections as follows: (1) red - bed; (2) orange - bed inferred; (3) green - initial reflection horizon; (4) pink - reflective horizon (5) blue - point reflector; (6) light-green - banded surface reflector. 


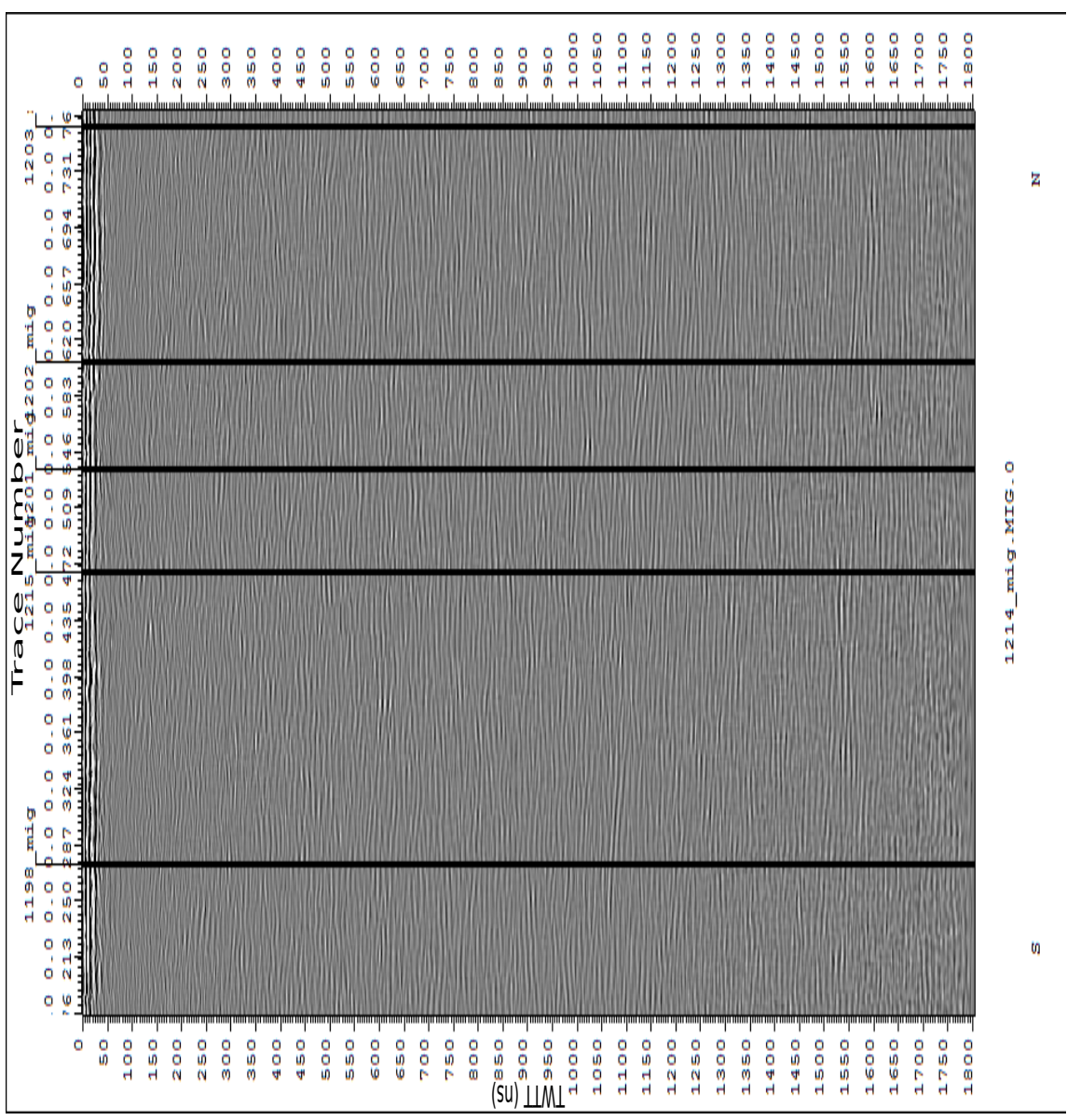

Figure 7.49: Profile 1214 December, showing picked englacial reflections as follows: (1) red - bed; (2) orange - bed inferred; (3) green - initial reflection horizon; (4) pink - reflective horizon (5) blue - point reflector; (6) light-green - banded surface reflector. 


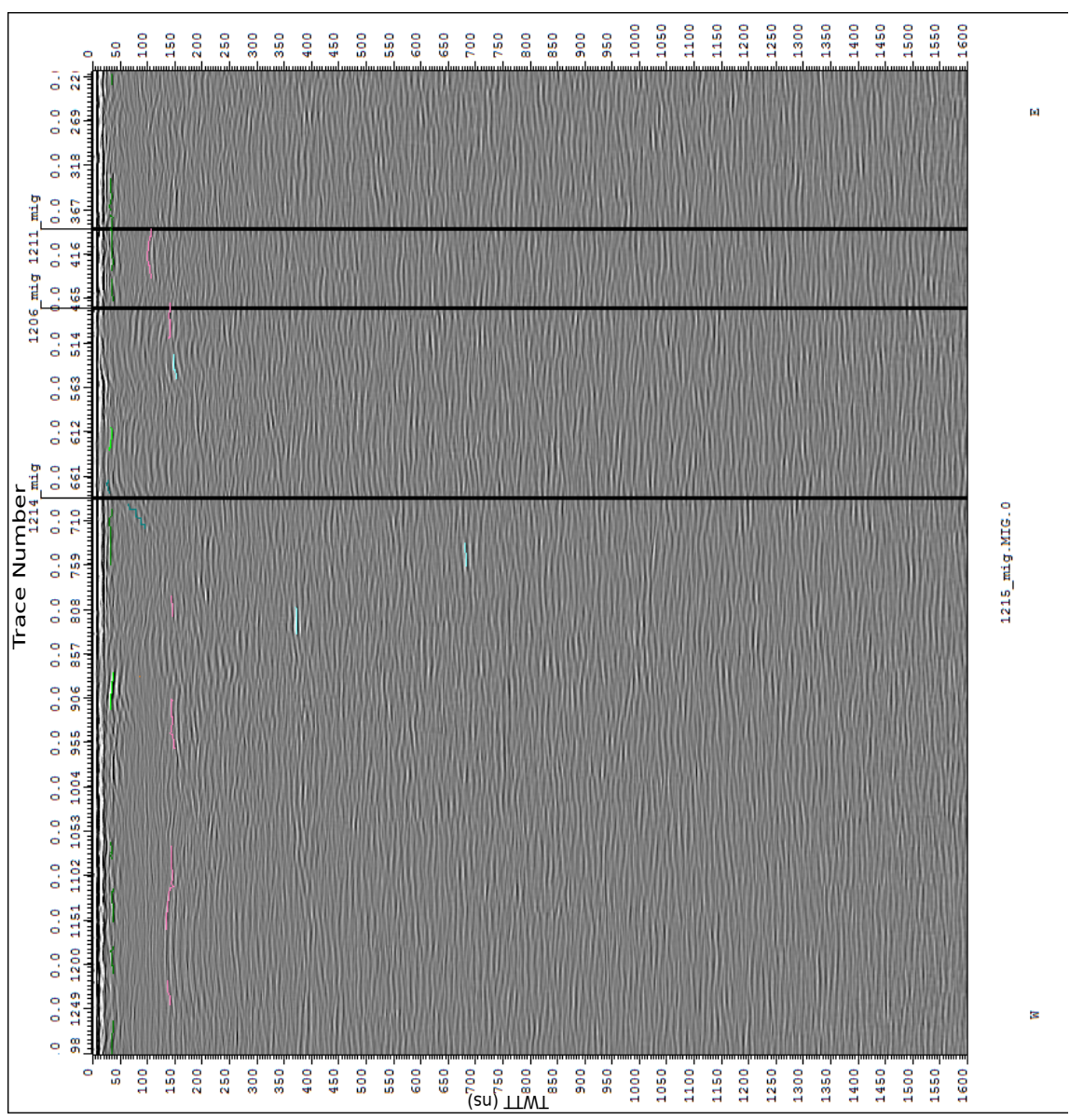

Figure 7.50: Profile 1215 December, showing picked englacial reflections as follows: (1) red - bed; (2) orange - bed inferred; (3) green - initial reflection horizon; (4) pink - reflective horizon (5) blue - point reflector; (6) light-green - banded surface reflector. 